\title{
Coaching life skills through sport: An application of the teaching personal and social responsibility model to youth sport in eSwatini
}

\author{
Zenzi Huysmans \\ zehuysmans@mix.wvu.edu
}

Follow this and additional works at: https://researchrepository.wvu.edu/etd

Part of the Other Psychology Commons, and the Sports Studies Commons

\section{Recommended Citation}

Huysmans, Zenzi, "Coaching life skills through sport: An application of the teaching personal and social responsibility model to youth sport in eSwatini" (2018). Graduate Theses, Dissertations, and Problem Reports. 3717.

https://researchrepository.wvu.edu/etd/3717

This Dissertation is protected by copyright and/or related rights. It has been brought to you by the The Research Repository @ WVU with permission from the rights-holder(s). You are free to use this Dissertation in any way that is permitted by the copyright and related rights legislation that applies to your use. For other uses you must obtain permission from the rights-holder(s) directly, unless additional rights are indicated by a Creative Commons license in the record and/ or on the work itself. This Dissertation has been accepted for inclusion in WVU Graduate Theses, Dissertations, and Problem Reports collection by an authorized administrator of The Research Repository @ WVU.

For more information, please contact researchrepository@mail.wvu.edu. 
Coaching life skills through sport: An application of the teaching personal and social responsibility model to youth sport in eSwatini

Zenzi Huysmans, M.S.

Dissertation submitted

to the College of Physical Activity and Sport Sciences

at West Virginia University

in partial fulfillment of the requirements for the degree of

Doctorate of Philosophy in Kinesiology with a Major in Sport, Exercise, and Performance Psychology

Sport and Exercise Psychology

Damien Clement, Ph.D., Chair

Sam Zizzi, Ed.D.

Christiaan Abildso, Ph.D., MPH

Meredith Whitley Ph.D., Adelphi University

Department of Sport Sciences

Morgantown, West Virginia

2018

Keywords: youth development, life skills, coaching, teaching personal and social responsibility model, eSwatini

Copyright 2018 Zenzi Huysmans 


\begin{abstract}
Coaching life skills through sport: An application of the teaching personal and social responsibility model to youth sport in eSwatini

Zenzi Huysmans
\end{abstract}

Adolescence is a formative developmental period where youth learn the life skills and values needed to become compassionate and civically-engaged young people and navigate increasingly challenging global environments. Youth in eSwatini face major context-specific challenges that impede their healthy development as well as limited engagement with government initiatives intended to support their development. This feasibility study aimed to employ youth sport as a creative and engaging context to facilitate life skills development in underprivileged youth in eSwatini. Specifically, this study explored the youth participation experiences, positive youth outcomes, and implementation successes and challenges of a sport program for underprivileged youth in a community in eSwatini. The sport program was designed using the teaching personal and social responsibility (TPSR) model, which is a well-established instructional model for life skills education through sport. Although this model had been widely applied in Western contexts, the current study explored how the model might operate differently in a non-Western context where youth face different developmental challenges. An intervention design was employed to implement a three-week sport program for youth in a small community in the Lobamba region of eSwatini. Local coaches were the primary implementers of the program and participants were youth $(N=33)$, aged $11-15$ years old, who attended the grade six and seven literacy development afternoon club at a community-based children's organization. Findings from the current feasibility study provided further support for the value of using the TPSR framework in the design and implementation of sport-based life skills education programming in a novel youth context in eSwatini. The focus of the model on building caring coach-youth relationships, creating an enjoyable sport experience, fostering small successes, and providing intentional opportunities for youth to actively practice and engage in their own learning were the most meaningful elements of the model in the current youth context. The developmental outcomes and changes in life skills associated with participation in the current program may also be highly pertinent to helping youth navigate the most salient health and resource challenges in the community. Notably, the current study also identified culture and context-specific considerations that should be made when implementing TPSR-based youth programming in eSwatini. These included, but are not limited to, adaptations to the awareness talk and selfreflection time, the use of active learning strategies and behavioral management techniques, and the provision of fruit and food to meet basic survival needs. Continued future explorations of the program design elements and coaching strategies that most meaningfully contribute to a holistic youth development and a positive sport participation experience in eSwatini is warranted. 


\title{
Acknowledgements
}

\author{
Traveler, the path is your tracks \\ And nothing more \\ Traveler, there is no path \\ The path is made by walking
}

- Antonio Machado -

It takes a village to raise a child and I have had so many supporting hands help me get to this point. To the family, friends, and community in eSwatini who believed in me from the very beginning, "I am because we are". What a beautiful thing to have been shaped by so many kind hearts over the years. Siyabonga kakhulu!

To the children of the Moya Center, the staff, and the coaches who helped me bring this dissertation to life. It was an immense privilege to develop this program alongside you all. You are the reason why I do what I do. To the community members, key informants, coaches, and students who participated in the needs assessment that grounded this dissertation, thank you! Your voices are present in every chapter of this dissertation story!

To my wonderful SEP colleagues. As the African proverb says, "If you want to go fast, go alone, if you want to go far, go together." We have journeyed far together... and what an adventure it has been! Over the years we have shared so many moments of laughter and joy, and also experiences of sadness and challenge. In those difficult times, your support and kindness have meant everything to me. I will cherish both; the deep belly laughter and also the compassion you have shown me! Thank you! Matt and Tammy...not all heroes wear capes! Thank you for investing yourselves so fully in the coding process of my dissertation. Your enthusiasm and dedication to my work was a beautiful thing to witness.

To the SEP and Counseling faculty members and my dissertation committee. I have been lucky to grow both personally and professionally under the wings of such compassionate, dedicated, and pioneering people. Dr. Clement: over the years you have pushed me to become the best possible version of me. You have supported my independence while also reaching out a helping hand when I needed it. Dr. Zizzi: You have helped me trust my way of being and enjoy the journey as it unfolds. Your kindness has been so appreciated. Dr. Etzel: it has meant more than you know to journey around the world with you through our chats about music, books, recipes, and life experiences. Thank you for trusting and nurturing my vision for consulting when I was still searching for my professional identity. Dr. Whitley: You have dedicated your life's work to using sport as a platform for the positive and holistic development of youth all over the world. Your passion and work ethic is truly an inspiration. I hope to emulate that in my own professional journey. Dr. Abildso: Thank you for taking a leap with me. I look forward to continuing to explore the intersection of sport and community-based public health programming under your mentorship.

To my dearest friends, you are my heart and soul connections for life! The greatest gifts of life are friendships, and I have been blessed with some truly beautiful ones. See you in eSwatini one day! Killeen, it's hard to describe how you have impacted my life. In some of my most difficult 
moments of challenge, you were an unwavering presence. You give to everyone around you so selflessly. I feel privileged to have shared this chapter with you, to have watched your continued growth into a strong, compassionate, and balanced woman. Aaron. Morgantown will always be synonymous with you. Your way with people is something that will stick with me. You have an incredible ability to connect with others and make everyone you meet feel valued. Thank you for giving me a space to share the contents of my heart. Sofia, in you I have found a kindred spirit. A playful, optimistic, and deeply values-oriented soul. Thank you for the light you have brought to my life! Jay. Your determination and resilience have been pillars for me. Challenge upon challenge has been thrown your way and you have stepped up to the plate every time. Please know that even when you feel alone in those experiences, you are shaping the lives of those who are watching your fighting spirit. Thank you for all the laughter and roasts. I have met my match...but never underestimate the slow roast! :) Bobby. We have truly adventured far and wide together...through the depths of some personal sorrows, through the dark but also beautiful caves of consulting and counseling internship, all the way to the humor and authentic connection that characterizes our friendship. Thank you! August...our journey did not go the direction we imagined it. But you were my pillar and biggest supporter for a very long time. Thank you for growing with me and loving me. I will forever cherish the depth of the love we shared.

Most of all, thank you to my family, klavertje vier - AZRA - for showing me how to put love, kindness, and compassion at the center of all things. To my sister, Aissa...my moon spirit...my life companion - for journeying through life with me and showing me what the purest form of love feels like. "Both sun and moon blissfully call the tune. The one at midnight, the other at noon." Rolf Huysmans. "You are imperfect, you are wired for struggle, but you are worthy of love and belonging.” Brené Brown. To my mammsy, Ann...my pillar of strength - for grounding me so firmly in optimism, kindness, and determination. "The way we talk to our children becomes their inner voice." Peggy O'Mara. To my wonderful dad, Rolfinho - your presence is eternally missed. Not a day goes by that I don't reflect on how incredibly fortunate I was to have your light of integrity, beauty, and vision guiding me. You were truly an exceptional human. You and mammsy showed me what love really means... when it is unconditional, when it is reflected in our everyday choices of how we treat others. Merci beaucoup!

Quand on n'a que l'amour

Pour unique raison

Pour unique chanson

Et unique secours...

Quand on n'a que l'amour

Pour tracer un chemin

Et forcer le destin

A chaque carrefour...

Alors sans avoir rien

Que la force d'aimer

Nous aurons dans nos mains

Amis le monde entire.

- Jacques Brel - 
Table of Contents

Chapter 1: Introduction 1

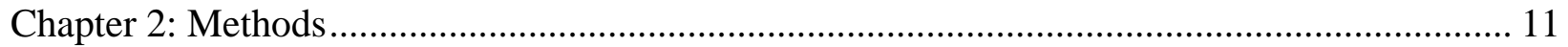

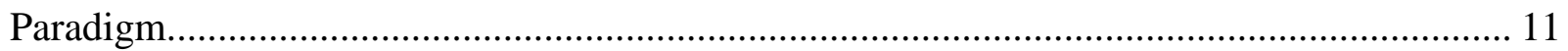

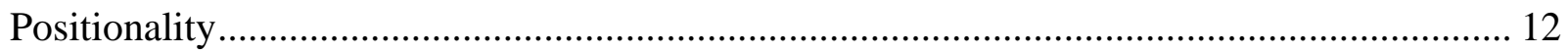

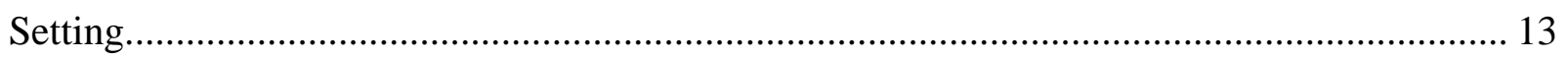

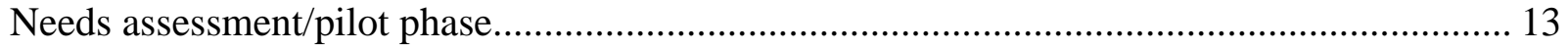

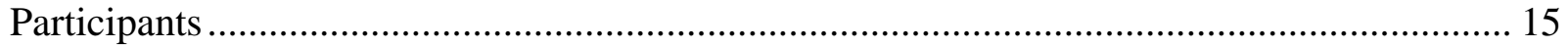

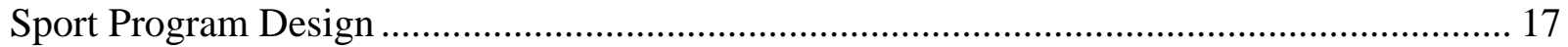

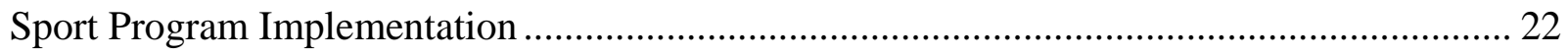

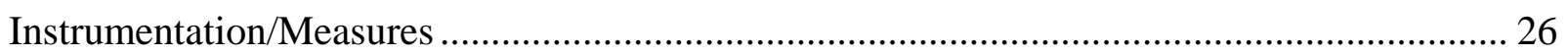

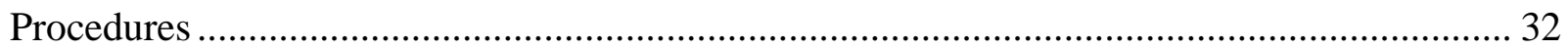

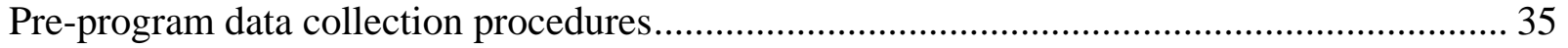

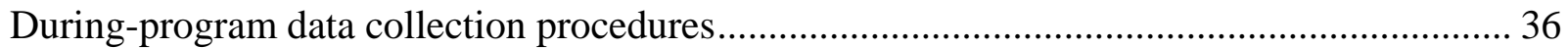

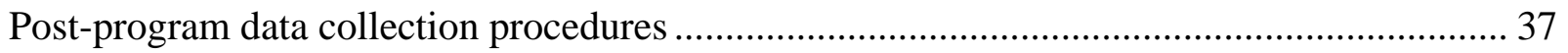

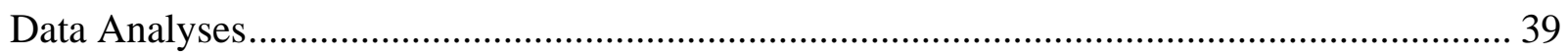

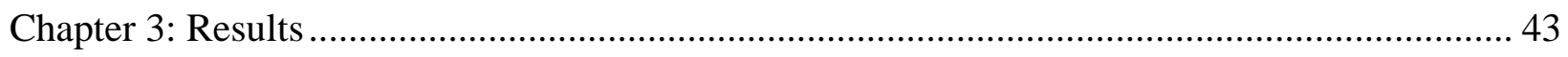

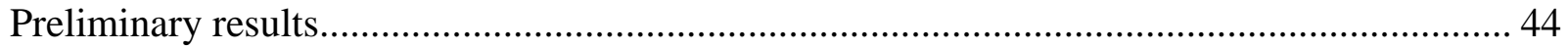

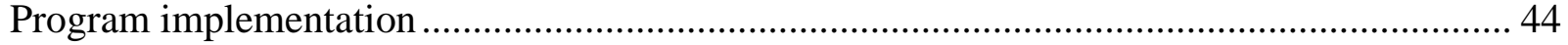

RQ1: What is the youth participation experience in a TPSR-based youth sport program in

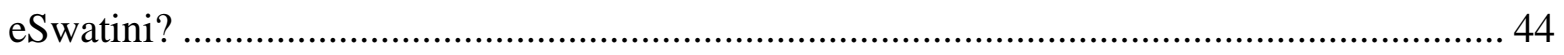

RQ2: What are the coaching strategies and program design elements (strengths and weaknesses of coach training and sport program) that contribute most strongly to life skills learning in a TPSR-based youth sport program in eSwatini?....................................... 54

RQ3: To what extent was fidelity to the TPSR model achieved in terms of daily structure, youth responsibility behaviors, and coaching strategies?........................................ 82

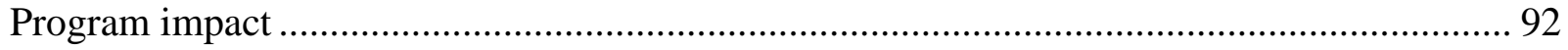

RQ4: What positive developmental outcomes and changes in life skills are associated with youth participation in a TPSR-based youth sport program in eSwatini? ........................... 92

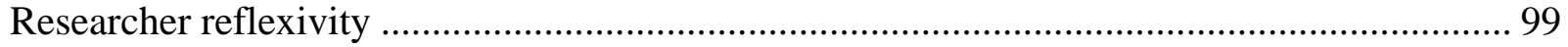

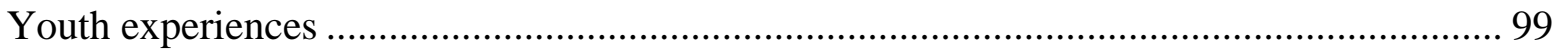

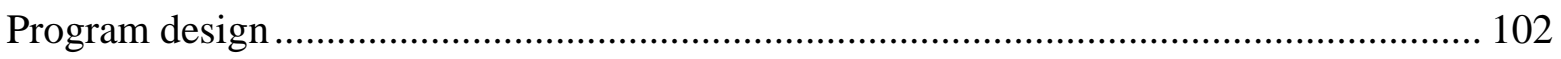

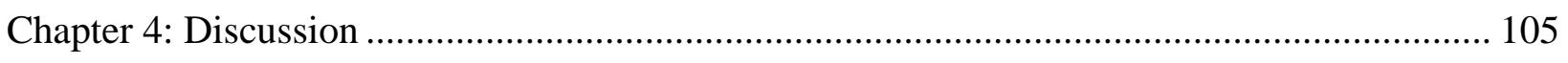

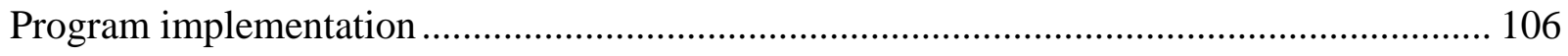


Research question one: youth participation experiences ........................................... 106

Research question two: coaching strategies and program design elements ...................... 112

Research question three: fidelity to the TPSR model ...................................................... 131

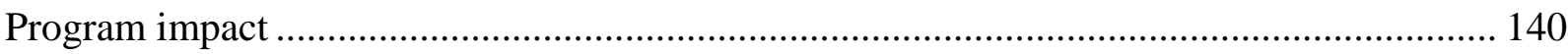

Research question four: youth positive developmental outcomes and life skills .............. 140

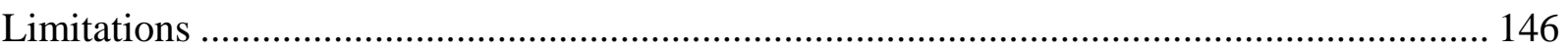

Practical Implications and Future Directions ............................................................. 148

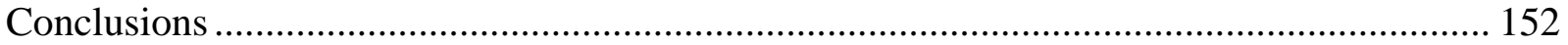

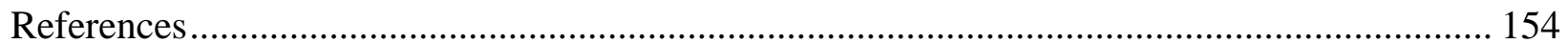

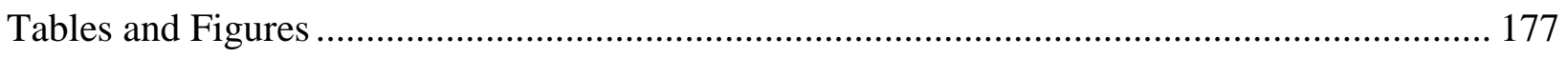

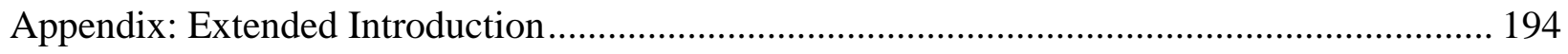

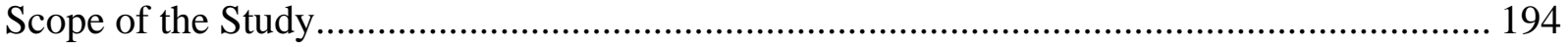

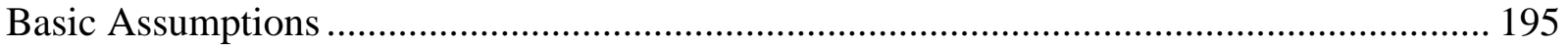

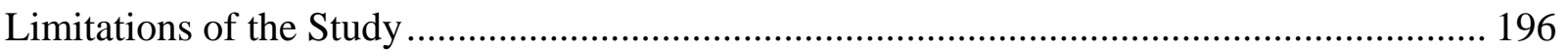

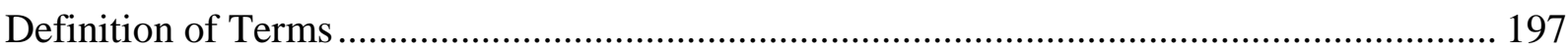

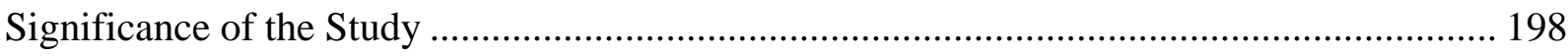

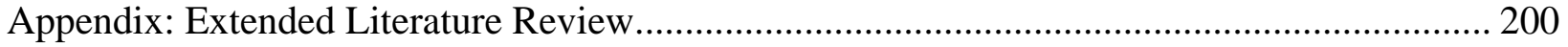

Youth, development, and sport: eSwatini context.......................................................... 201

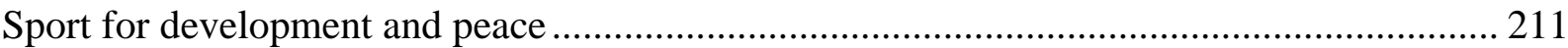

Sport for development in South Africa and eSwatini ...................................................... 223

Youth coaching in Southern Africa and eSwatini ........................................................ 232

Role of coaches in positive youth development and sport for development........................ 240

Teaching personal and social responsibility through sport …............................................ 248

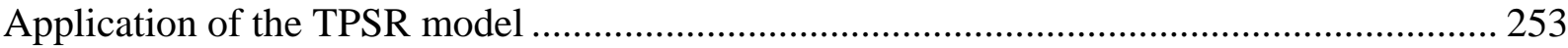

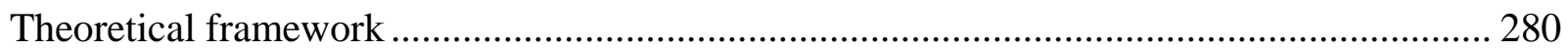

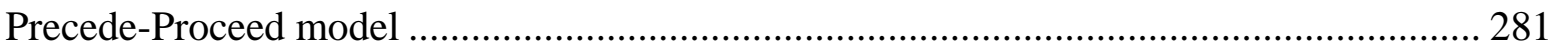

Needs assessment/pilot phase (PRECEDE) to inform dissertation feasibility study ......... 283

Youth sport program: Theoretical framework ............................................................ 290

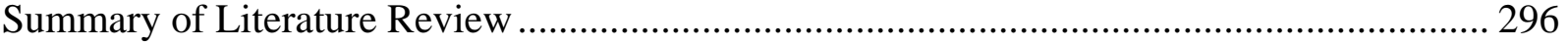

Appendix A: Sport Program Outline .................................................................................. 299

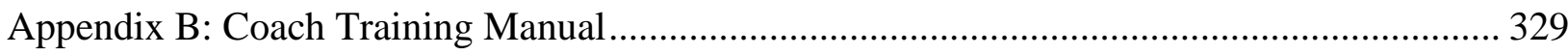

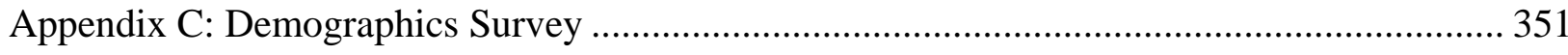


Appendix D: Demographics and Personal and Social Responsibility Questionnaire (PSRQ)... 352

Appendix E: Multidimensional Scales of Perceived Self-Efficacy (MSPSE) .......................... 353

Appendix F: Student Learning Quiz .................................................................................... 357

Appendix G: Coach Focus Group Guide ..................................................................... 358

Appendix H: Youth Focus Group Guide ..................................................................... 359

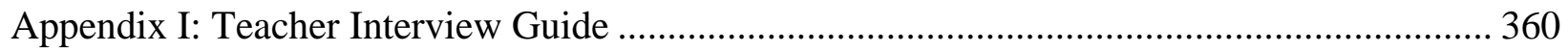

Appendix J: Tool for Assessing Responsibility-Based Education (TARE) - Post-Teaching

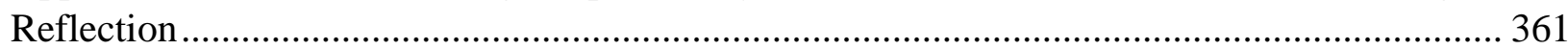

Appendix K: TPSR Implementation Checklist............................................................ 365

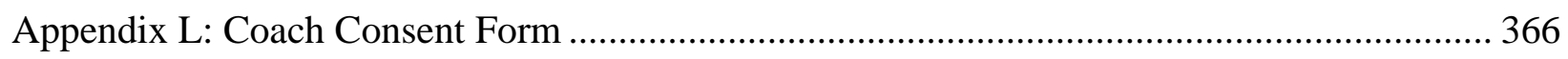

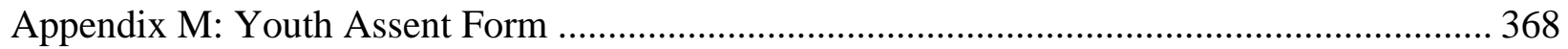

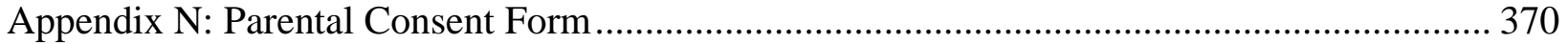

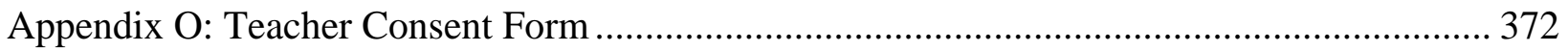




\section{Chapter 1: Introduction}

Adolescence is a formative period in the healthy development of youth and lays the foundation for future well-being and fulfillment (Holt, 2008; Fatusi \& Hindin, 2010). In developing countries, this age demographic makes up the largest proportion of the population (UNFPA, 2015). However, young people in these areas are facing significant health-related challenges as well as limited resources to support their development (Fatusi \& Hindin, 2010). In the Kingdom of eSwatini (formerly known as Swaziland), a small country in Southern Africa, $36 \%$ of the population is between the ages of 10-24 years (WHO 2013; Mavundla, Dlamini, Nyoni, \& Mac-Ikemenjima, 2015). While youth in eSwatini struggle with the more universal challenges associated with adolescence such as social identity development and peer pressure, emaSwati youth are also faced with major context-specific challenges. These include but are not limited to economic and resources concerns such as unemployment, low school attendance, and high poverty rates as well as health challenges such as risk for HIV/AIDS (Huysmans, Clement, Hilliard, \& Hansell, 2017). Specifically, the population-level poverty rate in eSwatini is 63\%, unemployment for youth aged $15-24$ is $42.6 \%$, and only about half of youth attend school (Mavundla et al., 2015; Ministry of Sports, Culture and Youth Affairs, 2015).

Of even more concern is the fact that eSwatini has the highest global prevalence of HIV/AIDS; almost $30 \%$ of adults (15-49 years old) are infected (UNAIDS, 2016). The high prevalence of HIV/AIDS in eSwatini has not only put youth at significantly higher risk for infection (AVERT, 2014), but it has also had psychological, social, and economic effects on the lives of young emaSwati (Foster \& Williamson, 2000). These include, but are not limited to, becoming the caretaker of a sick parent, experiencing increased financial pressure in already poor living situations, having to drop out of school to earn a living, and experiencing the death of one or both parents (AVERT, 2014; Foster \& Williamson, 2000). This is consequential given the 
significant body of research that indicates that exposure to adverse childhood experiences (ACEs) such as neglect or chronic illness and the death of a parent put children at greater risk for future cognitive, emotional, social and health impairments (Anda, Butchart, Felitti, \& Brown, 2010; Felitti et al., 1998). Furthermore, the high adult mortality rates due to the HIV epidemic in eSwatini has resulted in a youth population (under 18 years of age) composed of almost 50\% orphans and vulnerable children (AVERT, 2014). This is concerning because emaSwati (Swazi) youth are therefore not only exposed to adverse childhood experiences alongside health and resources challenges, but they are also lacking guidance and mentorship from adult role models to support their healthy development. Investing in youth development and mentorship initiatives in eSwatini should therefore be prioritized.

Although there are government-led policies, and initiatives, for youth development operating at the national and community level in eSwatini, youth buy-in to these systems is limited (Mavundla et al., 2015; Ministry of Sports, Culture and Youth Affairs, 2015). Moreover, the gap between provision, and adoption, of youth services may suggest that there is a need to find ways to engage young people in their own development through creative, fun, and intentional programming. Sport-based youth development programming may be one avenue through which to achieve this goal (Beutler, 2008). Sport is seen as an appropriate vehicle through which to deliver youth development initiatives because it is an engaging and well-liked avenue for health promotion and behavior change in adolescents (Kaufman, Spencer, \& Ross, 2013). It is also valued as an innovative, practical, and cost-effective tool for development (Beutler, 2008). On a global scale, a multitude of research supports the role of sport as a vehicle for youth development (Schulenkorf, Sherry, \& Rowe, 2016; Svensson \& Woods, 2017). 
The role of sport in youth development is conceptualized as a fertilizer (Coakley, 2011) that can create the right environment to help cultivate socially desirable skills that all young people have the innate potential to develop (Coakley, 2011). Positive youth sport experiences have been found to not only meaningfully contribute to performance outcomes and future sport participation, but also personal development (Côté \& Hancock, 2016). It also exposes youth to positive role models, social connections, and constructive environments that may buffer the negative impacts of ACEs and developmental trauma (Hughes, Ford, Davies, Homolova, \& Bellis, 2018; Whitley, Massey, \& Wilkison, 2018), build resilience (Bellis et al., 2018), and help them grow into civically engaged and conscientious adults (Beutler, 2008; Coakley, 2011). For socially vulnerable populations, sport participation can also help youth develop the life skills needed to overcome the challenges of everyday life and "succeed in the different environments in which they live, such as school, home and in their neighborhoods" (Danish, Forneris, Hodge, \& Heke, 2004, p.40). Life skills may be important for socially vulnerable youth to develop due to the increased likelihood that they face stressors, mental health issues, and social isolation (Hermens, Super, Verkooijen, \& Koelen, 2017). Sport-based life skills development programming may therefore be a potential vehicle through which to support the healthy development of emaSwati youth.

Several studies in eSwatini indicate a large percentage of youth hold positive attitudes toward sport and its benefits on health and well-being (Huysmans et al., 2017; Ndlangamandla, Burnett, \& Roux, 2012; Toriola, 2010). Both male and female youth have indicated that sport helps them develop life skills including but not limited to discipline, respect, team work, and managing emotions (Huysmans et al., 2017). Youth also reported that sport has the potential to help them overcome some of their developmental and community challenges by serving as a positive 
distraction and teaching them helpful skills. In addition, youth expressed that sport may help them interact with peers who share similar struggles, and support them in building the confidence and self-esteem to progress through adversity (Huysmans et al., 2017).

However, only a small percentage of youth actually participate in sport or physical education at school (Huysmans et al., 2017; Ndlangamandla et al., 2012; Toriola, 2010). Further, female perceptions of competence and participation in sport is generally much lower than for males and decreases significantly from primary school to secondary school (Toriola, 2010). This is partly affected by a culture of male dominance combined with a lack of female role models in sport (Toriola, 2010). In addition, financial, structural, and equipment barriers also limit higher youth sport participation levels (Huysmans et al., 2017; Ndlangamandla et al., 2012; Toriola, 2010). Therefore, despite youth enjoyment of sport and awareness of its positive benefits, there are significant systemic and cultural barriers that limit youth sport participation, especially for girls. Further, there is negligible programming that utilizes sport as a context for youth life skills development in eSwatini.

Although there is limited sport for development programming in eSwatini, successful implementation of sport-based life skills initiatives in South Africa suggests there is potential for these programs to create meaningful developmental outcomes for emaSwati youth. South Africa is a comparable context to eSwatini given that $66 \%$ of the population is below the age of 35 and youth face similar developmental challenges (UNFPA South Africa, 2011). These include high unemployment, teenage pregnancy, poverty, HIV, and youth-led households (UNFPA South Africa, 2011). In the Kayamandi township of South Africa, research indicates that sport participation helped youth develop valuable intrapersonal, and interpersonal, life skills as well as overcome significant community challenges (Whitley, Hayden, \& Gould, 2016). Sport 
participation helped youth overcome community challenges by creating an environment of positive peer influences and support, keeping youth out of trouble, and giving them a reason not to make bad decisions (Whitley, Hayden, \& Gould, 2013).

These findings are further supported in the Buffalo Soccer Coaching Club (BSCC) in the Eastern Cape province of South Africa (Draper \& Coalter, 2016). That is, youth experienced personal development across several life skills and also reported positive experiences in the program including social connection with peers and a sense of safety and belonging (Draper \& Coalter, 2016). Burnett's (2014) work with Might Metres in South Africa also emphasizes the positive impact of sport-based programming on youth pro-social behavior and building teacherlearner relationships built on trust and enjoyment (Burnett, 2014). These findings from South Africa are consistent with studies from North America that support the role of youth sport participation in facilitating cognitive, emotional, and social life skills outcomes for normal adolescent development as well as for socially vulnerable or at-risk youth (Camiré, Trudel, \& Bernard, 2013; Danish, Forneris, \& Wallace, 2005; Gould, Collins, Lauer, \& Chung, 2007; Hermens et al., 2017; Holt et al., 2017; Martinek \& Hellison, 2016).

The work of sport for development (SFD) and life skills programming in South Africa (Burnett, 2014; Whitley et al., 2013; Whitley, Wright, \& Gould, 2016) and in Western contexts such as the USA and Canada (Hermens et al., 2017; Martinek \& Hellison, 2016) support the value of investing in sport-based youth development programs in under-privileged contexts. However, sport participation does not automatically result in life skills outcomes (Coakley, 2011). Positive development outcomes associated with sport are contingent upon a wide range of factors. These include the culture of the sport environment, the social connections established during sport participation, the meaning and values associated with sport participation, and the 
coach-athlete relationship (Coakley, 2011; Holt et al., 2017). Therefore, the people in charge of establishing the sport climate such as the coach become especially important in ensuring life skills learning (Gould et al., 2007).

Coaches are the gatekeepers of the youth sport experience and are also often viewed by athletes as important mentors in their development (Bean \& Forneris, 2016; Giges, Petitpas, \& Vernacchia, 2004; Gould et al., 2007; Holt et al., 2017; Vella, Oades, \& Crowe, 2011). Coaches are therefore in a unique position to be facilitating life skills development through sport (Gould et al., 2007). Specifically, when the coach is able to foster a caring and supporting sporting environment, personal development and positive developmental outcomes are more likely to occur (Spaaij, 2009; Vella et al., 2011). This is consistent with the positive youth development (PYD) framework that states that every adolescent is capable of positive developmental change but that the interaction between the individual and their sport context will heavily influence their personal development (Holt \& Neely, 2011). This means that the extent to which coaches carefully craft a nurturing sport environment and include intentional life skills building activities will determine the resultant life skills outcomes (Bean \& Forneris, 2016; Gould et al., 2007; Holt et al., 2017; Vella et al., 2011).

In South Africa, coaching effectiveness frameworks explicitly outline the role of coaches in engendering outcomes in youth participants that are more holistic than just sport-specific outcomes (International Council for Coaching Excellence, Association of Summer Olympic International Federations, \& Leeds Metropolitan University, 2013). Several studies have explored the role of youth coaches in intentionally facilitating life skills learning and positive youth development in South Africa (Meir, 2017; Whitley et al., 2013; Whitley, Wright, \& Gould, 2016). These studies have found that coaches were cognizant of the challenges facing youth in 
the community and therefore intentionally employed strategies to build life skills (Whitley et al., 2013). These strategies included building close relationships with youth, creating safe and caring sport climates, engaging youth in discussion, and providing opportunities to practice skills.

Further strategies identified were encouraging self-reflection, modeling behavior, and empowering youth to problem-solve. (Whitley et al., 2013; Whitley, Wright, \& Gould, 2016). These findings support empirical and review research in North America that emphasize the twofold role of coaches in creating a caring and positive sport climate and using explicit life skills building strategies (Collins, Gould, Lauer, \& Chung, 2009; Gould \& Carson, 2008; Gould et al., 2007; Holt et al., 2017; Santos, Camiré, \& Campos, 2016).

Despite the valuable role of coaches in facilitating life skills outcomes for youth sport participants, coaches often struggle to articulate the explicit strategies that they employ to build life skills (Camiré et al., 2013; Gould et al., 2007; Santos et al., 2016) or they face significant barriers to emphasizing life skills in their coaching (Whitley, Gould, Wright, \& Hayden, 2017). Coaches have voiced concerns over the incompatibility of performance and life skills foci and the pressure to teach tactical and technical sport skills over life skills (Santos et al., 2016; Whitley et al., 2017). Further, coaches have expressed that coaching education curricula are lacking in PYD emphases and do not effectively communicate how to facilitate personal development outcomes (Santos et al., 2016). In addition, life skills development is often absent from coaching philosophies to begin with (Whitley et al., 2017). Therefore, although there is justification for the use of coaches as implementers of youth life skills programming, there is a need to first identify the barriers that prevent coaches from adequately emphasizing life skills in their coaching (Whitley et al., 2017) as well as for further coach education on the successful integration of life skills and performance foci (Santos et al., 2016). Coaches may also benefit 
from training that develop teaching strategies to facilitate youth life skills learning and provides opportunities to practice those strategies (Santos et al., 2016; Whitley et al., 2013). In addition, there is limited research on this topic in non-Western contexts where youth could benefit from positive coach mentors and sport-based life skills programs. One possible solution to equipping coaches with the skills they need to deliver youth development programming would be to train them in the use of a more structured model that integrates physical and life skills objectives.

One of the most well-known instructional models for life skills education through sport in North America is Hellison's (2011) Teaching Personal and Social Responsibility model (TPSR; Hellison, 2011). The TPSR model is designed to help youth develop the necessary skills to take more responsibility for their well-being and for the welfare of others (Hellison, 2011; Martinek \& Hellison, 2016). It is an intentionally structured model that employs active learning strategies to help youth achieve small successes that build confidence and self-efficacy to engage in their own development. The TPSR framework includes five responsibility levels, or goals, that youth need to take ownership of along their developmental journey: 1) respecting the rights and feelings of others; 2) effort and cooperation; 3) self-direction; 4) helping others and leadership; and 5) transfer. In helping youth attain these responsibility goals, program instructors are expected to use the following strategies: empowerment, self-reflection, integration of physical activity and life skills, being relational with kids, and transfer to life outside sport. In addition, there is a standard daily structure for TPSR sessions that allow for relationship building, group and individual reflection, life skills awareness-building, and physical activity time (Hellison, 2011; Martinek \& Helison, 2016).

The TPSR model has been used as the guiding framework in a multitude of youth development programs (Gordon \& Doyle, 2015; Hellison, 2011; Martinek \& Hellison, 2016). 
These programs have primarily targeted underprivileged or at-risk youth and have been implemented in numerous settings ranging from in-school physical education classes to community-based programs (Caballero-Blanco, Delgado-Noguera, \& Escartí Carbonell, 2013; Gordon \& Doyle, 2015; Martinek \& Hellison, 2016). The effectiveness of TPSR programs in engendering positive developmental outcomes is supported by significant literature. Multiple studies have demonstrated improvements in self-control, effort, reaching goals, leadership, and helping or cooperative behaviors (Bean, Kendellen, \& Forneris, 2016; Caballero-Blanco et al. 2013; Cryan \& Martinek, 2017; Escarti, Gutiérrez, Pascual, \& Marín., 2010). Further, qualitative accounts of participant experiences during TPSR programs indicate high levels of enjoyment, experiencing caring adult relationships, developing a sense of belonging, and feeling safe (Caballero-Blanco et al. 2013; Escarti et al., 2010; Hellison \& Walsh, 2002; Whitley, Coble \& Jewell, 2016). In addition, studies also support the transfer of intrapersonal and interpersonal skills such as self-control, emotion regulation, effort, respect, and social skills to domains such as school, home, and peer groups (Bean et al., 2016; Caballero-Blanco et al. 2013; Hellison \& Walsh, 2002; Hemphill \& Richards, 2016; Whitley, Coble, \& Jewell, 2016).

Two noteworthy TPSR programs are the 'Girls Just Wanna Have Fun' (GJWHF) program in Ontario, Canada (Bean, Forneris, \& Halsall, 2014; Bean et al., 2016) and the Refugee Sport Club (RSC) in Lansing, Michigan (Whitley \& Gould, 2010; Whitley, Coble, \& Jewell, 2016). Both programs successfully created safe, empathetic and supportive youth environments for sport participation and contributed to the holistic development of youth participants. These programs provided key lessons for future TPSR programming including useful program design elements and coaching strategies that contribute to positive youth development outcomes. Further, the 
RSC program illustrated the value in adapting the program to the cultural context of the participants through taking a collaborative approach to program design.

The aforementioned research indicates that the TPSR model may be a useful guiding framework to help coaches deliver life skills-focused sport programming across multiple youth contexts. In eSwatini, the TPSR model could provide the foundation for the design of sportbased youth development initiatives that use coaches as primary program implementers. Moreover, there is justification for exploring this type of programming given the significant need to find more creative and effective platforms to address the developmental challenges facing emaSwati youth. In addition, there is evidence for the success of sport-based youth life skills development programs in South Africa where youth face similar developmental challenges.

However, any further explorations of sport-based youth life skills programming should be theory-driven and need to employ more rigorous monitoring and program evaluation as weak methodologies have been over-relied on (Coalter, 2015; Levermore, 2011; Spaaij, 2009). In addition, although the TPSR model has demonstrated significant success in fostering life skills with at-risk youth, the majority of TPSR programs have been implemented in Western contexts where youth challenges are culture-specific (Caballero-Blanco et al., 2013; Gordon \& Doyle, 2015; Whitley, Coble, \& Jewell, 2016). An exploration of TPSR programming in eSwatini would therefore provide an opportunity to explore how the model might operate differently in a distinct youth context (Wright, Jacobs, Ressler, \& Jung, 2016).

The multitude of research in North America supporting the value of the TPSR model in cultivating positive developmental outcomes for underprivileged youth suggests that it would be an appropriate framework for sport-based youth life skills programming in eSwatini. The main aim of this feasibility study was therefore to explore the youth participation experiences and 
successes/challenges associated with implementing a TPSR sport program for underprivileged youth in a community in eSwatini. A secondary aim of the study was to examine the positive youth outcomes and changes in life skills associated with participating in a TPSR sport program. The specific research questions were as follows: RQ1: What is the youth participation experience in a TPSR-based youth sport program in eSwatini?; RQ2: What are the coaching strategies and program design elements (strengths, weaknesses, and improvements of program and coach training) that contribute most strongly to life skills learning in a TPSR-based youth sport program in eSwatini?; RQ3: To what extent was fidelity to the TPSR model achieved in terms of daily structure, youth responsibility behaviors, and coaching strategies?; and RQ4: What positive developmental outcomes and changes in life skills are associated with youth participation in a TPSR-based youth sport program in eSwatini?

\section{Chapter 2: Methods}

\section{Paradigm}

The current study was guided by a social constructionist paradigm (Crotty, 1998). Social constructionism is grounded in the belief that there is no singular objective truth. Rather, we create and construct meaning through our interactions with our social and cultural context. This means that individuals may experience the same phenomenon differently and construct varying, and equally valid, "truths" related to those experiences (Crotty, 1998; Ponterotto, 2005). One of the central aims of constructionist research is therefore to understand the lived experience of the research participant as expressed from their viewpoint (Ponterotto, 2005). This epistemological stance was chosen because the author posited that the youth experience in the sport program, and the successes and challenges encountered in implementing the program, would be influenced by the social and cultural context of the community. 


\section{Positionality}

The emphasis on co-construction of meaning in social constructionism makes it necessary to examine the background of the primary researcher that may influence the interpretations made along the research journey (Creswell, 2007; Ponterotto, 2005). I was born and raised in eSwatini, Southern Africa, but my ethnic heritage is European, as my parents grew up in Belgium. Consequently, I was raised with a mixture of Swati and Belgian cultural influences, in a home environment that subscribed to European belief systems and a school and social environment that was rooted in Swati culture and beliefs. From a young age I experienced life in eSwatini both as an insider as well as an outsider. That is, I grew up in eSwatini, I attended a public primary school and had majority emaSwati (Swazi) friends, but I was also White in a nation where $97 \%$ of the population is Black.

After attending a local public primary school in eSwatini, I attended a United World College (UWC) for high school. Waterford Kamhlaba, a UWC located in eSwatini, is an international high school that attracts students of over 60 nationalities. Being surrounded by students from all over the world was a pivotal experience in shaping what I consider to be a multicultural worldview. However, this worldview is sometimes at odds with the more traditional beliefs in Swati culture. Waterford was then the stepping stone to gain a scholarship to attend college in the United States, at Duke University.

At 19, I left eSwatini to start my tertiary education in the United States. My educational experiences at Duke, and then at West Virginia University as a doctoral student, have significantly shaped my identity as an academic and a scholar. However, throughout my undergraduate, and graduate, educational experiences, I have made strong efforts to connect the material I was learning to life in eSwatini, and to the belief systems that are valued there. 
Nonetheless, I am aware that the majority of my higher education was experienced in a culture different from my home country, where I conducted my doctoral research. These experiences were likely to influence how I interacted with the research process; from choice of methodology, to program implementation and data analysis. From the participants' perspective, it was also likely that I was considered an outsider (ethnicity and identity as a researcher). However, my ability to speak conversational SiSwati and the fact that I was born and raised in eSwatini may have given me, somewhat of, an insider status.

\section{Setting}

The feasibility study took place at a community-based children's organization that operates in the Lobamba region of eSwatini. The children's organization is a non-profit that provides psychosocial services and school funding support for underprivileged youth in the community including orphans and vulnerable children (OVC's). In addition, the organization offers parenting skills programs for members of the community and infrastructure support for local schools. The organization also facilitates skill-building workshops in local schools on topics surrounding school administration, HIV/AIDS, abuse, grief, health, and basic counseling interventions. On a daily basis, the organization also provides pre-school education for OVC's in the community and afternoon clubs (i.e. classes) to assist primary school-aged children with literacy development. During these afternoon clubs, children are provided with a light meal (mahewu - a maize-based drink). The grounds of the children's organization have a vegetable garden, a sheltered outdoor play area as well as a soccer field.

\section{Needs assessment/pilot phase}


Based on the preliminary results from the needs assessment/pilot phase, several decisions were made to guide the development of the feasibility study (current dissertation). First, sport is a beloved and creative context through which to engage emaSwati (Swazi) youth in positive development. Using sport as the platform for youth programming in the feasibility study was therefore an appropriate path forward. Second, HIV/AIDS prevention is an immensely complex issue that requires long-term investment, strong community connections, and a multidisciplinary approach. The feasibility study therefore took out the HIV/AIDS component and instead focused on developing the life skills that HIV/AIDS experts identified as most valuable for HIV/AIDS prevention i.e. the PRE factors from phase 3. These included: self-belief, social \& personal responsibility, goal-setting, decision-making, self-efficacy, and emotional expression. Third, youth within the 15-24 years old demographic have already developed a strong set of beliefs related to relationships, gender roles, sexual intimacy etc. It would therefore be more effective to engage younger age demographics in youth development programming.

Fourth, emaSwati youth are lacking caring and empathetic adult mentors. Given that coaches believed in their role as mentors and educators for youth athletes, they were an appropriate population to engage with to implement sport-based positive youth development feasibility programming. Fifth, coaches were keen to learn strategies and approaches to strengthen their ability to facilitate life skills learning for their athletes. Using the Teaching Personal and Social Responsibility (TPSR) model to guide coach education for the feasibility study was therefore a viable option. Sixth, emaSwati youth were interested in engaging in mixedgender sport-based programming where they could learn multiple sports. The feasibility study was therefore designed to include these elements. Last, social cognitive theory and the positive youth development (PYD) framework were used as the theoretical foundation of the feasibility 
study. The emphasis of PYD on creating positive sporting environments and treating youth as inherently capable of becoming successful complemented the emphasis of social cognitive theory on human agency and the active role that youth may play in their development. The use of both implicit and explicit PYD learning pathways also provided the right social environment for self-efficacy beliefs to emerge in youth sport participants.

\section{Participants}

Youth participants were thirty-three students $(N=33,22$ females and 11 males $)$ aged 1115 years old $(M=12.6$ years old, range $=11-15)$ who attended the grades 6 and 7 afternoon club (grade $6(n=24)$, grade $7(n=9))$ at the community-based children's organization. Sample size at the outset was intended to be 15 youth participants as this has been found to be optimal for group activities and to create a caring climate (Cryan \& Martinek; Whitley \& Gould, 2010). However, all youth who attended the afternoon class at the time were keen to participate so the primary researcher decided not to deny participation to any youth given the ethos of the program. Eligibility criteria for participation included: 1) current enrollment in a primary school in the Lobamba area of eSwatini; 2) current attendance at the afternoon club at the children's organization; 3) conversational English language proficiency; 4) aged 10-15 years old; and 5) signed parental consent and youth assent to participate in the study. Although all youth who attended the organization were either single or double orphans, they all lived in a household where there was an adult guardian who could sign a consent form. Youth were recruited through convenience sampling from an afternoon club at the community-based children's organization that they attended.

Coach participants in the study were three $(N=3)$ male youth coaches ( 2 emaSwati, 1 Zimbabwean; $M=27.3$ years old) from the Lobamba region of eSwatini. This sample size was 
chosen given recommendations that the ratio of coaches to youth participants should not exceed 1:5 to provide the opportunity for quality one-on-one interaction (Cryan \& Martinek; Whitley \& Gould, 2010). Evidently this coach to youth ratio could not be retained given the significant increase in the number of youth participants. In addition, after one week of the sport program a coach had to drop out because he finally got a full-time job after two years of unemployment. The remaining two coaches ran the last 2 weeks of the program on their own. Coach eligibility criteria included: 1) at least two years of experience coaching a youth or adolescent sport team; 2) at least 18 years old; 3) English language proficiency; and 4) SiSwati language proficiency. The coaches included in the study had an average of 5.5 years of coaching experience and previous expertise coaching a range of sporting codes including basketball, soccer, volleyball, athletics, badminton, and aerobics. All coaches had a background coaching a similar age-group (U12 and U14) to the youth participants in the sport program. Two of the coaches had grown up in the same community as the youth participants while the third coach shared a similar socioeconomic background to the youth although he had grown up in a different country. Two of the three coaches had no prior training in positive youth development while the third coach had partially completed a training course in positive youth development.

Initial contact with coaches began via phone and email while the primary researcher was still in the United States. This was reasonable given the connections that were established through the researcher's study the previous summer on youth coaches in eSwatini. Every effort was made to recruit at least one male and female coach, but this was not possible given the limited number of female coaches in the country. The primary researcher also aimed to recruit coaches who were relatable (i.e. similar ethnicity and gender, and less than 20 years older than youth) to the youth and could be viewed as mentors. Relatability and the mentorship role of 
coaches has been found to be an important predictor of positive youth development outcomes through sport participation (Gould, Collins, Lauer, \& Chung, 2007). Moreover, during recruitment, the primary researcher emphasized the youth participant demographics with the coaches to highlight the privileged role they would be in as role models and trusted adults in the lives of the youth participants. Only coaches who seemed invested in that mentorship and educator role were asked to participate in the study. Coaches received a financial incentive and certificate for participating in the program, which they were informed of during the consent process.

\section{Sport Program Design}

The overall research objectives of the sport program (intervention) were to: 1 ) explore the youth participation experiences and successes/challenges associated with implementing a Teaching Personal and Social Responsibility (TPSR) sport program in eSwatini; and 2) examine the positive youth outcomes and life skills associated with participating in a TPSR-based sport program. Separate from these research objectives, the goals of the sport program for the youth and coach participants were to: 1) provide youth with opportunities to be physically active; 2 ) provide youth with opportunities to participate in a range of different sports and physical activity-based games; 3) provide youth with opportunities to have fun; 4) facilitate youth life skills development through sport; and 5) provide coaches with the opportunity to learn new coaching strategies to promote life skills development through sport. The sport program was named "Talabasha - Temidlalo Nemfundvo", which means "Youth time - Of sports and education/learning" in SiSwati. This name was chosen together with the coaches during the coach training. 
The sport program took place for 75-100 min every week day for three weeks with a total of 15 sessions. This was consistent with recommendations from prior TPSR programs that sport sessions occur at least two to three times per week for 60 minutes (Cryan \& Martinek, 2017; Whitley \& Gould, 2010). Although three weeks was a short amount of time to achieve sustainable program outcomes (Bean, Kendellen, \& Forneris, 2016), the current program was intended to be a feasibility study. The successes and challenges of implementing this type of youth sport programming will be used to inform more long-term programming in eSwatini. Sessions took place either on the soccer field or in the outdoor play area of the children's organization during the afternoon club slot between 2:30 and 4:10 pm every day. Sport equipment was purchased for use in the program thanks to the Association for Applied Sport Psychology (AASP) Gualberto Cremades International Research Grant. This included volleyballs, basketballs, soccer balls, netballs, frisbees, pinnies, cones, a volleyball net, and a video camera. This equipment was gifted to the children's organization after the end of the sport program.

The sport program was designed, and implemented, according to the key programmatic features of the TPSR model as well as using the information gathered during the needs assessment/pilot phase. The program was therefore grounded in the foundational TPSR principles of holistic youth positive development, youth centered approaches, and fostering human decency (Hellison, 2011; Martinek \& Hellison, 2016). The TPSR model was chosen over other life skills education through sport models for the following reasons: 1) the option to tailor the life skills focus to values and skills that are appropriate to the cultural and youth context that the program operated in; 2) the focus on teaching coaches how to use intentional strategies to 
facilitate the learning of life skills; and 3) the emphasis on transfer of life skills learning in the sport setting to domains outside of sport (Hellison, 2011; Martinek \& Hellsion, 2016).

As a brief overview, the sport program was designed using the standard TPSR daily structure (relational time, awareness talk, physical activity, group reflection, and individual reflection) and responsibility levels/goals (respecting others, effort and cooperation, selfdirection, helping and leadership, and transfer). Specific design elements from several successful TPSR-based youth sport programs also informed the development of the program. These TPSRbased programs included the 'Girls Just Wanna Have Fun' (GJWHF) program in Ontario, Canada (Bean, Forneris, \& Halsall, 2014; Bean et al., 2016), the 'Refugee Sport Club' in Lansing, Michigan (Whitley \& Gould, 2010; Whitley, Coble, \& Jewell, 2016), and the Soccer Coaching Club in central North Carolina (Cryan \& Martinek, 2016). Each day of the program followed the same TPSR daily structure except for session one. Session one was used for ice breakers and to briefly introduce youth to all the responsibility levels and the expectations for the program. The remaining 14 sessions used the same daily structure: 1$)$ relational time (10 minutes); 2) awareness talk (20-45 minutes); 3) physical activity (30 minutes); 4) group reflection (10 minutes); and 5) individual reflection (5 minutes). Details of the program design will now be described.

Each day started with a brief period dedicated to building the relationship between the coaches and the youth i.e. relational time. Coaches made an effort to briefly chat with as many youths as possible and build a caring and meaningful coach-youth relationship. Various pieces of sport equipment were available for the youth to play around with as they relaxed and refocused after their day at school. To encourage timeliness, youth were given a small piece of candy for arriving on time. A local maize-based drink (emahewu) was also made available for the youth to 
consume as this was something that was normally provided by the children's organization for their afternoon club classes.

The awareness talk followed the relational time and was an opportunity for the coaches to teach the youth a life skill or responsibility that is valuable to develop. Awareness talks took place under a large tree on the sport field as it is customary in Swati culture to have group discussions under the shade of a tree. Although the awareness talks were intended to be facilitated in a mixture of English and SiSwati, it became apparent very quickly that youth confidence was very low in English so SiSwati was used as the primary means of communication. This decision ultimately promoted higher youth participation in discussion. Each day of the program focused on a specific responsibility level and main life skill. As the weeks progressed, the responsibility level foci shifted to the more complex responsibility behaviors i.e. moving from respect (level 1) to effort (level 2) to self-direction (level 3) and to caring and leadership (level 4). The final level, transfer (level 5), was included in every session given that this is an integral component of the TPSR model and previous programs have recommended integrating transfer into as many sessions as possible (Bean et al., 2016; Whitley, Coble, Jewell, 2016; Walsh, Ozaeta, \& Wright, 2010). Transfer was operationally defined as any individual conversations, reflection opportunities or discussions related to applying life skills and responsibility concepts learned in the program to other domains of life such as school. Visual posters defining each life skill in English and siSwati were hung on and around the tree to aid learning. Using visual aids is an effective teaching strategy that accommodates for differences in the developmental needs and learning styles of youth (Allison \& Rehm, 2007). A whiteboard was also used in most sessions where the poster for the life skill focus of that day was placed for easy reference. Although the sport program was delivered primarily in SiSwati, the use of the 
visual aids that translated each SiSwati concept into English nonetheless helped youth learn about how the concepts could be referred to in English.

In an effort to make the awareness talk an interactive and engaging component of the daily structure, there was always an activity integrated into the awareness talk that focused on the responsibility level and life skills of the day. These structured life skills learning activities were drawn from the Sports United to Promote Education and Recreation (SUPER) model (Danish, Forneris, Hodge, \& Heke, 2004) of life skills education through sport (e.g. Dare to Dream activity) as well as sport psychology literature (e.g. deep breathing and muscle relaxation). An extended version of the awareness talk was used to provide time for the integration of those activities into the awareness talk. However, although the awareness talk was intended to be 20 minutes, most days had awareness talks that lasted between 30 and 45 minutes. Swati culture has a strong oral tradition which is typified by very deliberate and slow-paced discussion where talking points are emphasized multiple times during the same conversation. For this reason, it was necessary to have a longer awareness talk.

The awareness talk was followed by the physical activity period. This phase was where youth were guided in a physical, or sport, activity that provides them with an opportunity to learn a physical, or sport-specific, skill and also practice some of the life skills and responsibilities from the awareness talk. The program was designed such that youth learned about, and participated in, multiple different sports including, but not limited to, soccer, basketball, ultimate frisbee, and volleyball. This decision was based off the findings from the focus groups with youth (Huysmans et al., 2017) in the needs assessment phase of this feasibility study, which indicated that youth were interested in playing multiple sports and learning new sports and physical activity-based activities. Providing the opportunity to participate in multiple sports 
therefore met the expressed needs of the local youth and also helped keep youth engaged and increased enjoyment (Bean et al., 2014; Whitley, Coble, \& Jewell 2016).

In the group reflection period, the youth and coaches gathered together to explore the main lessons of the day and the youth experiences in integrating the life skills/responsibility lesson into their physical activity component. The group debrief time was specifically structured to include discussions on how the life skills lessons of the day might transfer to life outside of the sport program (Bean et al., 2016; Whitley, Coble, Jewell, 2016). The special spot under the shade of the tree was referred to as the 'Reflection Corner' where the visual aids were used to support group reflection (Whitley \& Gould, 2010). The large group was often split into two or three smaller groups to facilitate more effective and in-depth discussion. Last, youth had an opportunity to briefly self-reflect on how the life skills lessons applied to their own life and what they enjoyed about the day's activities. On several days, the primary researcher also supervised a "structured play" period at the end of the day's session when the coaches had to leave but the youth still wanted to have an extra 30 minutes to compete in a game against one another. Youth received a banana and an orange at the end of each day's session and received a chocolate treat on the Friday sessions. See appendix A for a detailed outline of the sport program.

\section{Sport Program Implementation}

The sport program was designed such that local coaches were the primary implementers of the program. Local coaches were recruited as the primary instructors of the sport program because they are highly respected by youth and interact with them on a frequent basis (Conroy \& Coatsworth, 2006). Coaches were also appropriate primary implementers for TPSR programming given the emphasis placed in Hellison's model on using instructors who are competent at teaching physical education and/or sport skills (Hellison, 2011). Further, training 
coaches on how to integrate a TPSR framework and youth development concepts into their coaching has been found to have positive impacts on the youth sport experience (Conroy \& Coatsworth, 2006) and would also give the coaches a skill that they could carry forward in their future coaching.

For the current study, a train-the-trainer approach was used whereby the primary researcher trained coaches how to implement the sport program (Blom et al., 2015a). Coach training was composed of three sessions of five hours each (15 hours total) that occurred across three days and was conducted by the primary researcher (Bean et al., 2014; Cryan \& Martinek, 2017; Escarti, Gutierrez, Pascual, \& Marin, 2010). A blended learning approach was utilized that integrated multiple learning strategies (e.g. experiential learning, discussion, self-reflection, didactic presentations etc.) to deliver the training (Blom et al., 2015b; Pearce et al., 2012). Coach education research indicates that coaches prefer educational approaches that include multiple learning experiences, focus strongly on practical and pedagogical knowledge, and integrate research (Cassidy, Potrac, \& McKenzie, 2006; McCullick, Belcher, \& Schempp, 2005; Mesquita, Ribeiro, Santos, \& Morgan, 2014). In addition, coaches value being able to reflect on personal experiences and share those background stories with other coaches. This is consistent with adult learning theory, which states that learning should be a multidimensional experience that involves meaning making, critical reflection, dialogue, and connecting new knowledge with life experiences (Merriam, 2008). Coaches have also stated that educator characteristics such as enthusiasm, level of preparedness, and relatability are important alongside creating a learning environment where coaches are actively engaged in their own learning (McCullick et al., 2005; Nelson, Cushion, \& Potrac, 2013). During recruitment of coaches, the primary researcher 
emphasized recruiting coaches who were open to exploring their own identity and displayed energy and excitement at the prospect of adding a new tool to their coaching repertoire.

The coach training program was designed using key concepts from the following areas: positive youth development (PYD) (Camiré, Forneris, Trudel, \& Bernard, 2011; Collins, Gould, Lauer, \& Chung, 2009; Holt \& Neely, 2011), sport-for-development (SFD) (Blom et al., 2015a; Blom et al., 2015b; Coakley, 2011), sport psychology (Keegan, Spray, Harwood, \& Lavallee, 2010; Rhind \& Jowett, 2010), coach education (Gilbert, Nater, Siwik, \& Gallimore, 2010; Smith, Smoll, \& Cumming, 2007; Van Mullem \& Brunner, 2013; Vealey, 2005), social cognitive theory (Bandura, 2001; Blom et al., 2015a), adult learning theory (Merriam, 2008), and TPSR programming (Escarti, Wright, Pascual, \& Gutierrez, 2015; Hellison, 2011; Bean et al., 2016; Whitley, 2012; Whitley \& Gould, 2010). The coach training program was reviewed by a doctoral colleague in the field of coaching and teaching studies.

Across the three-day training coaches learned positive youth development principles, TPSR core values, themes, and teaching strategies, as well as current examples of TPSR programs. Specifically, coaches explored the values, youth-centered principles, and coaching strategies inherent to PYD approaches to coaching. That is, coaches learned how to create a safe, high energy, and caring environment where youth feel respected and supported. This included learning how to relate to each youth participant as an individual and provide unconditional positive regard. Previous research indicates that coaches respond positively to learning about youth-centered approaches to coaching and also to adopting TPSR principles (Wright, Jacobs, Ressler, \& Jung, 2016). In addition, coaches learned how to adopt a youth-centered approach of empowerment and self-efficacy through providing opportunities for youth to lead and participate in discussion. Coaches also explored their own motivations and personal aspirations for coaching 
and learned to connect these with PYD values. Personal and group reflection was used to prompt coaches to think about the relevance of sport in their own lives, the current sport and youth context in eSwatini, and their identity as a coach in being a change agent for young people (Wright et al., 2016). Coaches also learned how to create a coaching philosophy grounded in PYD principles.

In addition, coaches learned about the foundational values of the TPSR model as well as the responsibility levels and daily structure that are central to the framework. This included an exploration of how the model might need to be adapted to the cultural context of eSwatini. Coaches explored how to integrate the core TPSR instructor themes (empowerment, selfreflection, integration, transfer, and being relational with kids) into every session. They were also taught how to use the explicit teaching strategies from the Tool for Assessing Responsibilitybased Education 2.0 (TARE 2.0) (Escarti et al., 2015) to foster life skills outcomes in the youth participants. The TARE 2.0 is described in detail in a later section. Coaches also specifically learned coaching strategies that promote transfer of learning. These included strategies such as self-reflection, providing feedback when youth demonstrate a skill, and providing youth with opportunities to practice the life skills they learn in each session. During training coaches discussed the differences between the TARE teaching strategies and also practiced and role played the use of these strategies. Further, examples of previous and current TPSR programs were discussed and examined to better understand how TPSR programs are designed and implemented.

On the last day of training, coaches reviewed, in detail, the proposed session outlines for the sport program and were given the opportunity to change, or add to, the sport program's implementation. Although modules had already been created for the sport program, coaches were 
encouraged to contribute as many ideas as they wished so they could take ownership of the program. They were also encouraged to identify any activities that needed to be revised for cultural appropriateness. The original modules simply served as a backup plan if coaches wanted ideas for activities. This was consistent with taking a collaborative, bottom-up approach that integrates local knowledge to create more effective programming and stronger shared ownership (Hartmann \& Kwauk, 2011; Whitley, Forneris, \& Barker, 2014). Following input from the coaches, minor changes were made to the content of some of the awareness talk activities as well as the choice of sports in order to best meet the cultural and developmental needs of the youth as well as the competencies of the coaches.

Once program modules had been finalized, coaches practiced some of the life skills activities and divided leadership roles for implementation of the program. Together with the primary researcher, the coaches also practiced completing the TARE reflections that were a part of data collection. The primary researcher also discussed the role of evaluation and critical feedback with the coaches to help them buy in to the importance of their honesty and effort in completing the evaluations throughout the program. The researcher emphasized that a major aim of the program was to figure out what worked well and what didn't work well in order for the program to be better for youth in the future. Their role as sources of critical feedback was therefore pivotal. At the end of the training coaches completed an evaluation of the coach training and provided some feedback on their preparedness to implement the sport program. Coaches received a training manual with lesson plans and TPSR/PYD theoretical content. See appendix B for a detailed description of the coach training program.

\section{Instrumentation/Measures}


Demographics: Basic demographics were collected from the youth and coach participants including age, gender, ethnicity, and year in school. See appendix C.

Personal and Social Responsibility Questionnaire: The PSRQ (PSRQ; Li, Wright, Rukavina, \& Pickering, 2008) is a 14-item self-report measure of personal and social responsibility composed of 2 scales (i.e. personal responsibility and social responsibility) with 7 items each. Social responsibility aligns with the two TPSR levels of respect and caring for others. Sample items include, "I respect others" and "I am helpful to others". Personal responsibility scale aligns with the two TPSR levels of effort and self-direction. Sample items include, "I try hard" and "I set goals for myself". The measure does not assess the fifth responsibility level of transfer. Items are scored on a 6-point Likert scale ranging from 1 (strongly disagree) to 6 (strongly agree) with total scores ranging from 14 (low social and personal responsibility) to 84 (high social and personal responsibility). It is a psychometrically valid instrument with adequate internal consistency (0.79-0.81) (Li et al., 2008). Research indicates that the PSRQ can be triangulated with other forms of qualitative and quantitative data for process and outcome evaluation of TPSR programming (Li et al., 2008). In addition, although the PSRQ does not measure transfer and concepts such as team work and peer coaching, it does encompass the most simple and fundamental concepts of the TPSR model. This is useful because it assesses concepts such as effort that can apply to any activity (Li et al., 2008). The original English version of the PSRQ was translated into SiSwati for the purposes of this study. Although it was not possible to pilot the translated version, the SiSwati version was back-translated by three youth in the same age bracket as the program participants. See appendix D for the full scale. 
Multidimensional Scales of Perceived Self-Efficacy: The MSPSE (MSPSE; Bandura, 1990, 2001) is a self-report measure of personal and social self-efficacy and is composed of 57 items and nine subscales representing Bandura's nine proposed domains of self-efficacy: enlisting social resources (four items), academic achievement (nine items), self-regulated learning (11 items), leisure-time skill and extracurricular activities (eight items), self-regulatory efficacy to resist peer-pressure (nine items), meet others expectations (four items), social selfefficacy (four items), self-assertive efficacy (four items), and enlisting parental and community support (four items). A 7-point Likert scale is used to rate responses to each item from 1 (not well at all) to 7 (very well). For each of the domains of self-efficacy, scores are summed and averaged to yield a minimum score of 1 (low self-efficacy) and a maximum score of 7 (high selfefficacy) for each domain. The MSPSE has demonstrated adequate validity and internal consistency $(\alpha>0.70)$ for all nine subscales (Choi, Fuqua, \& Griffin, 2001). For the current study, the five most relevant subscales (32 items total) were chosen that aligned most strongly with the research questions and objectives of the study: enlisting social resources, self-regulated learning, self-regulatory efficacy to resist peer pressure, self-assertive self-efficacy, and social selfefficacy. This also reduced the cognitive load of the combined survey packet and is consistent with previous research that also selected the most applicable subscales (Escarti et al., 2010). The original English version of the MSPSE was translated into SiSwati for the purposes of this study. Although it was not possible to pilot the translated version, the SiSwati version was backtranslated by three youth in the same age bracket as the program participants. See appendix E for the list of MSPSE items.

Student learning quiz: The student learning quiz (Hellison, 2011; Wright \& Burton, 2008) is a brief assessment of three life skills or responsibilities that the youth learned over the 
course of the program. Student learning quizzes can be appropriate ways to identify life skills outcomes in youth participants (Hellison, 2011; Wright \& Burton, 2008). Youth are asked to first identify 3 life skills that they learned during the program and then for each of the life skills or responsibilities identified give an example of how this life skill might be applied in a different domain of their life outside of the sport program (see appendix F). The life skills quiz was translated into SiSwati.

Coach focus group: Focus groups were conducted with the coaches to explore their experiences implementing the program. This included identifying the successes and challenges related to program implementation as well as suggestions for improvement. Specific focus was placed on identifying the strategies coaches found to be most impactful for promoting life skills outcomes. The focus group guide was developed using previous studies exploring implementation and outcomes of TPSR programming (Bean et al., 2016; Wright et al., 2016). The guide was reviewed by a sport psychology professional with significant experience with TPSR programming and qualitative methodologies. Minor changes were made to the guide based on this feedback (see appendix G).

Youth focus groups: Youth focus groups focused on their experiences participating in the program as well as some reflection on personal development. This included reflections on what they learned in the program, how they might use those skills in other domains of life, and what they liked and disliked about the program. The youth focus group guide was developed from questions used in the GJWHF (Bean et al., 2014; Bean et al., 2016) and RSC program (Whitley, Coble, \& Jewell, 2016) and was reviewed by a sport psychology professional with significant experience with TPSR programming and qualitative methodologies. Minor changes were made to the guide based on this feedback (see appendix $\mathrm{H}$ ). The focus guide was translated into 
SiSwati to provide youth with the option to conduct the interview in the language they felt most proficient in.

Teacher interview: A semi-structured interview was conducted with the afternoon club teacher two weeks after the culmination of the sport program. The objective of the teacher interview was to gather information on any transfer of learning that had been observed in the youth after their participation in the program. Given that the teacher was also an observer of the sport program, additional questions focused on any strengths and weaknesses of the program as well as suggested improvements (see appendix I).

Tool for Assessing Responsibility-Based Education (TARE) (Post-Teaching Reflection): The TARE post-teaching reflection (Wright \& Craig, 2011) is an adapted version of the TARE observation tool. Although the observation tool version of the TARE has been revised to create the TARE 2.0 version (TARE 2.0; Escarti et al., 2015), the post-teaching reflection has not yet been revised. However, after contacting the first author of the TARE 2.0, it was decided that the TARE post-teaching reflection could be modified for the current study to better align with the revised TARE 2.0 observation tool. After making the modifications for the current study, the tool was sent back to the first author for review and approval. The modifications were approved without any suggested changes.

The modified version of the TARE post-teaching reflection that was used in this study is a self-report measure that is completed by the instructor (i.e. coaches) to assess their own use of the nine TARE teaching strategies and their observations of student behaviors. The TARE postteaching reflection is divided into two sections: 1) responsibility-based teaching strategies; and 2) student responsibility behaviors. The teaching strategies section identifies nine core teaching strategies that instructors should be employing during TPSR programming to foster 
responsibility outcomes in youth participants. These nine teaching strategies are: modeling respect, setting expectations, providing opportunities for success, fostering social interaction, assigning manageable tasks, providing leadership opportunities, giving choices and voices, role in assessment, and encouraging transfer. The teaching strategies are assessed using a 0 (absent) to 4 (very strong) Likert scale. The observed student responsibility behaviors include nine behaviors that align with outcomes identified in positive youth development and TPSR literature. These behaviors are: participation, engagement, showing respect, cooperating with peers, encouraging others, helping others, leading, expressing voice, and asking for help. The presence of the nine student responsibility behaviors is rated using a 4-point Likert scale from 0 (very weak) to 4 (very strong). See appendix $\mathrm{J}$ for a full example of the TARE post-teaching reflection tool.

TPSR Implementation Checklist: The TPSR Implementation Checklist (Wright \& Walsh, in press) is an assessment of the implementation of the TPSR daily structure, responsibility levels addressed, key teaching strategies, and observation of student responsibility behaviors. The TPSR daily structure section identifies the components of the daily structure that were implemented in the session i.e. relational time, awareness talk, physical activity, group meeting, and reflection time. The responsibility levels identify the responsibility goals addressed in the session: respect, self-motivation, self-direction, caring, and transfer. The key teaching strategies identify which of the nine TARE 2.0 teaching strategies were employed while the student responsibility behaviors focus on the nine responsibility behaviors of the TARE 2.0. A full version of the TPSR Implementation Checklist is available in appendix $\mathrm{K}$.

Field notes: Daily field notes (Cryan \& Martinek, 2017; Walsh et al., 2010; Whitley, 2012) were composed of the primary researcher's observations of each program session, notes 
from the daily coach debrief, and a daily TPSR implementation checklist (see description above) that will be completed by the primary researcher at the end of every session. Researcher daily observations included descriptions of observable coach and youth behaviors, critical/meaningful incidents, and general successes and challenges of the day. Notes from the daily coach debrief included comments on what coaches thought worked well, what the challenges were, any critical incidents, and any thoughts on improvements for the next day.

\section{Procedures}

Study methods and rationale were submitted to the Institutional Review Board of West Virginia University as well as the Ethics Board of eSwatini to gain permission to conduct the study. Following approval from both ethics committees, the primary researcher contacted the director of the community-based children's organization in eSwatini to explain the purposes and objectives of the proposed TPSR-based sport program. This initial contact was first done via email and then through a skype conversation. The aims of this initial contact were threefold: 1) to determine whether the organization would be willing to host the sport program; 2) to explore whether the vision of the children's organization aligned with the objectives of the sport program; and 3) to examine whether the program would be likely to be well-received by the community. Logistics of the sport program (i.e. availability of sport field and access to youth) were also discussed to identify and explore access to the youth that could potentially participate in the TPSR program.

Once permission to use the children's organization as the primary site for program implementation had been obtained, the primary researcher began to contact prospective youth coaches. Coaches were recruited using purposive and snowball sampling using email and phone contact. As previously explained, this process started while the primary researcher was still in the 
United States given the established local coach connections from previous research in eSwatini. Once the primary researcher had arrived in eSwatini, an initial meeting was arranged with each of the prospective coaches within that first week. The coaches chose the location and time of this meeting. During the meeting, the primary researcher assessed coach suitability for the program in terms of buy-in to their mentorship and educator role for the youth as well as willingness to invest in the evaluation component of the program. Coaches who met these parameters were asked to attend the coach training, which took place the ensuing week.

Within the same first week of the primary researcher arriving in eSwatini, a meeting was also arranged with the afternoon club teacher and the director of the children's organization. At this meeting, the primary researcher introduced the objectives and ethos of the sport program to the teacher and solicited his input on the logistics of the youth recruitment and consent procedures. As a result of this discussion, the following decisions were made: 1) all youth in the grades 6 and 7 class $(N=40)$ would likely wish to participate so the maximum participant number was expanded; 2) organizing a meeting with youth guardians or parents would not be necessary as the youth were generally fairly good with returning documents given to them by the children's organization; 3) although youth did attend English-speaking schools, their English language proficiency would not be high enough to complete the surveys in English. All surveys, life skills quizzes, and focus group questions would therefore be presented in SiSwati; 4) youth reading comprehension skills were poor so the baseline and post surveys would have to be administered partially as an oral assessment i.e. the teacher would help them read each item out loud to ensure comprehension; and 5) the afternoon club teacher would serve as the videorecorder during the duration of the program as he was keen on being a part of the program. It was 
then decided that the primary researcher would attend the afternoon club class the following week to recruit the youth participants.

At the start of the following week, the primary researcher attended the grade six and seven afternoon club class to speak to the youth. The purpose of this visit was to explain the aims of the sport program to the youth attendees. The afternoon club teacher helped with translating the more complex concepts and also helped build the rapport between the youth and the primary researcher. The teacher had clearly established a very strong bond with the youth and was a valuable resource for the primary researcher. Youth who expressed interest in participating in the study were given an assent form (see appendix M), which was reviewed together with the primary researcher. Before signing the assent form, the youth were asked to take the assent form home with them and review it with their parents or guardians. Youth were also given a parental consent form (see appendix $\mathrm{N}$ ) for a parent or guardian to complete. Youth assent forms and parental consent forms were presented in SiSwati. The teacher reminded the class that only youth who returned both the consent and assent forms by the following day would be eligible to participate in the sport program. Over the course of the program several more new youth showed up. Although these youth were allowed to participate in the sport program, they did not complete any data collection measures or procedures.

The day after recruitment of the youth participants, coach training began. The primary researcher was responsible for conducting the 15-hr coach training, which occurred in a conference room at the school where two of the coaches worked. After working through several ice-breaker games, the primary researcher presented an informed consent (see appendix L) to the coaches to review its contents. After signing the informed consent, coach training official began. Upon completion of the coach training, the sport program was scheduled to begin on the Monday 
of the following week. Once the program started, coaches were responsible for implementing all aspects of the daily sport program. The role of the primary researcher was to observe each session, take notes of observations, and provide assistance to the coaches if needed. From the start of the program it was emphasized that the primary researcher would be an ally and would not be grading the coaches on how well they were doing. Coaches met with the primary researcher for an hour at the beginning of each day's session to debrief the successes and challenges of the previous day and prepare for the upcoming session. The coaches and primary researcher discussed and decided together how the lessons from previous sessions could be used to improve the delivery of the ensuing sessions. All discussion points were included in the primary researcher's field notes.

\section{Pre-program data collection procedures}

Overall, data collection employed a mixed methods approach that triangulated data from quantitative and qualitative sources. Data was collected from multiple sources including youth participants, coaches, the afternoon club teacher, and observations from the primary researcher. Data collection methods involved baseline and post-program surveys (Escarti et al., 2010; Cryan \& Martinek, 2017), student learning quizzes (Hellison, 2011; Wright \& Burton, 2008), focus groups with youth and coaches (Bean et al., 2014; Gordon, Jacobs, \& Wright, 2016; Whitley, Coble, \& Jewell, 2016; Wright et al., 2016)), a semi-structured interview with the teacher, coach reflections (Bean et al., 2014; Whitley, 2012), and field notes (Cryan \& Martinek; Gordon et al., 2016; Walsh et al., 2010; Whitley \& Gould, 2010). The selection and triangulation of these forms of data collection was reviewed and approved by a leading researcher in TPSR-based youth programs. 
Baseline data collection began on the Wednesday before the start of the sport program. The primary researcher visited the grade six and seven afternoon club class and asked the participating youth to complete two baseline surveys: the PSRQ (Li et al., 2008) and the MSPSE (Bandura, 1990, 2001); SiSwati versions. Several demographic questions were also included in this baseline assessment. All youth in attendance that day had returned their parental consent and assent forms. The teacher helped with translating and explaining the instructions for completion of the surveys and also helped to orally administer the surveys by reading each item out loud. The teacher reminded the youth that their responses to the surveys would not be seen by him or any other staff member at the children's organization; only the primary researcher would see them. This oral administration of the surveys took about 30-minutes to complete. The primary researcher was informed at the end that a group of youth were not in attendance that day because they hadn't returned their forms but that they would have them for the following day. These same survey procedures were therefore repeated the following day for the second group of participating youth.

\section{During-program data collection procedures}

During the sport program, youth completed a written student learning quiz at the end of each week during the reflection time. The learning quizzes (SiSwati version) identified the most salient life skills lessons youth took away from the program sessions each week. Coaches were responsible for administering the student learning quizzes. This was chosen as an appropriate approach such that the quizzes would be more likely to be perceived as part of their learning with the coaches instead of being part of the research. Coaches explained to the youth that the quizzes were a way for the coaches to see what was resonating the most with each of them. Youth were reminded that there were no right or wrong answers. 
On two occasions during each week of the sport program (i.e. middle and end of week), the coaches were asked to complete the modified TARE post-teaching reflection at the end of the day's session. As previously described, the TARE post-teaching reflection explores the teaching strategies and TPSR themes that coaches employed during the sport session. It also addresses the responsibility behaviors coaches observed in the youth participants. These reflections were completed at their respective homes between daily program sessions.

Across the duration of the program, the primary researcher also took field notes of her daily observations during program delivery. Using field notes is a data collection method that has been employed in numerous TPSR studies (Cryan \& Martinek, 2017; Gordon et al., 2016; Walsh et al., 2010; Whitley, 2012). Field notes included observations of the successes and challenges of each day's session, student and coach behaviors, as well as meaningful moments of learning. Field notes also included a TPSR checklist that the primary researcher completed at the end of every session. In addition, the field notes included minutes from the daily debrief between the coaches and the primary researcher.

\section{Post-program data collection procedures}

On the Tuesday and Wednesday after the conclusion of the program, youth completed both baseline survey measures again i.e. the PSRQ (Li et al., 2008) and the MSPSE (Bandura, 1990, 2001); SiSwati versions. The same oral administration procedures were used. For this postprogram data collection, the boys and girls completed the surveys on separate days. On the Tuesday, the boys completed the surveys during their regular afternoon club class time and the girls completed the surveys on Wednesday. In conjunction with the surveys, focus groups were also conducted with the participating youth. Focus groups were divided by gender and took place immediately after the completion of the surveys i.e. boys' focus group on Tuesday and girls' 
focus group on Wednesday. Focus groups were audio-recorded, were conducted in SiSwati and lasted approximately 30-minutes. The focus groups were conducted by a different staff member who had been trained by the primary researcher last summer in basic research methods and focus group and interviewing techniques for a previous study. This staff member had an established relationship and comfort level with the youth because of their work at the children's center. Youth were therefore more likely to be open and honest in their responses (Heath, Brooks, Cleaver, \& Ireland, 2009). Focus groups explored youth participation experiences and learning outcomes in the sport program. At the start of the focus groups, youth were told that the objective of the focus group was to gather information to help make the program better so it was important that they be honest with their answers. There would be no repercussions for their responses and only the researcher would hear the audio-recording.

The day after the concluding focus groups, youth participants were also asked by the staff of the children's organization to present some thoughts on their experiences participating in the program and the life skills they learned about. In front of the staff and the pre-school children, eight youth presented what they had learned, shared stories, and did several demonstrations of the skills they had acquired e.g. belly breathing. Although there was no data collection involved in this event, it was an additional opportunity for youth to present and reflect on what they had learned during the sport program.

In addition, at the end of the program, coaches participated in a 45-60-minute audiorecorded focus group exploring their experiences in the program as well as suggestions for improvement. The coach who had to leave the program mid-way through participated in a separate interview on his own because of schedule conflicts. The primary researcher conducted the focus group and interview with the coaches. The collaborative approach that was taken 
throughout the sport program (i.e. coach input in program design, researcher as ally, and daily debrief sessions to improve program) helped build the comfort level between the primary researcher and the coaches. This contributed to open feedback during the focus group and interview. Coaches also received their financial incentive prior to participating in the interviews to reduce their fear that honest feedback might jeopardize their incentive. In addition, the primary researcher emphasized that critical feedback would be the most helpful form of feedback to make the program better for future youth participants. At the start of the focus group and interview, coaches watched a 30-minute clip of their coaching during the program and were given the opportunity to discuss their observations with the primary researcher and receive some feedback. All forms of assessments with the coaches were conducted in English.

Two weeks after the completion of the sport program a final interview was also conducted with the afternoon club teacher. The aim of this interview was to gather information related to student transfer of life skills learned during the sport program. Questions also focused on strengths and weaknesses of the program given that the teacher observed the whole program. The teacher completed a consent form (see appendix O) prior to the audio-recorded interview, which lasted approximately 20-minutes.

\section{Data Analyses}

Data analysis included analyses of program implementation (i.e. process evaluation of participant experiences, effective coaching strategies, and program fidelity) and program impact (i.e. outcome evaluation of youth positive outcomes and life skills changes). This was achieved through the concurrent analysis and triangulation of data from the following sources: youth baseline and post-program quantitative surveys, student learning quizzes, youth and coach focus 
groups, teacher interview, coach reflections, field notes, and video-recordings. See Table 1 for a visual representation of the complete analytical approach.

To address research question (RQ) one and examine the youth participant experience during the sport program (process evaluation), content analysis was used to analyze the youth and coach focus groups, the teacher interview, and the primary researcher's field notes (Elo \& Kyngas, 2008; Hsieh \& Shannon, 2005). This analytic approach was appropriate given that this was an exploratory feasibility study with the primary aim to examine the experiences and outcomes of youth participants and the successes and challenges of implementing a TPSR program in eSwatini. A combination of an inductive and deductive approach was used to allow for new codes to emerge but also for specific codes related to program implementation and positive youth development outcomes to be identified (Flick, 2014; Wright et al., 2016). Data from the interview, focus groups, and field notes were first transcribed verbatim from the audiorecordings (focus groups and interview) or from the written notes (i.e. field notes) (Côté, Salmela, Baria, \& Russell, 1993; Flick, 2014; Hsieh \& Shannon, 2005). Focus groups that were conducted in SiSwati were translated back to English for content analysis. Two researchers then began the process of independently conducting the content analysis. Each researcher began by familiarizing themselves with the content of the transcripts by reading over them multiple times.

Next, researchers re-examined the transcripts and highlighted and tagged text that captured key initial thoughts. This was followed by open coding of themes, and the identification of quotes of meaningful participant commentary (i.e. raw data). Once all themes were coded, these codes were categorized and organized into lower and higher order codes that reflected the relationship between different codes (Côté et al., 1993; Flick, 2014; Hsieh \& Shannon, 2005). Iterative consensus validation was used to allow the researchers to compare their initial thoughts, 
open codes, raw data themes, and lower/higher codes and to reach consensus and resolve any differences that arose (Whitley et al., 2016). A third researcher was also used as a 'critical friend' (Smith \& McGannon, 2017). Their primary role was to prompt the two primary coders to reflect on alternative interpretations of the data. When content analysis was completed for each of the data sources (i.e. youth and coach focus groups, the teacher interview, and the primary researcher's field notes), the findings were triangulated and compiled.

To address the first part of RQ2 and examine the coaching strategies (process evaluation) that contributed most strongly to youth life skills learning, content analysis was used to analyze the coach focus groups and field notes. The same content analysis steps described previously were utilized. To address part two of RQ2 and identify program design strengths and weaknesses (process evaluation), content analysis was used to analyze the youth and coach focus groups, the teacher interview, the evaluation of coach training, and the primary researcher's field notes. Analyses from the aforementioned sources were triangulated to generate overall findings for RQ2.

To address RQ3 and assess fidelity to the TPSR model in terms of TPSR daily structure, youth responsibility level behaviors, and coaching strategies, several different analytical strategies were used. First, descriptive statistics were generated from the TPSR checklist to assess fidelity to the TPSR daily structure. That is, frequency and percentage figures were calculated to determine the proportion of sessions in the program that adhered to the TPSR daily structure. To assess fidelity to the youth responsibility behaviors, content analysis of the field notes, coach focus groups, and the teacher interview was used. In addition, descriptive statistics were generated from the TPSR checklists and the coach reflections (TARE post-teaching selfreflection) to assess youth responsibility behaviors. Specifically, from the TPSR implementation 
checklist, frequency and percentage figures were calculated to determine the proportion of the nine youth responsibility behaviors that were present in each session of the program. From the coach reflections, a mean $(\mu)$ score of presence of responsibility behaviors was generated ranging from 0 to 4 with $0=$ very weak, $1=$ weak, $2=$ moderate, $3=$ strong, $4=$ very strong. Last, fidelity to the TPSR coaching strategies was analyzed using descriptive statistics (i.e. frequency and percentages) from the TPSR implementation checklist. Similar to the youth responsibility behaviors, the coach reflections were used to generate a mean $(\mu)$ score of utilization of TARE coaching strategies ranging from 0 to 4 with $0=$ absent, $1=$ weak, $2=$ moderate, 3 = strong, 4 = very strong. The results from the content analysis from RQ2 were also used to support findings related to fidelity to the TPSR coaching strategies.

To address RQ4 and analyze program impact (outcome evaluation) as measured by youth positive outcomes and changes in life skills, data from the quantitative assessments (i.e. PSRQ and MSPSE) with youth participants was analyzed using t-tests to examine pre-to post-program changes in personal responsibility, social responsibility, and dimensions of self-efficacy. Descriptive statistics (mean $(M)$ and standard deviation $(S D)$ ) were also used to describe mean and range of life skills outcome scores across participants. Content analysis was used to analyze the data from the student learning quizzes, youth and coach focus groups, field notes, and the teacher interview which helped further address RQ4 and identify the youth positive outcomes and life skills that resulted from their participation in the sport program and potentially transferred to domains outside of sport. Content analysis results from each of the aforementioned data sources were triangulated to generate overall positive outcome findings and were considered alongside the t-tests.

Table 1. 
Pathway from research questions to analysis strategies

\begin{tabular}{|c|c|c|c|}
\hline$\underline{\mathrm{RQ}}$ & Measure/Method & DV & Analysis \\
\hline \multirow{4}{*}{$\begin{array}{l}\text { RQ1: What is the youth } \\
\text { participation experience in a } \\
\text { TPSR-based youth sport } \\
\text { program in eSwatini? }\end{array}$} & Youth focus group & \multirow{4}{*}{$\begin{array}{l}\text { Youth participation } \\
\text { experience }\end{array}$} & \multirow{4}{*}{$\begin{array}{l}\text { Content } \\
\text { analysis }\end{array}$} \\
\hline & Coach focus group & & \\
\hline & Teacher interview & & \\
\hline & Field notes & & \\
\hline \multirow{7}{*}{$\begin{array}{l}\text { RQ2: What are the coaching } \\
\text { strategies and program } \\
\text { design elements (strengths, } \\
\text { weaknesses, improvements) } \\
\text { that contribute most } \\
\text { strongly to life skills } \\
\text { learning in a TPSR-based } \\
\text { youth sport program in } \\
\text { eSwatini? }\end{array}$} & Coach focus group & \multirow[t]{2}{*}{ Coaching strategies } & \multirow{2}{*}{$\begin{array}{l}\text { Content } \\
\text { analysis }\end{array}$} \\
\hline & Field notes & & \\
\hline & Coach focus group & \multirow{5}{*}{$\begin{array}{l}\text { Program design } \\
\text { strengths, } \\
\text { weaknesses, and } \\
\text { improvements }\end{array}$} & \multirow{5}{*}{$\begin{array}{l}\text { Content } \\
\text { analysis }\end{array}$} \\
\hline & Youth focus group & & \\
\hline & Teacher interview & & \\
\hline & Field notes & & \\
\hline & Coach training evaluation & & \\
\hline \multirow{8}{*}{$\begin{array}{l}\text { RQ3: To what extent was } \\
\text { fidelity to the TPSR model } \\
\text { achieved in terms of daily } \\
\text { structure, youth } \\
\text { responsibility behaviors, } \\
\text { and coaching strategies? }\end{array}$} & TPSR checklist & Daily structure & Descriptives \\
\hline & Field notes & \multirow{3}{*}{$\begin{array}{l}\text { Youth responsibility } \\
\text { behaviors }\end{array}$} & \multirow{3}{*}{$\begin{array}{l}\text { Content } \\
\text { analysis }\end{array}$} \\
\hline & Coach focus group & & \\
\hline & Teacher interview & & \\
\hline & TPSR checklist & \multirow{2}{*}{$\begin{array}{l}\text { Youth responsibility } \\
\text { behaviors and } \\
\text { coaching strategies }\end{array}$} & \multirow{2}{*}{ Descriptives } \\
\hline & Coach reflections (TARE) & & \\
\hline & Coach focus group & \multirow[t]{2}{*}{ Coaching strategies } & \multirow{2}{*}{$\begin{array}{l}\text { Content } \\
\text { analysis }\end{array}$} \\
\hline & Field notes & & \\
\hline \multirow{5}{*}{$\begin{array}{l}\text { RQ4: What positive } \\
\text { developmental outcomes } \\
\text { and changes in life skills are } \\
\text { associated with youth } \\
\text { participation in a TPSR- } \\
\text { based youth sport program } \\
\text { in eSwatini? }\end{array}$} & Surveys & $\begin{array}{l}\text { Changes in life } \\
\text { skills }\end{array}$ & t-tests \\
\hline & Learning quizzes & \multirow{4}{*}{ Positive outcomes } & \multirow{4}{*}{$\begin{array}{l}\text { Content } \\
\text { analysis }\end{array}$} \\
\hline & Coach focus groups & & \\
\hline & Youth focus groups & & \\
\hline & Teacher interview & & \\
\hline
\end{tabular}

\section{Chapter 3: Results}

The results section is divided into two main sections that encompass each of the four primary research questions: 1) program implementation results and; 2) program impact results. Program implementation results address research questions one to three i.e. RQ1: What is the youth participation experience in a TPSR-based youth sport program in eSwatini?; RQ2: What 
are the coaching strategies and program design elements (strengths, weaknesses, and improvements of program and coach training) that contribute most strongly to life skills learning in a TPSR-based youth sport program in eSwatini?; and RQ3: To what extent was fidelity to the TPSR model achieved in terms of daily structure, youth responsibility behaviors, and coaching strategies? Program impact results address research question four i.e. RQ4: What positive developmental outcomes and changes in life skills are associated with youth participation in a TPSR-based youth sport program in eSwatini? Data is presented as a triangulated collective to address each research question.

\section{Preliminary results}

Overall, the combined inductive and deductive content analysis approach yielded 2288 raw meaning units. After completion of content analysis, this was synthesized into 39 higher order codes (See Table 2). Baseline and post-program youth quantitative surveys were analyzed for normality indices of kurtosis and skewness. All quantitative data fell within the range of normality.

\section{Program implementation}

RQ1: What is the youth participation experience in a TPSR-based youth sport program in eSwatini? 


\section{Youth participation experiences}

Content analysis of the youth and coach focus groups, teacher interview, and field notes were triangulated to collectively yield 199 raw meaning units related to the youth participation experience. This coalesced into 6 higher order codes: positive psychological experiences, program features, sport-specific, negative psychological experiences, social relationships, and gendered experiences (See Figures 1 and 2).

\section{Positive psychological experiences}

The most frequently cited youth participation experiences were related to the higher order code of positive psychological experiences in the sport program. Positive psychological experiences referred to rewarding or meaningful personal youth experiences during the program that contributed to individual youth emotional or cognitive well-being. These positive psychological experiences were grouped into lower order codes related to general positive experiences, positive emotional experiences, and positive cognitive experiences.

General positive youth experiences most frequently cited were enjoyment and fun, and experiencing small successes and feelings of competency. Consistently across all data collection sources (i.e. coach and youth focus groups, teacher interview and field notes), enjoyment and fun were frequently commented on. As the coaches stated, "I think they definitely enjoyed it....and overall it was very positive." It was evident that the program was well-received by the youth and that overall it was a positive and fun experience e.g. "working with our coaches was fun!" In addition, youth often experienced small moments of success or a sense of competency that positively impacted their participation experience. This was experienced during activities presented in the awareness talk where tasks could be completed successfully, through answering questions posed by the coaches during discussion, or through sport activities that youth were familiar with and felt competent in. For example, the field notes stated that there was "loud 
applause and lots of smiling and demonstrations of confidence when they figured out the riddle." Novel experiences were also identified as positive psychological experiences for the youth. For example, in the focus groups, several boys stated that they enjoyed learning new sports that they typically did not get the opportunity to learn: "I liked netball because it was something new to us boys" and "I liked volleyball because it was completely new." The field notes also captured the following:

Lots of giggles during belly breathing - seemed like belly breathing was a completely new concept for the youth... Volleyball was clearly a new sport for most of the youth so they needed to focus to learn.

The most salient positive emotional experiences for youth centered on experiencing leadership opportunities, receiving social recognition and validation from peers, and experiencing the excitement of competition. As stated in the field notes, "youth were excited to stand at the front and lead the group in the team cheer" and the girls who were asked to lead netball drills "took this job very seriously and put lots of effort." Throughout the program different youth were also asked to lead the daily diaphragmatic breathing and "one girl led belly breathing with confidence!" It was also evident that receiving social recognition from peers for participating was a central emotional experience as noted in the field notes:

Youth responded with energy, enthusiasm, and enjoyment to the high 5's from peers...Youth also excitedly gave others high 5's when examples were offered. Although cited less frequently, other noteworthy positive emotional experiences for youth included feeling validated and treated with respect, having their voice heard, experiencing the program as an escape from life at home, and engaging with discomfort. The following was stated in the girls' focus group: 
I liked the fact that we were very respectful to each other and communicating well with each other...We liked that our coaches listened to our needs and concerns.... and that our coaches treated us well and with respect.

Positive cognitive youth experiences included general learning during the program and experiencing a psychologically safe learning environment. For example, connected to the code of positive novel experiences but also general learning, youth stated that they liked the sport program because "a lot of what they taught us was new to us" and "because when I get worried about something and start panicking I can always do the breathing exercises to feel way better." In addition, in the field notes it was specified that youth felt comfortable enough to start singing and also to consistently use humor due to the creation of a psychologically safe learning environment.

Program features

The next most frequently cited higher order code that contributed to the youth participation experience were specific features of the program and how it was designed. Across all data sources (teacher, coaches, field notes, and youth), it was evident that the provision of daily fruits and food, as well as the use of small treats like chocolate and sweets contributed positively to the youth participation experience. For example, one youth stated that they liked receiving daily fruits "because sometimes we do not get fruits at home." In the field notes it was stated on a daily basis that "youth enjoyed their sweet treat and their mahewu (maize-based drink)". Other elements related to the design of the program that contributed positively to the youth participation experience were the activities included in every awareness talk (e.g. the telephone riddle, the leadership blind-fold game, the compliments activity, and the STAR acronym). During these active learning activities, frequent observations were made of "high 
energy, enjoyment...high engagement and effortful participation... and lots of laughter and enjoyment alongside focus." In addition, it was also evident that the relational time contributed positively to the youth experience as captured in the field notes:

Youth were smiling a lot and eagerly answering questions about members of parliament...Lots of laughter and joking between coaches and youth during relational time - youth called Trevor "coach Trevor Noah" and also "Coach Ndebele" because the coaches had introduced Trevor as originating from Zimbabwe.

Additional program features that contributed positively to the youth experience was youth exposure to multiple sports and also the role of the coaches as teachers. One youth stated that they liked that the coaches "taught us a lot about things that we did not know." The role of coaches as mentors and educators was therefore one that was appreciated by the youth. Notably, there was also one program feature that contributed negatively to the youth participation experience and that was the short sport time. In the focus groups youth stated that "sometimes we had too little time to play." Finally, the addition of a free play period at the end of the daily program structure was well received by the youth. The field notes recorded the following observations:

Everyone was very excited to have a game-like situation at the end during free play...Fun during unstructured/free play afterwards...For free play, lots of energy, especially from the boys. Highly competitive.

\section{Sport-specific}

A separate higher order code that was related to program features and design were the sport-specific youth participation experiences. Overall, sport enjoyment and developing sportspecific skills were a significant contributors to the youth participation experience. During the 
physical activity component of each session, consistent comments were made about "high energy, engagement, and effortful participation" from the youth. In addition, as one youth stated, "I learnt how to play soccer well" so it was evidently important that sport-specific development, and not just sport participation, was also something that youth experienced during the program. Further, the inclusion of culturally relevant sports such as netball and soccer was appreciated by the youth and generated a lot of excitement. Youth, coaches, the teacher, and the field notes also commented on the positive impact of learning new sports on youth enjoyment. The coaches noted that "when the youth were learning about volleyball and basketball they were all keen to learn how it's done and they never held back." The afternoon club teacher commented that: ...the variety of the sports provided was something they [the youth] commented on. Here we only get to play soccer all the time and the girls sort of just socialize on their own. It [the inclusion of multiple sports] helped them all participate.

On the negative side, sport-specific elements of the youth participation experience also included physical fatigue and injury. Youth, and especially the girls, tired very easily during the physical activity component and there was also several instances of youth injuries, although all minor injuries such as getting hit in the stomach by a soccer ball. Negative psychological experiences

Although most youth experiences in the program were overwhelmingly positive, a higher order code also emerged related to negative psychological experiences. Similar to the positive psychological experiences, this higher order code was categorized according to general negative experiences, negative emotional experiences, and negative cognitive experiences. The most salient general negative psychological experience was the experience of negative novel experiences. These were often related to learning a new sport, and often a sport that was more 
commonly played by the opposite gender, where youth did not feel competent and where they were being pushed out of their comfort zone, as noted in the coach focus groups. As one youth stated, "I hated it [netball] because I am not good at it...I am not used to playing netball." However, other youth participants also stated that they enjoyed learning new sports despite the lack of competency or the fact that it was more commonly played by the opposite gender e.g. "I liked netball because it was something new to us boys." Equal number of comments supported enjoyment of learning sports as lack of enjoyment of learning new sports.

Negative emotional experiences for youth participants included sadness for the program ending and the mid-program loss of a coach. As stated in the field notes, "youth expressed that they were sad that the program is ending and that they will miss the coaches." One coach also noted that, "Aye they were so sad when we were saying goodbye." Feelings of invalidation were also noted twice during one session of the program. Both of these instances of invalidation occurred when the coaches were distracted and did not respond with encouragement to youth input during discussion as observed in the field notes.

Negative cognitive experiences during the program included youth difficulty understanding instructions and processing learning, low confidence in English, behavioral disruption of new participants, and hunger impacting focus. Across the duration of the program coaches made adjustments to the developmental level (i.e. age, English language proficiency, and general learning level) of the youth participants in order to accommodate their difficulty with understanding instructions and processing learning. That is, instructions were often repeated and simplified, and the primary language of communication was switched to SiSwati. A final notable negative cognitive experience of the youth participants was the experience of concentration difficulties due to hunger. On the fifth day of the program, the field notes captured the following: 
Focus was really off in the beginning when youth hadn't eaten the mahewu (maize-based drink) - highly important context-specific factor as youth don't eat much at home so food from the children's center is very important.

\section{Social relationships}

A further meaningful higher order code related to youth participation experiences was focused on social relationships. Social relationships included the emotional and cognitive interactions and connections experienced amongst peers and also between youth and coaches. Amongst peers, the positive experience of sharing with others was identified and the negative experience of fear of peer ridicule was also commented on. Sharing with others encompassed youth behaviors of sharing stories and experiences with their peers. For example, the field notes captured the following: "3 groups were laughing a lot and enjoying the sharing and discussion with each other. Youth raised their hands to respond and share their examples...youth enjoyed hearing the responses of others (giggles and smiles)." The negative experience of fear of peer ridicule was observed several times during the program by both the primary researcher and the coaches. When commenting on the boys' reluctance to engage in discussion as strongly as the girls, one coach stated that:

I think basically it was that they were scared to be laughed at. Ya, it's always the case of "If I say the wrong answer they will laugh at me."

Under the higher order code of social relationships, multiple experiences were related to positive youth interactions with the coaches. That is, all data sources (youth, coaches, teacher, and primary researcher) noted that the positive bond between the youth and coaches was a significant contributor to the youth experience in the program. One coach commented on the fact that "in a very short space of time, we managed to create a bond with them [the youth]. So they 
were more okay with us, they were enjoying the time with us, more than they were enjoying the sweets, the playing, the learning, they were enjoying the environment and the bond." Notably, the coach-youth bond was also significant because it was characterized by fun, empathy, a mentorship role, and creating a different adult-youth relationship. In describing the different adult-youth relationship, one coach stated the following:

You know in Swaziland it's very...I explained to someone in the States that the relationship between a child and an adult is kind of more a 'tell you what to do '.... I think what was positive is that even though it was something that was new to them, they tried to kind of like...they tried to build a different relationship. And I think that even in society in Swaziland when you look at, like, not just with an adult but even with someone that is a little bit older than you, they are, I don't want to say bullying, but trying to instruct you to do something...It's not like trying to teach someone a lesson so that they look up to you. So I think that it was positive that they were able to be able to learn something from us.

\section{Gendered experiences}

The last higher order code related to the youth participation experience highlighted the gender differences in how the program was experienced. Consistently across different data sources it emerged that while some youth experiences were similar across gender (i.e. many of the previously mentioned higher order codes), there were some very distinct gender differences in experiences. Specifically, during the awareness talk and group discussion components of the program, part of the female youth experience was an eagerness and engagement in learning. Girls also experienced some frustration with the lack of discipline and engagement in learning from the boys e.g. "Well, the boys were a bit disrespectful. When told not to go down to where 
the [sugarcane] trucks were they just ignored that instruction." However, female youth were not as engaged as the male youth during the physical activity components. The coaches commented on this during the coach focus group:

Ya but the boys were enjoying more the sport part. That's what they enjoyed the most. The girls would ask you a few questions, the meanings of some words. The boys wouldn't ask but when you ask them the meaning of a word, that's when you know that they didn't actually understand. And you'll see the girls helping them while you are still waiting for them to respond. Whereas with the girls they would know the answer.

In addition, there were several contradicting experiences related to improvements in focus when genders were separated, but greater enjoyment of the program when genders were mixed. Further, there was frustration when genders were mixed during sport participation due to differences in competency levels and gendered peer exclusion during sport. However, this was coupled with an enjoyment of inter-gender competition during the physical activity components. The following excerpts from the coach focus group, youth focus groups, and field notes capture these contradicting experiences:

I wanted to say that mixing them is more fun to them: "We're girls playing with boys". It's more fun, versus when they play separately it's more serious (coach focus group) But I noticed one thing that when we'd split them, when the boys must play alone and the girls must play alone, there was so much order (coach focus group)

Yes. Having mixed teams was bad because the girls are bad at soccer (boys focus group) Sometimes there were just too many rules. I did not like that. Like when we had to take steps and did not get it right. The girls would laugh at us (boys focus group) 
I think basically it was that they were scared to be laughed at. Ya, it's always the case of

"If I say the wrong answer they will laugh at me" (coach focus group)

For soccer, the boys became very competitive and eager to play but weren't passing the ball much to the girls (field notes)

RQ2: What are the coaching strategies and program design elements (strengths and weaknesses of coach training and sport program) that contribute most strongly to life skills learning in a TPSR-based youth sport program in eSwatini?

The first part of this section presents the results related to the coaching strategies that contributed to the youth experience and outcomes.

\section{Coaching strategies}

Content analysis of the coach focus group, coach reflections, and field notes yielded 639 raw meaning units related to coaching strategies (See Figures 3-5). This was spread across 7 higher order codes: TARE coaching strategies (211), learning strategies (250), behavioral management (50), building coach-youth relationship (42), coach adaptations (10), youth engagement and focus strategies (66), ineffective coach strategies (10), and preparing youth for end of program (2).

\section{TARE coaching strategies}

Two hundred and eleven raw meaning units were captured that could be coalesced under nine middle order codes that represented the nine TARE coaching strategies.

Modeling respect: this code referred to coach behavior that modeled respectful communication and unconditional positive regard for the youth. Specific strategies included the use of cultural norms for demonstrating respect (i.e. greeting in SiSwati and asking how each youth was doing as they arrived), modeling desired responsibility behaviors (e.g. never shouting at youth, always communicating in a friendly and respectful manner, and coach participation in 
all activities), and using positive body language such as smiling. In the coach reflections, the following illustration of modeling respect was captured:

Asked students to raise their hands if they have something to say...communicated appropriately with youth...I made sure I used respectful words with the youth and emphasized that type of communication.

Coaches also made use of acknowledging youth emotions and expressing gratitude to the youth. For example, at the end of the program, the field notes captured the following: "Coaches expressed gratitude to the youth for allowing them to get to know them."

Setting expectations: included under setting expectations were strategies that communicated behavioral expectations to the youth. Specific strategies to set expectations were holding youth accountable to and encouraging responsibility behaviors, and reminding the youth of group behavioral expectations. For example, to hold youth accountable, coaches began a tradition of asking the youth that arrived late to apologize to their team-mates for being late and not respecting their time. Coaches would also point out to youth when their behaviors were not in line with the group agreements and responsibility levels established collectively at the start of the program. In the coach reflections, the following examples were captured:

Went back to group agreements to ensure students know what we expect, practices are safe, rules and procedures are used to guide every session.

We make sure that the kids do follow the rules that we all came up with as a group and if one breaks the rules we get punished for it.

Providing opportunities for success: this code focused on coach strategies that ensured that all youth had equal chances to be included and participate in all components of the program. A frequently used strategy in this domain was to encourage effort and participation over sport 
skill during the physical activity components. The purpose behind this strategy was to encourage youth to participate even if they were not highly competent in that particular sport. Examples from the field notes are as follows:

Encouraged youth after every effort to return the volleyball during drills (even if the movement needed to be corrected)...Coaches encouraged youth to try hard and participate during yoga...Coaches encouraging everyone to participate and give high effort.

Fostering social interactions: fostering social interactions was defined as strategies used to promote youth-youth interactions whether this was through collectively working towards completing a task or resolving conflict etc. The most commonly employed strategy was to use peer social recognition to validate youth participation in discussion. That is, coaches encouraged peers to give one another high fives when a thoughtful response was given during discussion. The purpose behind this strategy was to help youth feel validated for their input and also prompt them to positively interact with one another. Consider the following excerpts from the field notes:

Positively re-enforced through round of applause when youth spoke up and contributed... Prompted applause for the youth who were brave and offered responses...Prompted high 5's from peers for youth who offered a response...Used clapping of knees to reward those who were courageous to answer questions... Solicited applause for the volunteer. An additional strategy was to encourage sharing of personal examples with peers in their group to help youth connect on an emotional and psychological level. For example, the field notes captured the following two examples of encouraging personal sharing: 
Asked youth to share a dream that each of them had...Asked youth to share what their goals were for the sport program - prompted applause for youth that shared.

A final coach strategy was to encourage peer social connection through mixing girls and boys in teams, and encouraging hip checks and high fives with team mates.

Assigning management tasks: this code included strategies to give small responsibilities to the youth to help run or manage sections of each daily session. The primary strategy used by coaches in this category was to assign youth the responsibility of taking attendance. Illustrations of these strategies from the coach reflections are as follows:

Assigning role call and helping in demonstrations.

Asking youth to set and collect different piece of equipment.

Promoting leadership: promoting leadership referred to coach strategies to allow youth to be in charge or demonstrate in front of the group. Specifically, coaches provided opportunities for leadership by asking different youth to lead drills (e.g. boys led soccer drills and girls led netball drills), assigning leaders for awareness talk activities, and asking a different youth to demonstrate belly breathing on a daily basis. Note the following examples from the coach reflections and the field notes:

Leading the breathing exercise, during the telephone game each group was asked to have a leader (coach reflections)

Group leaders during awareness talk and to lead aerobics (coach reflections) Asked two boys to lead the group in aerobics. Then rotated out different leaders (field notes)

Giving voices and choices: giving voices and choices centered on coach strategies to allow the youth voice to be heard in discussion and in sharing opinions and feedback on how the 
program was going. Coaches used strategies such as soliciting youth assessment of enjoyment of learning and the sport component of each day (i.e. thumbs up and down), using democratic decision-making when making group decisions (i.e. youth vote), and adapting the program based on youth feedback. For example, the field notes stated that youth asked coaches whether they could split the boys and girls for the physical activity component the next day. Consequently, coaches used inter-gender competition during the next day's session. Below are two illustrations of giving voices and choices as noted in the coach reflections:

Whenever we introduce a new concept we asked youth to raise hands and give their own definitions/opinions, group is involved in discussions, they ask questions, make suggestions and also share opinions, giving them the platform to take and try to explain what they understand about a certain skill.

Encouraging youth to ask questions and make suggestions, we help them take ownership of the program and speak their mind.

Involving students in assessment: this code focused on giving the youth an opportunity to assess themselves or their peers on some aspect of behavior, attitude, or learning progress in the program. This was achieved through the use of the written life skills learning quiz where youth self-reported their learning, and also through asking youth questions to assess how much they were understanding so far. The coaches noted the following in their weekly reflections: "We have been sitting them in pairs to try to discuss what they learnt so far in the course of the program."

Addressing transfer: this code encompassed the coaching strategies that promoted transfer of learning in the sport program to domains outside of sport e.g. school and home life. The primary strategies to address transfer were the use of real-world examples to illustrate how 
life skills could be applied outside sport, emphasizing the value of transferring positive developmental outcomes to all domains of life, and also using personal coach examples of how they used the life skills in their own lives. The following excerpts from the field notes and coach reflections capture addressing transfer:

Explaining to youth the power of words, and giving examples...Led group through examples of how words are used in real life situations (field notes)

Gave real life examples of transfer and asked students if they implemented skills at home (coach reflections)

Encouraging youth to use the dove conflict style to solve obstacles at home and school (coach reflections)

\section{Learning strategies}

Outside of the TARE teaching strategies, the strongest higher order code that emerged for coaching strategies was very specific to strategies employed by the coaches to facilitate youth learning and transfer of the life skills lessons. These learning strategies were divided into 6 middle order codes, four of which aligned with Bloom's taxonomy of learning: general, orienting, remember, understand, apply, and analyze.

General: this code captured the general structural and process-oriented strategies employed by coaches to promote youth learning. Specifically, this most often involved the use of visual aids, the use of group debriefs, and the use of pairs for self-reflection where the coach monitored and facilitated discussion in pairs. An important general learning process that coaches employed was also coach validation of youth input. For example, as captured in the field notes, "coaches showed excitement and energy for good examples" and "high fived youth that spoke about how they had applied a skill they learned in the program at school or at home." 
Orienting: orienting referred to the coach strategies that helped direct youth during each session. That is, strategies such as providing instructions and explanations for each activity, briefly introducing each life skill concept, and providing sport instruction were incorporated in this code of orienting. For example, the following excerpts from the field notes capture the coach strategy of orienting:

Coaches explained instructions for awareness activity...Explained to youth the instructions for the awareness activity and that the activity would test their teamwork and communication... Coaches explained the goals of the activity and the life skills they would have to use.

Remember: this code encompassed the strategies that aided youth ability to recall or recognize concepts and life skills learned in the program. Specific strategies employed by coaches included reviewing previous life skills lessons, multiple repetitions of concepts during a single session, and the use of oral recitation of concepts. For example:

During relational time, engaging youth in discussion about life skills learned so far... Discussing together the lessons from the previous day...Briefly asked youth to identify the life skills from yesterday (field notes)

Understand: strategies centered on understanding were aimed to promote basic youth comprehension and interpretation of what the life skills and concepts meant. To help youth understand life skills and concepts, coaches most often asked youth to provide their own definition of each concept, prompted youth to elaborate on things they said in order to ascertain understanding level, used familiar behaviors to illustrate concepts to the youth, and broke down each concept into simpler words and ideas. Another impactful strategy employed by coaches was the use of scaffolding youth learning within the zone of proximal development. That is, certain 
life skills concepts were perhaps a bit too complex for youth to understand or apply but with the help of coach scaffolding of learning through guidance and encouragement, youth would eventually grasp the complex concept. Consider the following excerpt from the field notes that captures the idea of scaffolding learning:

Youth seemed a bit stuck so coaches helped them work through an example...Coaches affirmed their responses and asked boys who the leaders are in the sport setting when boys got stuck thinking of leaders outside sport...Coaches asked what makes a bad leader - youth got stuck so coaches said they would give them a clue through a real-life example. Coach repeated question but youth still had trouble defining a bad leader. Coaches broke down the question even more - youth figured it out and offered responses. Apply: Application strategies referred to coaching strategies that strengthened youth ability to apply life skills and learning concepts to life outside sport i.e. transfer. The two primary strategies adopted to help youth apply their knowledge were to: 1) ask youth to give examples of how the life skills could be used outside sport; and 2) ask how youth themselves had applied the life skills in their everyday lives. Below are examples from the coach focus group and field notes that illustrated the two primary application strategies:

Um, every time we would teach them a life skill we would ask them to think about where they can use this life skill at home so every time you give an example and then they would start giving examples of when they are doing this or that, this is what I have to do. So it keeps them trying to apply this everywhere. So making an example and relating them also helps (coach focus group) Asking "how did they use emotion regulation since yesterday?"...Asked about whether youth had applied emotion regulation strategies at home or at school...Asked youth for 
examples of how they used communication and team work that day during the lesson (field notes)

Analyze: Helping youth develop analysis skills was targeted at cultivating more complex learning that involved understanding the relationship between different concepts and the ability to take a more critical lens. The most frequently employed strategy was to prompt youth critical thought. This was often achieved through asking critical thinking questions that pushed youth to really think through the steps involved in each concept they were learning about. For example, as captured in the field notes, during the goal-setting and dreaming activity, coaches asked youth to think about the small, everyday steps that needed to be taken in order to realize a dream. For other awareness talk activities they would ask youth questions about the tools youth thought they would need to complete each task and what challenges they might encounter. Coaches also cultivated more complex analysis skills in the youth through integrating different life skills e.g. making connections between how we can only get to our goals if we persevere through challenges, if we work hard, and if we have the courage to resist peer pressure for poor risktaking behaviors. Several examples from the field notes capture this integrating strategy:

Coaches explained to youth how dreams, confidence, and hard work tie together and used an example to demonstrate...Coaches tied the concept of compliments to positive talk and compassion... Coaches tied idea of compassion to the STAR technique and linked back level 4 responsibility.

\section{Behavioral management}

An additional higher order code that emerged strongly from the data was coaching strategies related to managing youth behavior. The most frequently cited lower order codes under behavioral management were the use of punishment, the use of spotlighting, and the use of 
incentives. Punishment usually involved sport-specific tasks such as push-ups or squats. The coaches tended to enact the punishment publicly in front of the group of youth in order to set the example that lack of discipline would not be accepted. On several occasions coaches also punished the group as a collective to encourage group responsibility and accountability for behavior. An interesting strategy used by coaches to manage misbehaving youth was 'spotlighting'. This referred to moments when coaches called youth out by name and directly engaged them in the learning component to bring their focus back to the group. Spotlighting was captured in the field notes in the following excerpt:

Distracted boys were spotlighted and asked to give suggestions of words...Directly asked one of the youth in the back who was distracting others to give an example of the life skill.

Incentives were also frequently used to encourage behaviors such as timeliness. Further, several coaching strategies were employed that served to organize or divide the youth to better manage the group size. Specifically, these were strategies such as the use of smaller groups, the use of concurrent matches and drills (i.e. each coach leading a specific component), and the use of purposeful seating arrangements to separate misbehaving peer groups and friendships groups. Asked group to sit in a circle and alternate girls and boys... Coaches moved boys around so they didn't loiter at the back...During awareness talk, asked youth to sit behind cones to divide friendship groups.

\section{Building coach-youth relationship}

Forty-two raw meaning units were identified that reflected coach strategies to build the coach-youth relationship. The most common strategy employed by coaches was the use of 
humor. Across the duration of the program this was a very consistent strategy used by coaches that was received well by the youth. The field notes captured the following moment:

One coach joked with a youth that the sport program won't include any more soccer from now onward because no African teams went through the group stages in the world cup. The youth was very sad to hear that!

Another frequently employed coaching strategy was to ask youth about their weekend, about school, and about life at home. This was complemented by the coach strategies of showing interest in the topics and activities that interested the youth (e.g. play jump rope with them or chatting about music), using relevant youth language, and also opening up to youth about their own background and interests. Finally, asking for and using youth names was considered to be valuable in connecting with youth.

\section{Coach adaptations}

Notably, a higher order code emerged that emphasized the coaching strategies of being able to adapt the coaching approach dependent on situational and youth factors. The most significant adaptation made by the coaches was a language adaptation. Although the program was originally intended to be implemented using a balance of English and SiSwati, as identified in the field notes, coaches quickly realized that youth confidence in English was very low and consequently there was a hesitancy to participate in discussion. Coaches therefore shifted to primarily using SiSwati while still infusing English words on occasion. Another noteworthy adaptation made by coaches was to adapt sessions to the immediate youth response. This occurred frequently during learning, when coaches adapted to the cognitive ability and comprehension level of the youth. It also occurred on occasion during the physical activity component. For example, the field notes captured a moment during the Frisbee session where 
youth were struggling to grasp the physical movements and were experiencing a lot of frustration. Coaches made the decision mid-way through the session to switch to using a different piece of sport equipment i.e. a netball, to demonstrate the same drill. Youth enjoyment and participation markedly improved after that decision. This was captured in the following comment during the coach focus group:

Ya I think it would depend on how they are responding to what you are teaching. So if they are interested you keep going. Because you see even with the frisbee when we had to play the frisbee game. It wasn't going well so we ended up changing to use the netballs.

\section{Youth engagement and focus strategies}

The higher order code of youth engagement and focus strategies encompassed coach strategies to energize and engage the youth, or to re-capture their focus when their attention was drifting. These coaching strategies were captured primarily in the researcher field notes. Movement-based refocusing and energizing strategies were most often utilized by the coaches. Some of these strategies were similar to those used to foster peer social connection i.e. high 5's and hip checks. That is, those strategies served a dual purpose. Other movement-based strategies that were effective were the clapping of knees and the stomping of feet. Youth energy and enjoyment was always very high during those movement-based activities. The team cheer was also identified as a helpful strategy to keep youth engaged as was reminding youth that the more engaged they were in discussion, the more time there would be for sport participation i.e. facilitating youth buy-in for learning. The following excerpt from the field notes illustrates this idea: 
Ya so that would be based on the model, like what you told us to do, if we have a problem then this is what we do, maybe the team cheer, the high five-ing. It kind of motivated them. So that was...I guess that was successful.

In addition, coach energy levels were also notable sources of youth energy and engagement; the more energetic coaches were and the more they encouraged energy, the more youth were engaged. This was captured in the field notes:

Highly energetic and humorous coaches. Youth responded positively to that...Great facilitation and energy from the coaches...High energy and smiling from the coaches during aerobics.

Finally, as captured in the field notes, youth engagement appeared to be consistently higher when there was a competitive element to the learning component or the physical activity. It was evident that the youth loved to dance and celebrate so having more opportunities for celebration through competition was well received. The coaches reflected on this during the focus group:

They really liked it (laughs). When you group them into groups and say, "This is our goal, we need to do this. First team to get there is the winning team." They just loved that.

\section{Ineffective coach strategies}

Although this was a much less frequently cited higher order code with only 8 raw meaning units, there were several coaching strategies that were not effective in creating a positive youth participation experience or facilitating life skills outcomes. First, monitoring youth behaviors versus use of teaching moments was noted as ineffective. That is, when coaches focused too much on umpiring a game instead of integrating life skills into the sport practice, 
youth learning was minimal. Enjoyment was still high as youth were always highly engaged in the sport component but the learning/TPSR element was lost. In addition, because the youth group size was so large, there were several instances where youth were not engaged in physical activity during the sport session because there were too many youth to monitor. For example, the field notes observed that "youth sitting out for soccer were out for too long and lost focus." Last, when a teacher-centered approach to learning was adopted during the awareness talk, youth engagement, focus, and participation was minimal e.g. "Intro to emotion regulation was very lecture-based and seemed to lose focus of youth" (field notes). Activity and discussion-based learning yielded much greater attentiveness, enjoyment, and participation in learning. Preparing youth for end of program

Finally, as the end of the program approached, coaches were very intentional about preparing youth for the end. They reminded the youth on several occasions that the program would soon be coming to an end so they should be preparing for that. This strategy was isolated to the final few days of the program.

\section{Program design}

The second part of this section presents the results related to the program design elements (coach training, and program strengths, weaknesses, and improvements) that contributed to the youth experience and outcomes.

\section{Coach training}

Content analysis of coach feedback on the coach training (16 raw meaning units) was categorized into three higher order codes: facilitation of coach learning, content of coach learning, and miscellaneous. See Figure 6.

Facilitation of coach learning 
Relative to facilitation of coach learning during the coach training, coaches valued the use of self-reflection, learning props and discussion, and soliciting coach expression of voice. Specifically, one coach stated that "it was inviting because it allowed the coaches to input their own opinions." However, they felt that the training needed to be longer and could be extended to a week in length. Other improvements included the use of videos for skill demonstration and the continued use of videos during program implementation as support tools for further coach learning.

\section{Content of coach learning}

Included within the higher order code of content of learning during the coach training, coaches appreciated the focus on the coach-athlete relationship and environment, and the focus on life skills building strategies. For examples, one coach stated: "It focuses more on caring and supportive sport environments and also to incorporate life skills development into sport activities." Weaknesses identified in this area included the need for a stronger cultural focus, and a team-building section that was too short: "This was a very good coach training but somehow it has to consider the different cultures when it is being implemented." Improvements identified by the coaches included a focus on sport-specific skills training, a focus on confidence building, and a stronger emphasis on learning TPSR integration strategies and using teaching moments.

\section{Miscellaneous}

Coaches also commented on the positives of the organization of the training as well as the training being empowering for the coaches. One coach stated:

As a coach I feel empowered in the sense that this training made me reflect on myself and I saw that I have been doing good and have been doing most of this that we discussed. It 
is also a learning curve as it states that learning will never end. The program makes you open up and be honest to yourself as an individual.

The qualitative content analysis feedback from the coaches is further supported by the quantitative results from the coach evaluation of training. That is, findings indicated that on average, coaches either strongly agreed or agreed that the training helped them feel prepared to create a caring and supportive sport environment $(M=5.00)$, think about their coaching motivations and identity $(M=4.33)$, and feel prepared to incorporate life skills development into their coaching $(M=4.67)$. These elements are all related to the previously described 'content of learning' higher order code. Coaches felt less prepared to incorporate the TPSR model into their coaching $(M=3.67)$ and neither agreed nor disagreed that they felt confident to implement the youth sport program $(M=3.67)$. Overall, coaches agreed that the coach training was engaging and enjoyable $(M=4.33)$ and that they felt prepared to implement the youth sport program $(M=4.00)$, which corroborates the previously described content analysis findings that the training was overall an empowering experience for the coaches. See Table 3 for full coach training quantitative results.

\section{Program design: strengths}

Content analysis of the youth and coach focus groups, teacher interview, and field notes yielded 72 raw meaning units related to program strengths. The 5 higher order codes related to program strengths were: program operations, coach characteristics, facilitation of learning, content of learning, and participant experiences. There were also three higher order codes with only one lower order code: positive relationship between researcher and youth, interest in future extensions of programming, and youth retention. See Figure 7.

\section{Program operations}


The program operations higher order code explored the strengths of the features of the program and how it was logistically managed. Some of these strengths were already explored in the section addressing the youth participation experience and will therefore not be elaborated upon again. These included the provision of daily fruits and food, the use of incentives (i.e. sweets), the inclusion of multiple sports and culturally relevant sports, and also the choice to have a mixed-gender program. In terms of program operations, findings indicated that the organization of the program, the provision of sport equipment, and the use of multiple coaches were significant strengths. The teacher commented on the fact that for all sports, the appropriate equipment was provided so that nothing needed to be improvised. He also noted that the use of multiple coaches meant that "if they [the youth] didn't understand what one coach was saying it could easily translate to another [coach]." This was re-iterated by one coach who stated that the presence of multiple coaches helped the youth grow and learn because "if someone [a youth] is struggling with something then you [a coach] just step in.”

Coaches also stated that the daily coach planning significantly aided the implementation of the program as it ensured that everyone was always prepared for the day. Further, the inclusion of "free play" as an additional component of the TPSR model was well-received by the youth. As previously mentioned, youth felt that there was often too little sport time so the inclusion of free play at the end of several of the sessions helped to keep youth engaged in the ethos of the program. Finally, the integration of a stable and caring authority figure (i.e. the afternoon club teacher) into the daily operations of the program was identified as a positive decision. On a daily basis the youth would arrive at the field and greet the teacher with a smile and a friendly hello. It was clear that there was mutual respect between the youth and the teacher. This turned out to be something that could be used to help the coaches when they struggled with 
maintaining youth discipline. That is, the following was observed by the primary researcher after several days of poor discipline:

Before the start of the day's session the teacher gathered the youth in a group. Youth responded very quickly to the teacher's request and sat quietly. It was very clear that the teacher had established a norm of disciplined behavior with them. The teacher spoke to the youth about respecting the time and presence of the coaches who were their elders, and to maintain the ground rules from their afternoon club classroom. The youth listened respectfully and agreed with teacher. Coaches then took over and greeted group.

\section{Coach characteristics}

A key area of strength of the program was centered on the characteristics of the coaches that were selected to be a part of the program. Specifically, findings indicated that coach characteristics such as being relationally-focused, being a team player, emphasizing the mentorship role, and investment in the program were particularly important. Recruiting coaches that were confident and attuned to the youth were also cited as strengths of the program. As stated by the youth, "We liked that our coaches listened to our needs and concerns and taught us a lot about what we did not know." Two observations made in the field notes also exemplify these coach characteristics:

There is a great bond between the coaches and the youth - a clear emotional attachment! Coaches can read the youth very well and appropriately elaborate more on learning when they notice that the group doesn't understand.

\section{Facilitation of youth learning}

A frequently cited area of strength of the program was related to the life skills learning emphasis i.e. facilitation of youth learning and content of youth learning. Facilitation of youth 
learning referred to the strategies or processes used to help youth learn life skills i.e. the "how" of learning. First, learning was facilitated even before the program started by using sport as a buy-in for learning. The creation of a sport-based life skills program was the engagement tool to bring youth to the program. Other facilitation processes for learning were integration of life skills into sport practice, soliciting youth expression of voice, and building a strong relationship between youth and coaches to create investment in learning. Specifically, while sport was used as a tool for youth buy-in, the integration of life skills into sport practice emerged as a significant strength of the program. As the teacher stated, "what's good about this [program] is that you actually do the things practically. So you know let's say we are having a soccer match, and one or two of them start an argument. And then you say, "What did we talk about? Respect. Do you think you are portraying this by doing such?" So in that manner it sort of gets instilled." In terms of soliciting youth expression of voice, the teacher also made the following comment:

I liked the fact that [the youth] were given the opportunity to actually voice out what they thought and you know actually bring something new to the table and opening the room for them to actually express what they think.

Regarding the role of building the coach-youth bond and emphasizing relational time, the field notes provided a clear example of how learning was not as effective when there was no relational time: "One group arrived late. It was much more difficult to engage this group as they didn't have relational time to settle and bond with the coaches and their peers." Another noteworthy facilitation strategy was to promote learning by pushing youth outside their comfort zone. Although this was noted by youth as both a positive and negative participation experience, coaches stated that this was ultimately a strength of the program as it helped youth grow. Additional facilitation strategies that were viewed as strengths of the program were the inclusion 
of daily belly breathing to help youth relax after their day at school, the use of the team cheer for engagement and focus, and the use of written learning quizzes to consolidate life skills lessons. One of the coaches stated that the written learning quizzes "pushed [the youth] to at least think, and focus whenever they were learning, to at least grasp a few concepts and words to just focus on so they would be able to fill out their learning forms."

\section{Content of youth learning}

The higher order code of content of learning centered on the "what" of the learning component of the program i.e. the strengths related to the life skills content that was emphasized. Specifically, two significant learning content strengths were the appropriate selection of life skills and responsibility levels and the emphasis on confidence-building. In reference to the selection of appropriate life skills, the teacher commented that, “...respect, self-control, compassion and all that. It's something that is good to have there. I wouldn't say that there's something that you left out." In addition, on the program emphasis on confidence-building, the teacher stated the following: "Confidence...I really love the fact that you included that in the program. You know, most of our peers lack self-confidence and I'd say that it's something that has to be advocated, it has to be taken seriously...because without it I don't think there's anything you can pretty much do." One of the coaches further emphasized the value of focusing on confidence in the following excerpt about building youth confidence through the mentorship role:

It's that cultural barrier of you [youth] not being taught to be confident in yourself from the onset...for Swazi kids it's more like, "If I pay your school fees, you go to school." And that's it. You never know how you tackle situations such as, “Okay I'm stressed. How should I react?” Or, “I'm not confident. I want to do this but I'm not confident.” It's 
something that kids don't get to learn in Swaziland and that kind of affects their future aspirations and their goals. So having this kind of sports program will actually be helpful if it was done at an earlier stage for them to get the confidence and to know that if they have a problem with this, this is what they can do.

Two final noteworthy strengths related to content of learning were the inclusion of the STAR activity and daily belly breathing as well as the emphasis on transfer. In reference to the daily belly breathing to help youth relax and reset after their day at school, one coach stated that "For most of them it was working. Especially for the girls, I think it was helping. The girls would do it and them afterwards they would say, "Ah now I feel much better!" On the topic of transfer, at the end of the program one coach shared the following two examples about the positive impact of the emphasis on transfer:

They [the youth] will come when we try to interact with them [during relational time] and they'll try tell you, 'Hey today I did this at school and I didn't shout at that person. Instead I just took a moment...breathe in, breathe out.” And someone said that when they were writing an exam that day and they didn't get an answer they did the breathing exercise. So transfer.

\section{Participant experiences}

Outside of the program operations, coach characteristics, and learning components of the program, findings also highlighted the strengths of the program as it related to the participant experiences of the youth as well as the coaches. The youth participation experience has already been explored extensively, but it is also meaningful to note that the program was experienced in a very positive way by the coaches as well. 
The sports program was really eye opening for me and I think it should be done more for kids especially from underprivileged backgrounds.

Ah it was a great experience for us as coaches. Ya, because even now at work we are even using some of the activities. Like to try and make them enjoy the things they learn and especially when they are warming up. Ya so we are trying to use it.

\section{Higher order codes with one lower order code}

The final three codes related to program strengths were the positive relationship between researcher and youth, youth retention, and interest in future extensions of programming. Although future youth programming with a similar structure to this sport program may not include a researcher as an observer, it is worth noting that the primary researcher also developed her own relationship with the youth that was experienced positively by both the youth and the researcher. The researcher also interacted with the youth before and after each day's session and was of course significantly involved in data collection procedures. During the teacher interview, the teacher noted that when the youth spoke about the sport program after its conclusion, they would mention that "Sisi (sister) Zenzi taught us this." One particular moment that was quite illustrative of the positive relationship between the researcher and the youth was captured in the field notes:

One youth came to tell me at the end of the session that he had a spelling bee the next day and asked whether I could wish him good luck. I chatted with him about trusting himself and believing in himself. I asked him to tell me tomorrow how it went. He smiled, said thank you, and said he would do so.

Finally, the overall positive response to the program was illustrated by consistent youth attendance during the program (i.e. youth retention), the presence of new youth throughout 
implementation of the program, and also the youth, coach, and teacher interest in further programming.

I'd say you should come back maybe later during the year because they really liked it and I think it's something that's quite beneficial. It's important that they are more exposed to such things once in a while.

\section{Program design: weaknesses}

Content analysis of the youth and coach focus groups, teacher interview, and field notes yielded 33 raw meaning units related to program weaknesses. The three higher order codes related to program weaknesses were: logistics, youth management, and cultural elements. See Figure 8.

Logistics

Program weaknesses related to logistics centered on the organization and implementation of program resources, people, and facilities. The most frequently cited weaknesses related to logistics were the youth group size, time-keeping during the sessions, and the lack of an indoor facility. Logistically, the large group size of the youth participants was difficult for the coaches to manage. Time keeping was a re-occurring problem across the duration of the program: most often the time keeping issues stemmed from the awareness talk and the group reflection that went longer than planned. Consequently, the sport time often couldn't be extended. In addition, lack of access to an indoor facility became challenging on the colder days as the sport program was run outside. Youth attendance was slightly lower on those cold days. Related to difficulties with time-keeping was the program weakness of sport time that was considered to be too short by the youth participants as well as the length of each daily session, which needed to be extended to accommodate the longer awareness talks and the desire for more sport time. 
The higher order code of youth management encompassed the processes related to controlling and organizing the youth participants. Coach management of discipline was the most frequently identified weakness. The afternoon club teacher stated the following related to the balancing act of creating a warm and supportive environment but still commanding the respect of the youth participants:

And as for weaknesses, the issue of discipline. Yes you said something about being friendly and approachable but having a strong hand. That's something that you should maybe look upon.

Other weaknesses included in youth management were maintaining youth responsibility behaviors, initial setting of expectations, and facilitating inter gender cooperation. In reference to maintaining responsibility behaviors, coaches reflected on their difficulty in "...trying to ensure respect. I think we tried to emphasize more on that because it always was kind of, people would forget that we should be respectful of each other." On the topic of facilitating inter gender cooperation, another coach stated that "it was a challenge. In terms of when they are playing, the boys would pass only to the boys."

\section{Cultural elements}

Several program weaknesses were also identified related to the higher order code of cultural elements of the program. Specifically, coaches stated that there were occasionally issues with the cultural applicability of the awareness talk metaphors. For example:

Maybe instead of a volcano we use a river. Ya it's a big river! Everyone knows you can't walk on a river. And in the river there are crocodiles. And they know they have to run away from that so they are used to that [reference]. 
One coach also stated that the use of SiSwati as the predominant instructional language was a weakness of the program.

The original plan was that we were going to speak English and translate but we ended up putting a lot of SiSwati. And I mean we are trying to teach these young kids to be empowered. And if we used the English more it would get them more comfortable with the language and gives them more confidence to understand that they can go out of their situation. Because in Swaziland English is...I mean it's supposed to be the passing subject in school but a lot of people can't really speak. I think forcing the program to be more English would have given them more confidence.

Finally, coaches noted that the selection of the physical activity/sport should also take into account cultural preferences: "like some of the games, the activities...the physical activity should be more related to things they know. For instance, I'll make an example of the Frisbee activity. They don't know it."

\section{Program design: improvements}

Content analysis of the youth and coach focus groups, teacher interview, and field notes yielded 77 raw meaning units related to program improvements. The four higher order codes related to program improvements were: program structure, youth learning, youth participation experience, and improvements made during implementation of the program. See Figure 9.

\section{Program structure}

The strongest higher order code for program improvements focused on elements of the program structure that could be changed to strengthen future programming. Under program structure, the following four middle order codes were addressed: length of program, TPSRspecific, program resources, and miscellaneous. Specifically, coaches commented on the general positive effect that lengthening the sport program would have on the youth participation 
experience and outcomes. That is, coaches felt that if the program was longer, there would be a greater opportunity to build up youth confidence in English, develop youth confidence in leadership, cultivate a supportive peer culture, and repeat each sport multiple times for sportspecific development and enjoyment.

If we had a sport that we focused on during the week, and then on the weekend we tried to give more time to play that would have made them enjoy the sport more. Like for instance, like how I said the yoga was maybe a little bit uncomfortable... If we had more time to do that then you'll find that with time people will get more comfortable and in that way, it would stay on them the reasons for why this is important because maybe they would see the results if there was more time.

Several suggestions for improvements centered on making small changes to the TPSR structure. First, the most frequently cited change was to somehow divide the week between sessions that focused more heavily on life skills learning and sessions that emphasized the sportspecific development. In this way, there would be enough time for in-depth learning on some days and then adequate time for physical and sport development on other days. The afternoon club teacher made the following suggestion:

I'd say maybe from Monday to Wednesday it would be the learning part and Thursday/Friday would be sport. Because as the week deteriorates, everyone is fast losing interest. So the better way to bring the hype back would be to just take them back to the sports field and revitalize the spirit.

It was also suggested that the overall length of each daily session be extended to accommodate a longer awareness talk and more sport time. Coaches also noted that it may be helpful to combine the group and self-reflection as the youth responded with more engagement 
and thought to the group reflection versus having to reflect on their own. Program resources that were cited as improvements were: 1) having access to an indoor facility; 2) providing sport attire to the youth; and 3) recruiting a greater number of coaches to support the youth experience. Last, coaches noted that if the research component continues, it would be preferable to include a diverse range of coach assessments instead of completing the same TARE reflection tool.

\section{Youth learning}

Specific to the higher order code of youth learning, improvements were suggested that broadly coalesced into two middle order codes: learning content and facilitation strategies. The salient improvements under learning content were to include culturally relevant metaphors in the awareness talks (e.g. rivers and crocodiles instead of volcanoes), to teach youth how to teach their peers about the life skills learned in the program, and to focus some of the learning on embracing alternative gender roles. Related to learning facilitation strategies, future programming can place a stronger emphasis on providing youth leadership and responsibility opportunities, and to make more use of teaching moments and integration of life skills into practice. Coaches also suggested that transfer of learning could be better facilitated using a diverse range of strategies such as motivational speakers or movies. Using a motivational speaker would also provide youth with an additional adult role model to aspire toward. As one coach stated:

Yes or [someone] who has gone through maybe a hard time. Say someone has gone through an experience to get to where they are now and like how they overcome difficulties through certain life skills they had to grasp along the way and where they are now. It makes it more relatable. 
To improve the self-reflection component of the program, coaches also felt that having a writing component or journal during self-reflection would help the youth focus and would give them more ownership of the self-reflection portion.

\section{Youth participation experience}

Data from across all data sources also presented suggestions for how the youth participation experience could be improved both from a youth management perspective and from a sport-specific perspective. Under the middle order code of youth management, the most frequently cited changes were to improve coach management of discipline, find a balance between mixing and separating genders, and having fewer youth participants. These areas of improvement have been highlighted in previous sections already. Similarly, sport-specific improvements that have highlighted previously included facilitating better inclusive play across genders and gradually introducing novel sport experiences so youth can gain confidence and competence in experiences outside their comfort zone. Other changes to sport-specific elements of the youth participation experience were stretching after each sport session and providing more opportunities for competition between youth and against other sport clubs. In the focus groups, youth stated: "We should stretch more after games" and "We would like to play other teams." Improvements made during implementation of the program

A last significant higher order code under program improvements captured the improvements that were made during the implementation of the program. First and most importantly, a decision was made to provide mahewu (maize-based drink) during every session after the first one. As noted in previous sections, this was a decision that positively impacted the youth participation experience and was also a strength of the program. Two other noteworthy improvements made during the program were the frequent use of small groups to manage youth 
behavior and discipline as well as the use of pairs during self-reflection. Early on it became evident that youth were distractible during the self-reflection so pairing them up to discuss was an improvement that was made. Specifically, the field notes captured this decision-making process through the following observations:

Lots of chatter during self-reflection instead of solo reflection. Consider pairing youth together during self-reflection so they can share with one another...Used pairs today continue self-reflection in pairs with coaches moving around engaging pairs in discussion. Continue with pairs for self-reflection.

\section{RQ3: To what extent was fidelity to the TPSR model achieved in terms of daily structure, youth responsibility behaviors, and coaching strategies?}

\section{Fidelity to the TPSR model}

Fidelity to the TPSR model was evaluated using three key programmatic elements of the

TPSR model: 1) adherence to the daily structure; 2) coaching strategies that align with the TARE; and 3) presence of youth responsibility behaviors.

Daily structure: Frequency statistics from the TPSR implementation checklist indicated that the relational time, awareness talk, physical activity, and group meeting were included in every session of the program i.e. $100 \%$ fidelity. Self-reflection was included in 11 of the 15 sessions (73\%). In addition, free play was included at the end of four of the 15 sessions (27\%).

Coaching strategies: Frequency statistics from the TPSR implementation checklist indicated that in 11 of the 15 sessions (73.3\%), all 9 of the TARE teaching strategies for employed. In 13 of the 15 sessions (87\%), at least 8 of the 9 TARE teaching strategies were employed. Finally, all program sessions employed at least 6 of the 9 TARE teaching strategies. Assigning management tasks, promoting leadership, and involving students in assessment were 
the least frequently employed teaching strategies and were each employed in at least 12 of the 15 sessions.

These findings are supported by the data from the coach reflections that indicated that for 8 of the 9 TARE teaching strategies, coaches on average rated themselves as strong or very strong in utilizing those strategies. Role in assessment was given an average self-rating of between moderate and strong. See Table 4 for the average coach self-ratings on the TARE teaching strategies as well as comments from the coaches describing their use of each teaching strategy. In addition, these findings are further complemented by the content analysis results from the previous section that explored program design elements and coaching strategies.

Youth responsibility behaviors: Concerning fidelity to the youth responsibility behaviors, frequency statistics from the TPSR implementation checklist supported the presence of youth responsibility behaviors that align with the TPSR model. Specifically, findings from the TPSR implementation checklist indicated that in 11 of the 15 program sessions (73\%), at least 8 of the 9 youth responsibility behaviors were present. Across all 15 sessions, at least 6 of the 9 responsibility behaviors were present. The least frequently observed youth responsibility behaviors were helping others and asking for help, which were observed in 11 of the 15 (73\%) and 9 of the 15 sessions $(60 \%)$ respectively.

In the coach reflections, coaches indicated that on average, youth presented with at least moderate levels of all nine of the responsibility behaviors. In addition, 4 of the 9 responsibility behaviors were rated as on average either strong or very strong in the youth participants. These included participating, engaging, expressing voice, and asking for help. See Table 5 for the average coach ratings on the TARE youth responsibility behaviors, comments from the coaches 
describing examples of each of the responsibility behaviors, as well as sample strategies from the content analysis that reflected each TARE responsibility behavior.

Data from the content analysis yielded further findings related to youth behaviors during the program. Overall, content analysis of the coach focus group, teacher interview, and field notes yielded 587 raw meaning units related to youth behaviors that coalesced into five higher order codes (See Figures 10-13). The first higher order code was the strongest (479 raw meaning units) and encompassed the nine TARE responsibility behaviors. The four other higher order codes were gender differences in responsibility behaviors (38), social connection (29), foodrelated behaviors (33), and caring and compassion (8).

\section{TARE responsibility behaviors}

The nine TARE responsibility behaviors were defined as follows:

Participating: behaviors where youth were 'on task' and taking part in the program activities (learning and sport-related). The most frequently noted lower order codes for positive participation were participation in discussion, effortful participation in sport, effortful participation in awareness activity, and participation despite discomfort. Negative participation behaviors included lapses in focus and discipline, although this was also noted as a behavior that improved across the duration of the program. The field notes captured the following behaviors related to participation:

Generally good participation and effort to answer questions during awareness talk...Practicing belly breathing and engaging in discussion about emotion regulation...During group discussion, youth raised hands to give responses and participated in numbers...Lots of laughter, effort, and listening to instructions during volleyball drills... Yoga was clearly new to the youth but they listened and tried hard. -- 
Very excited to play soccer - high participation, effort, and cooperation...Y Youth participated with energy and effort in basketball drills - fun and smiling. Some chatter and loss of focus...Some distractibility during instructions for drills... Some youth at the back were distractible and unfocused.

Engaging: behaviors that reflected high motivation and interest and consequently active contribution to program activities. This was divided into two middle order codes of general engagement and learning engagement. On the positive side of general engagement behaviors, youth energy, laughter, celebratory dancing and cheering, and positive engagement with the coaches were most frequently noted. Negative general engagement behaviors included hesitancy for unfamiliar sports. The field notes captured several examples of general engagement:

Responsive to the coaches - answering and smiling... Youth giggled and smiled at example of coach complimenting other coach...Coach infused humor into his story and concluded that his differences are something he appreciates now even though he was teased about it. Youth listened intently and laughed at his jokes...Coaches joked about disorder amongst boys. Youth laughed and chatted... Dancing and cheering in celebration...Celebrated the win with cheers and dancing...Grand celebrations for goals... Some laughter and hesitancy. Also clearly a very effortful form of exercise for them.

Under the middle order code of learning engagement, the most frequently cited lower order codes were thoughtfulness and active reflection during discussion, providing examples of application of life skills, and engagement during learning activities. Negative learning engagement behaviors included lack of engagement during self-reflection. 
Some youth quiet and reflecting hard when asked to figure out a different way to respond when someone hits them...Thought hard about how to reach their dreams... During awareness activity, youth discussed and planned how to reach the goal for the activity alongside help of coaches...During debrief, group 1 explained that there was limited team work and talking, which is why they failed... Lots of chatter during self-reflection instead of solo reflection.

Showing respect: behaviors that reflected respect for peers and coaches. This included listening to peers and coaches, greeting coaches and peers etc. The most common lower order codes for showing respect were listening to coaches and raising hands. For example, the field notes captured the following examples:

Youth listened well to forming groups from numbering off ...Y Youth listened attentively to instructions for soccer drills.

Youth greeted coaches in a friendly way as they arrived.

Youth listened to others while they were speaking and raised hands to contribute. Negative demonstrations of respect included tardiness and poor listening to coach instructions, although this was also noted as a behavior that improved across the duration of the program.

Cooperating: social behaviors where youth worked together to complete a task or cooperated with the instructions of a peer leader. This most often included behaviors such as practicing belly breathing with peer leadership and displaying teamwork. For example, the field notes stated the following: "Youth practiced belly breathing as a group again with one youth leading the practice after volunteering to do so. Rest of group followed his lead and applauded 
his effort after." Negative cooperation behaviors included cheating and negative competitive behaviors.

Encouraging others: behaviors where youth supported their peers. The two lower order codes in this category included holding peers accountable to responsibility behaviors, and peer encouragement. For example (field notes):

Youth chatting with one another and reminding each other to be respectful in their interactions... Youth chat with one another and encourage one another to return cups...Encouraged one another to listen to the coaches.

Helping others: helping behaviors. Examples of helping behaviors captured in the field notes were as follows:

Youth helping one another figure out the instructions during the activity...Goal post fell over on next field and youth went to help to put it back up... Showing peers how to hit and dig the ball correctly when someone made an error.

Leading: behaviors where youth take charge of a task. Leadership behaviors most commonly referred to demonstrations of leadership and initiative-taking.

Practiced belly breathing as a group again with one youth leading the practice after volunteering to do so. One girl took charge of filling cups of mahewu for other youth...2 boy leaders of aerobics very excited to lead... First youth who arrived asked to do the attendance for the day. --Start of awareness activity - youth initiate "team team - yes team" cheer.

Expressing voice: behaviors where youth voiced their opinions or expressed things that reflect who they are as people. The most frequently noted lower order codes were giving voice and voicing opinions. For examples (field notes): 
Youth contributed many ideas to the group expectations list... Girls eager to provide comparison of netball rules to basketball rules... Fun during unstructured play afterwards although girls often had to tell boys to pass and not be selfish with the ball...During group discussion, offered lessons of the day and gave opinions.

Asking for help: behaviors where youth asked for assistance from the coaches or their peers. This included asking questions to clarify instructions e.g. "youth listened to instructions and asked questions to clarify."

\section{Gender differences in responsibility behaviors}

Consistent with the content analysis results from the youth participation experience, a higher order code emerged that reflected gender differences in youth responsibility behaviors. Specifically, related to participation behaviors, there were higher levels of distractibility/lack of focus in the boys. One coach stated the following:

Especially more with the boys. Ya with this group that we had, the girls were more focused than the boys. Because they are of the same age, I think it points to gender and that the girls are maturing faster than the boys. So the boys, aye they were so playful. Further, although overall participation levels were strong, the boys were generally much more engaged in the sport component than the girls. Additional gender differences in participation included greater participation in discussion from the girls, and greater focus for learning in the girls. Overall, gender differences in participation reflected higher participation in boys during sport-related components and higher effort and focus for girls during learningrelated components of the program. This was captured by one of the coaches:

It would depend on the part of the session..."What are we doing now?" In the awareness talk the girls were active, giving answers and stuff. Only if there is a motivation, maybe 
sweets, that's when the boys would take part. That's what he means by them holding back. Then in the physical activity...they [the boys] were only focusing on the physical part so the boys would be there doing a lot and the girls would hold back a bit thinking that "If I do this, then the boys will be like that so I don't want to mess up". So it was depending on the part of the session.

For engagement-related behaviors, a similar thread emerged of gendered engagement dependent on the section of the daily session i.e. girls were more engaged during learning, and boys displayed more motivation and interest during the physical activity sections. However, general engagement was overall quite strong across all sections for both boys and girls despite the small gender differences. For cooperation and helping behaviors, boys were more likely to engage in sport behaviors that did not reflect inclusive play while girls more frequently displayed helping behaviors. As captured in the field notes, "For soccer, boys became very competitive and eager to play but weren't passing the ball much to the girls." Finally, girls were also more likely to ask for help in understanding or for clarification than the boys.

\section{Social connection}

The higher order code of social connection included youth behaviors that reflected a desire to interact and connect with peers, coaches and other adult figures on an emotional or social level. The two most frequently cited lower order codes in this category were chatting amongst coaches and peers, and joking with coaches and peers. Consistently across the program it was evident that the youth group was a very social group that enjoyed laughter and humor and a strong desire to positively connect with others. However, it was also noted that there was initially a reluctance to engage with different peer groups. The field notes captured the following: 
When split in 3 groups, youth tried to hide behind one another so they could be grouped with their friends...For group discussion, when counting off to form teams - youth trying to re-arrange themselves to be in a group with friends... Group very slow moving in picking teams and youth hiding to try to be picked into friend group.

Notably, this was a behavior that lessened across the duration of the program and youth improved in their willingness to engage with different peer groups. That is, the field notes observed the following: "Youth didn't really pick according to friends today, which was cool to see...Youth fairly orderly - no hiding behind others anymore when picking teams." Additional behaviors that reflected a desire for social connection included frequent instances of spontaneous play where youth began playing jump rope or started singing while interacting with one another during relational time. Finally, youth also interacted directly with the primary researcher through greeting her as they arrived and through more meaningful interactions such as asking about life in the United States or the SiSwati origins of my name.

\section{Food-related behaviors}

As noted in the program design elements and in the youth participation experience, the provision of fruits and food and the use of small sweet incentives were valuable positive components of the program. Consistent with these findings, a higher order code emerged for youth behaviors that centered on food-related behaviors. Specifically, the two most frequently cited behaviors were eagerness to receive fruit and food and also eagerness to receive treats. Examples of these behaviors from the field notes were:

Youth eager to receive sweet for arriving early...High excitement and happiness for Friday chocolates at end...Y Youth started chatting amongst themselves wondering whether there would be sweets for arriving early. Ate mahewu (maize-based drink) first before 
joining circle... Rushed to line up for fruit at end...Generally youth would arrive, say hi, receive their sweet, and then go drink a cup of mahewu.

Further food-related behaviors were a need to re-fuel on a frequent basis (i.e. go get a second cup of mahewu mid-program) as well as concern over missing out on food. This concern over missing out on food was reflected in behaviors such as pushing in line to receive fruits and chocolate, or frantically scrambling to be the first in line to receive fruits in case we ran out of fruits. This was a consistent behavior across the program.

\section{Caring and compassion}

A final higher order code of youth behaviors was youth actions that reflected caring, kindness, and compassion towards others. The most frequently cited lower order code under this category was caring for others, which included behaviors such as demonstrating concern when a peer got hit by a soccer ball or ensuring that every youth received at least one cup of mahewu before other peers took a second cup. The field notes also captured a poignant moment of kindness when one youth arrived early to the session and approached the researcher:

She asked me, "Where is coach Trevor? Is he coming today because I have a gift for him and I must make sure I give it to him.” She opened her hand to reveal several Panado tablets (painkiller for headaches) wrapped in a tissue. Coach Trevor had been feeling sick the previous week so she had brought him something to make him feel better. It had taken her a week to organize the tablets - what an act of kindness! 


\section{Program impact}

\section{RQ4: What positive developmental outcomes and changes in life skills are associated with youth participation in a TPSR-based youth sport program in eSwatini?}

\section{Youth developmental outcomes}

Content analysis of the youth focus groups, teacher interview, and life skills learning quizzes yielded 361 raw meaning units related to youth outcomes. The 6 higher order codes related to youth outcomes were organized according to the 5 responsibility levels of the TPSR model as well as one general code: respect and self-control, participation and effort, selfdirection, caring/helping/leadership, transferred outcomes, and general outcomes. See Figure 14. Respect and self-control

This responsibility level was characterized by youth outcomes and life skills that reflected youth respect for the rights and feelings of others. This included taking ownership and responsibility of controlling their own behavior, attitudes, and emotions, and acknowledging how their behaviors may impact their peers and coaches. The most frequently cited lower order codes in this category were respect, self-control, and emotion regulation. Youth spoke about respect in the following ways:

At school, I can show respect by listening to other people before speaking.

Respecting others so you receive the same treatment.

You can respect yourself and you can respect your mother and father.

Youth referred to self-control and emotion regulation interchangeably and described it as:

You must practice self-control when working with other people.

Regulating your emotional state for example when you are angry you do belly breathing, 3 seconds in and 3 seconds out. 
The ability to control your emotions when there are difficult situations at home or at school.

If you are stressed or angry you should regulate your emotions e.g. breathing.

\section{Participation and effort}

The higher order code of participation and effort encompassed outcomes and life skills related to putting effort into every task, taking personal responsibility for improvement through hard work and effort, and working together with others such that everyone can learn and grow. Specifically, effort/hard work, team work, and communication were most frequently identified as positive developmental outcomes. When describing hard work and effort, youth stated things such as, "to try hard and participate", "putting effort in whatever you are doing even when you are going through difficult times", and "dedicating yourself in whatever you are doing for instance at work."

When referring to team work, youth stated the following:

I can talk to other people so we can help each other on different things.

Working well with other people at home school and in the community.

We must work as a team in school or anywhere, for instance we work as a team in class when solving problems.

When describing outcomes related to communication, youth spoke of the following: "I learnt that we should discuss arising issues at home or school." "I can talk to other people if I have problems at school." "We can communicate when we are playing and communicate at home." Self-direction 
Self-direction incorporated outcomes and life skills related to orienting yourself toward the future, and taking stronger levels of responsibility for crafting and working toward personal goals. This also included putting in the effort and work to overcome the obstacles and challenges to reaching those goals. Self-direction was divided into two middle order codes of life skills related to planning for the future, and resilience-related skills that reflected the ability to keep moving forward and making healthy decisions despite obstacles. Specifically, the most frequently cited outcomes under planning were self-direction, goal-setting, and decision-making. Youth understood self-direction as "knowing where you are going in life." Goal-setting was described by youth as "choosing what you want to become in the future", "setting goals for yourself and working hard until you reach those goals", and "to set goals for yourself for what you want to achieve in school." When commenting on learning about decision-making, youth stated the following:

When people say I must do something with them, I say no and make my own decision. We must decide what to do when someone tells you to do something.

Controlling your decisions such as deciding not to succumb to peer pressure.

Under the middle-order code of resilience, the most frequently cited outcomes were confidence and perseverance. Youth described confidence as "having faith in ourselves" or "[being] confident when doing things that I do not trust myself in." They also mentioned "believing in your own ability when playing soccer with friends" or using confidence "when you are in front of people." Youth responses centered on the outcome of perseverance reflected an understanding of the need to continue working hard despite challenges and obstacles:

Perseverance- I learnt that in most things I do there will be challenges. 
What I have to do is not run away from the challenges, I just need to have more perseverance.

The ability to keep going when things are not looking good.

\section{Caring, helping, and leadership}

This higher code was characterized by youth outcomes that demonstrated interpersonal skills of caring and compassionate responses to others. In addition, it included leadership behaviors that reflected a willingness to contribute to the growth and development of others. This higher order code was divided into three middle order codes of caring and helping, conflict management, and leadership. Caring and helping was composed of the youth outcomes of compassion and caring/helping. When reflecting on the outcome of compassion, youth provided a range of responses that highlighted a genuine care for others:

Having compassion towards people in your community, school and home as well as being helpful to people who are stressed.

You can show remorse to a friend when they have lost a loved one or when someone falls.

We must feel sorry for those who suffer. For instance, when a person does not have something help him or her.

I learnt that to be compassionate means you should feel sorry for others, which includes people who are going through suffering

Under the middle order code of conflict management, youth identified conflict resolution as well as the STAR acronym (S-Stop, T-Think, A-Anticipate, R-Respond) as positive developmental outcomes. During the program, four different animals were used to illustrate different conflict resolution styles (i.e. teddy bear, turtle, shark, and dove). In a separate activity, 
the STAR acronym was used to teach youth how to effectively deal with interpersonal conflict. For the lower order code of conflict resolution, youth commented on the outcome of more effectively dealing with interpersonal problems:

Solving problems when they arise as opposed to letting people destroy each other. There is a teddy bear, shark, turtle and a dove. You can use it to understand someone's personality. A teddy bear is soft and always listen to other people's opinion, a turtle hides from problems, a dove is a peacemaker while a shark has no compassion and is aggressive.

In reflecting on the STAR acronym, two different youth interpretations emerged. First, youth understood it as a strategy to find a more effective response to an unpleasant situation i.e. "S means stop, T means think, A means attention and R means respond. You can use it when someone angers you." Second, youth used it as a reminder that they were worthy and valuable despite being subjected to an unpleasant situation i.e. "You should tell yourself that you are a star in your community and whenever someone mistreats, you should tell yourself you are a star.", "Showing people that you are a star, such that when someone steps on you ignore it with a positive attitude." For the last middle code of leadership, youth described the leadership outcome as follows: "That we should care for other people and help them out if we are to become leaders." The leadership outcome was the least frequently cited outcome under this higher order code.

\section{Transferred outcomes}

Transferred outcomes were those life skills and positive developmental outcomes that youth successfully applied to their everyday lives and domains outside of sport such as school and home life. The teacher interview and some of the youth responses during the focus group 
were the primary sources of the transferred outcomes. As one youth said, "Yes, we are able to apply these skills in everyday life. We are able to use these skills at school.” The transferred outcomes were organized according to the responsibility levels. That is, under the responsibility level of respect and self-control, the following three outcomes were identified: respect, selfcontrol, and responsibility. To address transfer of respect, the afternoon club teacher stated the following:

Let me put it this way, from aspects of respect, there has been an improvement. In fact, having participated in the sport program has made them aware of how they should conduct themselves...for respect it's something I've seen quite a tremendous change in. To describe the transfer of self-control, youth stated "when I am in a high stress situation or having a problem, I do my breathing exercises." The afternoon club teacher reflected that responsibility-taking has improved as evidenced by youth being more organized and doing their homework on time, and have also been taking responsibility for attending the afternoon club classes on a more consistent basis.

To describe the transfer of participation and effort, youth described the following examples of their use of effort, team work, cooperation, and communication outside of sport:

Well now I am able to study well when I am in a group with other students.

Yes. Applying yourself to something. Well, we just recently took a test in class and I really applied myself to get good grades.

Pertaining to self-direction, outcomes that were successfully transferred were goalsetting, perseverance, and decision-making. Examples included: "Yes. Goal-setting. I now know my purpose for going to school" and "Just how to make better decisions in my life." The 
afternoon club teacher spoke to the transfer of the responsibility level of caring for others in the following excerpt:

I can say maybe having to care about the next person. Because previously they wouldn't come to me telling me about someone else [a peer] having a problem with uniform or something but now they are much more comfortable in coming to me and telling me such things.

Under the fourth responsibility level of caring, helping, and leadership, youth briefly mentioned "applying leadership when we help out other people." This was the weakest area of transfer.

\section{General outcomes}

The final higher order code of general outcomes was composed of life skills comprehension outcomes as well as sport-specific outcomes. Life skills comprehension outcomes encompassed data that reflected significant youth understanding and learning of the life skills taught in the program. Specific examples included the following ways that youth described their understanding of life skills in the program:

Self-control: Self-control is a way you preside over yourself and your emotions so that you can conduct yourself appropriately.

Goal-setting: I learnt about goal setting. I can describe it as my dream in life. A goal is what you aspire to be, like how I can say I want to be a doctor or a nurse. That would be goal setting.

STAR: Stop, Think, Anticipate, and Respond. You think of the best choice.

Sport-specific general outcomes included how to be physically active and also sport skill development e.g. "I learnt how to play soccer well." 


\section{Youth changes in life skills}

As described previously, to assess youth changes in positive developmental outcomes as a result of the program, youth completed baseline surveys of the PSRQ that assessed four of the five responsibility levels of the TPSR model, as well as five domains of the MSPSE, which examines self-efficacy. Although youth scores increased from baseline to post-program across all quantitative measures (i.e. all five domains of the MSPSE as well as the total PSRQ score) paired t-tests indicated that only the increase in personal and social responsibility (PSRQ) from baseline $(M=68.04, S D=4.95)$ to post-program $(M=72.75, S D=5.57)$ was statistically significant $(t(21)=-$ 2.891, $p=0.009)$. Changes in self-efficacy scores in the domain of self-assertive self-efficacy from baseline $(M=4.10, S D=1.26)$ to post-program $(M=4.52, S D=1.22)$ approached significance $(t(20)=-1.958, p=0.064)$. See Table 6 .

\section{Researcher reflexivity}

Across the duration of the preparation and implementation phase of the sport program, the primary researcher also kept a reflexivity journal where she reflected on key personal observations, themes, and thought processes. Some of the excerpts of those narratives are presented below under major themes. The purpose of including these narratives is to provide a richer description of some of the codes that emerged previously in relation to youth experiences and program design.

\section{Youth experiences}

Youth interest in program was high from the very beginning

After I had introduced the ideas behind the program, the kids asked questions... What kinds of sports will we play? What should we wear? (Something you are comfortable in but no need for any sport-specific clothes or shoes as we know those are expensive. 
Barefoot is fine too as we are in a safe, grassy area.) Why is it only starting next week and not tomorrow? (They were sad about that.) Can the program be 4 weeks instead of 3 weeks? (We agreed that at the end of the three weeks we would all decided together what they liked and what they didn't like about the program and then we'd see whether they still wanted to have another week of the program.) Can I also bring my other friends to the program? (For now it will just be this classroom, because we want to figure out what you all like and don't like about the program so we can make it better. Then afterwards we will make it an even bigger program and then you can invite all your friends.). ** Note: program was extended by a week at the end, but included only an additional week of sport participation and no new life skills learning content. The primary researcher facilitated free play sessions with youth after school for one week postprogram.

\section{Theme of issues with discipline - especially with boys}

Theme of discipline- has been somewhat of a challenge for the first two weeks. The school system is very strict with discipline, to the point where kids don't really have a voice. This is similar societally as kids are meant to be seen but not heard. This sport program is grounded in coaches building empathetic, friendly, and caring relationships. It has been evident that that this type of relationship with an adult is something that is unfamiliar to these kids so they take advantage of the flexibility and the result is chaos of sorts. I wonder whether kids aren't learning to regulate their own emotions and behaviors in school and at home because there are always externally opposed regulators and rules. So now when they come into a space of more openness, they don't know how to control themselves. So within this cultural factor, how do coaches balance the empathy with 
some level of discipline and teaching kids to regulate their own behavior? Having said that, discipline and respectful participation in discussion has gotten better over the past week and a half.

Punishment - this is a core part of how kids are disciplined in Swazi society. It seems that some form of punishment will likely have to be employed for a sport program within the community setting. However, we can think carefully about what the content of the punishment is i.e. positive punishments that have some utility e.g. group push-ups as a team to promote team accountability.

\section{SiSwati as primary program delivery language}

Teaching the program in half English-half SiSwati hasn't worked very well. The youth are not at all confident in English and they are also learning a new style of interacting with a teacher/coach i.e. discussion and active thinking versus the teachercentered/authoritarian style from the school system, so allowing them to first work through this in SiSwati and not forcing English makes more sense. In a longer term program it might be more successful to slowly introduce the English conversation. Right now it is an issue of building a sense of competency and small successes, which is central to the TPSR model. This can only happen in SiSwati for now.

\section{Coach training as positive experience for coaches}

Coaches were encouraged and motivated after the first day. They realized that a lot of the concepts and strategies were things they already did to some extent, so they felt validated and empowered to continue doing those things, and to also work towards doing those things more and adding the strategies that they had been overlooking. A big confidencebuilder for them. 


\section{Program design}

Afternoon club teacher as ally in program implementation

First impressions of the teacher: intelligent, quick on his feet, very personable. Bought into the objectives of the sport program very quickly. We discussed whether he wanted to somehow help with the program or if he wanted to teach the kids who didn't participate in the program. He definitely wanted to be a part of it and advised that I ask all the kids to participate in the program or they will feel left out...

Immediate impressions of his interactions with the kids was that he had a very strong relationship with them. They listened to him and responded to his requests very quickly. He was gentle and not at all authoritarian. It was clear that they respected him. He went on to explain to them that he wanted them to be respectful of the sport program and participate enthusiastically if they were interested, because respect and participation are already important values in this classroom, so they should show the same to Zenzi and to the sport program.

Collaborative approach with teacher ended up being very important. The close relationship between the teacher and the students was also a great strength. It helped the kids buy into the sport program. The reputation of the children's center in the community was also a significant driver for buy-in.

Importance of providing fruits and food

Critical incident during first Friday session - there had been a break-in at the children's center in the morning on Friday so the mahewu (maize-based drink) for the afternoon club hadn't been made. While I organized a different source of food, the kids started the sport session without having had anything to eat. It was VERY evident that focus was not 
there because of how hungry the kids were. We decided to start the session with the fruits instead of ending it with the fruits. This helped their focus A LOT. Fruits are also often effective incentives for participation. Clearly this is a very specific cultural factor and social factor of the population that this program is working with. Attendance on that Friday session (usually no afternoon club) was still at 32 because of the fruit that was being given out at each session and also because there would be chocolate on Fridays, a rare treat for those kids.

\section{Inclusion of unstructured play}

Youth want even more time to be able to participate in the sport component so we will add a free/unstructured play time as a new section at end of each session where youth can play using their own rules and structure. Although the focus of session 2 was volleyball, the youth immediately used the volleyballs as soccer balls during the free play. Some of the girls continued playing volleyball. A group of male youth also asked again when the program would be playing soccer - interesting given that the focus groups did indicate that youth wanted to learn multiple new sports.

Unstructured play at end of each session is useful opportunity for youth to self-govern and to also get more energy out. They tend to like to play matches, to feed their competitive side. Both girls and boys are clearly quite competitive and celebrate joyously when their team scores a goal. The girls are also not afraid to call the boys out when they don't pass or when they make a poor play. Today during the unstructured play we divided the youth into teams and then each team came up with a name...Lobamba Cyclones, Real Madrid...one team spontaneously stood in a line and decided to sing the national anthem before they started playing. Hilarious to watch! 


\section{Length of awareness talk}

Trend over the past couple of weeks that it's difficult for the coaches to keep time during the awareness talk. It usually ends up being about 35 or 40 minutes. This is due both to the slow-moving nature of the kids in organizing groups etc., but also in the coaches' style of conversing and discussing with the kids. Swazi culture has many oral traditions circular conversations where talking very deliberately and slowly is valued -Swazi culture is also very laid back and easy-going, so sport programming structured in the TPSR model might need to consider lengthening the time allocated for each session to account for this.

Awareness talk was very long again today. Coaches reflected that awareness talks often also go long because the youth take a bit longer to understand the concepts, so the coaches use a lot of elaboration and examples. Coach Trevor also reflected that the youth sometimes know the answer (or have thoughtful responses) but aren't forthcoming with their responses - issue of confidence? Issue of this being a different learning style than in school where discussion and asking of opinions is not done a lot? Critical cultural consideration for the program.

\section{Including the community in the program}

On Thursday, the youth participants helped present the sport equipment as a gift to the children's center. In front of the staff and pre-school children in the other afternoon clubs, two elected youth participants (one girl and one boy) spoke to the audience and explained what they had been doing for the previous 3 weeks and what they had learned. Six other youth helped hold up the posters because they were also eager to be involved in presenting to the group. In some ways it was another way to see what they had learned in 
the sport program. They used the life skills visual posters to help explain each of the life skills to the staff and especially to the pre-school children. They then added examples of application and interpretations for many of those life skills. The girl spoke with so much animation and energy! She spoke directly to the pre-school children and engaged them as a story-teller would, with facial expressions and dramatic hand gestures. The boy even demonstrated to the group how to do belly breathing when he was talking about emotion regulation and got the whole group to practice - he then gave the example of Cristiano Ronaldo using deep breathing when taking a penalty kick during the World Cup. Lovely! Leadership in action! The pre-school children listened very attentively and seemed to enjoy listening to the older kids. For me it was quite a poignant moment...their energy and engagement in presenting what they had learned was a very special experience.

\section{Chapter 4: Discussion}

Given the formative developmental period that adolescence represents (Holt, 2008; Fatusi \& Hindin, 2010) as well as the unique contextual challenges that youth in eSwatini (Swaziland) face (Mavundla et al., 2015; UNAIDS, 2016), this feasibility study aimed to explore the implementation of a sport-based life skills development program for emaSwati (Swazi) youth. The sport program was designed using the teaching personal and social responsibility (TPSR) model, which is a well-established instructional model for life skills education through sport (Hellison, 2011). Although this model has been widely applied in Western contexts (CaballeroBlanco et al., 2013; Gordon \& Doyle, 2015; Whitley, Coble, \& Jewell, 2016), few explorations have been made into its implementation in non-Western contexts where the model might operate differently (Wright, Jacobs, Ressler, \& Jung, 2016). The specific aims of this feasibility study were therefore to examine youth experiences and implementation challenges and successes of a TPSR sport program for underprivileged youth in eSwatini. In addition, the study aimed to 
explore the positive youth developmental outcomes that emerged from participating in such a program.

\section{Program implementation}

\section{Research question one: youth participation experiences}

The following section integrates findings and discussion points related to research question one that addressed the youth participation experience in a TPSR-based youth sport program in eSwatini. The role of sport as a context for youth development is largely dependent on whether a sport environment has been created that provides a positive sport experience and subsequently helps cultivate life skills learning (Coakley, 2011). Moreover, sport participation does not automatically lead to positive developmental outcomes and can in fact be a negative experience for youth (Coakley, 2011). Therefore, crafting the right sport environment where youth have positive participation experiences is a necessary precursor to personal development (Côté \& Hancock, 2016). The findings from the current study indicated that overall, youth experienced the program as a positive addition to their daily routine. Specifically, findings supported positive emotional and cognitive experiences such as enjoyment and fun, social validation from peers, leadership opportunities, experiencing small successes and feelings of competency, and learning new things. The experience of enjoyment and fun in youth sport has been cited as one of the primary contributing factors in initiation and maintenance of sport participation (Visek et al., 2015) and has also been found to be a principal need during sport participation in vulnerable populations (Whitley \& Gould, 2010; Whitley, Coble, Jewell, 2016). Previous research in eSwatini also noted the need to create sport programming that was enjoyable in order to increase youth participation in sport, especially for females (Huysmans, Clement, Hilliard, \& Hansell, 2018). This is consequential because the longer youth commit to 
sport participation, the more likely they are to experience the benefits of youth sport (Holt \& Neely, 2011; Whitley, Massey, \& Wilkison, 2018). For youth in eSwatini who face significant resource and health challenges, crafting a youth sport experience that is fun may subsequently prolong engagement in sport, which increases the likelihood for positive developmental outcomes to occur.

Further, youth participation experiences in the current study also included a feeling of social connection and validation from peers as well as positive social relationships with the coaches. Exposure to role models and experiencing positive coach and peer connections have been found to be core contributors to creating a positive sport experience where personal development can occur (Holt et al., 2017). Hermens and colleagues (2017) review indicates that for socially vulnerable youth (which may include orphans and vulnerable children) who face significant stressors and are often socially isolated, creating a conducive sport environment with positive peer and coach-youth relationships provides the foundation for optimum sport experiences and life skills learning (Danish et al., 2004; Hermens et al., 2017; Whitley, Massey, \& Wilkison, 2018). Further, building strong relationships with adults has also been identified as a primary need and motive for youth sport participation in vulnerable youth populations (Whitley \& Gould, 2010; Whitley, Coble, Jewell, 2016). For the youth in the current study, developing these empathetic and mentoring coach relationships and positive social connections may therefore have been especially valuable given that they were all single or double orphans from low socioeconomic contexts and backgrounds of abuse.

This desire for interpersonal attachments and for a sense of belonging with peers and adult figures is a fundamental human motivation that impacts health and happiness, strongly shapes cognitive experiences, and generates positive emotions (Baumeister \& Leary, 1995). 
Human beings therefore instinctively seek out social connection and are strongly impacted on multiple levels of health and well-being by the absence or presence of these interpersonal attachments (Baumeister \& Leary, 1995). The positive social connections between youth and their peers as well as youth and the coaches in the current feasibility study may therefore have met this fundamental human motivation. Given that across eSwatini just about half of the population is under the age of 20 years old and almost half of youth are orphans (AVERT, 2014), sport-based programming could be a viable context through which to expose these youth to positive adult relationships and role models. Moreover, although previous studies in eSwatini have indicated that youth (males and females) have positive attitudes towards sport participation and enjoy sport when they do get the opportunity to play, the vast majority of school-going youth do not actually participate in physical education or sport at school as it is not a required subject (Ndlangamandla et al., 2012; Toriola, 2010). The findings from the current study therefore provide further justification for the positive experiences that emaSwati youth can be exposed to if concerted efforts are made to invest in sport-based positive developmental experiences. In addition, the coaching bonds developed through this program were described by the youth and coaches as positive but also vastly different from the normal adult-child relationships experienced by youth (and especially socially vulnerable youth) in eSwatini that are typified as autocratic with unequal power dynamics (Motsa \& Morojele, 2016). This type of sport programming therefore exposed youth to opportunities for positive attachment and connection to adult figures that are not normally available to them in their larger everyday lived experience.

Further notable positive experiences for youth in the current study were related to experiencing small successes and feelings of competency, and having the opportunity to lead. The TPSR model is grounded in the core value of providing youth with sport experiences that 
help them build self-efficacy through small experiences of success (Hellison, 2011). The finding that both male and female youth experienced these moments of success and experiences of leadership is promising as it provides further justification for the value of the TPSR model in a different cultural and youth context. Rather, in eSwatini, participation in sport for female youth has been found to decrease with age alongside perceptions of competency in sport (Toriola, 2010). The focus of the TPSR model on creating small experiences of success may therefore be appropriate and useful in promoting female perceptions of competency and continued participation in sport across the lifespan. Cultivating feelings of competency and experiencing opportunities to practice the life skills learned (i.e. practicing leadership) is also consistent with the theoretical frameworks of the current study i.e. social cognitive theory (Bandura, 2001) and positive youth development (Holt et al., 2017). However, there were also two notable negative experiences related to youth experiences of competency. First, although youth enjoyed exposure to positive novel experiences such as learning new sports, they also sometimes did not enjoy some of the new sports because they didn't feel competent e.g. ultimate Frisbee. Second, low confidence in speaking in English was identified as a negative experience of competence. These two experiences are consistent with Harter's (1988) competence motivation theory that suggests that a primary human motivation is to feel competent and worthy. Consequently, individuals are more likely to enjoy activities (or sport-related tasks), and therefore persist in those activities, where they feel greater competency. For emaSwati youth in the current study, their overall experiences in the sport program were therefore significantly influenced by opportunities that either fostered a sense of competency or undermined their competency, which has implications for the design and implementation of future programming. 
Several other youth experiences are also worth exploring that were specifically related to program features. First, consistent with youth appreciation and enjoyment of the social connections established in the program, youth valued the daily relational time component of the TPSR model (Hellison, 2011) where youth and coaches could get to know one another. For these youth, having a specifically allocated time where they could socially connect and build an interpersonal attachment with an adult mentor whom they likely did not have in their lives outside of sport (i.e. social isolation of socially vulnerable populations (Hermens et al., 2017)), was a central experience in the sport program. The emotional and psychosocial value of this period of relational time for these youth aligns with the need-for-belonging hypothesis that states that positive interpersonal attachments significantly influence happiness and fosters positive emotions (Baumeister \& Leary, 1995). Several very context-specific program features that contributed to the youth experience included the provision of daily food, fruits, and treats, the experience of fatigue and focus issues, and also the use of active learning elements. In a country where $63 \%$ of the population lives below the poverty line and food insecurity is high (Mavundla et al., 2015), providing food is an important contextual element that positively contributed to youth enjoyment and experiences in the program. The provision of food may be even more pivotal for these programs given that a negative aspect of the youth sport experience was related to several instances of physical fatigue and hunger impacting focus. That is, generally youth tired easily and would need to take breaks to rest or eat some more food. In addition, when youth had not received anything to eat, there were very evident lapses in concentration and on-task behaviors. Physical fatigue and concentration issues were likely linked to the socioeconomic background of the youth in the current study and the limited amount of food they receive on a daily basis at home. The value of providing food for youth concentration and energy 
maintenance is consistent with education research in areas of South Africa where food insecurity is high or where there are large proportions of vulnerable student populations (Bayat, Louw, \& Rena, 2014; Hochfeld, Graham, Patel, Moodley, \& Ross, 2016; Mwoma \& Pillay, 2016. Specifically, the provision of meals and snacks through school-based nutritional programs in South Africa has been found to be a significant contributor to academic performance (Bayat et al., 2014; Mwoma \& Pillay, 2016) through its impacts on greater concentration in class and also more consistent attendance at school (Hochfeld et al., 2016).

Also related to context-specific factors was youth enjoyment of the active learning element of the program. Youth enjoyment of being actively engaged in their own learning during the program may be reflective of experiencing a different style of learning than is usually employed in the school systems in eSwatini. Specifically, teacher-centered approaches are predominantly employed across the country. Ndandwe and Dlamini's (2014) exploration of teaching competencies of Agriculture teachers in Swaziland (eSwatini) indicated that teachers rely on more traditional teacher-centered approaches to classroom learning including lecturing and demonstration and have low competency in more active and engaging strategies such as role plays, experiential learning, and problem-solving. Conversely, in the current sport program, coaches adopted a student-centered learning (SCL) approach to support autonomous learning and promote student engagement (Lee \& Hannafin, 2016). Student-centered learning is an approach to teaching that is grounded in the belief that students should be active participants in their own learning. Consequently, the SCL approach cultivates empowered learners who take responsibility for their learning and develop the skills to autonomously process and analyze information in a critical way (Lee \& Hannafin, 2016). Findings from the current sport program indicated that this SCL approach to learning was well received and enjoyed by the youth and is a valuable 
programmatic element to carry forward into future youth sport programming. The identification of learning as a positive and enjoyable participation experience for youth also aligns with Visek and colleagues' (2015) exploration of the fundamental tenets that contribute to making a sport participation experience fun. What is also notable about their findings is that internal fundamentals such as learning and improving, social fundamentals such as team friendships and social connection, and external fundamentals such as positive coaching were all major contributors to fun (Visek et al., 2015). All of these fundamentals were identified as a part of the youth participation experience in the current study.

\section{Research question two: coaching strategies and program design elements}

The following section integrates findings and discussion points related to research question two: what are the coaching strategies and program design elements (strengths and weaknesses of program and coach training) that contribute most strongly to life skills learning in a TPSR-based youth sport program in eSwatini?

\section{Coaching strategies}

Given the importance of creating a safe and empathetic youth sport environment that allows for life skills outcomes to emerge, the adults in charge of facilitating the youth sport participation experience are especially important (Spaaij, 2009; Vella et al., 2011). Coaches are the primary designers and overseers of the youth sport experience and are therefore in a unique position to intentionally create an environment where personal development and life skills learning can occur (Bean \& Forneris, 2016; Gould et al., 2007; Holt et al., 2017; Vella et al., 2011). Specifically, coaches are best situated to facilitate life skills learning through two main learning pathways: implicit and explicit strategies. Implicit learning refers to the development of life skills without intentional coaching efforts to discuss life skills learning while explicit 
learning outlines the role of strategic, intentional, and deliberate efforts to promote positive developmental outcomes (Bean \& Forneris, 2016).

Implicit strategies, as outlined by Holt and colleagues' (2017) model of positive youth development through sport, refers to the PYD climate that is created by the coaches. The PYD climate encompasses the social environment and relationships within the sport experience (i.e. peers, coaches, and other adults) that support holistic learning. For youth to develop life skills through sport participation and for these skills to subsequently transfer to life outside, maintaining a positive coach-athlete relationship has consistently been shown to be pivotal (Pierce, Kendellen, Camiré, \& Gould, 2018). Findings from the current study indicated that a major higher order coaching strategy was to focus on building the coach-youth relationship. Two primary strategies employed by coaches to build the coach-youth relationship were asking about home and school life, and using humor. This mirrors what Pierce and colleagues (2018) argued in their review that when coaches show interest in the personal lives of their athletes such as asking about school life or asking about examples or application of life skills outside sport, transfer of life skills learned in sport is more likely to occur. Furthermore, this is consistent with the core focus on building the relationship with the youth participants in the TPSR model (Hellison, 2011).

The use of humor by coaches was also very effective in building a positive relationship with the youth. Within the context of education, the use of humor is considered to be an active teaching strategy that increases student engagement in learning, creates a positive learning environment, fosters strong relationships, and aids in the management of misbehaving students (Nasiri \& Mafakhori, 2015; Noon, 2017). The use of humor has also become a pedagogical hallmark of a "good teacher" in recent decades (Noon, 2017). From the researcher's perspective, 
it was an exceptionally beautiful thing to witness this empathetic, caring, and playful relationship being built with youth who loved to laugh and be joyful despite the gravity of their personal lives outside of the sport program. The fact that youth expressed sadness for the end of the program was evidence of the effectiveness of the coaches in building these caring, humor-infused relationships.

The strong coach emphasis on building an empathetic coach-youth relationship may be an especially appropriate strategy to use in sport-based youth development programming in eSwatini given the limited resources to support coach development through formal education courses (Huysmans, Clement, Hilliard, \& Hansell, 2018). A recent study of coach strategies to support life skills development through sport in eSwatini found that modeling appropriate behaviors through an empathetic and empowering coach-athlete relationship was a primary strategy employed by coaches to support holistic athlete development (Huysmans et al., 2018). Notably, these were with youth coaches who had little to no formal training in positive youth development approaches. For coaches in eSwatini, an emphasis on developing the coach-athlete relationship is therefore appropriate and something that is already being employed. Extant literature on coaches working with underserved children in similar socio-economic backgrounds in South Africa also indicates that coaches are aware of the impact of their behavior on their athletes and therefore adopt an intentional approach of modeling life skills (Whitley, Wright, \& Gould, 2016). They also place specific emphasis on cultivating warm and friendly relationships with their athletes in order to help youth overcome the salient context-specific challenges they face in their communities (Whitley, Hayden, \& Gould, 2013).

In the current study, it is also worth noting that the coaches really acknowledged the privileged position they were in to be building caring relationships with youth who had few other 
positive attachments in their lives. Specifically, this was evidenced by the intentionality of the coaches in preparing the youth for the end of the program. That is, over the last few days of the program coaches spent time letting the youth know that the program would be ending soon but that the coaches would open up the opportunity for youth to maintain the relationship afterwards e.g. giving out cellphone number so that youth could contact the coaches. This gesture was reflective of the respectful and empathetic relationship that had been built and also illustrated the coaches' awareness that they were role models for the youth and needed to be intentional in demonstrating that they were trustworthy mentors who wouldn't abandon them. Being intentional in the emphases and life skills that coaches focus on has been found to be a significant strategy in facilitating life skills learning in at-risk youth groups in South Africa (Whitley, Wright, \& Gould, 2016). Moreover, these studies reflect coaches' consideration of the lived experiences and contextual challenges of the youth they are working with in intentionally selecting life skills foci that meet youth needs.

The second pathway for coach facilitation of life skills learning through youth sport participation is the explicit learning pathway. Extant literature indicates that while the implicit pathway is valuable and has merits for life skills learning and transfer, it is essential that coaches also plan for and adopt intentional and explicit life skills teaching strategies (Bean \& Forneris, 2017). Moreover, the TPSR model, itself, emphasizes the use of intentional life skills building strategies and teaching in addition to a foundation of an empathetic coach-athlete relationship (Hellison, 2011). Specifically, nine teaching strategies have been identified that align most strongly with the core principles and objectives of the TPSR model. The Tool for ResponsibilityBased Education (TARE) is used to assess the presence of these teaching strategies in TPSR program implementation (Escarti et al., 2015). This tool has been employed in multiple studies 
as a useful measure for program evaluation, assessment of fidelity, and evaluation of the link between teaching strategies and student outcomes (Escarti et al., 2015; Hellison, 2011; Hemphill, Templin, \& Wright, 2015).

The findings from the current study highlighted the use of the nine TARE teaching strategies to facilitate youth life skills and responsibility outcomes. Specifically, across the duration of the program coaches employed almost all of the teaching strategies on a consistent basis. Fostering social interaction and setting expectations were two of the most frequently identified strategies. Coaches primarily fostered peer interaction through using peer validation of participation in discussion i.e. use of peer high 5's, applause etc. as well as encouraging peers to share personal stories in the group. As has been previously identified, fostering peer interaction serves to create a psychologically safe and caring sport environment where implicit learning of life skills can then occur (Holt et al., 2017). Setting expectations was often utilized by coaches and encompassed strategies such as reminding youth of group expectations and holding them accountable to those responsibility behaviors. Setting clear expectations and reminding youth of the behaviors that are appropriate for the learning environment have been found to be a critical component of behavior management in classrooms in order to maximize student engagement and learning (Pas, Cash, O’Brennan, Debnam, \& Bradshaw, 2015).

Notably, behavior management was identified as a significant category of coaching strategies. According to Evertson and Weinstein (as cited in Korpershoek, Harms, de Boer, van Kuijk, \& Doolard, 2016), behavior (or classroom) management refers to "the actions teachers take to create a supportive environment for the academic and social-emotional learning of students" (p. 644). Given the magnitude of the youth group size ( $N=33)$, effective behavior management was a key area of emphasis. The primary behavior management strategies 
employed by the coaches were the use of incentives/rewards, punishment, other disciplinary strategies, and smaller groups. Principles of reinforcement have a long history in the education system to influence student behavior and the combined use of punishment and reward has been identified as an effective behavioral management strategy (Hamilton, 2016). In the school system in eSwatini, the use of punishment and reward is a widespread practice so it is a behavior management strategy that youth experience frequently (Motsa \& Morojele, 2016). Notably, one study conducted in eSwatini reported that the use of corporal punishment is often higher for vulnerable children given that they often fail to comply with strict school rules related to homework completion and dress code because of their social circumstances of neglect (Motsa \& Morojele, 2016). However, the use of rewards, and punishment, as disciplinary strategies are extrinsic motivators for behaviors that do not facilitate the strengthening of intrinsic motivation or the internal regulation of youth behavior (Deci, 1972).

In the education system this idea has been explored within the context of selfdetermination theory, and posits that all children have an innate curiosity to want to learn (i.e. intrinsic motivation) and naturally seek out challenging situations that will help them develop (Ryan \& Deci, 2016). Children are innately driven and motivated to seek out experiences that foster their sense of autonomy and competency. Therefore, when external regulators or motivators such as rewards or punishment are introduced, this sense of autonomy is undermined and consequently intrinsic motivation to learn or behave in ways that promote learning are undercut (Ryan \& Deci, 2016). Thus, if the aim of the TPSR model is to help develop autonomous and confident young adults (Hellison, 2011), then behavior management strategies would ideally not be employed that undermine intrinsic motivation (Deci, 1972). Nonetheless, using punishment was a decision that was eventually made during the current study for two 
primary reasons. First, punishment was helpful in the management of such a large group of youth. Second, it was quickly understood that establishing a program climate where youth could develop intrinsic motivation to pay attention and learn would take time to build, especially because the school system was concurrently reinforcing a different style of behavior management.

One of the strongest categories of explicit coaching strategies employed in the current study was the collection of learning-related techniques employed by the coaches. Learning strategies were grouped together as general, orienting, remember, understand, apply, and analyze. Notably, the latter four categories of learning strategies (i.e. remembering, understanding, applying, and analyzing) employed by coaches were consistent with Bloom's taxonomy of learning, which is a helpful framework for determining whether program activities are meeting educational objectives (Krathwohl, 2002). Noteworthy general learning strategies included the use of props and visual aids to support learning. In the Refugee Sport Club (RSC), a TPSR-based program in Lansing, Michigan, innovative learning tools such as visual evaluation strategies and poster-board drawings were effectively used to promote learning in refugee populations (Whitley \& Gould, 2010; Whitley, Coble, \& Jewell, 2016). The intention behind using these strategies was to navigate the language differences between the youth and the facilitators. In the case of the current study, the use of visual aids helped youth integrate English and SiSwati understanding of life skills concepts and also supported different learning styles of the youth participants. Given that youth confidence was generally low in English, yet English is a required passing subject in the school system in eSwatini, promoting English language proficiency through the use of visual aids in future programming is valuable. 
Across all four of the learning categories that aligned with Bloom's taxonomy (i.e. remembering, understanding, applying, and analyzing), coaches employed active learning strategies that directly engaged the youth in their own learning instead of approaching teaching in a passive, lecture-based way. For example, to promote understanding of concepts, coaches asked for youth definitions of concepts and prompted youth elaboration. Likewise, to facilitate application, coaches solicited youth examples of life skills use outside of sport. Coaches also employed a range of interactive, movement-based strategies to increase youth engagement and focus. These included things like coach energy, movement, and team cheers. Extant literature indicates that coach/teacher energy and body language is an important contributing factor to creating the classroom environment (Martin et al., 2016). Overall, the emphasis on active learning strategies is consequential because this approach has been associated with more meaningful learning outcomes including the ability to engage in high-order thinking tasks such as analysis, synthesis and reflection (Tabrizi \& Rideout, 2017). It is also a very different approach than what is used in the school systems in eSwatini where more passive approaches such as lectures and reading are employed (Ndandwe \& Dlamini, 2014). Within the larger culture of eSwatini, youth are also not often given the opportunity to engage in discussion and be active participants in community life and decision-making because children are supposed to be seen but not heard (Long, 2013). The active learning approach employed by coaches in the current study was therefore a valuable opportunity for a meaningful learning experience for the youth participants.

In addition, what is most notable is that coaches equally employed (as indicated by similar frequency of codes) strategies related to the lower levels of Bloom's taxonomy i.e. remembering and understanding, as those related to the higher and more complex levels of 
learning i.e. applying and analyzing. Applying and analyzing are considered to be higher-order thinking tasks and therefore reflect more meaningful learning and greater capacity for abstract thinking on the part of the youth (Tabrizi \& Rideout, 2017). The higher levels of Bloom's taxonomy are also considered to be strategies that foster active learning behaviors (Tabrizi \& Rideout, 2017). This means that coaches were successfully supporting both simple learning outcomes such as remembering but also more complex learning outcomes such as applying and analyzing that are consistent with critical and meaningful thinking. Further, the application category of Bloom's taxonomy also aligns with the TPSR focus on addressing transfer. Within the 'apply' code, coaches primarily employed strategies such as asking for youth examples of the use of life skills outside of the sport setting and also prompting youth application of these life skills and forethought about how challenges such as peer pressure might need to be overcome in order to successfully apply life skills. The former strategy is an example of a "hugging" strategy to promote transfer i.e. discussion-based activities where similarities are discussed between sport learning and school or home application (Jacobs et al., 2017).

The presence of these transfer strategies in the current program is a major finding given that the TPSR model's emphasis on transfer is a unique component of the framework (Martinek \& Hellison, 2011). Further, the definition of life skills development through sport specifically identifies transfer as a necessary condition for a youth sport outcome to be classified as a life skill to begin with (Gould, Carson, \& Blanton, 2013). For youth in eSwatini who face significant challenges to their successful transition from adolescence to adulthood, the transfer of life skills from sport is pivotal. Therefore, the significant emphasis of coaches in the current study on employing learning-related strategies that align with Bloom's taxonomy and higher-order 
thinking is significant given that the goals of the program were to create a positive sport experience where youth learned life skills that transfer to their everyday lives.

\section{Program design}

Closely intertwined with the coaching strategies employed to intentionally facilitate life skills learning for youth sport participants are the program design and structure elements that also contribute to this positive developmental objective. Extant literature indicates that intentionally structured programs more effectively lead to positive developmental outcomes and score higher on program quality indicators (Bean \& Forneris, 2016). Moreover, as stated in the international sport coaching framework, "the needs and motives of people taking part in sport change at different stages of their lives" (International Council for Coaching Excellence, Association of Summer Olympic International Federations, \& Leeds Metropolitan University, 2013 , p. 21). Therefore, the context in which youth sport program operate in needs to be integrated into the design and objectives of the program as well as the approach chosen by the coach facilitators. However, extant literature specific to the TPSR model has also found that although significant research indicates that TPSR programmers are doing meaningful work with youth and children, there is a lack of clarity on the specific coaching strategies and program design elements that directly facilitate those positive developmental outcomes (Bean \& Forneris, 2014; Hermens et al., 2017; Whitley et al., 2018). The findings from this feasibility study therefore helped elucidate some of those successful and unsuccessful program design elements.

Specific strengths of the design of the current program that have already been identified (and discussed) within effective coaching strategies and/or elements of the youth experience include coach characteristics and elements of the learning component. Coach characteristics such as being relationally-focused, being invested in the program, and buying-in to the mentorship role were identified as positive contributors to the youth experience and to positive 
developmental outcomes. These coach characteristics are consistent with the TPSR foundational values of putting kids first and emphasizing the coach-youth relationship (Hellison 2011; Martinek \& Hellison, 2016). The presence of multiple coaches also helped facilitate more frequent one-on-one interactions with the youth in order to build quality relationships. This aligns with suggestions made by TPSR program implementers that the ratio of youth to coaches not exceed 5:1 such that coaches have sufficient opportunities to individually interact with each youth (Cryan \& Martinek, 2017; Whitley \& Gould, 2010). The involvement of other adult figures such as the classroom teacher and the primary researcher in the implementation of the program was also valued as a source of positive adult relationships. For underprivileged youth in eSwatini who lack role models and caring adult figures in their lives, involving as many positive role models in these sport-based programs is pivotal. In the Buffalo City Soccer School in the Eastern Cape of South Africa, the involvement of both classroom instructors (life skills) and coaches as caring adult figures who emphasized character, social connection, and a sense of belonging was reported as highly valued by the youth participants (Draper \& Coalter, 2016). The findings from the current study are also consistent with Lyras and Peachy's (2011) recently conceptualized sport for development theory (SFDT) that delineates the processes, conditions, and change agents that lead to positive developmental outcomes. Specifically, SFDT states that the facilitators of the sport experience have to be role models (observable examples of caring and empathetic relationship behaviors) in order for positive outcomes to occur (Lyras \& Peachy, 2011).

Specific to the learning component, the use of active learning strategies, giving youth a voice during discussion, and integrating an active component to the awareness talk were identified as strengths of the program. Within the framework of program design and intentionally 
structuring sport-based programming, the use of active learning and giving voice through discussion has been identified as an indicator of program quality for out of school time (OST) programs (Hemphill \& Richards, 2016). This is because youth are better able to cultivate critical thinking skills when presented with opportunities to problem-solve and engage in their own learning (Hermens et al., 2017). For youth in eSwatini who do not often have the opportunity to voice their opinions, this was a unique design element of the program. In addition, the program strength of including an active and structured learning activity to every awareness talk component of the current sport program is consistent with Bean and colleagues (2014) findings. That is, including well thought-out structured activities in TPSR programs provides opportunities to practice skills and also creates a positive group climate (Bean et al., 2014). Some of the awareness talk activities that youth responded to very positively were the movement-based goalsetting activity, the blindfold activity for leadership, daily belly breathing, and the STAR activity for conflict resolution. Deep breathing has been used effectively in the long-term 'girls just wanna have fun' (GJWHF) TPSR program for young girls in Ontario, Canada (Bean et al., 2016). Another learning element that contributed positively to the quality of the current program was the emphasis on confidence-building, which was noted by both the teacher and the coaches as a central element to the program. Confidence or self-efficacy, with the latter emphasizing both an "affirmation of capability and strength of that belief" (Bandura, 1997, p. 382), is traditionally not emphasized in children in eSwatini yet it is a central life skill that influences whether or not youth can subsequently put other life skills into practice. Moreover, fostering a sense of selfefficacy and resilience in the face of significant hardship is necessary in order for orphans and vulnerable youth in eSwatini to lead happy and meaningful lives (Motsa \& Morojele, 2017). This emphasis on confidence-building aligns with the core value of the TPSR model to focus on 
creating small successes during sport participation in order to build confident youth (Hellison, 2011). These findings therefore provide further support for using a framework such as the TPSR model to guide youth sport programming in eSwatini.

A significant area of program design to also explore was the coach training. Previous TPSR research indicates that adequate leader training is often difficult to achieve (Whitley, 2012; Wright, Whitley, \& Sabolboro, 2012). For the current study, a 3-day (15 hour) training was implemented with the coaches. Previous coach trainings in TPSR programs have been highly variable in terms of length and have ranged from 1 hour prior to each session (Whitley, 2012) to two classroom sessions (Cryan \& Martinek, 2012), one day (Bean et al., 2014), 30 hours (Escarti et al., 2010), or to implementers with years of experience (Walsh et al., 2010). After participating in the training, coaches in the current study reported feeling prepared to create a caring and empathetic learning environment and infuse life skills into their coaching. This aligns with the aforementioned coaching strategies that identified effective coach use of the positive coachathlete bond and a range of learning strategies to facilitate positive youth outcomes and experiences in the program. Coaches also reflected that they felt empowered by the training and also really enjoyed the program, which supports the emphasis on self-efficacy and social cognitive theory as the guiding framework for the feasibility study. Based on these positive findings, a 15-hour training may be an appropriate length of time to prepare coaches to implement this type of sport programming. Further, the emphasis of the training on combining experiential learning activities with didactic discussion and self-reflection, may have been a successful approach and is consistent with suggestions from previous train-the-trainer programs (Blom et al., 2015a). Overall coach increases in PYD and life skills content, coach satisfaction with their training experience, and coach preparedness to use the coaching strategies during the 
program is also supported by extant trainer-the-trainer literature in sport for development programming (Blom et al., 2015a).

However, coaches did score lower on their perceived preparedness to incorporate the TPSR model. Qualitative feedback related to improving the coach training identified including a greater emphasis on learning TPSR integration strategies as well as a stronger focus on coach confidence-building. Thus, while a shorter coach training was sufficient to help coaches feel prepared to integrate PYD principles (i.e. empathetic climate and life skills lesson) into their coaching, longer trainings might be needed to strengthen familiarity with the specific tenets of the TPSR model. The necessity for a longer coach training is consistent with extant literature that has pointed to this need (Whitley, 2012; Wright, Whitley, \& Sabolboro, 2012). Other suggestions for additional positive changes to the training component of TPSR programs include integrating previous participants as leaders of subsequent programming in order to provide them with more intentional leadership experiences (Whitlet et al., 2012). However, it is also noteworthy that despite feeling less prepared to implement the TPSR components immediately after the coach training, coaches implemented a lot of positive coaching strategies, many of which aligned with the PYD and TPSR literature, and also contributed to positive youth outcomes. Therefore, although coaches in eSwatini might not have the available coaching resources to participate in extensive formal coach education programs led by trained coach educators, shorter trainings could be implemented with meaningful impact. This is supported by the positive changes in facilitator behaviors in Whitley's (2012) work in the Kayamandi township of South Africa where facilitator trainings were limited to one hour before each sport session. Specifically, the author noted changes in facilitator perceptions of the value of showing interest in the development and experiences of youth, the frequency of facilitator use of questions, and the use of more open- 
ended questions that provided youth with the opportunity to share opinions and thoughts, thereby cultivating student sense of empowerment (Whitley, 2012). Moreover, as suggested by Whitley, Gould, Wright, and Hayden (2017) from their work in South Africa, coaches can also engage in additional non-formal learning contexts such as online education or coach learning communities to better prepare them to integrate life skills into their coaching and build their confidence in adopting this more holistic coaching role. Finally, it is necessary to consider that even when coach training or education curricula are extensive and well-implemented, there is often a contrast between coach idealistic beliefs about the role of sport in youth holistic development and the reality of what coaching looks like in practice (Gould et al., 2007; Santos et al., 2016; Whitley et al., 2017). That is, coaches may acknowledge that sport is a context for positive youth development but in reality they experience significant pressure to deliver performance outcomes (Santos et al., 2016) and focus on teaching tactical and technical skills over life skills (Whitley et al., 2017). Conscious efforts therefore have to be made to overcome this perceived incompatibility between performance and life skills and bridge the gap between the ideals and the reality of coaching life skills.

A final area of program structure to explore were the program design elements that were strongly tied to cultural or contextual factors. The context in which a youth sport program operates needs to be strongly considered within the design and coaching approach that is adopted (International Council for Coaching Excellence, Association of Summer Olympic International Federations, \& Leeds Metropolitan University, 2013). First, a notable program design element that had to be introduced during implementation of the sport program was the use of SiSwati as the instructional language. Although the program was intended to be implemented with a balance of English and SiSwati in order to support youth confidence-building in their spoken English (as 
it is a required passing subject in school), it became evident quite quickly that the youth participation experience would have been markedly less positive if English had been emphasized. As described in the results section, one coach identified the use of SiSwati as a weakness of the program because he felt that learning to speak English was in itself a life skill needed for job interviews, doing well in school etc. This was a more contentious area of discussion as the other two coaches felt that SiSwati had to be used in order to encourage youth participation in learning and discussion. That is, youth had low confidence to participate in discussion (which was a new approach to learning for them) so asking them to use English, which they were not confident or highly competent in, would have resulted in no participation at all. Extant literature on the use of inclusive practices in sport for development research has highlighted this issue of the use of English for research purposes in a cultural context where English might be the official government language but is not the first language of the majority of the program participants (Sherry, Shulenkorf, Seal, Nicholson, \& Hoye, 2017). Sherry and colleagues (2017) noted that introducing an English language requirement can induce feelings of shame, distress, and discomfort, especially in group settings where the perception of social evaluation is high. The current program's adaptation to youth needs related to English language confidence and proficiency was therefore appropriate.

A further contextual factor related to program design concerned decision-making around the maximum number of youth that could feasibly be included in the implementation of such a program. Originally, youth participant sample size was capped at around 15 youth given recommendations from extant TPSR research that group size should not exceed 15 participants (Cryan \& Martinek, 2017; Whitley \& Gould, 2010). However, during youth recruitment it emerged that a much larger number of youth were keen to participate and would feel left out if 
they were not given the opportunity to do so. Almost 40 youth attended each sport session, which was a large number for the coaches to manage. This was also not ideal given the suggestions made by previous TPSR program implementers that the ratio of youth to coaches should not exceed 5 to 1 (Cryan \& Martinek; Whitley \& Gould, 2010). Whitley’s (2012) work in the Kayamandi township also encountered similar issues related to the youth attendance size. In the case of the Kayamandi township, the author made the decision to allow the large group size to persist across the program duration given that the main aim of the program was to engage local youth in a positive and safe way and provide them with an opportunity to have fun (Whitley, 2012). In the current feasibility study, a similar decision was made collaboratively by the coaches and the primary researcher given that the research purposes of the program were secondary to the opportunity that the program was providing for underprivileged youth to have a positive and meaningful sport experience. This echoes a similar debate that exists in the sport for development world concerning evaluation research and whether 'making an impact' is more important that 'proving that there is an impact' (Levermore, 2011). This issue of youth participant size prompted the primary researcher to reflect on the question of which is more important; to provide a positive youth development opportunity to as many youth as possible or to provide a higher quality opportunity to a smaller group of youth? In a low resource context such as eSwatini where youth need is very high (Mavundla et al., 2015), this is not a simple question to answer. Perhaps the focus in these contexts needs to be more on training coaches to more effectively manage larger group sizes while still cultivating meaningful outcomes for the youth participants. Alternatively, breaking the large group into smaller groups of five or six with two facilitators per group could help with behavioral management and can also help build social connection and peer relationships (Bean et al., 2014). 
An additional program design element tied to contextual factors was the coach strategy related to managing youth discipline and responsibility behaviors such as respect. The issue of discipline was a central behavioral theme across the program that stemmed both from the magnitude of the youth group as well as attempting to reinforce youth responsibility behaviors in a novel way (i.e. encouraging intrinsic motivators for learning and cooperation) while youth remained immersed in a school and home system where external motivators (i.e. punishment and reward) were used to shape behavior. As identified by the afternoon club teacher, the central concern with managing discipline was the challenge of balancing the environment of empathy and unconditional positive regard with a firm hand for discipline. Given that the school system in eSwatini uses very strict authoritarian discipline strategies (Motsa \& Morojele, 2016, 2017) and youth spend the majority of their days in school, it becomes challenging for an afternoon sport program to cultivate intrinsic regulators of behavior.

Three final program design elements rooted in the cultural and social context of the program were the need to lengthen the awareness talk, to ensure that the appropriate cultural metaphors were used during the awareness talk, and to provide fruits and food on a daily basis. During program design, 25 minutes were allocated for each daily awareness talk session. This was consistent with Bean and colleagues (2014) who chose to lengthen the awareness talk given that they wanted the learning component to be activity-based, much like the current program. For the current study, most awareness talks lasted between 30 and 45 minutes, which has yet to be explored in extant literature. The coaches explained that this was due to the need to be repetitive in covering material with the youth firstly because they were developmentally not as advanced as other youth their age. Based on their work with refugee youth, Whitley and Gould (2010) expressed the value in carefully assessing and considering the developmental capabilities of the 
potential participants in order to implement programming in a developmentally appropriate way. The need to be repetitive in covering material was also because liSwati oral culture is traditionally slow-paced, circular, and very deliberate. In eSwatini, people approach the concept of time very differently than Western nations; the passage of time largely mimics the way of nature i.e. there is no rush (Nwosu, 1988). Rather, "in Swaziland (eSwatini), as in the rest of Africa, time is the slave, Swazis the masters." (Nwosu, 1988, p. 149). Adapting the length of the awareness talk to fit the cultural context of eSwatini was therefore an appropriate change to make and will be necessary for future programming in eSwatini.

An additional cultural consideration encountered during the implementation of the current sport was related to including culturally relevant metaphors in the awareness talks. For example, when exploring the topic of overcoming challenges in reaching goals, lava was used as an obstacle in reaching the mountain top (i.e. goal). However, there are no volcanic mountains in eSwatini so a more appropriate analogy might have been the obstacles of crocodiles and hippos when trying to cross a river. Although previous TPSR programs have not explicitly explored the use of culturally relevant metaphors or analogies in program content, other programs have been successful in adapting the design and implementation to better fit the local youth context and needs (Whitley, 2012; Whitley \& Gould, 2010; Whitley, Coble, Jewell, 2016). For example, in the Refugee Sport Club (RFC), program goals were designed to specifically meet the expressed needs of the youth (i.e. fun, learning new sports, and building strong relationships with adults) and innovative pedagogical strategies were employed to address language barriers (Whitley \& Gould, 2010; Whitley, Coble, Jewell, 2016). Finally, as briefly mentioned previously, the provision of fruits, treats, and mahewu on a daily basis was a critical context-specific design element that strongly influenced the youth participation experience. The socioeconomic 
background of the youth in the current study meant that basic needs such as hunger and thirst first needed to be met before higher-order learning could occur. The necessity to provide food was very clearly demonstrated in the youth behaviors of eagerness to receive fruits and food, and significant concern over missing out on those treats, which manifested in pushing in line etc. Although these behaviors are not reflective of positive youth responsibility behaviors such as respect and self-control (Hellison, 2011), they are understandable given the socioeconomic context and family background of these youth.

\section{Research question three: fidelity to the TPSR model}

The following section integrates findings and discussion points related to research question three: to what extent was fidelity to the TPSR model achieved in terms of daily structure, coaching strategies, and youth responsibility behaviors? The TPSR model is a wellestablished and widely used model for sport-based youth development programs (Gordon \& Doyle, 2015; Hellison, 2011; Martinek \& Hellison, 2016). However, although the effectiveness of the TPSR model has been demonstrated in a multitude of studies (Bean, Kendellen, \& Forneris, 2016; Caballero-Blanco et al. 2013; Cryan \& Martinek, 2017; Escarti et al., 2010; Whitley, Coble, \& Jewell, 2016), questions still surround the power of the model in eliciting positive youth outcomes given the over-reliance on less than rigorous program evaluation methodologies (Caballero-Blanco et al., 2013; Coalter, 2015; Levermore, 2011; Whitley et al., 2018; Spaaij, 2009). One aim of the current feasibility study was therefore to examine program fidelity to the TPSR model in order to draw stronger causal conclusions about the role of the TPSR model in engendering positive youth development outcomes and experiences.

Findings from the current study related to fidelity to the TPSR daily structure supported strong fidelity to the model, which mirrors fidelity explorations in extant TPSR programs (Bean 
et al., 2014; Gordon et al., 2016). That is, every session of the program included relational time, the awareness talk, physical activity, and group reflection time. Although the self-reflection period was omitted on several days, it was still included in 11 of the 15 sessions. Moreover, TPSR programming has been found to retain its effectiveness in facilitating life skills learning even when individual reflection is intentionally not included in program design (Bean et al., 2014). The strong fidelity to the daily structure of the model suggests that adopting this specific structure to facilitate sport-based youth development may be a viable option for cultivating life skills outcomes in emaSwati youth. However, several small changes could be made to better meet the needs of the youth in this context. First, as has already been described, a longer awareness talk may be necessary to support the 'no rush' communication style in eSwatini (Nwosu, 1988). Consequently, each daily session might therefore also need to be longer to ensure that there is an adequate balance between learning time and sport participation, which was very important for the youth participants. It was also suggested by the coaches that for future programming, weekly sessions could be split between days that have a heavier life skills focus (i.e. longer awareness talk) and days that have more of a sport-specific focus (i.e. longer sport time) given that youth did enjoy learning but the sport-specific component also contributed to their positive participation experiences. The value of sport-specific development and experiences of healthy competition and physicality through sport programming has been identified as equally important to the learning components in youth sport initiatives (Whitley, Massey \& Wilkison, 2018). That is, the use of healthy competition and experiences of physicality should not be sacrificed in order to emphasize processing time for learning (Whitley, Massey, \& Wilkison, 2018). Alternatively, special consideration might be taken to more intentional about integrating 
the life skills learning and sport components in a way that allows for the sport activity itself to teach a specific life skills i.e. sport system re-design (McCarthy, Bergholz, \& Bartlett, 2016).

Second, as suggested by the coaches, the self-reflection time might be more effective if it was combined with the group reflection or if it included a writing or journaling component. Keeping a journal has been found to be a useful strategy to facilitate athlete reflection and promote transfer of life skills learned in sport-based youth development programs (Pierce et al., 2018). Self-reflection through writing might also encourage youth to reflect more deeply on how they can apply the life skills using a more active learning approach such as writing (Tabrizi \& Rideout, 2017) with the additional advantage of removing the element of fear of peer ridicule, which was cited as a participation concern for the youth in the current program. Alternatively, group and self-reflection could be combined as extant TPSR programming has already successfully explored completely removing the self-reflection component while still cultivating positive developmental outcomes in the youth participants (Bean et al., 2014). Finally, an additional change to the model might be to add a free play section at the end of each day. Free play, where youth decide how long and in what way they would like to engage with the sport equipment, has been found to cultivate creativity and team-work in youth sport participants (Martin \& Kaufman, 2017). Providing a free play period may therefore provide the opportunity for youth to practice autonomy in cultivating their own sport experience and navigating peer interactions, which supports the development of self-efficacy-related skills that are valued in TPSR programs. Further, it may create a space for youth to independently practice the life skills they learn.

The second dimension of fidelity to the TPSR model centered on the extent to which coaching strategies were employed that aligned with TPSR core values and principles. As 
described previously, a range of coaching strategies were identified in the inductive content analysis, the TPSR implementation checklist, and the coach reflections that aligned with the nine TARE teaching strategies. Fidelity to the TARE teaching strategies has been found to support positive youth outcomes in extant TPSR research (Bean et al., 2014; Gordon et al., 2016). Notably, fidelity was strong to the TARE strategy of providing leadership opportunities, which was also identified in the current study as a positive contributor to the youth participation experience. Other TPSR programs have found that providing leadership opportunities is important in facilitating youth developmental outcomes (Bean et al., 2014) and is also a useful strategy in helping youth intentionally practice skills during sport participation so they can be effectively transferred to domains outside sport (Pierce et al., 2018). Coach fidelity to approaches that addressed the TARE strategy of transfer also aligns with supporting youth in applying what they learned during sport participation to life at home and at school.

What is most significant about fidelity to the TPSR coaching strategies in the current study is that several other higher codes of strategies emerged that have not previously been included in TPSR implementation research. Specifically, the current study identified learning strategies and behavioral management strategies as significant categories of coaching strategies. Given that the TPSR model is a framework for life skills education through sport, it seems intuitive that coaching strategies should contain an element of learning facilitation and behavioral management in order to cultivate life skills outcomes. As was described in the previous section, learning facilitation strategies that adopt active learning approaches and emphasize application and transfer are effective in promoting meaningful higher-order thinking (Tabrizi \& Rideout, 2017). Likewise, behavioral management strategies are necessary to create an optimum academic and socio-emotional learning environment (Evertson \& Weinstein, 2006). 
In eSwatini, where the education system struggles with youth access and enrollment in education, as well as minimal resources to support student learning and teacher professional development, youth might benefit significantly from learning opportunities that occur during their participation in sport (Hamid, Bisschoff, \& Botha, 2015). The primary researcher of this study suggests that helping coaches develop strategies that align with educational pedagogies (e.g. active learning and behavioral management) will better equip coaches to meaningfully contribute to the holistic development of young emaSwati. This has yet to be studied within the context of sport-based youth development in eSwatini.

The final dimension of fidelity to the TPSR model was the presence of youth responsibility behaviors. Data drawn from multiple sources supported the presence of youth responsibility behaviors that align with TPSR core values and principles and the TARE, which captures TPSR student responsibility behaviors. First, content analysis identified the presence of all nine responsibility behaviors across the duration of the program. Second, coach reflections identified moderate levels of all nine responsibility behaviors. Third, the implementation checklist noted the consistent presence of 6 of the 9 responsibility behaviors during all 15 program sessions. The presence of at least moderate levels of all the TARE responsibility behaviors is promising in light of providing evidence for the model's utility in promoting these behaviors as program outcomes. Several previous studies have demonstrated the presence of, or improvements in, responsibility behaviors as a result of programming that utilized the TPSR structure (Bean et al., 2016; Cryan \& Martinek, 2017; Escarti, Gutiérrez, Pascual, \& Marín, 2010). For example, Bean and colleagues evaluation of the GJWHF TPSR program in Ontario found that adopting a TPSR approach to sport-based youth development was successful in helping youth develop responsibility behaviors such as respect, responsibility, emotion 
regulation, goal-setting, and social skills. Notably, these skills were successfully transferred outside the gym (Bean et al., 2016). Similarly, Escarti and colleagues (2010) examination of the impact of a long-term TPSR program found that the model was successful in eliciting positive changes in responsibility behaviors such as self-control, respect for others (i.e. less insulting, more conversation, admitting mistakes), communication and cooperation, teamwork, willingness to discuss problems, and confidence to speak up when something could be better (Escarti et al., 2010). Although these studies provide support for the utility of the TPSR approach in engendering responsibility outcomes, few studies (Cryan \& Martinek, 2017; Gordon et al., 2016) have explicitly assessed the causal association between fidelity to TPSR teaching strategies and principles and resultant responsibility behavior outcomes. The current study therefore helps elucidate causal evidence for fidelity to the TPSR model and coaching strategies leading to positive life skills outcomes and responsibility behaviors.

However, as noted in the content analysis and the coach reflections, for the majority of the TARE behaviors there were positive demonstrations of the behaviors but also negative instances. For example, participation behaviors, engagement in sport and learning, and respectful behaviors were high (i.e. most frequently coded), but there were also many observed instances of lapses in focus and issues with discipline and listening to coach instructions. On the positive end, high engagement, participation and demonstration of learning behaviors is consistent with Whitley's (2012) findings in the Kayamandi township in South Africa, where youth face similar contextual challenges to emaSwati youth. This suggests that the TPSR model may be appropriate for engendering these types of youth behaviors in youth contexts such as Swaziland and eSwatini. In addition, high engagement, participation, and respect in both the learning and sport components is likely an indication that the coaching strategies and program design elements 
described previously were effective in drawing out those youth behaviors. This aligns with both Gordon and colleagues' (2016) and Cryan and Martinek's (2017) findings that when fidelity to TPSR principles and strategies was high and those techniques were consistently during sessions, participants experienced positive developmental outcomes (Cryan \& Martinek, 2017) and social and emotional learning outcomes (Gordon et al., 2016). Furthermore, the presence of the TARE behaviors of youth expressing voice was valued by both the coaches and the teacher as a central point of emphasis in the current program and something that should be carried forward as emaSwati youth do not often have the opportunity to actively engage in discussion and have their voices heard in school or community life. Expressing voice is a behavioral reflection of youth confidence and self-efficacy to give opinions and express their identity to their peers and coaches, which is consistent with the theoretical framework of the current study i.e. social cognitive theory and self-efficacy-related principles (Bandura, 2001).

Although negative examples were also present for some of the TARE responsibility behaviors e.g. issues related to focus and discipline, which have already been explored, these behaviors were also identified as areas that improved significantly over the course of the program. This, therefore, suggests that the model was effective in initiating and strengthening the presence of positive reflections of participation, engagement, and respectful youth behaviors. A longer program, where youth are exposed to an empathetic and caring learning environment and the coach strategies for a prolonged period, might therefore more effectively draw out the positive reflections of the TARE responsibility behaviors. Further, longer programming might also strengthen the frequency of the TARE behaviors that are associated with the higher responsibility levels such as such as leading, cooperating, and asking for help. Extant long-term TPSR programs that have shown success in building positive sporting environments where sense 
of belonging and empathy is high and where significant positive changes are observed in responsibility behaviors support adopting a more long-term approach to cultivate the aforementioned outcomes (Bean et al., 2016; Gordon et al., 2016; Whitley, Coble, \& Jewell, 2016).

A major finding related to youth behaviors in the current study was the gender differences noted in the observed TARE behaviors. Specifically, female youth tended to be more engaged in the learning component, while the male youth were more engaged in the physical activity time and also displayed more frequent discipline and focus issues. Within the educational setting, this is consistent with research indicating that boys tend to display lower engagement at school and also have more negative attitudes towards school than girls (Kessels, Heyder, Latsch, \& Hannover, 2014). Further, facilitating inter-gender cooperative behaviors was challenging and was identified as a negative experience, especially for the female youth in the program, as peer exclusion and lack of discipline was frustrating for the girls. Although previous TPSR programs have not explicitly addressed or explored gender issues, the GJWHF program, which included only female participants, was highly successful in engaging their female participants in learning and physical activity (Bean et al., 206). The authors suggested that it was the female-only environment that fostered a sense of confidence in the youth, which helped them engage fully in the physical activity and learning components and successfully transfer them to domains outside of sport. Gender differences in engagement in TPSR programming is an interesting fidelity issue because it points to the need to think more creatively and critically about the role of gender and socialization processes on youth experiences and behaviors in sport-based youth programming in eSwatini. In the wider context of sport for development programming, similar challenges have been identified. That is, there is limited focus in these programs on 
gender relations and deconstructing gendered power dynamics (Hayhurst, MacNeill, \& Kidd, \& Koppers, 2014). Separating youth programming in eSwatini by gender or at least including a much stronger focus on gender considerations may be an appropriate direction to take given that eSwatini is a very patriarchal society with rigid gender norms of male dominance and female submissive behaviors (Buseh et al., 2002; Mofolo, 2011). That is, gender norms of male dominance in sport participation and competency might have contributed to lack of peer inclusion between male and female youth and also female hesitancy to fully engage in the physical activity component (Toriola, 2010). Further, gender roles and dynamics may be important to integrate more strongly into sport-based youth programming because they are significant drivers of the sub-Saharan HIV/AIDS epidemic, which is a major health issue for youth, and especially female youth, in South Africa (Dellar et al., 2015; Wamoyi et al., 2014) eSwatini (Buseh et al., 2002; Mofolo, 2011). The empowerment of women and the overcoming of gender inequalities are pivotal for the development (which includes specific aims for reductions in HIV/AIDS prevalence) of eSwatini and Africa as a continent (Mofolo, 2011). Rather, of the $69 \%$ of the population that live below the poverty line in Swaziland, 63\% are women. This "feminization of poverty" in combination with gender inequality (i.e. subordinate status), and perceptions about relationships, are the driving force behind the HIV/AIDS epidemic in Swaziland (Buseh, Glass, \& McElmurry, 2002; Mofolo, 2011). In addition, studies in education have found that low male engagement in learning is related to gendered self-concepts of masculinity (Kessels et al., 2014) therefore suggesting that breaking down rigid gender roles and self-concepts is valuable. Addressing gender roles and dynamics should therefore be strongly considered in future TPSR-based youth programming in eSwatini. 
Two other categories of youth behaviors that emerged were social connection behaviors and moments of kindness and compassion. The presence of youth behaviors that reflected social connection with coaches and peers is a significant indicator that a PYD climate was successfully established in the sport program (Gano-Overway, 2014). As has been previously noted, the cultivation of a PYD climate is a necessary precursor for life skills outcomes to occur (Holt et al., 2017). For socially vulnerable youth, creating a climate where youth can connect with others and build strong relationships is a primary motivation for sport participation (Gano-Overway \& Guiverneau, 2018; Whitley \& Gould, 2010; Whitley, Coble, Jewell, 2016), and was also previously discussed as a central positive experience for underprivileged emaSwati youth. The social connection element that was characterized by a lot of laughter, chatting, and humor between coaches and youth and amongst peers, was a very meaningful experience for the primary researcher as well, given her knowledge of how much adversity these youth had already faced. Likewise, the observation of behaviors that reflected kindness and compassion was highly poignant because it captured the capacity of the human spirit to retain compassion and kindness despite significant suffering (Lim \& DeSteno, 2016). Therefore, the emphasis of the TPSR model on promoting pro-social values and developmental outcomes such as social responsibility and values such as compassion through relational learning (Martinek \& Hellison, 2016) is worthwhile and highly relevant to the context of youth in eSwatini.

\section{Program impact}

\section{Research question four: youth positive developmental outcomes and life skills}

The following section integrates findings and discussion points related to research question four: what positive developmental outcomes and changes in life skills are associated with youth participation in a TPSR-based youth sport program in eSwatini? The ultimate aim of 
PYD programming and TPSR-based initiatives is to transform communities and the lives of youth (Martinek \& Hellison, 2016). Specifically, the TPSR model is designed to help youth develop the necessary skills to take more responsibility for their well-being and for the welfare of others (Hellison, 2011; Martinek \& Hellison, 2016). Exploring the extent to which the current study successfully facilitated life skills learning and positive developmental outcomes was therefore a central area to address. Moreover, sport participation does not automatically result in positive developmental outcomes (Coakley, 2011), so it is necessary to determine whether the TPSR model helps intentionally create a sport environment where life skills learning can occur. Further, extant literature indicates that while there is evidence for the emergence of a range of positive developmental outcomes as a result of TPSR programming (Bean et al., 2016; Cryan \& Martinek, 2017; Escarti et al., 2010; Hellison \& Walsh, 2002; Hemphill \& Richards, 2016), there is limited research on whether these outcomes successfully transfer to other domains of life (Gordon \& Doyle, 2015). By definition, life skills need to be applied and transferred to domains outside of the sport context in order for them to be defined as a "life skill" (Gould et al., 2013).

Qualitative findings from the current study indicated that youth learning outcomes were identified that aligned with all five of the TPSR personal and social responsibility levels. Results from the PSRQ supported statistically significant increases in personal and social responsibility as a result of participation in the sport program. Further, youth were also able to talk about the responsibility outcomes and life skills in an in-depth way (versus a superficial understanding of the life skills lessons), as identified by the "life skills comprehension" outcome. These results support the findings from TPSR studies in Western contexts that have demonstrated improvements in self-control, effort, and helping or cooperative behaviors (Bean et al., 2016; Cryan \& Martinek, 2017; Escarti, Gutiérrez, Pascual, \& Marín, 2010). Other positive youth 
outcomes from extant TPSR literature have indicated increases in on-task independence, success in reaching goals, self-direction of learning, and the development of strong interpersonal relationships (Caballero-Blanco et al. 2013; Hellison \& Walsh, 2002). In non-Western contexts, Whitley's (2012) findings in the Kayamandi township in South Africa support youth application and understanding of respect and teamwork concepts as a result of TPSR programming.

While it is noteworthy that youth could identify learning outcomes related to all TPSR responsibility levels, discussion will focus more on the outcomes that youth and the teacher identified as transferred outcomes. As has been explained previously, transfer of life skills is central to the definition of what a life skill is and is also a core aim of the TPSR approach. The two strongest developmental outcomes that were transferred were the TPSR responsibility levels of respect and self-control and participation and effort. The effective transfer of responsibility behaviors such as respect and self-control was demonstrated in the GJWHF program where female participants were able to transfer skills such as respect, responsibility, and emotion regulation to other domains of their lives (Bean et al., 2016). Cryan and Martinek (2017), Gordon and colleagues (2016), and Escarti and colleagues (2010) also found significant increases in level 1 behaviors such as respect and self-control as a result of their programs. However, they did not explicitly measure transfer of these responsibility behaviors (Cryan \& Martinek, 2017; Escarti et al., 2010; Gordon et al., 2016). The finding from the current feasibility study that respect and self-control were successfully transferred can be considered alongside program design elements. That is, in the design of the current sport program, respect and selfcontrol as well as participation and effort were directly addressed and included in over two-thirds of the sessions (73\% and $67 \%$ respectively); more than any other responsibility level outside of transfer, which was addressed in every session. For youth in eSwatini, the development of 
respect and self-control that can be transferred to domains outside of sport is a consequential impact of the current sport program given the resource and health-related challenges facing emaSwati youth. Specifically, within a youth context of high teenage pregnancy, gender-based violence, and HIV/AIDS infection rates (Mavundla et al., 2015; Ministry of Sports, Culture and Youth Affairs, 2015; UAIDS, 2016), learning to behave in ways that are respectful of the rights of others and understanding how our actions and attitudes influence our peers and relationship partners is highly significant (Buseh et al., 2002; Huysmans et al., 2017; Mofolo, 2011). In the needs assessment phase to inform this feasibility study, personal responsibility and respectful behaviors towards others were cited by the HIV experts as critical skills in lowering HIV infection rates in eSwatini. Further, HIV research in eSwatini has indicated that gender-based power dynamics and perceptions and beliefs surrounding relationships strongly influence the incidence of unprotected sex and the subsequent spread of HIV (Buseh et al., 2002; Jones, 2006).

Other outcomes that were identified by the youth and the teacher as transferred outcomes were participation and effort (i.e. effort to improve yourself and to work as a team, cooperate, and communicate with others), and self-direction as it related to goal-setting, perseverance, and decision-making. Extant TPSR programs have demonstrated the effective transfer of outcomes related to goal-setting and social skills such as cooperation (Bean et al., 2016), as well as the development of positive decision-making skills (Gordon et al., 2016) although the transfer of decision-making outcomes was not explored. For the youth in the current program, developing life skills such as hard work/effort and perseverance are notable because of the significant challenges and barriers they face to creating meaningful lives for themselves. Decision-making and communication skills have also been identified as pivotal contributing factors to lowering youth susceptibility to contracting HIV due to the role of decision-making and communication in 
negotiating sexual health decision and relationship dynamics (Buseh et al., 2002; Jones, 2006;

Wamoyi et al., 2014). Notably, transferred outcomes also included interpersonal skills related to caring and helping others, which is the social responsibility component of the TPSR model. Caring for others (i.e. empathy) is a necessary precursor to developing a sense of social responsibility and creating better kids who are civically engaged (Gano-Overway, 2014). Moreover, social and emotional learning outcomes such as relationship skills, decision-making, setting goals, and fostering positive relationships have been found to be important educational outcomes that will help youth develop into adults who can make healthy decisions for themselves, manage their own emotions and behaviors, and build lasting and positive social connections (Gordon et al., 2016).

A final program outcome to examine was leadership. Leadership is often cited as a pivotal life skill to develop through sport participation given the role of leadership in developing compassionate and civically-engaged young people as well as the increasingly challenging environment that youth are facing and need to successfully navigate on a global level (Dupuis, Bloom, \& Loughead, 2006; Gould \& Voelker, 2012; Voelker, Gould, \& Crawford, 2011; Martinek \& Hellison, 2009). Despite the value of developing leadership skills, results from the current program indicated that leadership was the least strongly transferred outcome. This can be partially explained by the program structure. Specifically, leadership is one of the highest responsibility levels of the TPSR model and was also not focused on as frequently as the responsibility levels of respect and self-control, and participation and effort during the current program due to time constraints. However, if future sport-based youth development programming in eSwatini wish to create meaningful and long-term impact on the lives of young emaSwati, stronger emphasis will have to be placed on developing youth who can be pioneers 
and leaders in navigating the salient youth challenges of this generation (Gould \& Voelker, 2012; Martinek \& Hellison, 2009). Further, programs should carefully consider that implementing TPSR programing in low-income areas with marginalized youth with the specific aim of transferring life skills can be difficult when youth are surrounded by social and environmental contexts that don't support the same values as the sport program (Jacobs, Lawson, Ivy, \& Richards, 2017). Youth may subsequently receive contradictory messages from the program versus their social context, which can lower the likelihood of transfer. In addition, youth might also receive active resistance from the community to the messages disseminated in the program. For example, in a martial arts sports-based program for the empowerment of young women in Uganda, female participants were ridiculed and harassed as a result of their participation in the sport program (Hayhurst et al., 2014). Employing highly explicit life skills teaching strategies (e.g. role playing, or peer coaching after participating in the program), to develop life skills such as leadership, is therefore necessary because there may be strong contextual factors that impede the transfer of life skills learned during sport programming to community life (Jacobs et al., 2017).

Moreover, it is likely also necessary to adopt a more systems theory approach to these programs, which recognizes the role of macro-level structures in society (e.g. community norms, organizational structures, policies etc.) in preventing long-term changes in youth development (Hartmann \& Kwauk, 2011; Massey, Whitley, Blom, \& Gernstein, 2015). This systems theory lens recognizes that a young adult's ability to become successful and "transform themselves" does not lie completely within their own control (Coakley, 2011). Personal development of youth needs to be combined with community development and social change (Coakley, 2011; Coalter, 2015). Extending TPSR programming to include partnerships with organizations that engage 
parents in collectively working towards changing school and community contexts (Collective Parental Engagement) may be one useful approach (Jacobs et al., 2017). If TPSR programming truly wishes to make long-lasting positive impacts on youth, partnerships will have to be forged with initiatives that work to change the values and norms of the larger socializing forces i.e. parents and schools. Alternatively, in cultural or community contexts where it is more difficult to initiate partnerships that cross social-ecological levels, greater emphasis may need to be placed during the TPSR programming on how young people can transfer skills to the larger environment when the reality is that they may receive resistance to that transfer (Jacobs et al., 2017).

\section{Limitations}

This feasibility study acknowledges several potential limitations that should be considered alongside the primary findings. First, the intended sample size for the youth participants was originally 15 , but almost 40 youth participated daily. This had implications for the coach to athlete ratio, which previous TPSR studies have suggested should not exceed 1:5 (Cryan \& Martinek; Whitley \& Gould, 2010). The youth participant size therefore reduced the number of opportunities for quality one-on-one interactions between the youth and coaches, which may have altered the youth participation experience as well as the developmental outcomes. One of the participating coaches also had to drop out of the program mid-way through, which may have impacted the coach-athlete relationship dynamic, the frequency of quality one-on-one interactions, and the coaches' potential impact on youth life skills outcomes. Further, the sport program was only three weeks in length, which may not have been long enough for meaningful long-term impact on the lives of the youth participants (Bean, Kendellen, \& Forneris, 2016). Assessments of transfer of outcomes also relied on youth self-report of outcomes and the afternoon club teacher's observations of transfer in the two weeks following 
the program. Consequently, any definitive conclusions related to transfer of outcomes need to be minimized. In addition, the primary researcher was not an expert in TPSR programming, which potentially influenced the quality of coach training in TPSR core values, principles, and strategies. Many previous TPSR programs have been guided by practitioners with years of experience working with the model (Cryan \& Martinek, 2017; Walsh, Ozaeta, \& Wright, 2010; Whitley, Coble, \& Jewell, 2016). The coaches recruited for the program also did not have TPSR program implementation experience or a history of working with youth in underprivileged contexts, which may have limited their effectiveness. However, all coaches did come from underprivileged backgrounds themselves.

Further, the sport program session outlines were not developed in complete collaboration with the coaches. Rather, a program outline was created before-hand that was then changed and added to by the coaches during the coach training. This was a limitation of the study given the critique that too many sport for development programs adopt a top-down, neo-liberal approach to programming (Hartmann \& Kwauk, 2011; Spaaij, 2009). As noted by the coaches, a couple of metaphors used in the awareness talk were not culturally applicable, so a more collaborative approach could have prevented this. In addition, in terms of assessment of fidelity to the TPSR daily structure, the TPSR implementation checklist only assessed frequency of the presence of each component of the model i.e. quality and content of each of these sections was not assessed. Similarly, the presence of TARE coaching strategies identified using the TPSR implementation checklist did not allow for the number of times each coaching strategy was used per session to be identified i.e. it was either marked as present or not present. This would have been possible to analyze using video footage of program implementation, which was originally intended, but due to poor quality footage this was not possible. Notably, video footage was still collected as during 
each of the program sessions, which also means that there was potential for youth participants and coaches to change their behavior because of being observed (video-recorded) (McCambridge, Witton, \& Elbourne, 2014). A final research limitation concerned the employment of the primary researcher as the main observer of program implementation and collection of field notes. Given the primary researcher's role in the design and implementation of the program, there was potential for bias to occur in the recording of field notes and also for the youth and coaches to change their behavior due to the presence of the primary researcher.

\section{Practical Implications and Future Directions}

The findings from this feasibility study have several practical implications that may be used to inform the design and implementation of future sport-based youth development programming in eSwatini. First, the cultivation of a diverse range of youth development outcomes and participation experiences in the current study suggest that sport as a platform to engage youth in their holistic development may be an appropriate avenue in eSwatini. Moreover, the specific positive developmental outcomes facilitated by the current feasibility study were life skills and responsibilities that could help address the salient youth developmental challenges in eSwatini, which makes this type of programming especially relevant.

However, some of the more significant findings from this feasibility study apply to the conditions and mechanisms that may be most appropriate when conducting sport-based youth development programming (Whitley et al., 2018). Specifically, programs that focus on creating an enjoyable youth sport experience where participants can build strong, empathetic relationships with coaches and peers may be particularly meaningful. Programming may also focus on helping youth achieve small successes and moments of competency (i.e. build self-efficacy), have the opportunity to lead, and learn relevant life skills. All of these features of the youth participation 
experience identified in the current study align with the principle tenets and core values of the TPSR model, suggesting that this framework can be successfully implemented in eSwatini (Martinek \& Hellison, 2016). Further, in eSwatini, where almost half of the population is below the age of 20 years old and many children and youth lack positive role models, the relational focus of the TPSR may be especially meaningful. For the youth in the current study, the development of an empathetic and humor-infused bond with the coaches was a central positive contributor to their experience and to the developmental of personal development outcomes. The model is also highly adaptable and the life skills foci can be modified to best meet the needs of the local youth population. Further, the TPSR model is a structured framework that demonstrated efficacy in the current study even with a shorter coach training. This has utility in a coaching setting where there are limited resources and time for more formal coach education coursework. Specific to the emphasis of the TPSR model on creating moments of success and competency (Hellison, 2011), the identification of several negative experiences of competency where selfefficacy was not adequately targeted (Bandura, 2001) and small successes were not experienced, is a significant change to be made in future programming in order to create a positive sporting experience that is grounded in self-efficacy and provides the foundation for effective life skills learning (Côté \& Hancock, 2016).

Although the findings from the study suggest that the TPSR model may be appropriate for future programming, the results related to the successes and challenges of implementing the TPSR model in the context of eSwatini present several adaptations to the model (i.e. program conditions and mechanisms that lead to positive outcomes) that may allow it to operate more effectively in this novel youth context. First, the awareness talk component of the model needs to be extended for the current cultural context. The slow-paced and deliberate conversational 
style that is traditional to Swati culture necessitates more time to be allocated to the awareness talk. In addition, the inclusion of active learning strategies and activity-based learning during the awareness (Bean et al., 2014), which was enjoyed by the youth participants and promoted indepth learning, also requires a longer awareness talk. A further adaptation to consider would be the use of journaling during the self-reflection period. Individual reflection without an active engagement strategy such as writing was not very effective in the current study. Third, the addition of a 'free play' section to the daily structure will likely increase youth enjoyment and also promote autonomy, teamwork and creativity. Finally, although the current study identified coaching strategies that aligned with the TARE strategies as effective approaches to support youth learning, two other significant categories emerged that should be considered in future TPSR programs: behavioral management strategies and learning strategies. Behavioral management strategies are integral components to creating a learning environment that supports academic and socioemotional learning (Evertson \& Weinstein, 2006). For the current youth context, the high youth participant number and interest in sport-based programming brings the importance of behavioral management to the forefront. Further, with youth spending the majority of their time outside of the sport program in a school system where external reinforcers such as reward and punishment are primarily used to shape youth behavior, careful consideration will need to be made for how intrinsic motivators for personal and social behaviors can be cultivated. More long-term programming might lend itself more strongly to creating sport environments where youth can learn to autonomously regulate their behaviors. Specific to the category of learning strategies, this study demonstrated the utility of including pedagogical strategies such as active learning that promoted in-depth learning of life skills. If a major aim of sport-based programming for youth in eSwatini is to facilitate meaningful learning outcomes, then 
intentionally employing teaching strategies that support this learning is necessary (Tabrizi \& Rideout, 2017).

Other very context-specific elements of program implementation to consider for future programming are the use of SiSwati as the instructional language, gender differences in youth behaviors and responsibility behaviors, exposure to multiple sports, participant size, and the provision of fruits and food. In the current study it emerged that while the use of English as the instructional language might be beneficial for youth in the long-term for success in school and in the work place, youth were not confident or competent enough in their English language proficiency. English was therefore not appropriate as the primary means of instruction. Designing a more long-term program may allow for this confidence and self-efficacy to build in using English selectively during the program, which might then also strengthen the program as it could then also be considered a safe environment to practice their English competency and confidence. It is also notable that there were gender differences in the program participation experiences and responsibility behaviors of the youth. Given the rigid gender roles in eSwatini, a stronger focus on gender dynamics and roles in future programming will help facilitate meaningful learning outcomes and positive participation experiences for all youth.

Further, youth in the current study both enjoyed but also struggled with exposure to multiple sports. Although the inclusion of multiple sport addressed the expressed needs of the local youth (Bean et al., 2014; Whitley, Coble, \& Jewell 2016), as determined in the needs assessment phase, a careful balance needs to be found between pushing youth out of their comfort zone with new sports and helping build confidence and competence in familiar sports. Future programming will also need to consider the appropriate number of youth participants to include in the study that both honors the coach to youth ratio (Cryan \& Martinek; Whitley \& 
Gould, 2010) that is emphasized in the TPSR approach, as well as the high youth need for positive engagement in eSwatini. Finally, as evidenced across multiple data sources in the current study, the provision of fruits and food will be a necessary inclusion for youth programming that involves physical activity and also operates in a context where poverty levels are extremely high. For future sport-based programming it will also be necessary to provide sport equipment but creative problem-solving will have to be used to overcome the challenge of access to sport facilities. The identification of the aforementioned context and culture-specific program design elements emphasize the overarching necessity to include the community in the development and ownership of youth sport programming, which was achieved to a certain extent in the current feasibility study (Hartmann \& Kwauk, 2011; Spaaij, 2009).

\section{Conclusions}

The current feasibility study provided further support for the value of using the TPSR framework in the design and implementation of sport-based life skills education programming in a novel youth context in eSwatini. The focus of the model on building caring coach-youth relationships, creating an enjoyable sport experience, fostering small successes, and providing intentional opportunities for youth to actively practice and engage in their own learning were the most meaningful elements of the model in the current youth context. The developmental outcomes and changes in life skills associated with participation in the current program may also be highly pertinent to helping youth navigate the most salient health and resource challenges in the community. Notably, the current study also identified culture and context-specific considerations that should be made when implementing TPSR-based youth programming in eSwatini. These included, but are not limited to, adaptations to the awareness talk and selfreflection time, the use of active learning strategies and behavioral management techniques, and 
the provision of fruit and food to meet basic survival needs. Continued future explorations of the program design elements and coaching strategies that most meaningfully contribute to a holistic youth development and a positive sport participation experience in eSwatini is warranted. 


\section{References}

Allison, B.N., \& Rehm, M.L. (2007). Effective teaching strategies for middle school learners in multicultural, multilingual classrooms. Middle School Journal, 39(2), 12-18, doi: 10.1080/00940771.2007.11461619

Anda, R.F., Butchart, A., Felitti, V.J., \& Brown, D.W. (2010). Building a framework for global surveillance of the public health implications of adverse childhood experiences. American Journal of Preventative Medicine, 39 (1), 93-98.

AVERTing HIV and AIDS (AVERT). (2014). HIV and AIDS in Swaziland. Retrieved from http://www.avert.org/professionals/hiv-around-world/sub-saharan-africa/swaziland

Bailey, R., \& Dismore, H. (2005). Physical education and school sport: the international sport in education project (SPINED). African Journal for Physical Activity and Health Sciences, 11(1). 1-5.

Bandura, A. (1990). Multidimensional Scales of Perceived Self-Efficacy. Stanford, CA: Stanford University.

Bandura, A. (1997). Self-efficacy: The exercise of control. New York, NY: Freeman.

Bandura, A. (2001). Social cognitive theory: An agentic perspective. Annual Review of Psychology, 52, 1-26.

Baumeister, R.F., \& Leary, M.R. (1995). The need to belong: Desire for interpersonal attachments as a fundamental human motivation. Psychological Bulletin, 117(3), 497529.

Bayat, A., Louw, W., \& Rena, R. (2014). The impact of socio-economic factors on performance of selected high school learners in the Western Cape Province, South Africa. Journal of Human Ecology, 45 (3), 183-196. 
Bean, C.N. \& Forneris, T. (2016) Examining the importance of intentionally structuring the youth sport context to facilitate positive youth development, Journal of Applied Sport Psychology, 28(4), 410-425. doi: 10.1080/10413200.2016.1164764

Bean, C.N. \& Forneris, T. (2017). Is life skill development a by-product of sport participation? Perceptions of youth sport coaches. Journal of Applied Sport Psychology, 29 (2), 234250.

Bean, C.N., Forneris, T., \& Halsall, T. (2014). Girls just wanna have fun: a process evaluation of a female youth-driven physical activity-based life skills program. SpringerPlus, 3, 401.

Bean, C.N., Kendellen, K., \& Forneris, T. (2016). Moving beyond the gym: Exploring life skill transfer within a female physical activity-based life skills program. Journal of Applied Sport Psychology, 28, 274-290.

Bellis, M.A., Hughes, K., Ford, K., Hardcastle, K.A., Sharp, C.A., Wood, S...Davies, A. (2018). Adverse childhood experiences and sources of childhood resilience: a retrospective study of their combined relationships with child health and educational attendance. BMC Public Health, 18: 792.

Beutler, I. (2008). Sport Serving Development and Peace: Achieving the Goals of the United Nations through Sport'. Sport in Society, 11(4), 359-69.

Blom, L.C., Gerstein, L., Stedman, K., Judge, L., Sink, A., \& Pierce, D. (2015a). Soccer for peace: Evaluation of in-country workshops with Jordanian coaches. Journal of Sport for Development, 3(4), 1-12.

Blom, L.C., Judge, L., Whitley, M.W., Gernstein, L., Huffman, A., \& Hillyer, S. (2015b). Sport for development and peace: Experiences conducting U.S. and international programs. Journal of Sport Psychology in Action, 6, 1-16. 
Buckle, M.E., \& Walsh, D.S. (2013). Teaching responsibility to gang affiliated youths. Journal of Physical Education, Recreation \& Dance, 84(2), 53-58.

Burnett, C. (2010). Sport-for-development approaches in the South African context: a case study analysis. South African Journal for Research in Sport, Physical Education and Recreation, 32(1), 29-42.

Burnett, C. (2014). The impact of a sport-for-education programme in the South Africa context of poverty. Sport in Society, 17 (6), 722-735.

Buseh, A. G., Glass, L. K., \& McElmurry, B. J. (2002). Cultural and gender issues related to HIV/AIDS prevention in rural Swaziland: a focus group analysis. Health Care for Women International, 23(2), 173-184.

Caballero-Blanco, P., Delgado-Noguera, M.A., \& Escarti-Carbonell, A. (2013). Analysis of teaching personal and social responsibility model-based programmes applied in USA and Spain. Journal of Human Sport and Exercise, 8(2), 427-441.

Camiré, M., Forneris, T., Trudel, P., \& Bernard, D. (2011). Strategies for helping coaches facilitate positive youth development through sport. Journal of Sport Psychology in Action, 2, 92-99.

Camiré, M., Trudel, P., \& Bernard, D. (2013). A case study of a high school sport program designed to teach athletes life skills and values. The Sport Psychologist, 27, 188-200.

Cassidy, T., Potrac, P., \& McKenzie, A. (2006). Evaluating and reflecting upon a coach education initiative: The CoDe of Rugby. The Sport Psychologist, 20, 145-161.

Catalano, R.F., Berglund, M.L., Ryan, J.A., Lonczak, H.S., \& Hawkins, J.D. (2004). Positive youth development in the United States: Research findings on evaluations of positive 
youth development programs. The ANNALS of the American Academy of Political and Social Science, 591, 98-124. doi: 10.1177/0002716203260102

Choi, N., Fuqua, D.R., \& Griffin, B.W. (2001). Exploratory analysis of the structure of scores from the multidimensional scales of perceived self-efficacy. Educational and Psychological Measurement, 61 (3), 475-489.

Coakley, J. (2011). Youth sports: What counts as “positive development?” Journal of Sport and Social Issues, 35(3), 306-324.

Coalter, F. (2007). Sports clubs, social capital and social regeneration: Ill-defined interventions with hard to follow outcomes. Sport in Society, 10, 537-559.

Coalter, F. (2015). Sport-for-change: Some thoughts from a sceptic. Social Inclusion, 3(3), 1923. doi: $10.17645 /$ si.v3i3.222

Collins, K., Gould, D., Lauer, L., \& Chung, Y. (2009). Coaching Life Skills through Football: Philosophical Beliefs of Outstanding High School Football Coaches. International Journal of Coaching Science, 3(1), 29-54.

Conroy, D.E., \& Coatsworth, J.D. (2006). Coach training as a strategy for promoting youth social development. The Sport Psychologist, 20, 128-144.

Côté, J., \& Hancock, D.J. (2016). Evidence-based policies for youth sport programmes. International Journal of Sport Policy and Politics, 8(1), 51-65. doi: $10.1080 / 19406940.2014 .919338$

Côté, J., Salmela, J.H., Baria, A., \& Russell, S.J. (1993). Organizing and interpreting unstructured qualitative data. The Sport Psychologist, 7, 127-137.

Cowan, F., \& Pettifor, A. (2009). HIV in adolescents in sub-Saharan Africa. Current Opinion in HIV and AIDS, 4(4), 288-293. 
Creswell, J. W. (2007). Qualitative inquiry and research design: Choosing among five approaches (2nd ed.). Thousand Oaks, CA: Sage.

Crotty, M. (1998). The foundations of social research: Meaning and perspective in the research process. Sage.

Cryan, M., \& Martinek, T. (2017). Youth sport development through soccer: An evaluation of an after-school program using the TPSR model. The Physical Educator, 74, 127-149.

Danish, S., Forneris, T., Hodge, K., \& Heke, I. (2004). Enhancing youth development through sport. World Leisure Journal, 46(3), 38-49.

Danish, S. J., Forneris, T., \& Wallace, I. (2005). Sport-based life skills programming in the schools. Journal of Applied School Psychology, 21(2), 41-62

Deci, E.L. (1972). The effects of contingent and non-contingent rewards and controls on intrinsic motivation. Organizational Behavior and Human Performance, 8, 217-229.

Dellar, R. C., Dlamini, S., \& Karim, Q. A. (2015). Adolescent girls and young women: key populations for HIV epidemic control. Journal of the International AIDS Society, 18 (1), 64-70.

Delva, W., Michielsen, K., Meulders, B., Groeninck, S., Wasonga, E., Ajwang, P...Vanreusel, B. (2010). HIV prevention through sport: the case of the Mathare Youth Sport Association in Kenya. AIDS Care, 22 (8), 1012-1020.

Dupuis, M., Bloom, G. A., \& Loughead, T. M. (2006). Team captains' perceptions of athlete leadership. Journal of Sport Behavior, 29(1), 60.

Draper, C.E., \& Coalter, F. (2016). “There's just something about this club. It's been my family." An analysis of the experiences of youth in a South African sport-fordevelopment programme. Internal Review for the Sociology of Sport, 51(1), 44-60. 
Eldredge, K.B., Markham, C.M., Ruiter, R.A., Fernandez, M.E., Kok, G., \& Parcel, G. (2016). Planning health promotion programs: An intervention mapping approach (4 $4^{\text {th }} \mathrm{ed}$.). USA: John Wiley \& Sons.

Elo, S., \& Kyngas, H. (2008) The qualitative content analysis process. Journal of Advanced Nursing, 62 (1), 107-115. doi: 10.1111/j.1365-2648.2007.04569.x

Escartí, A., Gutiérrez, M., Pascual, C., \& Marín, D. (2010). Application of Hellison's teaching personal and social responsibility model in physical education to improve self-efficacy for adolescents at risk of dropping-out of school. The Spanish Journal of Psychology, $13(2), 667-676$.

Escartí, A., Wright, P.M., Pascual, C., \& Gutiérrez, M. (2015). Tool for assessing responsibilitybased education (TARE) 2.0: Instrument revisions, inter-rater reliability, and correlations between observed teaching strategies and student behaviors. Universal Journal of Psychology, 3(2), 55-63.

Fatusi, A.O., \& Hindin., M.J. (2010). Adolescents and youth in developing countries: Health and development issues in context. Journal of Adolescence, 33, 499-508.

Felitti, V.J., Anda, R.F., Nordenberg, D., Williamson, D.F., Spitz, A.M., Edwards, V... Marks, J.S. (1998). Relationship of childhood abuse and household dysfunction to many leading causes of death in adults. American Journal of Preventative Medicine, 14 (4), 245-258.

Flick, U. (Ed.). (2014). The SAGE handbook of qualitative data analysis. Thousand Oaks, CA: Sage.

Forde, S.D. (2014). Look after yourself, or look after one another? An analysis of life skills in sport for development and peace HIV prevention curriculum. Sociology of Sport Journal, 31, 287-303. 
Foster, G., \& Williamson, J. (2000). A review of current literature of the impact of HIV/AIDS on children in sub-Saharan Africa. AIDS, 14(3), 275-284.

Fuller, C.W., Junge, A., Dorasami, C., DeCelles, J., Dvorak, J. (2011). '11 for Health', a football-based health education programme for children: a two-cohort study in Mauritius and Zimbabwe. British Journal of Sports Medicine, 45, 612-618. doi:10.1136/bjsm.2011.084905

Gano-Overway, L. (2014). The caring climate: How sport environments can develop empathy in young people. Organizing through Empathy, 167-183.

Gano-Overway, L., \& Guiverneau, M. (2018). Setting the SCENE: Developing a caring youth sport environment. Journal of Sport Psychology in Action, 9, 2, 83-93.

Giges, B., Petipas, A.J., \& Vernacchia, R.A. (2004). Helping coaches meet their own needs: Challenges for the sport psychology consultant. The Sport Psychologist, 18, 430-444.

Gilbert, W., Nater, S., Siwik, M., \& Gallimore, R. (2010). The pyramid of teaching success in sport: Lessons from applied science and effective coaches. Journal of Sport Psychology in Action, 1, 86-94.

Gordon, B. (2009). Merging teaching personal and social responsibility with sport education: A marriage made in heaven or hell? ACHPER Healthy Lifestyles Journal, 56(3/4), 13-16.

Gordon, B., \& Doyle, S. (2015). Teaching personal and social responsibility and transfer of learning: Opportunities and challenges for teachers and coaches. Journal of Teaching in Physical Education, 34, 152-161.

Gordon, B., Jacobs, J.M., \& Wright, P.M. (2016). Social and emotional learning through a teaching personal and social responsibility based after-school program for disengaged middle-school boys. Journal of Teaching in Physical Education, 35, 358-369. 
Gould, D., \& Carson, S. (2008). Life skills development through sport: Current status and future directions. International Review of Sport and Exercise Psychology, 1(1), 58-78. doi: $10.1080 / 17509840701834573$

Gould, D., Carson, S., \& Blanton, J. (2013). Coaching life skills. In P. Protrac, W. Gilbert, \& J. Denison (Eds.), Routledge handbook of sports coaching (pp. 259-270). London, UK: Routledge.

Gould, D., Collins, K., Lauer, L., \& Chung, Y. (2007). Coaching life skills through football: A study of award winning high school coaches. Journal of Applied Sport Psychology, 19(1), $16-37$.

Gould, D., \& Voelker, D. (2012). Enhancing youth leadership through sport and physical education. JOPERD, 83(8), 38-41.

Green, L.W., \& Kreuter, M.W. (1991). Health Promotion Planning: An Educational and Environmental Approach. Mountain View, CA: Mayfield Publishing.

Guest, G., Bunce, A., \& Johnson, L. (2006). How many interviews are enough? An experiment with data saturation and variability. Field Methods, 18, 59-82.

Ha, J., \& Lyras, A. (2013). Sport for refugee youth in a new society: The role of acculturation in sport for development and peace programming. South African Journal for Research in Sport, Physical Education and Recreation, 35(2), 121-140.

Hamid, Z., Bisschoff, C., \& Botha, C. (2015). An analysis of the Swaziland public educational environment and its role players. Problems and Perspectives in Management, 13(2), 129142.

Hansen, D. M., \& Larson, R. (2005). The youth experience survey 2.0: Instrument revisions and validity testing. (Unpublished). University of Illinois, Urbana-Champaign. 
Hansen, D. M., Larson, R. W., \& Dworkin, J. B. (2003). What adolescents learn in organized youth activities: A survey of self-reported developmental experiences. Journal of Research on Adolescence, 13, 25-35.

Harrison, A. (2008). Hidden love: Sexual ideologies and relationship ideals among rural South African adolescents in the context of HIV/AIDS. Culture, Health \& Sexuality, 10(2), 175-189.

Harter, S. (1988). Causes, correlates, and functional role of global self-worth: A life-span perspective. In J. Kolligan \& R. Sternberg (Eds.), Perceptions of competence and incompetence across the lifespan. New Haven, CT: Yale University Press.

Hartmann, D. (2003). Theorising Sport as Social Intervention: A View from the Grassroots. Quest, 55, 118-140.

Hartmann, D., \& Kwauk, C. (2011). Sport and development: An overview, critique, and reconstruction. Journal of Sport and Social Issues, 35(3), 284-305.

Hayhurst, L.M.N., MacNeill, M., Kidd, B., \& Knoppers, A. (2014). Gender relations, genderbased violence and sport for development and peace: Questions, concerns and cautions emerging from Uganda. Women's Studies International Forum, 47, 157-167.

Heath, S., Brooks, R., Cleaver, E., \& Ireland, E. (2009). Researching young people's lives. Thousand Oaks, CA: Sage Publications.

Hellison, D. R. (2011). Teaching personal and social responsibility through physical activity. Champaign, IL: Human Kinetics.

Hellison, D., \& Walsh, D. (2002). Responsibility-based youth programs evaluation: investigating the investigations. Quest, 54, 292-307. 
Hellison, D., \& Wright, P. (2003). Retention in an urban extended day program: A process-based assessment. Journal of Teaching in Physical Education, 22, 369-381.

Hemphill, M.A., \& Richards, A.R. (2016). Without the academic part, it wouldn't be squash": Youth development in an urban squash program. Journal of Teaching in Physical Education, 35, 263-276.

Hemphill, M. A., Templin, T. J., \& Wright, P. M. (2015). Implementation and outcomes of a responsibility-based continuing professional development protocol in physical education. Sport, Education and Society, 20 (3), 398-419. doi:10.1080/13573322.2012. 761966

Hermens, N., Super, S., Verkooijen, K.T. \& Koelen, M.A. (2017). A systematic review of life skill development through sports programs serving socially vulnerable youth. Research Quarterly for Exercise and Sport, 88(4), 408-424.

Hinson, L., Kapungu, C., Jessee, C., Skinner, M., Bardini, M. \& Evans-Whipp, T. (2016). Measuring Positive Youth Development Toolkit: A Guide for Implementers of Youth Programs. Washington, DC: Youth Power Learning, Making Cents International.

Hochfield, T., Graham, L., Patel, L., Moodley, J., \& Ross, E. (2016). Does school breakfast make a difference? An evaluation of an in-school breakfast programme in South Africa. International Journal of Educational Development, 51, 1-9.

Holt, N.L. (2008). Positive youth development through sport. New York, NY: Routledge.

Holt, N.L., \& Neely, K.C. (2011). Positive youth development through sport: A review. Revista Iberoamericana de Psicología del Ejercicio y el Deporte, 6(2), 229-316.

Holt, N.L., Neely, K.C., Slater, L.G., Camiré, M., Coté, J., Fraser-Thomas, J...Tamminem, K.A. (2017). A grounded theory of positive youth development through sport based on results 
from a qualitative meta-study. International Review of Sport and Exercise Psychology, 10(1), 1-49. doi: 10.1080/1750984X.2016.1180704

Hsieh, H.F. \& Shannon S. (2005). Three approaches to qualitative content analysis. Qualitative Health Research, 15, 1277-1288.

Hughes, K., Ford, K., Davies, A.R., Homolova, L., \& Bellis, M.A. (2018). Welsh adverse childhood experience (ACE) and resilience study. Public Health Wales NHS Trust.

Hulteen, R.M., Smith, J.J., Morgan, P.J., Barnett, P. Hallal, K. Colyvas, D. Lubansa, D.R. (2016). Global participation in sport and leisure-time physical activities: a systematic review and meta-analysis. Preventive Medicine, 95, 14-25.

Huysmans, Z., \& Clement, D. Hilliard, R., \& Hansell, A. (2017). Youth perceptions of sport as a context for life skills development and overcoming community challenges in Swaziland. (Unpublished). West Virginia University, Morgantown, WV.

Huysmans, Z., \& Clement, D. Hilliard, R., \& Hansell, A. (2018). Exploring the coach's role in youth life skills development in Southern Africa. International Sport Coaching Journal, Ahead of print, 1-14.

International Council for Coaching Excellence, Association of Summer Olympic International Federations, \& Leeds Metropolitan University. (2013). International sport coaching framework (version 1.2). Champaign, IL: Human Kinetics.

Jacobs, M.J., Ivy, N.I., Lawson, M., \& Richards, K.R. (2017). Enhancing the transfer of life skills from sport-based youth development programs to school, family, and community settings. Journal of Amateur Sport, 20-43.

Jones, L. (2006). Sexual discourse and decision-making by urban youth in AIDS-afflicted Swaziland. African Journal of AIDS Research, 5(2), 145-157. 
Kasedde, S., Luo, C., McClure, C., \& Chandan, U. (2013). Reducing HIV and AIDS in adolescents: opportunities and challenges. Current HIV/AIDS Reports, 10(2), 159-168.

Kasiram, M. I., Ngcobo, N., Oliphant, E., \& Roestenburg, E. (2013). HIV/AIDS and women: African and South African perspectives. Indilinga African Journal of Indigenous Knowledge Systems: Revisiting the Research Paradigm, 12(1), 62-79.

Kaufman, Z.A., Spencer, T.S., Ross, D.A. (2013). Effectiveness of sport-based HIV prevention interventions: A systematic review of the evidence. AIDS and Behaviour, 17, 987-1001.

Keegan, R., Spray, C., Harwood, C., \& Lavallee, D. (2010). The motivational atmosphere in youth sport: coach, parent, and peer influences on motivation in specializing sport participants. Journal of Applied Sport Psychology, 22, 87-105.

Kessels, U., Heyder, A., Latsch, M., \& Hannover, B. (2014). How gender differences in academic engagement relate to students' gender identity. Educational Research, 56 (2), 220-229.

Korpershoek, H., Harms, T., de Boer, H., van Kuijk, M, \& Doolard, S. (2016). A meta-analysis of the effects of classroom management strategies and classroom management programs on students' academic, behavioural, emotional, and motivational outcomes. Review of Educational Research, 86 (3), 643-680.

Krathwohl, D.R. (2002). A revision of Bloom's taxonomy: An overview. Theory into Practice, 41(4), 212-218.

Kruse, S. E. (2006). Review of kicking AIDS out: Is sport an effective tool in the fight against HIV/AIDS? (unpublished). NORAD. 
Larson, R. W., Hansen, D. M., \& Moneta, G. (2006). Differing profiles of developmental experiences across types of organized youth activities. Developmental Psychology, 42, 849-863.

Levermore, R. (2011). Evaluating sport-for-development: approaches and critical issues. Progress in Development Studies, 11(4), 339-353.

Li, W., Wright, P., Rukavina, P. B., \& Pickering, M. (2008). Measuring students' perceptions of personal and social responsibility and the relationship to intrinsic motivation in urban physical education. Journal of Teaching in Physical Education, 27, 167-178.

Lim, D, \& DeSteno, D. (2016). Suffering and compassion: the links among adverse life experiences, empathy, compassion, and prosocial behaviour. Emotion, 16(2), 175-182.

Lindsey, I., \& Chapman, T. (2017). Enhancing the contribution of sport to the sustainable development goals. London, UK: Commonwealth Secretariat.

Long, S. (2013). Protecting Swaziland's children: Strengthening Swaziland's child protection system: Mapping and assessment study 2013. USAID and PEPFAR.

Lumpkin, A., \& Cuneen, J. (2001). Developing a personal philosophy of sport. Journal of Physical Education, Recreation \& Dance, 72(8), 40-43.

Lyras, A., \& Peachey, J.W. (2011). Integrating sport-for-development theory and praxis. Sport Management Review, 14(4), 311-326. doi:10.1016/j.smr.2011.05.006

MacPhail, C., Pettifor, A., \& Rees, H. (2007). Contexts of risk: HIV/AIDS among young people in Africa and prevention opportunities. Africa Insight, 37(3), 473.

Martin, P.D., \& Kaufman, E.K. Double play: The need for 4-H to partner in youth sports. Journal of Extension, 55 (5). 
Martin, N.K., Schafer, N.J., McClowry, S., Emmer, E.T., Brekelmans, M...\& Wubbels, T. Expanding the definition of classroom management: Recurring themes and new conceptualizations. The Journal of Classroom Interaction, 51 (1), 31-41.

Martinek, T., \& Hellison, D. (2009). Youth leadership in sport and physical education. New York, NY: Palgrave Macmillan.

Martinek, T., \& Hellison, D. (2016). Teaching personal and social responsibility: Past, present and future. Journal of Physical Education, Recreation \& Dance, 87(5), 9-13.

Massey, W.V., Whitley, M.A., Blom, L., \& Gerstein, L.H. (2015). Sport for development and peace: A systems theory perspective on promoting sustainable change. International Journal of Sport Management and Marketing, 16(1/2), 18-35.

Whitley, M.A., Massey, W.V., Darnell, S.C., \& Smith, B. (Eds.). (2017). Sport in underresourced, underdeveloped, and conflict regions. Abingdon, UK: Taylor \& Francis Books.

Mavundla, S., Dlamini, N., Nyoni, N., \& Mac-Ikemenjima, D. (2015). Youth and Public Policy Swaziland. Youth Policy Press.

McCambridge, J., Witton, J., \& Elbourne, D.R. (2014). Systematic review of the Hathorne effect: New concepts are needed to study research participation effects. Journal of Clinical Epidemiology, 67, 267-277.

McCarthy, J., Bergholz, L., \& Bartlett, M. (2016). Re-designing youth sport-Change the game. New York, Y: Routledge.

McCullick, B.A., Belcher, D., \& Schempp, P.G. (2005). What works in coaching and sport instructor certification programs? The participants' view. Physical education and Sport Pedagogy, 10(2), 121-137. 
McSweeney, M.J. (2017). Critically exploring the institutional work in sport-for-development:

The case of a local programme in Swaziland. (Unpublished thesis). Brock University, Ontario, Canada.

Merriam, S. B. (2008). Adult Learning Theory for the Twenty-First Century. New Directions for Adult and Continuing Education, 119, 93-98.

Mesquita, I., Ribeiro, J., Santos, S., \& Morgan, K. (2014). Coach learning and coach education: Portuguese expert coaches' perspective. The Sport Psychologist, 28, 124-136.

Meir, D. (2017). "Leadership and empowerment through sport": The intentions, hopes, ambitions and reality of creating a sport-for-development organisation in Cape Town. Journal of Sport for Development, 5(8), 19-29.

Ministry of Sports, Culture and Youth Affairs (2015). Swaziland State of the Youth Report 2015. UNFPA.

Mofolo, T. (2011). Investigating the Factors Contributing to the Disempowerment of Women in Swaziland: Perceptions of Swazi Women and Non-governmental Organisations Operating in Swaziland. Africa Insight, 41(2), 110-129.

Motsa, N.D., \& Morojele, P.J. (2016). Vulnerability and children's real-life schooling experiences in Swaziland. Educational Research in Social Change (ERSC), 5 (2), 35-51.

Motsa, N.D., \& Morojele, P.J. (2017). High aspirations amidst challenging situations: narratives of six vulnerable primary school children in Swaziland. Journal of Asian and African Studies, 1-15.

Moya Centre. (n.d.). Retrieved from http://www.moya.org.sz/

Mwoma, T., \& Pillay, J. Educational support for orphans and vulnerable children in primary schools: Challenges and interventions. Issues in Educational Research, 26 (1), 82-97. 
Nasiri, F., \& Mafakheri, F. (2015). Higher education lecturing and humor: From perspectives to strategies. Higher Education Studies, 5(5), 26-31.

Ndandwe, S.B., \& Dlamini, B.M. (2014). A descriptive study of high school agriculture teachers' competencies in Swaziland. NACTA Journal, 88-94.

Ndlangamandla, E.D., Burnett, C., \& Roux, C.J. (2012). Participation of learners in Swaziland school sports. African Journal for Physical, Health Education, Recreation and Dance, 18 (4), 900-911.

Nelson, L., Cushion, C., \& Potrac, P. (2013). Enhancing the provision of coach education: The recommendations of UK coaching practitioners. Physical Education and Sport Pedagogy, $18(2), 2014-218$.

Noon, E. (2017). An interpretative phenomenological analysis of the barriers to the use of humour in the teaching of childhood studies. Journal of Perspectives in Applied Academic Practice, 5(3), 45-52.

Nwosu, P.E. (1988). Negotiating with Swazis. The Howard Journal of Communications, 1(3), $145-154$

Operario, D., Underhill, K., Chuong, C., Cluver, L. (2011). HIV infection and sexual risk behaviour among youth who have experienced orphanhood: Systematic review and metaanalysis. Journal of the International AIDS Society, 14(25).

Pas, E.T., Cash, A.H., O’Brennan, L., Debnam, K.J., \& Bradshaw, C.P. (2015). Profiles of classroom behaviour in high schools: Associations with teacher behaviour management strategies and classroom composition. Journal of School Psychology, 53, 137-148. 
Peacock-Villada, P., DeCelles, J., \& Banda, P.S. (2007). Grassroot Soccer resiliency pilot program: building resiliency through sport-based education in Zambia and South Africa. New Directions in Youth Development, 13, 141-154.

Pearce, J., Mann, M.K., Jones, C., Van Buschbach, S., Olff, M., \& Bisson, J.I. (2012). The most effective way of delivering a train-the-trainers program: A systematic review. Journal of Continuing Education in the Health Professions, 32(2), 215-226.

Pierce, S., Kendellen, K., Camiré, M., \& Gould, D. (2018). Strategies for coaching life skills transfer. Journal of Sport Psychology in Action, 9 (1), 11-20.

Ponterotto, J. G. (2005). Qualitative research in counseling psychology: A primer on research paradigms and philosophy of science. Journal of Counseling Psychology, 52, 126-136.

Porter, C.M. (2015). Revisiting Precede-Proceed: A leading model for ecological and ethical health promotion. Health Education Journal, 1-12.

Rajan, R., \& Franca-Koh, A.C. (2007). Health communication partnership: A qualitative endline evaluation of sports for life and youth action kit in Ethiopia. Ethiopia. Retrieved from https://www.staging.grassrootsoccer.org/wp-content/uploads/HCP_eval_2007.pdf

Riley, A., Anderson-Butcher, D., Logan, J., Newman, T.J., \& Davis, J. (2017) Staff Practices and Social Skill Outcomes in a Sport-Based Youth Program, Journal of Applied Sport Psychology, 29(1), 59-74. doi: 10.1080/10413200.2016.1179700

Rhind, D.J., \& Jowett, S. (2010) Relationship maintenance strategies in the coach-athlete relationship: The development of the COMPASS model, Journal of Applied Sport Psychology, 22(1), 106-121. doi: 10.1080/10413200903474472

Roth, J.L., \& Brooks-Gunn, J. (2016). Evaluating youth development programs: Progress and promise. Applied Developmental Science, 20 (3), 188-202. 
Ryan, R.M., \& Deci, E.L. (2016). Facilitating and hindering motivation, learning, and well-being in schools: Research and observations from self-determination theory. In K.R. Wentzel, \& D.B. Miele (Eds.), Handbook of motivation at school (pp. 96-119) New York, NY: Routledge.

Sackett, S. C., \& Gano-Overway, L. A. (2017). Coaching Life Skills Development: Best Practices and High School Tennis Coach Exemplar. International Sport Coaching Journal, 4(2), 206-219.

Sanders, B., Phillips, J., \& Vanreusel, B. (2014). Opportunities and challenges facing NGOs using sport as a vehicle for development in post-apartheid South Africa. Sport, Education and Society, 19(6), 789-805. doi: 10.1080/13573322.2012.711304

Santos, F., Camiré, M., \& Campos, P.H. (2016): Youth sport coaches' role in facilitating positive youth development in Portuguese field hockey. International Journal of Sport and Exercise Psychology. doi: 10.1080/1612197X.2016.1187655

Santos, F., Camiré, M., MacDonald, D.J., Campos, H., Conceicao, M., \& Silva, P. (2017). Youth sport coaches' perspective on positive youth development and its worth in mainstream coach education courses. International Sport Coaching Journal, 4, 38-46.

Schulenkorf, N., Sherry, E., \& Rowe, K. (2016). Sport for development: An integrated literature review. Journal of Sport Management, 30, 22-39.

Segwaba, J., Vardhan, D., \& Duffy, P. (2014). Coaching in South Africa. International Sport Coaching Journal, 1, 33-41.

Sherry, E., Schulenkorf, N., Seal, E., Nicholson, M., \& Hoye, R. (2017). Sport-for-development: Inclusive, reflexive, and meaningful research in low-and middle-income settings. Sport Management Review, 20, 69-80. 
Smith, R.E., Smoll, F.L., \& Cumming, S.P. (2007). Effects of motivational climate intervention for coaches on young athletes' sport performance anxiety. Journal of Sport \& Exercise Psychology, 29, 39-59.

Smith, B., \& McGannon, K. R. (2017). Developing rigor in qualitative research: Problems and opportunities within sport and exercise psychology. International Review of Sport and Exercise Psychology, 1-21.

South African Sport Confederation and Olympic Committee (SASCOC). (2011). The South African Coaching Framework. Johannesburg: Author.

Spaaij, R. (2009). The social impact of sport: diversities, complexities and contexts. Sport in Society, 12(9), 1109-1117. doi: 10.1080/17430430903137746

Spaaij, R., Oxford, S., \& Jeanes, R. (2016). Transforming communities through sport? Critical pedagogy and sport for development. Sport, Education and Society, 21 (4), 570-587.

Sport for Development International Working Group (SDPIWG) (2008). Harnessing the Power of Sport for Development and Peace. Right to Play, Toronto.

Svensson, P.G., \& Woods, H. (2017). A systematic overview of sport for development and peace organisations. Journal of Sport for Development, 5(9), 36-48.

Tabrizi, S., \& Rideout, G. (2017). Active learning: Using bloom's taxonomy to support critical pedagogy. International Journal of Cross-Disciplinary Subjects in Education, 8 (3). 3202-3209.

Toriola, O. M. (2010). Children's perception of physical education and school sport in Swaziland. The Shield (International Journal of Physical Education and Sport Science), $5,96-107$ 
United Nations (UN) (2017). World population prospects: The 2017 revision. Retrieved from https://www.un.org/development/desa/publications/world-population-prospects-the-2017revision.html

UNAIDS. (2016). Country facts sheets - Swaziland. Retrieved from http://aidsinfo.unaids.org/ United Nations General Assembly (UNGA) (2015), Transforming our World: The 2030 Agenda for Sustainable Development. Retrieved from www.un.org/ga/search/view_doc.asp?symbol=A/70/L.1andLang=E.

United Nations Population Fund (UNFPA) (2015). 10 things you didn't know about the world's population. Retrieved from http://www.un.org/youthenvoy/2015/04/10-things-didntknow-worlds-population/

United Nations Population Fund South Africa (UNFPA South Africa) (2011). Young People. Retrieved from http://southafrica.unfpa.org/en/topics/young-people-1

Van Mullem, \& Brunner, D. Developing a successful coaching philosophy: A step-by-step approach. Strategies, 26(3), 29-34. doi: 10.1080/08924562.2013.779873

Vealey, R. (2005). Coaching for the inner edge. Fitness Info Technology, Morgantown, WV Vella, S., Oades, L., \& Crowe, T. (2011). The role of the coach in facilitating positive youth development: Moving from theory to practice. Journal of Applied Sport Psychology, 23, $33-48$.

Visek, A.J., Achrati, S.M., Manning, McDonnell, K., Harris, B.S., \& DiPietro, L. (2015). The fun integration theory: towards sustaining children and adolescents sport participation. Journal of Physical Activity and Health, 12 (3), 424-433.

Voelker, D.K., Gould, D., \& Crawford, M.J. (2011). Understanding the experience of high school sport captains. The Sport Psychologist, 25, 47-66. 
Wagnsson, S., Augustsson, C., Patriksson, G. (2013) Associations between sport involvement and youth psychosocial development in Sweden: a longitudinal study. Journal of Sport for Development, 1(1): 37-47

Walsh, D.S., Ozaeta, J., \& Wright, P.M. (2010). Transference of responsibility model goals to the school environment: exploring the impact of a coaching club program. Physical Education and Sport Pedagogy, 15 (1), 15-28.

Wamoyi, J., Mshana, G., Mongi, A., Neke, N., Kapiga, S., \& Changalucha, J. (2014). A review of interventions addressing structural drivers of adolescents' sexual and reproductive health vulnerability in sub-Saharan Africa: Implications for sexual health programming. Reproductive Health, 11, 88.

Weiss, M.R., Bolter, N.D., \& Kipp, L.E. (2014). Assessing impact of physical activity-based youth development programs: Validation of the life skills transfer survey (LSTS). Research Quarterly for Exercise and Sport, 85(3), 263-278. doi: $10.1080 / 02701367.2014 .931558$

Whitley, M. A. (2012). The Ikhaya sport programs in the Kayamandi Township. Agora para la Educación Física y el Deporte, 14(1), 115-136.

Whitley, M. A., Coble, C., \& Jewell, G.S. (2016) Evaluation of a sport-based youth development programme for refugees. Leisure/Loisir, 40(2), 175-199.

Whitley, M. A., Forneris, T., \& Barker, B. (2014). The reality of evaluating community-based sport and physical activity programs to enhance the development of underserved youth: Challenges and potential strategies. Quest, 66(2), 218-232. 
Whitley, M, \& Gould, D. (2010). Psychosocial development in refugee children and youth through the personal-social responsibility model. Journal of Sport Psychology in Action, $1(3), 118-138$.

Whitley, M.A., Gould, D.E., Wright, M., \& Hayden, L.A. (2017). Barriers to holistic coaching for positive youth development in South Africa. Sport Coaching Review.

Whitley, M. A., Hayden, L. A., \& Gould, D. (2013). Growing up in the Kayamandi Township: I. The role of sport in helping young people overcome challenges within their community. Qualitative Research in Sport, Exercise and Health, 5(3), 373-397.

Whitley, M. A., Hayden, L. A., \& Gould, D. (2016). Growing up in the Kayamandi Township: II. Sport as a setting for the development and transfer of desirable competencies. International Journal of Sport and Exercise Psychology, 14(4), 305-322.

Whitley, M.A., Massey, W.V., Camiré, M., Blom, L.C., Chawansky, M., Forde, S., Boutet, S., Borbee, A., \& Darnell, S. (2018). A systematic review of sport for development interventions across six global cities. Sport Management Review, article in press.

Whitley, M.A., Massey, W.V., \& Wilkison, M. (2018). A systems theory of development through sport for traumatized and disadvantaged youth. Psychology of Sport \& Exercise, $38,116-125$.

Whitley, M. A., Wright, E. M., \& Gould, D. (2016). Coaches' perspectives on teaching life skills to underserved South African children and youth. International journal of Sports Science \& Coaching, 11(3), 312-326.

World Health organization (WHO) (2013). Retrieved from http://www.who.int/countries/swz/en/ 
Wright, P.M., \& Burton, S. (2008). Implementation and outcomes of a responsibility-based physical activity program integrated into an intact high school physical education class. Journal of Teaching in Physical Education, 27(2), 138-154.

Wright, P. M., \& Craig, M. W. (2011). Tool for assessing responsibility-based education (TARE): Instrument development and reliability testing. Measurement in Physical Education and Exercise Science, 15, 1-16.

Wright, P.M., Dyson, B. \& Moten, T. (2012). Exploring the individualized experiences of participants in a responsibility-based youth development program. Ágora, 14 (2),248263.

Wright, P.M., Jacobs, J.M., Ressler, J.D., \& Jung, J. (2016). Teaching for transformative educational experience in a sport for development program, Sport, Education and Society, 21 (4), 531-548. doi: 10.1080/13573322.2016.1142433

Wright. P., \& Walsh. D. (In Press). Teaching Personal and Social Responsibility. In W. Li, M. Wang, P. Ward, \& S. Sutherland (Eds.), Curricular/instructional models for secondary physical education: Theory and practice. Beijing, China: Higher Education.

Wright, E.M., Whitley, M.A., Sabolboro, G. (2012). Conducting a TPSR program for an undeserved girls' summer camp. Agora for PE and Sport, 14(1), 5-24. 
Table 2. Complete higher order codes according to research question

RQ1: What is the youth participation experience in a TPSR-based youth sport program in eSwatini?

Positive psychological experiences

Program features

Sport-specific

Negative psychological experiences

Social relationships

Gendered experiences

RQ2: What are the coaching strategies and program design elements (strengths and weaknesses) that contribute most strongly to life skills learning in a TPSR-based youth sport program in eSwatini?

Coach training

Facilitation of learning

Content of learning

Miscellaneous

Program design strengths

Program operations

Coach characteristics

Facilitation of learning

Content of learning

Participant experiences

Program design weaknesses

Logistics

Youth management

Cultural elements

Program design improvements

Program structure

Youth learning

Youth participation experience

Improvements made during implementation of program

Coaching strategies

TARE coaching strategies

Learning strategies

Behavioral management

Building coach-youth relationship

Coach adaptations

Youth engagement and focus strategies

Ineffective coaching strategies

Preparing youth for end of program

RQ3: To what extent was fidelity to the TPSR model achieved in terms of daily structure, youth responsibility behaviors, and coaching strategies?

TARE responsibility behaviors

Gender differences in responsibility behaviors

Social connection

Caring and compassion

Food-related behaviors

RQ4: What positive developmental outcomes and changes in life skills are associated with youth participation in a TPSR-based youth sport program in eSwatini?

Respect and self-control

Participation and effort

Self-direction

Caring, helping, and leadership

Transferred outcomes

General outcomes 
Figure 1. Youth experiences during sport program - part I

HIGHER ORDER CODES

Positive psychological experiences (72)

Program features (44)

\section{LOWER ORDER CODES}

(E) Program as escape (2)

(E) Engagement with discomfort (3)

(E) Having voice heard (1)

(E) Experiencing leadership opportunities (9)

(E) Treated with respect (1)

(E) Validation (1)

(E) Competition (5)

(E) Social recognition \& validation from peers (6)

(C) Psychologically safe learning environment (1)

(C) Learning (5)

(G) Enjoyment and fun (11)

(G) Laughter (1)

(G) Positive (4)

(G) Youth ownership \& autonomy (1)

(G) Novel experiences (6)

(G) Experiencing small successes \& competency (15)

(+) Receiving daily fruits and food (12)

(+) Receiving treats (13)

(+) Exposure to multiple sports (1)

(+) Free play at end (4)

(+) Relational time (4)

(+) Enjoyment of awareness talk activities (7)

(+) Receiving something to keep (1)

$(+)$ Coaches as teachers (1)

(-) Short sport time (1)

** $\mathrm{E}=$ emotional psychological experiences, $\mathrm{C}=$ cognitive psychological experiences, $\mathrm{G}=$ General psychological experiences, $(+)=$ Positive experience,$(-)=$ Negative experience 
Figure 2. Youth experiences during sport program - part II

HIGHER ORDER CODES

Sport-specific (22)

Negative psychological experiences (21)

Social relationships (19)

Gendered experiences (15)
LOWER ORDER CODES

(+) Sport enjoyment (4)

(+) Sport-skill development (2)

(+) Good exercise (1)

(+) Enjoyment of learning new sports (2)

(+) Universal enjoyment of soccer (1)

(+) Responsive to culturally relevant sports (6)

(-) Physical fatigue (3)

(-) Injury (3)

(E) Sadness for program ending (3)

(E) Boredom when sitting out (3)

(E) Mid-program loss of coach (1)

(E) Feelings of invalidation (1)

(C) Difficulty understanding instructions (1)

(C) Hunger impacting focus (1)

(C) Difficulty processing learning (3)

(C) Disruption of new participants (2)

(C) Low English confidence (1)

(G) Negative novel experiences (5)

(+) Positive bond with coaches (7)

(+) Experiencing a different adult-youth relationship (1)

(+) Coach mentorship (1)

(+) Empathetic coaches (1)

(+) Fun with coaches (1)

(+) Emotional attachment to program (1)

(+) Sharing with others (2)

(-) Fear of peer ridicule (5)

Frustration with lack of boys discipline (1)

Greater engagement in learning in girls (1)

Improvements in focus when genders separated (1)

Enjoyment of mixed-gender interactions (1)

Enjoyment of inter-gender competition (2)

Enjoyment of split-gender sport (1)

Gendered enjoyment of sport (1)

Frustration with learning new sport in boys (3)

Participation with mixed competencies across gender (1)

Gendered peer exclusion during sport (3)

** $\mathrm{E}=$ emotional psychological experiences, $\mathrm{C}=$ cognitive psychological experiences, $\mathrm{G}=$ General psychological experiences, $(+)=$ Positive experience, $(-)=$ Negative experience 


\section{Figure 3. TARE coaching strategies}

HIGHER ORDER CODES

TARE coaching strategies (211)
MIDDLE ORDER CODES

Modeling respect (23)

Setting expectations (34)

Providing opportunities for success (19)

Fostering social interaction (36)

Assigning management tasks (12)

Promoting leadership (27)

Giving voices and choices (28)

Addressing transfer (22)

\section{LOWER ORDER CODES}

Coach positive body language (4)

Modeling desired responsibility behaviors (5)

Use of cultural norms for demonstrating respect (12)

Acknowledging youth emotions (1)

Expressing gratitude to youth (1)

Revisiting program goals (3)

Reminder of group behavioral expectations (12)

Holding youth accountable and encouraging responsibility

behaviors (19)

Encouraging effort \& participation over skill (13)

Offering opportunities to demonstrate competency (5)

Emphasizing continual improvement (1)

Encouraging peer social connection (9)

Validation of youth participation via social recognition (18)

Encouraging personal examples/sharing with peer group (9)

$\{$ Assigning small youth responsibilities (11)

Encouraging confidence in responsibility task (1)

Providing opportunities for leadership (25)

- Providing opportunities for youth autonomy and ownership (2)

Soliciting youth assessment (23)

Limited use of authoritarian coaching style (1)

Use of democratic decision-making (2)

Adapting program based on youth feedback (2)

[ Use of written self-learning quiz (3)

Assessing youth understanding through questions (6)

Assessing youth understanding through clapping of knees (1)

Coach use of real-world examples of life skills use (13)

Emphasizing value of transfer (8)

Use of coach personal examples of life skills application (1) 
Figure 4. Coaching strategies focused on learning

HIGHER ORDER CODES

Learning strategies (250)
MIDDLE ORDER CODES

General (60)

Orienting (49)

Remember (28)

Understand (37)

Apply (35)

Analyze (40)

\section{LOWER ORDER CODES}

Coach collaboration (7)

Creating psychologically safe learning environment (2)

Use of visual aids (13)

Use of props (2)

Use of debrief (7)

Use of pairs for self-reflection (8)

Facilitating discussion in self-reflection pairs (5)

Coach validation of youth input (16)

Sport instruction (18)

Providing instructions and explanation (18)

Introduction of life skills concept (13)

Multiple repetitions of concepts during single session (9)

Reviewing previous life skills lessons (14)

Use of oral recitation (4)

Teaching physiological control skill (1)

Simplifying words (2)

Breaking down each concept (5)

Reframing (1)

Asking for youth definitions of concepts (15)

Prompting youth elaboration of concepts (3)

Use of familiar behaviors to illustrate concept (3)

Use of the zone of proximal development (5)

Prompting youth questions (2)

Encouraging self-reflection (1)

Soliciting youth examples of life skills use outside sport (19)

Asking about youth application of life skills in everyday life (16)

Prompting youth critical thought (25)

Integration of different life skills (10)

Use of teaching moments to integrate life skills into practice (5) 
Figure 5. General coaching strategies

HIGHER ORDER CODES

Behavioral management (50)

Building coach-youth relationship (42)
LOWER ORDER CODES

Purposeful use of seating arrangement (7)

Use of smaller groups (12)

Use of incentives (10)

Use of concurrent matches and drills (4)

Belly breathing to reset (1)

Split boys and girls (1)

Individual attention (1)

Use of disciplinary strategies (5)

Use of punishment (9)

Use of spotlighting distracted youth (4)

Use of self-disclosure (2)

Use of humor (11)

Personal conversations with all youth (3)

Use of relevant youth language (2)

Asking for and using names (4)

Asking about home, school, and weekend life (10)

Showing interest in youth interests (3)

Sharing personal skills (1)

Friendly and respectful interactions (1)

Quizzing on relevant youth topics (1)

Offering opportunity for long-term bond (1)

Building coach-youth bond (3)

\section{LOWER ORDER CODES}

Adaptation to youth needs (1)

Adapting sessions to immediate youth response (3)

Adapting to environmental circumstance (1)

Language adaptations (4)

Use of extra encouragement for girls (1)

Coach energy (9)

Team cheer for energy (13)

Encouraging high energy (13)

Movement-based refocusing strategies (17)

$$
\text { Use of competition (5) }
$$$$
\text { Use of incentives (1) }
$$

Use of motivational speech (2)

Use of engaging phrases/mottos (1)

Facilitating youth buy-in for learning (5)

No self-reflection (1) Monitoring behavior vs. use of teaching moments

Teacher-centered approach (1)

Lack of attentiveness to youth (2)

Lack of organization/preparedness (1)

Prolonged period of youth inactivity (1)

\section{HIGHER ORDER CODES}

Coach adaptations (10)

Youth engagement and focus strategies

(66)

Preparing youth for end of program (2) 
Figure 6. Coach feedback on coach training

HIGHER ORDER CODES

Facilitation of coach learning (7) $\left\{\begin{array}{l}\text { Strengths (3) } \\ \text { Weaknesses (1) } \\ \text { Improvements (3) }\end{array}\right.$

Content of coach learning (7) $\left\{\begin{array}{l}\text { Strengths (2) } \\ \text { Weaknesses (2) } \\ \text { Improvements (3) }\end{array}\right.$

Miscellaneous (2)
MIDDLE ORDER CODES

$\left\{\begin{array}{l}\text { Soliciting coach expression of voice (1) } \\ \text { Use of learning props and discussion (1) } \\ \text { Use of self-reflection (1) }\end{array}\right.$

$\{$ Longer training needed (1)

Week-long training (1)

Use of videos for skill demonstration (1)

Use of videos continuously during program implementation (1)

$\{$ Focus on coach-athlete relationship \& environment (1)

Focus on life skills building strategies (1)

$\{$ Team-building too short (1)

$\{$ Stronger cultural focus needed (1)

[ Inclusion of sport-specific skills training (1)

Focus on confidence-building (1)

Stronger emphasis on learning integration strategies and using teaching moments (1)

$\left\{\begin{array}{l}\text { Empowering for coaches (1) } \\ \text { Organization of training (1) }\end{array}\right.$

Table 3

Coach perceptions of coach training

Item

The coach training program prepared me to create a caring and supportive sport

$\underline{\mu \text { score }} \underline{\mathrm{SD}}$

environment

The coach training program helped me think about my coaching motivations and identity

The coach training program prepared me to incorporate life skills development into my coaching

The coach training program prepared me to incorporate the TPSR model into my coaching

Overall I found the coach training program engaging and enjoyable

I feel prepared to implement the youth sport program

$4.33 \quad 0.58$

I feel confident to implement the youth sport program

$4.67 \quad 0.58$

$3.67 \quad 0.58$

Note: $5=$ strongly agree, $4=$ agree, $3=$ neither agree nor disagree, $2=$ disagree, $1=$ strongly disagree 
Figure 7. Program strengths

HIGHER ORDER CODES

Program operations (26)

Coach characteristics (8)

\section{LOWER ORDER CODES}

Provision of daily fruits and food (6)

Use of incentives (2)

Total program length (1)

Organization of program (1)

Inter-gender programming (1)

Integration of stable and caring authority figure (3)

Use of multiple coaches (2)

Daily coach planning (1)

Use of free play at end (3)

Inclusion of multiple sports (2)

Inclusion of culturally relevant sports (3)

Provision of sport equipment (1)

Investment in ethos of program (1)

Relationally-focused (2)

Confident (1)

Attuned to youth (1)

Collaborative/team player (2)

Emphasizes mentorship role (1)
LOWER ORDER CODES

Sport as buy-in (1)

Integration of life skills into sport practice (3)

Soliciting youth expression of voice (2)

Inclusion of leadership opportunities (1)

Experiences outside youth comfort zone (3)

Relational time for bonding (3)

Daily belly breathing to reset (2)

Team cheer for engagement and focus (1) Use of written learning quiz (2)

Selection of life skills and responsibility levels (2)

Emphasis on confidence-building (2) Emphasis on transfer (1)

Inclusion of STAR activity and daily belly breathing (2)

Positive coach experience (3)

Positive youth participation and engagement (3)
HIGHER ORDER CODES

Facilitation of youth learning (18)

Content of youth learning (7)

Participant experience (6)
HIGHER ORDER CODES WITH ONE LOWER ORDER CODES (7)

Positive relationship between researcher and youth (4)

Interest in future extensions of programming (2)

Youth retention (1) 
Figure 8. Program weaknesses

HIGHER ORDER CODES

Logistics (23) $\left\{\begin{array}{l}\text { Time-keeping during sessions (8) } \\ \text { Youth group size (8) } \\ \text { Lack of indoor facility (3) } \\ \text { Length of daily session (1) } \\ \text { Length of sport time (1) } \\ \text { Too many activities per session (1) } \\ \text { Lack of coach experience with TPSR (1) }\end{array}\right.$

\section{LOWER ORDER CODES}

Coach management of discipline (3)

Maintaining youth responsibility behaviors (1)

Initial setting of expectations (1)

Facilitating inter-gender cooperation (1)

Use of SiSwati as instructional language (1)

Cultural specificity of sport selection (1)

Cultural applicability of awareness talk metaphors (2)
HIGHER ORDER CODES

Youth management (6)

Cultural elements (4) 
Figure 9. Program improvements

HIGHER ORDER CODES

Program structure (29)

Youth learning (18)

Youth participation experience (20)
MIDDLE ORDER CODES

TPSR-specific (12)

Length of program (5)

Program resources (3)

Miscellaneous (9)

Learning content (6)

Facilitation strategies (12)

Youth management (12)

Sport-related (8)

\section{LOWER ORDER CODES}

Repetition of sports (1)

Build up English use and confidence in youth (2)

Cultivate supportive peer culture (1)

Build exposure and confidence in leadership (1)

Add free play component (1)

Stronger relational time (1)

Longer daily sessions - awareness talk \& sport time (5)

Combine group \& self-reflection (1)

Scaling daily emphasis on life skills vs. sport-specific development (4)

Access to sport facilities (1)

Providing sport attire (1)

Recruiting greater number of coaches (1)

Better time-keeping (8)

Diversify coach assessment methods (1)

Use of culturally relevant metaphors (2)

Emphasis on creating culture of respect (1)

Discernment in selection of learning activities (1)

Teach youth how to teach life skills to peer (1)

Emphasis on alternative gender roles (1)

Greater use of teaching moments (2)

Leadership opportunities (3)

Assigning youth responsibilities (2)

Reflective writing during self-reflection (1)

Increase youth role during assessment (1)

Diversity of transfer facilitation (3)

Smaller participant size (1)

Coach management of discipline and focus (7)

Engagement of all youth during physical activity (1)

Balance of mixing and separating genders (3)

Increase inclusive play (1)

Stretching after sport participation (1)

Inclusion of tennis and skipping rope (1)

Cultural specificity of sport selection (1)

Gradual introduction of novel sport experiences (1)

Greater use of competition and rewards (3)

IMPROVEMENTS MADE DURING IMPLEMENTATION OF THE PROGRAM (10)

Use of pairs during self-reflection (2)

Revisiting program goals with new youth (1)
Use of small groups (3) Provision of food (2)
Use of collective punishment for accountability (1) Emphasis on transfer during self-reflection (1) 
Table 4. TARE post-teaching reflection - teaching strategies

\begin{tabular}{|c|c|c|c|}
\hline $\begin{array}{l}\text { Teaching } \\
\text { strategy }\end{array}$ & $\underline{\mu}$ & $\underline{\mathrm{SD}}$ & Coach comments \\
\hline $\begin{array}{l}\text { Modeling } \\
\text { respect }\end{array}$ & 3.86 & 0.22 & $\begin{array}{l}\text { "Appropriate communication and unconditional positive regard is } \\
\text { presented." "I made sure I used respectful words with the youth and } \\
\text { emphasized that type of communication." }\end{array}$ \\
\hline $\begin{array}{l}\text { Setting } \\
\text { expectations }\end{array}$ & 3.03 & 0.58 & $\begin{array}{l}\text { "Went back to group agreements to ensure students know what we expect, } \\
\text { practices are safe, rules and procedures are used to guide every session." }\end{array}$ \\
\hline $\begin{array}{l}\text { Opportunities } \\
\text { for success }\end{array}$ & 3.52 & 0.45 & $\begin{array}{l}\text { "All of them have equal chance to participate in any of the activities } \\
\text { regardless of gender like girls with soccer." }\end{array}$ \\
\hline $\begin{array}{l}\text { Fostering } \\
\text { social } \\
\text { interaction }\end{array}$ & 3.36 & 0.42 & $\begin{array}{l}\text { "Played the telephone game, which allowed the kids to interact, encouraging } \\
\text { teamwork and student-to-student interaction." }\end{array}$ \\
\hline $\begin{array}{l}\text { Assigning } \\
\text { management } \\
\text { tasks }\end{array}$ & 3.19 & 0.57 & "Assigning role call and helping in demonstrations." \\
\hline $\begin{array}{l}\text { Leadership } \\
\text { opportunities }\end{array}$ & 3.19 & 0.79 & $\begin{array}{l}\text { "Leading the breathing exercise, and during the telephone game each group } \\
\text { was asked to have a leader." }\end{array}$ \\
\hline $\begin{array}{l}\text { Giving voices } \\
\text { and choices }\end{array}$ & 3.64 & 0.20 & $\begin{array}{l}\text { "Whenever we introduce a new concept we asked youth to raise hands and } \\
\text { give their own definitions/opinions, group is involved in discussions, they } \\
\text { ask questions, make suggestions and also share opinions, giving them the } \\
\text { platform to take and try to explain what they understand about a certain } \\
\text { skill." }\end{array}$ \\
\hline $\begin{array}{l}\text { Role in } \\
\text { assessment }\end{array}$ & 2.33 & 0.60 & $\begin{array}{l}\text { "We have been sitting them in pairs to try to discuss what they learnt so far } \\
\text { in the course of the program." "Asking for thumbs up/down at end of class." }\end{array}$ \\
\hline Transfer & 3.28 & 0.48 & $\begin{array}{l}\text { "Encouraging youth to use the dove conflict style to solve obstacles at home } \\
\text { and school." "Gave real life examples of transfer and asked students if they } \\
\text { implemented skills at home." }\end{array}$ \\
\hline
\end{tabular}

Note: Responsibility-based teaching strategies- $0=$ absent, $1=$ weak, $2=$ moderate, $3=$ strong, $4=$ very strong. 
Figure 10. TARE responsibility behaviors - part I

HIGHER ORDER CODES

TARE responsibility behaviors (268)

MIDDLE ORDER CODES

Participation (93)

General Engagement $(90)$

Learning Engagement (85)

\section{LOWER ORDER CODES}

(+) Consistent attendance (1)

(+) General participation (1)

(+) Participation in discussion (27)

(+) Effortful participation in awareness activity (10)

(+) Effortful participation in sport (19)

(+) Participation despite discomfort (4)

(+) General focus (4)

(+) Focus during sport (1)

(-) Lapses in focus \& discipline (17)

(-) High distractibility at start of program (1)

(*) Improvements in discipline (1)

(*) Improvements in focus (5)

(*) Improvements in self-reflection (1)

(*) Focus improvements in small groups (1)

(+) Youth energy (19)

(+) Excitement (9)

(+) Laughter (10)

(+) Positive body language (6)

(+) Eagerness to play sport (1)

(+) Youth interest in program (1)

(+) Engagement with new experiences (1)

(+) Positive engagement with coaches (10)

(+) Excitement for team cheer (7)

(+) Excitement for culturally relevant sports (3)

(+) Engagement in relational time (1)

(+) Positive competitive behaviors (6)

(+) Celebratory dancing and cheering (13)

(-) Lack of engagement without relational time (1)

(-) Hesitancy for unfamiliar sports (2)

(+) Engagement in learning and discussion (6)

(+) Engagement during learning activities (10)

(+) Engagement during active learning portions (5)

(+) Engagement with coach use of real-world examples (3)

(+) Thoughtfulness and active reflection during discussion (11)

(+) Curiosity for learning (5)

(+) Responsiveness to use of props (1)

(+) Demonstration of learning (8)

(+) Providing examples of application of life skills (17)

(+) Internalizing responsibility behaviors (8)

(+) Ownership of group norms (3)

(+) Sharing personal examples (3)

(-) Lack of engagement during self-reflection (3)

(*) Improvements in engagement in learning (1)

(*) Better learning engagement in small groups (1)

Note: $(+)=$ Positive behavior, $(-)=$ Negative behavior, and $(*)=$ Improvement in behavior across program 


\section{Figure 11. TARE responsibility behaviors - part II}

\section{HIGHER ORDER CODES}

TARE responsibility behaviors (211)
MIDDLE ORDER CODES

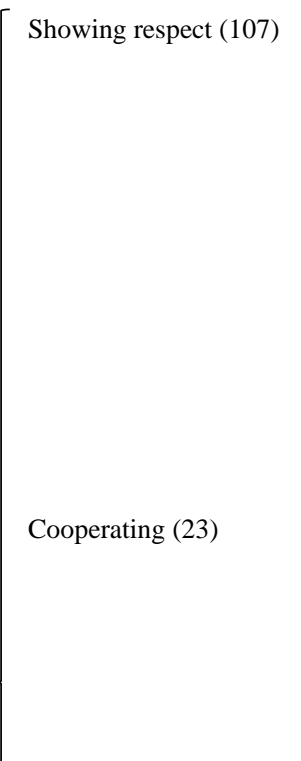

Encouraging others (8)

Leading (25)

Helping others (10)

Asking for help (6)

Expressing voice (32)

\section{LOWER ORDER CODES}

(+) Timeliness (10)

(+) Listening to coach instructions (23)

(+) Listening \& respect for peers (5)

(+) Greeting coaches and peers (13)

(+) Raising hands (22)

(+) Waiting patiently (1)

(-) Tardiness (10)

(-) Poor listening to coach instructions (6)

(-) Lack of respect (2)

(-) Chaos during sport (6)

(-) Deception (2)

(*) Improvements in listening to instructions (1)

(*) Improvements in responsiveness to coaches (8)

(+) Practicing belly breathing with peer leadership (7)

(+) Team work (8)

(+) Cooperation \& group decision-making (1)

(+) Communication (1)

(-) Negative competitive behaviors (2)

(-) Cheating (1)

(-) Lack of cooperation (1)

(-) Arguing and disagreements (2)

(+) Holding peers accountable to responsibility behaviors (4)

(+) Peer encouragement (4)

(+) Demonstration of leadership (13)

(+) Initiative-taking (5)

(+) Eagerness to lead (5)

(+) Natural leader (1)

(-) Reluctance to take on leadership responsibility (1)

(+) Helping others (10)

(+) Asking for help understanding (6)

(+) Giving voice (22)

(+) Voicing needs (1)

(+) Voicing opinions (6)

(+) Asking for more sport time (2)

(+) Spontaneous dance competition (1)

Note: $(+)=$ Positive behavior, $(-)=$ Negative behavior, and $(*)=$ Improvement in behavior across program 
Table 5. Responsibility behaviors from TARE post-teaching reflection and content analysis

\begin{tabular}{|c|c|c|c|c|c|}
\hline$\underline{\text { Responsibility }}$ & $\underline{\mu}$ & $\underline{\mathrm{SD}}$ & $\underline{\text { Sample coach comments }}$ & \multicolumn{2}{|c|}{$\underline{\text { Content analysis samples }}$} \\
\hline Participating & 4.00 & 0 & $\begin{array}{l}\text { "Everyone played netball, all of them tried } \\
\text { hard and enjoyed it." }\end{array}$ & $\begin{array}{l}\text { (+) participation in discussion } \\
\text { (+) effortful participation in awareness } \\
\text { activity } \\
(+) \text { effortful participation in sport }\end{array}$ & $\begin{array}{l}\text { (-) lapses in focus and discipline } \\
(*) \text { improvements in focus } \\
\text { across program }\end{array}$ \\
\hline Engaging & 3.42 & 0.23 & $\begin{array}{l}\text { "They were listening and motivated, all excited } \\
\text { and enjoyed the activity." "They are engaged } \\
\text { but easily disrupted." }\end{array}$ & $\begin{array}{l}\text { (+) youth energy } \\
\text { (+) positive body language } \\
\text { (+) excitement } \\
\text { (+) celebratory dancing and cheering } \\
\text { (+) positive engagement with coaches } \\
\text { (+) engagement during learning activities } \\
\text { (+) thoughtfulness and active reflection } \\
\text { during discussion }\end{array}$ & $\begin{array}{l}(-) \text { hesitancy for unfamiliar } \\
\text { sports } \\
(-) \text { lack of engagement in self- } \\
\text { reflection } \\
(*) \text { better learning engagement } \\
\text { in small groups } \\
(*) \text { improvements in } \\
\text { engagement in learning }\end{array}$ \\
\hline $\begin{array}{l}\text { Showing } \\
\text { respect }\end{array}$ & 2.86 & 0.50 & $\begin{array}{l}\text { "Listening to coach instructions." } \\
\text { "Concentration is low and they get distracted } \\
\text { easily." "To a certain extent they are showing } \\
\text { respect; they showed respect in some of the } \\
\text { rules." }\end{array}$ & $\begin{array}{l}(+) \text { listening to coach instructions } \\
(+) \text { greeting coaches and peers }(+) \text { raising } \\
\text { hands }\end{array}$ & $\begin{array}{l}(-) \text { tardiness } \\
(-) \text { poor listening to coach } \\
\text { instructions } \\
(*) \text { improvements in } \\
\text { responsiveness to coaches }\end{array}$ \\
\hline Cooperating & 2.50 & 0.63 & $\begin{array}{l}\text { "Allowing peers to speak, they try to work } \\
\text { together." "Only a few could cooperate." "The } \\
\text { boys didn't cooperate well with the girls." }\end{array}$ & $\begin{array}{l}\text { (+) practicing belly breathing with peer } \\
\text { leadership } \\
(+) \text { team work }\end{array}$ & $\begin{array}{l}\text { (-) negative competitive } \\
\text { behaviors } \\
\text { (-) cheating } \\
\text { (-) arguing and disagreements }\end{array}$ \\
\hline $\begin{array}{l}\text { Encouraging } \\
\text { others }\end{array}$ & 2.14 & 0.78 & $\begin{array}{l}\text { "Some display it but others still laugh at one } \\
\text { another." "Encouraging only when they scored } \\
\text { goals." }\end{array}$ & $\begin{array}{l}(+) \text { holding peers accountable to } \\
\text { responsibility behaviors } \\
(+) \text { peer encouragement }\end{array}$ & \\
\hline Helping others & 2.53 & 0.55 & $\begin{array}{l}\text { "Helping answer questions when someone gets } \\
\text { stuck, supportive of teammates." }\end{array}$ & (+) helping others & \\
\hline Leading & 2.86 & 0.88 & $\begin{array}{l}\text { "Team leaders taught others how to play, they } \\
\text { are doing it well and are liking the leadership } \\
\text { role." }\end{array}$ & $\begin{array}{l}(+) \text { demonstration of leadership } \\
(+) \text { eagerness to lead } \\
(+) \text { initiative-taking }\end{array}$ & $\begin{array}{l}(-) \text { reluctance to take on } \\
\text { leadership responsibility }\end{array}$ \\
\hline $\begin{array}{l}\text { Expressing } \\
\text { voice }\end{array}$ & 3.36 & 0.49 & $\begin{array}{l}\text { "Making suggestions during discussion, they } \\
\text { are able to talk and express how they feel." }\end{array}$ & $\begin{array}{l}(+) \text { giving voice } \\
(+) \text { voicing opinions }\end{array}$ & \\
\hline $\begin{array}{l}\text { Asking for } \\
\text { help }\end{array}$ & 3.50 & 0.55 & $\begin{array}{l}\text { "Asking when they needed something that } \\
\text { wasn't available, asking for assistance." }\end{array}$ & $(+)$ asking for help understanding & \\
\hline
\end{tabular}

Note: Student responsibility behaviors $\mu: 0=$ very weak, $1=$ weak, $2=$ moderate, $3=$ strong, $4=$ very strong. $(+)=$ Positive behavior, $(-)=$ Negative behavior, and $(*)=$ Improvement in behavior across program. 
Figure 12. Gender differences in TARE-related behaviors

HIGHER ORDER CODES
Gender differences in
responsibility behaviors (38) $\quad\left\{\begin{array}{l}\text { LOWER ORDER CODES } \\ \text { Focus for learning in girls (2) } \\ \text { Boys playfulness (1) } \\ \text { Gendered participation in sport (3) } \\ \text { Incentive-dependent engagement in learning for boys (1) } \\ \text { Discipline when genders separated (1) } \\ \text { Gendered participation in discussion (2) } \\ \text { Engagement (12) } \\ \text { Cooperating (3) } \\ \text { Helping others (1) }\end{array}\right.$

\section{Figure 13. Youth behaviors}

HIGHER ORDER CODES

Social connection (29)

Caring \& Compassion (8)

Food-related behaviors (33)

\section{LOWER ORDER CODES}

\footnotetext{
(+) Joking with coaches and peers (6)

$(+)$ Chatting amongst coaches and peers (9)

(+) Positive peer interactions (3)

(+) Creating personal connection through nicknames (1)

(+) Showing gratitude (3)

(+) Spontaneous play (5)

(+) Direct interaction with researcher (5)

(-) Reluctance to engage with different peer groups (3)

(*) Improvements in engaging with different peer groups (3)

$\left\{\begin{array}{l}\text { (+) Caring for others (4) } \\ (+) \text { Kindness to others (1) } \\ \text { (+) Compassion (1) } \\ \text { (+) Sharing with others (1) } \\ \text { (-) Boys lack of sharing (1) }\end{array}\right.$

(+) Eagerness for fruit and food (11)

(+) Eagerness to receive treats (11)

(-) Concern over missing out on food (9)

(-) Need to refuel (2)
}

Note: $(+)=$ Positive behavior, $(-)=$ Negative behavior, and $(*)=$ Improvement in behavior across program 
Figure 14. Youth outcomes

\begin{tabular}{|c|c|c|}
\hline HIGHER ORDER CODES & MIDDLE ORDER CODES & LOWER ORDER CODES \\
\hline \multirow{6}{*}{ (I) Respect \& Self-control (86) } & & Respect (50) \\
\hline & Respect (52) & Self-respect (1) \\
\hline & & Responsibility (2) \\
\hline & & Self-control (20) \\
\hline & & Physiological control (2) \\
\hline & Self-control (34) & Emotion regulation (11) \\
\hline \multirow{6}{*}{ (II) Participation \& Effort (98) } & & Personal responsibility for emotions (1) \\
\hline & Participation and effort (19 & Participation (1) \\
\hline & & Effort/hard work (18) \\
\hline & & Cooperation (1) \\
\hline & Harmony (79) & Team work (59) \\
\hline & & Communication (19) \\
\hline \multirow{10}{*}{ (III) Self-direction (59) } & & Self-direction (9) \\
\hline & Planning (30) & Goal-setting (13) \\
\hline & & Awareness of future (1) \\
\hline & & Decision-making (7) \\
\hline & & [ Confidence (16) \\
\hline & Resilience (29) & Courage (3) \\
\hline & & Perseverance (9) \\
\hline & & Managing peer pressure (1) \\
\hline & & Caring \& helping (7) \\
\hline & Caring \& helping (22) & Compassion (13) \\
\hline \multirow{4}{*}{ (IV) Caring, Helping, \& Leadership (60) } & & L Caring for others (2) \\
\hline & & [Conflict resolution (13) \\
\hline & Conflict management (36) & STAR (23) \\
\hline & Leadership (2) & Leadership (2) \\
\hline
\end{tabular}
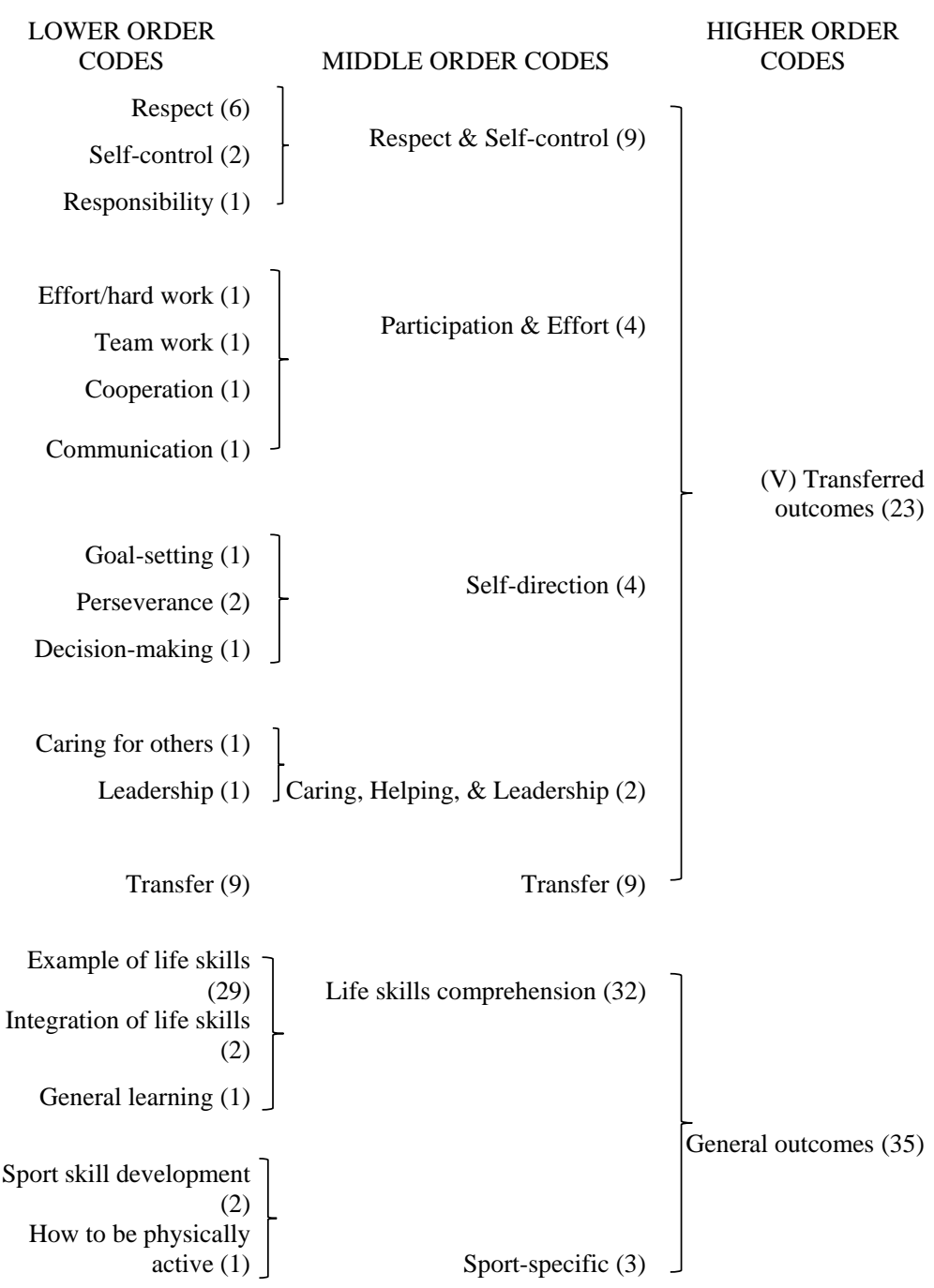
Table 6. PSRQ and MSPSE descriptive statistics

\begin{tabular}{|c|c|c|c|c|c|c|}
\hline & $\frac{\text { PSRQ }}{\frac{\text { total }}{(\mathrm{SD})}}$ & $\begin{array}{l}\frac{\text { Enlisting }}{\underline{\text { social }}} \\
\frac{\text { resources }}{(\mu)(\mathrm{SD})}\end{array}$ & $\frac{\frac{\text { Self- }}{\text { regulated }}}{\frac{\text { learning }}{(\mu)(\mathrm{SD})}}$ & $\begin{array}{l}\frac{\text { Self-regulatory }}{\frac{\text { efficacy to }}{\text { resist peer }}} \\
\frac{\text { pressure }(\mu)}{(\mathrm{SD})}\end{array}$ & $\begin{array}{l}\frac{\text { Social }}{\text { self- }} \\
\underline{\text { efficacy }} \\
(\mu)(\mathrm{SD})\end{array}$ & $\begin{array}{c}\begin{array}{c}\text { Self- } \\
\text { assertive } \\
\text { self-efficacy }\end{array} \\
\underline{(\mu)(\mathrm{SD})}\end{array}$ \\
\hline Baseline & $\begin{array}{l}68.04 \\
(4.95)\end{array}$ & $5.38(.93)$ & $5.57(.83)$ & $4.35(1.29)$ & $\begin{array}{c}4.81 \\
(1.19)\end{array}$ & $4.10(1.26)$ \\
\hline Post & $\begin{array}{l}72.75 \\
(5.57)\end{array}$ & $5.95(.84)$ & $6.06(.52)$ & $4.50(1.65)$ & $\begin{array}{c}5.27 \\
(1.39)\end{array}$ & $4.52(1.22)$ \\
\hline p-value & 0.009 & 0.139 & 0.131 & 0.648 & 0.172 & 0.064 \\
\hline $\mathrm{N}$ & 27 & 28 & 27 & 28 & 28 & 27 \\
\hline
\end{tabular}




\section{Appendix: Extended Introduction}

\section{Scope of the Study}

The feasibility study used an intervention design to implement a three-week sport program for youth in a small community in the Lobamba region of eSwatini. Local coaches were the primary implementers of the program. Program sessions occurred daily for 75 minutes with a total of 15 sessions across three weeks. The sport program took place at a community-based children's organization that provides psychosocial services and school funding support for underprivileged youth in the community. Participants in the sport program were youth $(N=33)$, aged 10-15 years old, who attended the grade six and seven literacy development afternoon club at the children's organization. Local coaches $(N=3)$ were recruited using purposive and convenience sampling. Coaches participated in a $15-\mathrm{hr}$ training to prepare them to implement the sport program.

The sport program was designed using the teaching personal and social responsibility (TPSR) model as the foundational framework. Specifically, the sport program was designed using the standard TPSR daily structure (relational time, awareness talk, physical activity, group reflection, and individual reflection) and responsibility levels/goals (respecting others, effort and cooperation, self-direction, helping and leadership, and transfer). Specific design elements from several successful TPSR-based youth sport programs such as 'Girls Just Wanna Have Fun' and Refugee Sport Club also informed the development of the program. Coaches were also given the opportunity to collaboratively design elements of the sport program during the coach training.

Data collection employed a mixed methods approach that triangulated data from quantitative and qualitative sources. Data was collected from multiple sources including youth participants, coaches, the afternoon club teacher, and observations from the primary researcher. Data 
collection methods involved baseline and post-program surveys (demographics, MSPSE;

Bandura, 1990, PSRQ; Li et al., 2008), student learning quizzes (Hellison, 2011; Wright \& Burton, 2008), focus groups with youth and coaches (Bean et al., 2014; Gordon, Jacobs, \& Wright, 2016; Whitley, Coble, \& Jewell, 2016; Wright et al., 2016)), coach reflections (Bean et al., 2014; Whitley, 2012), a semi-structured interview with the afternoon club teacher, and field notes (Cryan \& Martinek; Gordon et al., 2016; Walsh et al., 2010; Whitley \& Gould, 2010).

\section{Basic Assumptions}

The study made the following theoretical and methodological assumptions:

- Using sport as a context for youth development programming in eSwatini would be wellreceived and enjoyed by both male and female youth (Huysmans et al., 2017).

- In a sport environment that is intentionally crafted, sport can be a context for positive youth development (Coakley, 2011). In addition, behaviors learned within the sport environment can be transferred to life domains outside of sport, when intentionally facilitated (Gordon \& Doyle, 2015).

- The teaching personal and social responsibility model (TPSR) would be an appropriate life skills education model to apply to a novel youth context like eSwatini (Gordon, 2009; Martinek \& Hellison, 2016).

- A three-week daily sport program would be an adequate amount of time for short-term changes in life skills knowledge and behaviors to be observed (Caballero-Blanco et al., 2013).

- $\quad$ The pre and post surveys (PSRQ and MSPSE) would be valid, reliable, and appropriate instruments to use in this youth population. 


\section{Limitations of the Study}

The study acknowledged several potential weaknesses that may have affected the validity of the study.

- Youth were video-recorded during each of the sport sessions. Consistent with principles related to the Hawthorne effect, there was therefore potential for youth participants and coaches to change their behavior because of being observed (video-recorded) (McCambridge, Witton, \& Elbourne, 2014).

- The sport program session outlines were not developed in complete collaboration with the coaches. Rather, a program outline was created before-hand that was then changed and added to during the coach training. This was a limitation of the study given the critique that too many sport for development programs adopt a top-down, neo-liberal approach to programming (Hartmann \& Kwauk, 2011; Spaaij, 2009). However, giving coaches an opportunity to change as much of the proposed program as they wish still served to involve them in a meaningful manner in the program's design.

- The sport program was only three weeks in length, which may not have been not long enough for meaningful long-term impacts on the lives of the youth participants (Bean, Kendellen, \& Forneris, 2016). However, given that this was a feasibility study, the objective was for the lessons learned from this program to be carried forward to inform more long-term programming in eSwatini.

- The primary researcher was not an expert in TPSR programming. Many previous TPSR programs have been guided by practitioners with years of experience working with the model (Cryan \& Martinek, 2017; Walsh, Ozaeta, \& Wright, 2010; Whitley, Coble, \& Jewell, 2016). 
- The coaches selected to implement the program did not all have experience working with youth in underprivileged contexts. However, they did all come from underprivileged backgrounds themselves.

\section{Definition of Terms}

○ Adolescencelyouth: these terms are recognized as dynamic terms that vary according to geographical context, time period, and societal context. A universal definition of adolescence and youth is as follows: "'a period of transition', in which 'although no longer considered a child, the young person is not considered an adult' (McCauley \& Salter, 1995 as cited in Fatusi \& Hindin, 2010, p. 500).

○ Healthy development: ways of "enabling individuals to lead a healthy, satisfying, and productive life, as youth and later as adults, because they gain the competence to earn a living, to engage in civic activities, to nurture others, and to participate in social relations and cultural activities" (Hamilton, Hamilton, \& Pittman, 2004 as cited in Holt \& Neely, 2011).

○ Sport for development: "the use of sport to exert a positive influence on public health, the socialization of children, youths and adults, the social inclusion of the disadvantaged, the economic development of regions and states, and on fostering intercultural exchange and conflict resolution" (Lyras \& Welty Peachey, 2011, p. 311).

○ Life skills: the cognitive, emotional, and social skills needed by youth to overcome the challenges of everyday life and "succeed in the different environments in which they live, such as school, home and in their neighborhoods" (Danish, Forneris, Hodge, \& Heke, 2004, p.40). 
○ Positive youth development: "a strength-based approach to child and adolescent development based on the assumption that all youth have the potential for positive developmental change (Lerner, Brown, \& Kier, 2005 as cited in Holt \& Neely, 2011).

- Self-efficacy: an individual's "belief in their capability to exercise some measure of control over their own functioning and over environmental events" (Bandura, 2001, p.10).

\section{Significance of the Study}

The transition period from childhood to adulthood i.e. adolescence, is an important developmental stage that determines future social, cognitive, physical, and emotional well-being and success (Fatusi \& Hindin, 2010; Holt 2008). In the Kingdom of eSwatini (formerly known as Swaziland), a small country in Southern Africa, $36 \%$ of the population is between the ages of 1024 years (WHO 2013; Mavundla, Dlamini, Nyoni, \& Mac-Ikemenjima, 2015). While youth in eSwatini struggle with the more universal challenges associated with adolescence such as social identity development and peer pressure, emaSwati youth are also faced with major contextspecific challenges. These include economic and resources concerns such as unemployment, low school attendance, and high poverty rates as well as health challenges such as risk for HIV/AIDS (Huysmans, Clement, Hilliard, \& Hansell, 2017). Specifically, the population-level poverty rate in eSwatini is $63 \%$, unemployment for youth aged $15-24$ is $42.6 \%$, and only about half of youth attend school (Ministry of Sports, Culture and Youth Affairs, 2015; Mavundla et al., 2015). Of even more concern is the fact that eSwatini has the highest global prevalence of HIV/AIDS; almost $30 \%$ of adults (15-49 years old) are infected (UNAIDS, 2016). The high prevalence of HIV/AIDS in eSwatini has not only put youth at significantly higher risk for infection (AVERT, 2014), but it has also had psychological, social, and economic effects on the lives of young emaSwati (Foster \& Williamson, 2000). In addition, the immense adult mortality rates due to the 
HIV epidemic in eSwatini has resulted in a youth population (under 18 years of age) composed of almost 50\% orphans and vulnerable children (AVERT, 2014). This is concerning because emaSwati youth are therefore not only exposed to adverse childhood experiences alongside health and resources challenges, but they are also lacking guidance and mentorship from adult role models to support their healthy development. This study was an opportunity to invest in an initiative that supports youth development and mentorship in eSwatini.

In addition, although there are government-led policies and initiatives for youth development in eSwatini, youth buy-in to these systems is limited (Mavundla et al., 2015). Moreover, there is a significant gap between provision and adoption of youth services, which suggests that there is a need to find ways to engage youth in their own development through creative, fun, and intentional programming. Sport-based youth development programming may be one avenue through which to achieve this goal (Beutler, 2008). For socially vulnerable populations, sport participation may help youth develop the life skills needed to overcome the challenges of everyday life and "succeed in the different environments in which they live, such as school, home and in their neighborhoods" (Danish et al., 2004, p.40). Sport also exposes youth to positive coach role models and constructive environments that can help them grow into civically engaged adults (Coakley, 2011). For youth in eSwatini who are lacking positive role models as well as opportunities to build life skills, a sport-based life skills development program was a potential vehicle through which to support the healthy development of emaSwati youth in an engaging and enjoyable way.

Finally, this study was also an opportunity to further explore the validity of the teaching personal and social responsibility (TPSR) model as an effective framework for life skills education through sport in varying cultural contexts (Hellison, 2011). The TPSR model is 
conceptualized as a model that is applicable across different social and cultural contexts. That is, Hellison (2011) recognizes that the goals of the program and the TPSR responsibility levels are social constructions that can be modified to better fit different contexts as long as the core TPSR spirit is retained (Gordon, 2009; Martinek \& Hellison, 2016). However, the majority of TPSR programs have been implemented in Western contexts where youth challenges are specific to the youth social and cultural context (Caballero-Blanco et al., 2013). An exploration of a TPSRbased youth sport program in eSwatini therefore provided an opportunity to explore how the model operated differently in a distinct youth context. In addition, the findings from this exploratory study will be used to inform the development of more long-term sport-based youth development initiatives in eSwatini.

\section{Appendix: Extended Literature Review}

Over the past decade, sport-based youth development programming has expanded worldwide (Schulenkorf, Sherry, \& Rowe, 2016). As a well-liked, cost-effective, and engaging socializing agent, sport is viewed as a context where positive developmental outcomes such as life skills, social connection, character, and pro-social behaviors can be fostered (Beutler, 2008; Coakley, 2011; Gould \& Carson, 2008). The current literature review will lay the foundation to justify a sport-based life skills development program for youth in eSwatini, where youth face significant challenges that impede their ability to create meaningful lives for themselves. The literature review will begin by introducing the youth development context in eSwatini and the significant community challenges that youth face. This will be followed by an exploration of current youth sport participation in eSwatini. Next, a critical evaluation will be presented of the value of sport-based youth development (SBYD) programs in facilitating positive developmental and life skills outcomes on a global scale. A brief description will then be provided of the SBYD initiatives in eSwatini and South Africa. Later, the focus will shift to describing the role of 
coaches in successfully developing and implementing SBYD programming both in Southern Africa and around the world. In addition, research outlining the strengths and weaknesses of SBYD programming grounded in the Teaching Personal and Social Responsibility (TPSR) model will be presented and explored as a potential framework for the current study's SBYD program proposal. Last, a theoretical framework to ground the systematic development of the dissertation intervention study will be explored.

\section{Youth, development, and sport: eSwatini context}

Youth and adolescents, aged 10 to 24 years old, make up 1.8 billion of the world's population of 7.8 billion people (UNFPA, 2015; UN 2017). The largest concentration of these young people live in developing countries where they often make up the majority of the population (UNFPA, 2015). Adolescence is an important developmental time where many biological, psychosocial, and emotional changes take place (Holt, 2008). Successfully navigating these changes is an integral process in helping young people transition into adulthood and determining quality of life (Fatusi \& Hindin, 2010; Holt, 2008). However, over the past 25 years, the experience of adolescence has shifted as the global landscape has transformed and major health challenges such as HIV/AIDS have become much more acute (Fatusi \& Hindin, 2010). Globally, adolescents and youth populations are at a significantly higher risk for mortality and health challenges; a trend that is concerning given the historically good health of populations in this age group. A large proportion of these health challenges and mortality rates are most prevalent for youth in sub-Saharan Africa. Thus, for youth in these areas of the world where larger individual and structural-level health and developmental challenges are present, successfully transitioning to adulthood is an even more difficult process. For these groups of young people, increased focus needs to be placed on not only helping them reduce risky health 
behaviors, but more importantly developing the social skills, competencies, values, and behaviors to successfully navigate this transition (Fatusi \& Hindin, 2010).

In the Kingdom of eSwatini (formerly known as Swaziland), a small country in SubSaharan Africa, approximately half of the population is younger than 20 years old and $36 \%$ of the population is between the ages of 10-24 years (WHO, 2013; Mavundla, Dlamini, Nyoni, \& Mac-Ikemenjima, 2015). While youth in eSwatini struggle with the more widespread challenges associated with adolescence such as social identity and peer pressure, emaSwati youth are also faced with major context-specific challenges. A recent unpublished study examined youth perspectives of the most salient challenges that Swazi youth face in their communities (Huysmans, Clement, Hilliard, \& Hansell, 2017). Youth aged 15 to 24 years $(N=112,50$ males and 62 females) participated in focus groups $(M=50.4 \mathrm{~min})$ at two purposively sampled high schools in the Lobamba area of eSwatini. Preliminary findings indicated that youth struggled with normal adolescent challenges such as relationships, bullying, peer pressure, and low selfesteem. However, youth also described more significant challenges such as lack of resources like water and clothing, teenage pregnancy, unemployment, crime, and exposure to drugs and alcohol. Additional challenges included low parental support, few adult mentors (i.e. parents or teachers) to talk to about their problems, having no voice in the community, risk for HIV/AIDS infection, and high levels of poverty (Huysmans et al., 2017).

The major resource and health challenges such as poverty and unemployment identified by the youth in this study support data from national consensus reports (Mavundla et al., 2015; Ministry of Sports, Culture and Youth Affairs, 2015). Specifically, almost two-thirds of the population (63\%) lives below the poverty line and the vast majority of youth (70\%) lives in the rural areas of the country where poverty rates are highest (Mavundla et al., 2015). This operates 
in conjunction with high youth unemployment at $42.6 \%$ of $15-24$ year-olds and poor attendance rates $(50 \%)$ of secondary school-aged youth (Ministry of Sports, Culture and Youth Affairs, 2015). Further, gender-based violence rates are high with $80 \%$ of women reporting physical or sexual abuse (Mavundla et al., 2015). Even more concerning is the pervasive perception of male sexual dominance amongst young men as well as the belief that under certain circumstances men are justified in beating their wives (Mavundla et al., 2015).

Youth in eSwatini are also at risk for significant health problems that include but are not limited to tuberculosis, malaria, and HIV/AIDS (Mavundla et al., 2015). With an adult (15-49 years old) HIV/AIDS prevalence rate of 27.2\% [24.9-29.1] (UNAIDS, 2016), eSwatini has the highest burden of HIV/AIDS infection in the world. There are also almost 9,000 new infections every year (AVERT, 2016). Notably, in the sub-Saharan region in general, the prevalence of HIV increases steeply in youth between the ages of 15 and 24 (AVERT, 2014; Kasedde, Luo, McClure \& Chandan, 2013; Macphail, Pettifor, \& Rees, 2007). Within this youth population, young women are particularly vulnerable and are becoming infected at a faster rate than young men (Cowan \& Pettifor, 2009; Dellar, Dlamini, \& Karim, 2015; Harrison, 2008; Kasiram, Ngcobo, Oliphant, \& Roestenburg, 2013). In eSwatini, HIV prevalence is $17.6 \%$ [8.9-24.7\%] in young women aged 15-24 and 3.8\% [1.8-5.5] in young men (UNAIDS, 2016).

The HIV/AIDS epidemic in eSwatini is concerning from a youth development perspective because it has had a wide range of physical, psychological, social, and economic effects on the lives of young people in the country (Foster \& Williamson, 2000). The death of a substantial percentage of adults living with HIV/AIDS has resulted in over 230, 000 orphans and vulnerable children (OVC's) in eSwatini (AVERT, 2014). These OVC's account for almost half of individuals under the age of 18 (AVERT, 2014). At the household and community level, the 
impact of the prolonged illness or death of a parent, who is the primary breadwinner, can be the beginning of an inescapable cycle of poverty for children as well as an additional burden of care (Foster \& Williamson, 2000). Children become responsible for all household duties in addition to the care of the sick parent, which results in many of them dropping out of school and experiencing increased financial stressors (Foster \& Williamson, 2000). This is exacerbated by the fact that these communities are often already poor to begin with. Susceptibility to new HIV infection is also twice as high in HIV/AIDS orphans compared to non-orphaned youth (Operario, Underhill, Chuong \& Cluver, 2011).

The fact that $50 \%$ of the Swazi population is below the age of 20 years old and almost half of youth are OVC's is a direct result of the HIV/AIDS epidemic and the death of a significant proportion of adults when the virus first emerged (AVERT, 2014). The scale of this youth demographic is concerning because these young people are growing up without the adult mentorship and guidance needed to create healthy and meaningful lives for themselves. Rather, this youth group is moving into adulthood having experienced significant developmental trauma or adverse childhood events (ACE). This is concerning because ACE's have been linked to greater risk for prevalent diseases (e.g. heart disease, sexually transmitted diseases, HIV/AIDS), mental health issues, poor markers of sexual reproductive health (e.g. teenage pregnancy, early sexual debut), and general social and health problems (stress, relationships problems, low job productivity) (Anda, Butchart, Felitti, \& Brown, 2010; Felitti et al., 1998). Over the next decade this youth demographic in eSwatini will become the working age population and will be relied upon to be the largest contributors to the future of the country. Consequently, the healthy development and adult mentorship of eSwatini's youth and adolescent population should be a high priority. 
To address these developmental needs and concerns of young people in eSwatini, there are a range of youth participation structures that operate at the governmental and community level to support youth affairs (Mavundla et al., 2015; Ministry of Sports, Culture and Youth Affairs, 2015). The Ministry of Sports, Culture and Youth Affairs (MSCYA) was established in 2008 to help create access and opportunities for young people to contribute to the community. The MSCYA oversees and provides support to the eSwatini National Youth Council (SNYC), which is in charge of coordinating the implementation of all youth development and empowerment programming. The aims of the SNYC are capacity building, promoting selfreliance, and improving health and education for youth. Specifically, the SNYC organizes youth programming at the local and national level through building capacity of partner associations that are in charge of implementing these programs (Mavundla et al., 2015; Ministry of Sports, Culture and Youth Affairs, 2015).

Other structures that support youth development include the Tinkhundla Youth Committees (TYC), the Youth Development Consortium (YDC), and the eSwatini National Union of Students (SNUS) (Mavundla et al., 2015). The TYC's operate at the grassroots and community level in each of the 55 constituencies of eSwatini and are directly responsible for running community level youth programs. The YDC is composed of Non-Governmental Organizations (NGO's) that are led by youth or directly serve youth needs in eSwatini. The YDC provides NGO's with a platform to provide input on best practices and constraints to youth program implementation from their work with youth development programming that can then inform policy. Finally, SNUS is a student-led group at the University of eSwatini that advocates for the rights and welfare of young people through organized protest and lobbying. However, this group has been met with strong resistance from the government and the police as public dissent 
is not condoned across the country (Mavundla et al., 2015; Ministry of Sports, Culture and Youth Affairs, 2015).

All these youth structures in some way or other either deliver youth programming, help inform youth policy, or advocate for the rights and welfare of youth. However, despite the existence of these youth participation structures, many youth feel that they cannot connect to these efforts because their opinions and voice are not actively considered in the design of these initiatives (Mavundla et al., 2015). Furthermore, although these youth programs exist, youth participation in these structures and in decision-making for youth policy is restricted by strong cultural beliefs that youth should be seen but not heard. Consequently, the responsiveness of policies and resources to address the needs of young people is lowered. In addition, despite increased efforts to implement policies and programming for youth in eSwatini, the reality is that youth continue to face significant challenges in health, education, and employment domains (Mavundla et al., 2015; Ministry of Sports, Culture and Youth Affairs, 2015). Therefore, there continues to be a great need to find better ways to support the healthy development of youth in eSwatini. Moreover, the gap between provision and adoption of youth services suggests that there is a need to find ways to engage youth in their own development through creative, fun, and intentional programming.

Sport-based youth development programming may be one avenue through which to achieve this goal (Beutler, 2008). Sport is seen as an appropriate vehicle through which to deliver youth development initiatives because it is an engaging and well-liked avenue for development, health promotion, and behavior change in adolescents (Kaufman, Spencer, \& Ross, 2013). It is also valued as an innovative, practical, and cost-effective tool for development (Beutler, 2008). Anecdotally, in eSwatini and in many countries across the continent of Africa, 
youth sport and especially soccer is beloved. A common image in the most remote areas of eSwatini is one of a group of young children playing joyously and energetically with a "soccer ball" made of plastic bags tightly knotted together to make a ball. Surveillance data support youth sport participation rates in eSwatini and in Africa in general is, however, lacking (Hulteen et al., 2016).

Data from two peer-reviewed studies and one unpublished study do help shed some light on the youth sport experience in eSwatini. In the previously described unpublished study by Huysmans and colleagues (2017), youth recognized a variety of benefits of sport participation. Both female and male participants reported the value of sport participation for health and fitness, distraction from crime/drugs/alcohol, enjoyment, friendship, relaxation, and learning of life skills. However, they also reported that youth sport is not prioritized in eSwatini, that there is low parental support for sport participation as it can be a distraction from school, and that there is limited funding for equipment and facilities. In addition, female participants stated that girls are not given as much freedom to participate in sport, that responsibilities at home prevent sport participation, and that there is very low community support for female participation in sport (Huysmans et al., 2017). Therefore, despite youth awareness of the positive benefits of sport participation, there are significant systemic and cultural barriers that limit youth sport participation, especially for girls.

Ndlangamandla, Burnett and Roux (2012) examined attitudes toward physical education (PE) and sport participation in students $(N=405)$ in grades 6,9 , and 11 , teachers $(N=66)$, and principals $(N=68)$ at 80 schools around eSwatini. Student participants were randomly selected at the participating schools and were given a descriptive quantitative survey that they could complete over the course of a week. The authors did not provide any further details about the 
survey although several sample statements were provided for the questions addressing attitudes toward PE and sport. Statements were assessed using a Likert scale ranging from "strongly agree" to "strong disagree" and included: "Sports is fun." "We are taught of the importance of sports." "Sports are good for our health." "Sports should be played by everyone." (Ndlangamandla et al., 2012).

Findings indicated that the main sports played at school were soccer, netball and athletics (Ndlangamandla et al., 2012). Although 93\% of students reported enjoying sport and held positive attitudes toward sport and its health benefits, only $21.2 \%$ of students actually participated in sport or PE at school. Further, female participation in sport was generally low and was restricted to netball. In terms of resources to support sport participation, almost all the schools had at least one sport facility. However, most of these facilities catered to only one sport, usually soccer, netball or athletics, and there were no multipurpose facilities or indoor facilities. Lack of equipment, funding, and facilities were the biggest barriers against sport participation as well as buy-in from staff members to promote sport participation. In addition, gender differences in sport participation were hypothesized to be a product of offering mostly male-dominated sports at school as well as a lack of female sport teachers. The authors concluded that low participation in school sports in eSwatini could be addressed by promoting "sport for all programming" that emphasizes the recreational role of sport for young people. Investing in physical and personnel resources would also positively contribute to this goal (Ndlangamandla et al., 2012).

A second study of PE and sport participation in schools explored youth ( $n=225$ male, $n=180$ female) perceptions of physical education and school sport (PESS) in 5 primary and secondary schools in the Mbabane, Piggs Peak, and Manzini areas of eSwatini (Toriola, 2010). 
Participants aged 6-10, 11-14 and 15+ years old completed a modified version of the Sport in Education (Spin Ed) questionnaire (SpinEd; Bailey \& Dismore, 2005). The SPinEd explores perceptions of PE and school sport, relative importance of PESS to other school subjects, and feelings toward PESS. Results supported youth enjoyment of PESS (87\%) regardless of gender, although males (92\%) reported slightly higher positive perceptions of PESS than females (81\%) and female enjoyment also decreased with age i.e. $49 \%$ reported enjoyment of PESS in 6-10year-olds while only $12 \%$ reported enjoyment in $15+$ year-olds. Girls (44.2\%) were also more likely to perceive themselves as less competent in PESS than the boys (26\%). Similar to the enjoyment data, older girls perceived themselves as less competent than younger girls ( $58 \%$ in 15+ year-olds versus 9\% in 6-10-year-olds) (Toriola, 2010).

Both genders reported similar reasons for PESS participation including affective reasons such as increases in mood and happiness, and emotion regulation (Toriola, 2010). Students also reported lifestyle reasons such as fitness and weight maintenance. Last, youth reported that Science, Mathematics, and English were much more important in school than PE and sport, which may be reflective of the fact that PESS is not compulsory in Swazi schools. The authors discussed the role that a culture of male dominance combined with a lack of female role models in sport may play in female youth perceptions of sport competence and perceptions of PESS. Sport programming should consider including a variety of activities that accommodate varying skill levels such that females feel more confident to participate and enjoy PESS (Toriola, 2010). It is also noteworthy that students did not report social reasons (pro-social development and social connection) for participating in sport. This might be reflective of a youth sport environment that does not emphasize the value of the sport setting for personal and social development. 
Findings from the aforementioned research, consensus data, and national reports provide valuable insights and implications for future initiatives seeking to use sport as a platform for youth development in eSwatini. First, youth in eSwatini face significant challenges over and above the emotional, psychosocial, and physical changes associated with normal adolescent development. In a country where almost half of the population falls into this youth age group, investing resources and research efforts into developing programming that is impactful for youth is justified and necessary. Although there are existing governmental and grassroots structures that target youth development, youth continue to face significant challenges to their health and well-being, which points to the need for alternative approaches to youth development.

Second, the overall positive perceptions of youth toward PE and sport indicates that sport may be an appropriate site for youth development efforts because it will likely be a successful hook to draw youth in and engage them in skill-building and character development. Moreover, Swazi youth recognize that sport may be a fun and enjoyable activity where youth can experience a range of positive developmental outcomes including life skills learning, friendship, health, and fitness. However, gender differences in positive perceptions toward sport and sport competency, low community support for female engagement in sport, as well as declines in sport participation with age will need to be addressed.

Questions need to be asked about how youth sport programming can create more accessible and appealing sport opportunities for girls with special consideration of how sport competency and enjoyment can be fostered. In addition, as the statistics indicated, many youth are not in fact in school and therefore cannot benefit from school-based youth sport initiatives. Further, the lack of equipment and facilities points to the need to allocate program funding to this area and also direct efforts toward structural and policy level changes that promote a greater 
national focus on youth sport participation. In order to design effective sport-based youth development programs in eSwatini, evidence might be drawn from programs implemented elsewhere on the African continent and around the world.

\section{Sport for development and peace}

On a global scale, sport has been adopted as a possible vehicle for youth development (Schulenkorf et al., 2016). This is reflected in the proliferation of sport for development and peace (SFD) programming and specifically youth-focused SFD programming over the last decade (Schulenkorf et al., 2016). Svensson and Woods (2017) review of SFD programming indicates that there are 944 organizations operating in 121 countries around the world. The growth of sport as a tool for global development has been supported and encouraged by several prominent organizations. Specifically, the United Nations and the Commonwealth have been leaders in promoting global policy for the role of sport in development (Lindsey \& Chapman, 2017). Recently in the United Nations 2030 Agenda for Sustainable Development, special emphasis was placed on creating healthy environments that promote the health, well-being, and positive development of young people (Lindsey \& Chapman, 2017). Notably, sport was formally recognized as a tool to facilitate this social and personal development of youth (Lindsey \& Chapman, 2017). The United Nations identified:

" the growing contribution of sport to the realization of development and peace in its promotion of tolerance and respect and the contributions it makes to the empowerment of women and of young people, individuals and communities as well as to health, education and social inclusion objectives.

(UNGA 2015, para. 37, 10) 
The role of sport in youth development is conceptualized as a "fertilizer" (Coakley, 2011, p.208) that can create the right environment to help young people cultivate socially desirable skills that all young people have the innate potential to develop (Coakley, 2011). When youth have positive experiences in their sport participation, sport has the potential to positively impact not only performance outcomes and future sport participation but may also contribute to personal development (Côté \& Hancock, 2016). Research supports the impact of sport on personal development in areas such as self-esteem, physical and social competence (Wagnsson, Augustsson, Patriksson, 2013), character development, pro-social engagement, and social capital of young people (Coakley, 2011). It also exposes youth to positive role models, social connections, future-thinking and dreams, and constructive environments that can help them grow into civically engaged and conscientious adults (Beutler, 2008; Coakley, 2011). For socially vulnerable populations, sport participation can also help youth develop the life skills needed to overcome the challenges of everyday life and "succeed in the different environments in which they live, such as school, home and in their neighborhoods" (Danish, Forneris, Hodge, \& Heke, 2004, p.40). Specifically, life skills may be important for socially vulnerable youth to develop due to the increased likelihood that they face stressors, mental health issues, and social isolation (Hermens, Super, Verkooijen, \& Koelen, 2017). Competitive sport experiences for youth populations who have experienced significant developmental trauma (i.e. ACE's) have also been identified as contexts to support positive developmental outcomes (Whitley, Massey, \& Wilkison, 2018). Specifically, consistent sport participation where youth are also exposed to opportunities for competition and intense physicality has been found to help youth "connect the physical and emotional selves" (Whitley et al., 2018, p. 120) in a space where that type of expression in socially accepted. Competitive youth sport can therefore serve as a physical and 
mental escape from the lived experiences of youth athletes who have experienced trauma. It is also a space where youth can observe tangible improvements in their own physical competence, which fosters continual sport engagement and a sense of competency (Whitley et al., 2018).

Embedding life skills into physical activity and sport programs to target the development of under-served, at-risk, and socially vulnerable youth is an area of SFD programming that has also grown exponentially in recent years (Hellison, 2011; Martinek \& Hellison, 2016; Svensson \& Woods, 2017). Life skills are generally categorized as cognitive, emotional, and social life skills (Hermens et al. 2017). Emotional life skills are skills related to self-worth and mental health. Cognitive life skills refer to self-regulation, impulse control, and decision-making abilities while social life skills are interpersonal skills such as communication, social responsibility, and empathy. A multitude of studies support the role of youth sport participation in life skills development in all three of these domains primarily for normal adolescent development but increasingly so for socially vulnerable or at-risk youth (Camiré, Trudel, \& Bernard, 2013; Danish, Forneris, \& Wallace, 2005; Gould \& Carson, 2008; Gould, Collins, Lauer, \& Chung, 2007; Hermens et al., 2017; Holt \& Neely, 2011; Holt et al., 2017; Martinek \& Hellison, 2016).

For socially vulnerable and at-risk youth in developing areas of the world such as subSaharan Africa, a sizeable number of SFD programs have focused on helping youth develop the life skills necessary to promote health behaviors and prevent infection of communicable diseases such as HIV/AIDS. In Mauritius and Zimbabwe, '11 for Health' aimed to deliver health promotion messages and promote health-related life skills behaviors through soccer (Fuller, Junge, Dorasami, DeCelles, \& Dvorak, 2011). The soccer-based intervention was composed of eleven 90-minute sessions that were divided into two 45-minute halves: one session focused on 
teaching soccer skills and one session focused on a health promotion message. The health promotion messages centered on topics surrounding HIV/AIDS prevention, substance use, sanitation, nutrition, benefits of exercise, respect for girls, and fair play. Two coaches (one male and one female) implemented each session to groups of approximately 20 boys and girls. The coaches participated in a 5-day training and received an implementation manual. Additional details about the training program and manual were not provided by the authors. The program in Mauritius was delivered as an in-school program to adolescents aged $12-15$ years $(N=389)$ while the program in Zimbabwe was an out-of-school program delivered to adolescents aged 10-14 years $(N=395)$. Pre- and post-intervention, children were asked to complete a 30 -item health questionnaire that prompted 'true', 'false', or 'I don't know' fixed responses to health statements. These included statements such as, "It is important for boys to listen to girls", "Playing football will help to keep me healthy", "Mosquitos spread malaria", and "It is my choice whether or not I take drugs" (Fuller et al., 2011).

Results indicated that health knowledge was $17.8 \%$ higher in Mauritius and $18.4 \%$ higher in Zimbabwe than at baseline and was consistent across genders (Fuller et al., 2011). In addition, the program was well-liked by the participants as indicated by a greater than $88 \%$ agreement (across both genders and countries) that the sessions were enjoyable and easy to understand and that the program would be recommended to a friend (Fuller et al., 2011). Overall this study provided support for the use of soccer as a well-liked platform for health knowledge promotion for adolescents both in school and out of school. However, although the study aimed to reduce youth risk for communicable diseases and health-related issues, the study did not include an assessment of actual health behaviors or life skills that might contribute to engaging in healthy behaviors. Moreover, health-related knowledge does not necessarily translate to adoption of 
health-related behaviors. Future studies should therefore include program components that provide an opportunity for health-related life skills to be practiced and for discussions to take place that explore how these skills can be translated to health behaviors outside of the program setting. In addition, more rigorous monitoring evaluation approaches that use mixed-methods designs could help triangulate observations from multiple sources to generate more robust findings.

Other programs in sub-Saharan Africa that focus on teaching health-related life skills and knowledge include, but are not limited to, the Mathare Youth Sports Association (MYSA) (Delva et al., 2010), Grassroot Soccer (Peacock-Villada, DeCelles, \& Banda, 2007), and Right to Play (Forde, 2014). A strong example of this type of health-related life skills programming that was also grounded in theory and was the Sports For Life (SFL) program in Ethiopia. Sports For Life was developed by the Health Communication Partnership to teach life skills and lower HIV risk in Ethiopian youth (Rajan \& Franca-Koh, 2007). Specifically, SFL aimed to positively impact HIVrelated knowledge, attitudes and behaviors in at-risk youth, enhance group efficacy to address the issue of HIV as well as equip youth with the necessary life skills to make healthy sexual choices. The program was grounded in two theoretical frameworks: 1) the health belief model which states that attitudes about perceived risk and severity, and perceived benefits and barriers to action will affect behavior; and 2) social cognitive theory which delineates how group discussions and role plays can be used to target individual motivation to adopt behavior while life skills activities can be used to promote self-efficacy to perform behavior (Rajan \& Franca-Koh, 2007).

Soccer was the main sporting component of the program and was used to draw youth in (Rajan \& Franca-Koh, 2007). Participatory learning activities were used to teach seventh through eighth graders about knowledge of HIV/AIDS, and life skills to protect against contraction of the 
virus. The curriculum of learning activities sought to promote behavior change through positive role models, developing self-efficacy, encouraging gender equity, and promoting open communication about HIV/AIDS. Discussion groups were composed of a mixture of boys and girls to promote open communication between the sexes. During role plays participants were encouraged to play the role of someone of the opposite sex in order to understand a different perspective. In conjunction with Ministry of Youth Sports and Culture (MYSC) and World Vision (WV), SFL trainers taught the curriculum to PE teachers all around Ethiopia so that it could be implemented in the community as well as in the school systems, in urban and rural areas. Schools were given Champion status and won a prize if they successfully completed the curriculum (Rajan \& Franca-Koh, 2007).

Program evaluation was composed of both qualitative and quantitative components; surveys and interviews (Rajan \& Franca-Koh, 2007). A survey was administered at baseline and directly after the intervention (i.e. 1 year later) while interviews were conducted solely postintervention. The survey addressed knowledge about HIV/AIDS, sexual health behavior, and life skills such as communication, decision-making, self-confidence, goal setting and resistance to peer pressure. The interviews gathered in-depth information about the experience of leaders, parents and participants of the program. Interviews were conducted with 24 participants, 6 leaders and 6 parents across 6 schools in the regions of Amhara and Oromiya (Rajan \& Franca-Koh, 2007).

Evaluation results indicated that there was generally a positive attitude about the program from teachers, parents, and participants (Rajan \& Franca-Koh, 2007). Findings supported the program's impact on increasing knowledge of HIV transmission, correcting misconceptions about HIV risk and transmission, and positively shifting attitudes concerning faithfulness. Additional 
results included higher condom use and HIV testing, and lower stigma against people living with HIV/AIDS (PLHA's). Parents reported that the program helped improve their children's selfefficacy concerning protecting themselves against HIV although the participants were less verbal about SFL's impact on their self-efficacy. Program members also felt that participating in SFL allowed them to become valuable resources for the community in terms of HIV knowledge and prevention, thereby promoting group self-efficacy in the fight against HIV/AIDS. Parents also reported that they learned new HIV-related information from their children. Additionally, the program had clear impacts on participant life skill development including improved communication skills about HIV, and increased ability to handle peer pressure concerning unsafe sexual practices. Participants also reported more confidence and thoughtfulness related to decision-making, greater openness to the perspectives of others, and better relationships with parents (Rajan \& Franca-Koh, 2007).

This program illustrated the value of implementing sport programs within school systems in order to impact HIV prevention and promote life skill development (Rajan \& Franca-Koh, 2007). Youth at school are a captive audience that allows for youth development programming to more easily reach target demographics and make a positive impact. However, a large proportion of youth in these developing areas, as is the case in eSwatini, are not in fact in school so future programs should consider using a two-pronged approach that targets both in-and-out of school youth. An additional strength of the program was the involvement of parents in program evaluation. Health promotion and life skills development through sport does not mean much if youth are not able to transfer these skills to other domains including community and home life (Jacobs, Ivy, Lawson, \& Richards, 2017). Exploring parents' perceptions of youth transfer of 
knowledge to life at home provided evidence for some of that transfer of knowledge and should be considered in future studies.

An additional youth health promotion and life skills development program that has shown promise on the African continent is Kicking AIDS Out (KAO) (Kruse, 2006). Kicking AIDS Out began as a social change initiative that combined sport activities with HIV/AIDS prevention and life skills-building interventions in Zambia. It has since expanded to multiple other countries including Tanzania, Kenya, Zimbabwe, and South Africa. The overall goal of KAO is to promote empowerment, fair play and cooperation, as well as the development of leadership skills and self-esteem in African youth. Each session had a life skills objective (LSO) as well as a sport skills objective (SSO). For example, the LSO may be to understand the HIV prevalence rate in Lusaka while the SSO may be to learn how to change direction quickly while sprinting. Each session could be either an independent LSO or SSO session or an integrated session (Kruse, 2006).

To assess impact of the KAO program in Lusaka, surveys were administered to equal numbers of 14-18-year-old youth KAO participants $(n=40)$ as well as non-participants $(n=40)$. Program participants had been in KAO for between 6 months to one year. The survey consisted of 38 questions addressing 3 areas: knowledge about HIV/AIDS, self-assertiveness and life skills, and stigma towards HIV/AIDS. A secondary source of evaluative information used interviews to draw on observations made by members of the organizations involved (Kruse, 2006).

Findings indicated that that although there was no difference in HIV/AIDS knowledge and stigma between the control and KAO group, boys and girls who participated in the KAO sessions felt greater confidence in their ability to say no to sex and make independent decisions 
(92.5\% vs.40\%) (Kruse, 2006). This may in fact be more important than the gaining of additional HIV/AIDS knowledge given that life skills such as decision-making and confidence are key factors in the prevention of HIV/AIDS transmission. Other positive impacts included increasing the number of girls participating in the KAO programs, improving self-confidence, and reducing stigma toward persons living with HIV/AIDS (Kruse, 2006).

Kruse (2006) concluded that the combination of sporting activities with HIV prevention education and life skills development was a promising direction given the success that was achieved over a small amount of time. However, KAO was dependent on funding from the Norwegian Confederation of Sport (NIF) which raised questions about sustainability. Future programs would need to consider how this challenge might be addressed. Secondly, KAO did not manage to collaborate with other NGO's in the area that were also involved in HIV prevention and youth development programming. Grounding sport for development programs in wider community outreach initiatives and increasing collaborative efforts may strengthen the impact of these programs in youth development (Hartmann, 2003; SDPIWG, 2008).

Although sport-based life skills development programs for socially vulnerable youth have shown promise on a global level, many of these programs are not as effective as they could be. Sport for development programs too often erroneously adopt an idealistic view of sport participation without considering the reality that sport does not automatically result in positive life skills learning and it may in fact lead to negative outcomes (Svensson \& Woods, 2017). As Coakley (2011) stated, "by itself, the act of sport participation among young people leads to no regularly identifiable developmental outcomes.” (p. 309). Positive development outcomes associated with sport are contingent upon a wide range of factors and include but are not limited to the culture of the sport environment, the social connections established during sport 
participation, meaning and values associated with sport participation, and whether the youth athlete feels physically safe and valued (Coakley, 2011). Research indicates that intentional life skills learning activities need to be provided where youth can practice the life skills that are being emphasized and also explore how these skills can be transferred to domains outside of the sport setting (Hermens et al., 2017). Furthermore, the role of the coach has been emphasized in terms of the extent to which they explicitly teach their athletes to take responsibility for their own well-being and that of others (Coakley, 2011). In addition, research underlines the degree to which they establish positive coach-athlete relationships and a caring and supportive peer environment (Hermens et al., 2017).

Other concerns about life skills and SFD programming include the need for more rigorous monitoring and evaluation research (Coalter, 2015; Levermore, 2011; Spaaij, 2009; Schulenkorf et al., 2016). Anecdotal evidence for the efficacy of SFD and life skills programming has been over-relied on and the consequence is that resources and funding are being funneled into programs that may not even be effective. In addition, evaluation efforts also need to ensure that the methodologies and processes employed are culturally appropriate and locally informed (Whitley, Forneris, \& Barker, 2014). That is, there is strong criticism of the topdown, neo-colonialist approach that many SFD organizations take in determining the "need" and developmental outcomes that programming should address (Hartmann \& Kwauk, 2011; Spaaij, 2009). This approach ignores the local knowledge that could inform more effective programming and create stronger shared ownership of community development. It also often fails to acknowledge that development is a contextual definition. A top-down approach also reinforces the power dynamics that often exist between researchers and members of the local community (Whitley et al., 2014). Researchers need to prioritize collaborative efforts that include transfer of 
ownership to members of the community. The identification of culturally-specific competencies that may be developed through sport therefore warrants continued exploration. As Whitley and colleagues (2017) stated, the contribution of sport for development, and specifically in youth life skills development in under-resourced and under-privileged contexts, is complex. It requires that conscious efforts be made to explore the youth sport experience in those contexts and specifically the meaning they create about their sport experience (Whitley, Massey, Darnell, \& Smith, 2017).

Finally, SFD as a field has for a very long time been criticized for the limited use of theory in informing the design and implementation of youth sport programs (Coalter, 2007; Coalter, 2015; Hartmann, 2003; Roth \& Brooks-Gunn, 2016). As Coalter (2015, p.20) stated, a program theory identifies "the components, mechanisms, relationships and sequences of causes and effects which programme providers presume lead to desired impacts and outcomes - $\mathrm{a}$ theory of value, attitude and behaviour change." Thus, grounding youth programs in theory helps to explain the processes and sufficient conditions that lead to maximum program impact. Across the field of youth development in general there continues to be a lack of consensus and clarity surrounding the critical components and sufficient conditions that most effectively lead to positive developmental outcomes (Roth \& Brooks-Gunn, 2016).

However, over the past decade stronger efforts have been made to ground SFD programs in theory. A range of theories have been used to guide the development of such programming (Schulenkorf et al. 2016). According to Schulenkorf and colleagues' (2016) review, two of the most cited theoretical frameworks are social capital theory and positive youth development. Other theories include but are not limited to social cognitive theory, social inclusion theory, sport for development and peace (Schulenkorf et al., 2016), and Freire's critical pedagogy (Spaaij \& 
Jeanes, 2016). An attempt has also been made to create an overarching sport for development theory (SFDT) that delineates the organizational and environmental conditions necessary to create a quality youth sport experience (Lyras \& Peachey, 2011).

In addition, researchers have also advocated for taking a more systems theory approach to SFD programs (Massey, Whitley, Blom, \& Gernstein, 2015). A systems theory approach explores how macro-level structures in society (e.g. community norms, organizational structures, policies, laws etc.) prevent SFD programs from affecting long-term and systemic changes in society and vice versa. That is, a systems theory framework also considers how an SFD program could be designed to impact structural factors in society (Massey et al., 2015). This systems theory lens recognizes that a young adult's ability to become successful and "transform themselves" does not lie completely within their own control (Coakley, 2011). Personal development of youth needs to be combined with community development and social change (Coakley, 2011). Future SFD initiatives should carefully consider how to ground the design and implementation of their program in theory in order to identify the critical components and sufficient conditions that will lead to positive youth outcomes.

In summary, policy and funding support for sport-based youth development programs continues to grow on a global scale (Svensson \& Woods, 2017). Investment in these youth initiatives stems from the capacity for sport to provide experiences for young people to develop prosocial behaviors, build character, and facilitate life skills learning in social, emotional, and cognitive domains. For socially vulnerable youth in sub-Saharan Africa, sport has been co-opted as a platform for health promotion and health-related life skills development predominantly in relation to preventing communicable diseases such as HIV/AIDS. These programs have shown some success in increasing knowledge and attitudes related to health promotion as well as some 
increases in life skills such as communication, resisting peer pressure, and decision-making. However, there is a need for stronger monitoring and evaluation, intentional and theory-driven programming, and collaborative efforts between researchers and communities especially in Southern Africa where youth face significant developmental challenges. The next section will explore research focusing on sport for development and youth life skills programming in South Africa and eSwatini.

\section{Sport for development in South Africa and eSwatini}

Sport has the power to change the world. It has the power to unite in a way that little else does. It speaks to youth in a language they can understand. Sport can create hope where once there was only despair. It is more powerful than governments in breaking down racial barriers. It laughs in the face of all types of discrimination.

\section{- Nelson Mandela}

Anecdotally, the power of sport to positively engage young people and contribute to their development is supported in eSwatini. However, there is very limited research evidence to support this belief and also negligible programming that actually uses sport as a platform for life skills development. Some preliminary research conducted by Huysmans and colleagues (2017) does indicate that despite the lack of sport-based life skills programming in eSwatini, Swazi youth do believe that sport participation may help them develop life skills. Using the same methodology described previously, youth perceptions were explored using focus groups with 1524-year-old high school students at two schools in the Lobamba area of eSwatini.

Male youth reported that sport participation helped them develop life skills such as discipline, concentration, commitment, managing emotions, dealing with failure, and team work (Huysmans et al., 2017). They also mentioned skills such as communication, respect for different 
people, responsibility, perseverance, and fair play. Female youth reported the capacity for sport to teach many of the same life skills mentioned by the boys (i.e. discipline, respect, and team work) but also mentioned skills such as self-confidence, hard work, and feeling like they can achieve the same things as boys. Even more importantly, youth reported that sport has the potential to help them overcome some of their developmental and community challenges by serving as a positive distraction and teaching them helpful skills. Youth expressed that sport could help them find peers who share similar struggles, and support them in building confidence and self-esteem to progress through adversity. When asked whether they would be interested in participating in a sport-based youth program that helped them build some of those life skills and also provided a safe space to talk about their concerns, both male and female groups responded positively (Huysmans et al., 2017). These findings provide a good starting point to further explore the potential of sport-based youth life skills development programming in eSwatini.

As far as it is known, one organization in eSwatini is involved in sport-based youth programming; the Sport Success Center (SSC) (McSweeney, 2017). The SSC works under a larger parent organization - the eSwatini multi-games sport association (SMGSA), which is the governing body in charge of developing sport across the country. The main focus of the SMGSA is to support sport organizations that contribute to athlete development at the elite sport level as well as through SFD programming. The SSC is in charge of implementing the SFD programming at the community level although the SMGSA indirectly controls implementation through their regulation of funding, resources, and employment. The central mission of the SSC is to use physical activity to improve the lives of everyone involved with the center. The four main areas of work that are used to achieve this mission are: recreation, sport, education, and self-empowerment (McSweeney, 2017). McSweeney (2017) explored the sport-for-development 
work of the SSC through 4 months of participant observation of the SFD programming run through the SSC. Notably, the main aim of the study was to examine the social relations amongst the members of the organization and its impact on the SFD activities. There was therefore no evaluation of program effectiveness or life skills outcomes.

The SSC runs two SFD initiatives: The Leaders in Training (LIT) and the Life Values Programme (LVP) (McSweeney, 2017). Both of these programs combine sport development (i.e. athlete and coach development for elite sport) and sport-for-development. That is, the LVP program contains modules very specific to developing coaching expertise with some focus on values education while the LIT program focuses on helping youth become leaders and developing their own community-level sport clubs with some focus on life skills education. The LIT program was first created in 2003 and aims to teach young people how to become coach leaders and how to be able to create and manage their own recreation or sport center in the community. The program consists of 10 modules that cover topics surrounding leadership, coaching theory, roles of SSC leaders, organization, sustainability, fun, health and safety, life skills, and future development. The program was designed by two non-Swazi women using information from personal experiences in sport as well as "snippets" from the internet. No consultation with local youth, coaches, or administrators was utilized in the development of the program. The LIT program is supposed to be delivered as a 10-day program at various times during the year and is usually delivered by an intern, who is usually not local. However, during the observational period of McSweeney's (2017) study, LIT programming was usually only a day in length and included only select modules of the original program (McSweeney, 2017).

The LVP program was first created in 2015 and was meant to be a more developed version of the LIT (McSweeney, 2017). Again, a non-Swazi was primarily in charge of 
developing the program content and no advice was solicited from local sources. In the LVP, a similar focus is placed on developing leaders and coaches in the community who can run sport programming, but an additional emphasis is placed on teaching technical coaching expertise i.e. kinesthetics of sport movement, coaching exercises, lesson plans, and nutrition. In addition, instead of including a life skills component, there is a module on values and the six pillars of character: trust, respect, responsibility, caring, community, and fair play. No explanation was provided for why the life skills component was removed. The LVP is also meant to be delivered as a 10-day program but was only implemented as day-long trainings during the 4-month observational period of McSweeney's (2017) study). A second brief application of the LVP modules is also used to teach youth sport activities. This involves a specific focus on the six pillars of character which were intentionally discussed before the sport activity.

Findings from McSweeney's (2017) study indicated that although the LIT and LVP programs are described as SFD programs, very little of the actual program was implemented during the trainings that the author observed. Moreover, very few of the trainings observed during the study focused on the SFD components; the sport development and coaching expertise modules were more often included (McSweeney, 2017). Thus, although the LIT and LVP programs are presented as SFD programs, the implementation of these programs is lacking in their SFD focus. In addition, the design of these programs did not use any input from local youth, coaches, and youth sport stakeholders. Even more concerning is the fact that the main contributing sources of data for the development of the LIT and LVP programs were personal sport experiences and "snippets" from the internet, which provides little evidence for a deliberate, research-based approach to program development. There is currently also no existing 
program evaluation data that could provide evidence for the positive developmental outcomes that result from youth participation in these programs.

Although there is limited SFD programming in eSwatini, South Africa has been a site of significant sport-based youth development and life skills programming. As Svensson and Woods (2017) review of SFD programming indicates, there are 383 SFD organizations operating in Africa, and South Africa is one of the most common sites for these programs. However, despite the multitude of SFD organizations operating in this area, relatively little research has focused on life skills development through sport (Whitley, Wright, \& Gould, 2016). More recent studies have explored the capacity of sport to help young people overcome community challenges and teach them transferable life competencies (Whitley, Hayden, \& Gould, 2013; 2016).

In the Kayamandi Township of the Western Cape where sport-based youth programming were operating, Whitley and colleagues (2013) conducted semi-structured interviews with athletes $(N=19,11$ males and 8 females $)$, coaches $(N=10,9$ male and 1 female $)$, and community members $(N=11,5$ males and 6 females) to explore the role of sport in developing life skills and overcoming youth challenges (Whitley, Hayden, \& Gould, 2013). Findings indicated that sport helped youth overcome community and developmental challenges such as poor living conditions, major health-related issues, substance use, and crime. Specifically, participation in sport kept youth out of trouble, gave them a reason not to drink, and made them too tired to engage in risky behaviors such as crime and drugs/alcohol. Sport was also seen as a context for positive peer influences through creating a sense of belonging and social support (Whitley, Hayden, \& Gould, 2013).

Using the same methodology and Kayamandi population in South Africa, Whitley, Hayden, and Gould (2016) examined the life skills necessary to live a fulfilling life as well as the 
life skills youth develop through sport participation. They found that ubuntu (respect and caring for others), self-concept (e.g. self-reliance and self-belief), self-discipline (goal setting, selfdiscipline, perseverance), and group skills (e.g. leadership and interpersonal skills) were the most important life skills to develop to live a fulfilling life. Notably, participants stated that these same competencies were also successfully developed through sport participation and were being transferred to non-sport settings (Whitley, Hayden, \& Gould, 2016).

Another noteworthy program is the Buffalo City Soccer School (BCSS) in the Eastern Cape Province of South Africa (Draper \& Coalter, 2016). The program was grounded in objectives to increase perceived self-efficacy and to actively engage youth in their own development. Youth participants were young boys in the Buffalo Flats community ranging in age from under-11 to under 21. All youth participate were a part of a local soccer league that involved 3 days per week of soccer training, weekly matches on Saturdays, and 2 interactive group life skills sessions per week. The soccer trainings were delivered by coaches in the community while the life skills were taught by separate instructors. However, both components of the program were viewed as valuable by both coaches and instructors. The life skills addressed in the interactive sessions aligned strongly with social cognitive theory and included but were not limited to problem solving, teamwork, leadership, goal setting, self-awareness, selfconfidence, interpersonal skills, and decision-making (Draper \& Coalter, 2016).

Brief interviews were conducted with 10 youth participants to evaluate their experiences in BCSS, explore personal development due to the program, and identify the mechanisms that contributed to program effectiveness (Draper \& Coalter, 2016). Participants reported that they had positive experiences in the program specifically due to life skills program, which differentiated their soccer league from other leagues. In addition, youth referred to personal 
development and becoming "a better person" (p.52) as a result of the program. Notably, multiple youth reported that they had improved in several life skills related to self-efficacy i.e. confidence, self-belief, self-discipline, self-esteem, and comfort in their identity. This also included the ability to engage and communicate with others to more effectively address challenges. In addition, youth described increases in their capacity for prioritizing, futurethinking, and making positive decisions for their future. The vast majority of participants also mentioned the sense of family, safety, social connection, and belonging that they felt with their BCSS peers and staff. Importantly, youth commented that they appreciated that BCSS staff cared more about their character development and educational investment than their soccer performance. The authors concluded that the BCSS program was successful in many domains including life skills development, creating a sense of family and belonging, and cultivating positive social connections (Draper \& Coalter, 2016). In addition, Bandura's (2001) concepts of perceived self-efficacy and agency were appropriate theoretical concepts to ground youth development programming.

In the Eastern and Western Cape of South Africa, youth programming has also been implemented within schools instead of the community. The Mighty Metres program is a schoolbased sport-for-education program implemented in primary schools in impoverished areas of the South African Cape (Burnett, 2014). The primary aim of Might Metres was to help primaryschool aged youth develop healthy daily fitness habits and also promote positive educational outcomes through participating in running sessions. Teachers at the schools helped implement the program by aiding in daily goal-setting of healthy habits and also tracking the mileage of running each week. It was hypothesized that by engaging youth in constructive activities that promoted their health and well-being, there would also be noticeable improvements in youth pro- 
social behaviors and reductions in anti-social behaviors. To assess impact of the program in participating schools, interviews were conducted with leaders or coordinators at the schools, focus groups were conducted with teachers and youth participants, surveys were completed by teachers, and live observations were organized of the running sessions. Positive outcomes of the program at the school level included increases in school attendance, reductions in anti-social behavior, and a positive image of the schools as healthy and physically active learning environments. For the teachers and youth, the program helped strengthen a trusting teacher-youth relationship, improved physical fitness and enjoyment of physical activity, increased alertness in class, and facilitated positive recognition from parents for their involvement in the program. Notably, gender differences were observed with female youth reporting greater appreciation for the opportunity to be physically active and to learn how to be disciplined and behave in a prosocial way (Burnett, 2014). Within contexts where females do not have as many opportunities to participate in sport, structured programming such as Mighty Metres that facilitates female sport participation may be especially positive and well-received.

The findings from the aforementioned studies support the role of sport participation in youth life skills development and positive youth sport experiences in underserved communities in South Africa (Burnett, 2014; Draper \& Coalter, 2016; Whitley, Hayden, \& Gould, 2013; Whitley, Hayden, \& Gould, 2016). Notably, evidence is provided for the facilitative role of coaches (i.e. adult mentors) in helping youth develop competencies that aid them in successfully navigating the developing challenges of their everyday lives. The results from these studies emphasize the need for continued research in these non-Western contexts to explore which life skills are most valuable to develop. Continued exploration of the programming strategies that are most likely to promote positive developmental outcomes is also warranted. In addition, although 
these findings are promising, the youth participants in these studies were primarily athletes. It is therefore possible that non-athlete youth do not subscribe to the same beliefs regarding the capacity of sport to develop life skills that help in overcoming community challenges. Further, the findings from these studies relied on participant self-report, which can be biased. Future programs should consider including both youth athletes and non-athletes in programming to evaluate youth SFD programming and should also triangulate self-report data with observational data.

The work of SFD and life skills programming in South Africa presents an opportunity for learning in terms of best-practices for potential life skills programs in eSwatini. Burnett (2010) presented recommendations for programming based on the work of three SFD initiatives operating in South Africa: 1) The School Sport Mass Participation Programme, which has been implemented in schools at the national level across South Africa; 2) The Active community clubs which operates at the community level in several provinces in South Africa; and 3) The GTZ Youth Development through Football which partners with NGO's and municipal structures across the country to promote development. Recommendations for future programs included engaging governmental structures to mobilize funding and resources for sport programs according to national youth priorities and including sports that are not traditionally 'male sports' to promote sport participation across genders. The author also suggested involving the community in a participatory action framework that allows ownership to be taken of programming (Burnett, 2010).

Sanders, Phillips, and Vanreusel (2014) added that if SFD programs aim to use the school setting, special efforts must be made to establish strong relationships between the SFD program and the school staff and involve teachers in integrating sport into the daily school curriculum. 
Efforts can also be made to engage governmental bodies in raising the value placed on including sport in school curricula. This may be especially relevant in eSwatini where physical education is not required in school (Toriola, 2010). When working in under-served youth populations, Whitley, Hayden, and Gould (2013) suggest first attending to basic human needs such as hunger and thirst by providing food and water. They also recommend providing sport equipment and transportation funding and providing opportunities for engagement in a wide range of sports (not only the most popular ones or the male-dominated sports). Partnering with other community initiatives to widen the circle of positive influence on youth development is also suggested. In addition, the authors concluded that if coaches are going to be co-opted to facilitate SFD programming and life skills development in youth, more funding needs to be directed toward coaching education programs. These programs should include training modules that teach coaches how to integrate life skills programming into sport activities (Whitley, Hayden, Gould, 2013; 2016). In the Southern African and Swazi context, coaches may be appropriate facilitators of youth life skills learning given that mentorship and guidance for healthy development in youth is lacking.

\section{Youth coaching in Southern Africa and eSwatini}

In eSwatini, as far as it is known, no research exists on the role of coaches in facilitating life skills development through sport participation. However, strong literature does exist to support the potential role of the coach within the youth sport development context in North American settings (Gould et al., 2007; Holt et al., 2017; Vella, Oades, \& Crowe, 2011). Moreover, because sport participation does not automatically result in positive developmental outcomes (Coakley, 2011), the people in charge of facilitating youth sport programming become especially important in ensuring life skills learning (Gould et al., 2007). Coaches are the gatekeepers of the 
youth sport experience and are also often viewed by athletes as important mentors in their development (Bean \& Forneris, 2016; Giges, Petitpas, \& Vernacchia, 2004; Gould et al., 2007; Holt et al., 2017; Vella et al., 2011). Coaches are therefore in a unique position to be facilitating life skills development through sport (Gould et al., 2007). Specifically, when the coach is able to foster a caring and supporting sporting environment, personal development and positive developmental outcomes are more likely to occur (Spaaij, 2009; Vella et al., 2011). This is consistent with the positive youth development (PYD) framework that states that every adolescent is capable of positive developmental change but that the interaction between the individual and their sport context will heavily influence their personal development (Holt \& Neely, 2011). This means that the extent to which the coach carefully crafts a nurturing sport environment and includes intentional life skills building activities will determine whether or not youth sport participation results in life skills learning (Bean \& Forneris, 2016; Gould et al., 2007; Holt et al., 2017; Vella et al., 2011).

In South Africa, coaching effectiveness frameworks explicitly outline the role of coaches in engendering outcomes in youth participants that are more holistic than just sport-specific outcomes (International Council for Coaching Excellence, Association of Summer Olympic International Federations, \& Leeds Metropolitan University, 2013). Specifically, coaches should be aiming to develop youth competency in the following three areas: 1) sport competence (sportspecific physical and technical/tactical skills); 2) personal competence (holistic life skills development in social, cognitive, and emotional domains); and 3) life course competence (skills learned in sport contribute positive to the life course of the participant) (International Council for Coaching Excellence, Association of Summer Olympic International Federations, \& Leeds Metropolitan University, 2013). In addition, significant effort has been made over the last decade 
to create a formal South African Coaching Framework that more explicitly outlines the educational programming and training to support South African coaches (Segwaba, Vardhan, \& Duffy, 2014; SASCOC, 2011).

Several studies have explored the role of coaches in youth holistic development through sport in South Africa (Meir, 2017; Whitley, Hayden, \& Gould, 2013; Whitley, Wright, \& Gould, 2016). One example is the Leadership and Empowerment Through Sport (LETS) program in Cape Town (Meir, 2017). The LETS program was developed in response to a challenging youth environment in the country as well as inadequate educational systems to support the development of young people. Specifically, the authors cited challenges related to the national unemployment rate of $50 \%$ for youth under the age of 24 , the $50 \%$ matric pass rate, and the inevitable cycle of poverty that results from lack of education. The authors hypothesized that sport could be a context for youth education and holistic development. Overall, the program aimed to implement programs that contributed to the holistic development of youth as well as the development of future leaders. The program was grounded in social learning theory and structural development theory. Together these theories postulate that youth learning is influenced by their environment and the behaviors of others, as well as their observations of how peers and adult figures behave. Thus, the role of adult figures such as coaches and other leaders were suggested to be valuable in helping young people develop skills and values that would contribute to their meaningful development (Meir, 2017).

Guided by these two primary theories, the LETS program focused on developing programming in two main areas (Meir, 2017): 1) coach education programs; and 2) leadership programs for members of the community. The main objectives of the coach education programs were to teach coaches how to implement values-based youth sport programs that contributed to 
the holistic development of youth sport participants. For the leadership development programs in the community, the objective was to teach community leaders how to strengthen their leadership skills and use values-based approaches to developing and implementing community youth activities (Meir, 2017).

Although the current study did not explore youth life skills outcomes related to sport for development programming, the authors did illuminate some of the strengths and weakness of the program, as perceived by the participants. Focus groups $(N=27)$, qualitative questionnaires $(N=45)$, and interviews $(N=3)$ with participants and administrative staff were used to examine views of the coach education and youth leaders program. Thematic analysis revealed three main themes: 1) cultural awareness and community engagement; 2) curriculum design; and 3) monitoring and evaluation. Specific to cultural awareness and community engagement, a significant weakness of the program was that it was developed in the UK without adequate understanding of the local social, economic, cultural, and political context. This top-down approach (Hartmann \& Kwauk, 2011; Spaaij, 2009) was not effective and minimized the relevance and impact of the program. It also lowered community engagement in the program as community members were less forthcoming and did not open up to the program. As one participant stated, "We need to speak to the community." (Meir, 2017, p. 23). Future programming in the region should strongly consider using a bottom-up, collaborative participatory action approach to program design and implementation.

The second thematic area, curriculum design, revealed that participants resonated strongly with the values-based approach taken by the program (Meir, 2017). A values-based approach was identified by participants as a useful framework to address salient social challenges in the community. Values that were identified to be particularly important were 
empathy, respect, discipline, self-esteem, and ambition. Additional emphases that participants felt would be useful included a focus on entrepreneurial skills as well as a focus on recreational sport, and not solely formal sport (Meir, 2017). The positive response to values-based pedagogies is an element of program design that may be useful to carry forward to future programs. In addition, a collaborative approach should also be used in curriculum design. Last, the findings related to monitoring and evaluation indicated that this dimension of the program was almost non-existent, which resulted in the absence of data related to program successes. The biggest challenges in implementing effective evaluation were the geographical location (other side of the world) of the primary researcher, a lack of planning for evaluation, and also a lack of knowledge of how to implement evaluation on the part of the local implementers (Meir, 2017). Effective monitoring and evaluation of future programs should consider developing collaborative monitoring systems, training local staff and implementers, and generating community buy-in to sustain evaluation efforts.

The role of coaches as facilitators of youth life skills development was also explored in the previously mentioned study in the Kayamandi Township in South Africa. Specifically, Whitley, Hayden and Gould (2013) explored the coaching strategies employed to facilitate youth life skills outcomes. The most common strategy utilized by coaches ( $N=10,9$ male and 1 female) was to provide individual attention to youth and building close relationships. Showing youth that you truly cared for their well-being was reported as foundational. In addition, coaches were intentional about creating a sport climate where youth felt safe and supported. This safe environment then provided the conditions necessary to have open discussions about life skills learning and challenges faced by the youth. These team discussions provided the opportunity for 
youth to support one another and also for coaches to share their own experiences (Whitley, Hayden, \& Gould, 2013).

This study is one of the few SFD studies that has explored the voices of the local participants and stakeholders in SFD programming. Gathering this type of information is critical in remedying the heavy emphasis on top-down approaches to SFD program implementation. In addition, the coaches sampled in this study represented several different sport programs from within the community, which strengthens the external validity of the findings. One critique of this study pertains to the requirement that coaches be able to speak conversational English in order to participate in the study. South Africa has 11 official national language so English language proficiency may have excluded some meaningful voices.

A later study, by some of the same researchers, also explored the perceptions of South African coaches on life skills development through sport participation (Whitley, Wright, \& Gould, 2016). Focus groups were conducted with nineteen coaches (10 males, 9 females) who were recruited via purposive and snowball sampling. Coaches represented a wide range of racial backgrounds (colored=10, black=6, white=3) and coaching experience $(M=16.16, S D=8.95$, range $=3$ to 33 years). Findings from the focus groups were two-fold. First, coaches emphasized the development of the following life skills through their coaching: self-regulation, work ethic, social interaction, basic personal skills, emotional control, leadership, and substance abuse and disease prevention. Second, coaches identified a range of strategies that they employed to promote life skills development: 1) engaging youth in team discussion; 2) modeling life skills through their own behaviors; 3) being intentional about including life skills lessons in their physical activity plan; 4) providing youth with opportunities to practice life skills during sport participation or attend outside of sport experiences that would develop life skills (e.g. 
volunteering or attending conferences); 5) encouraging self-reflection on life experiences and future dreams; and 6) empowering youth to problem-solve on their own (Whitley, Wright, \& Gould, 2016).

The authors discussed the similarities that existed in the life skills focus of these coaches as well as the context-specific life skills that were developed (e.g. substance abuse and disease prevention) that addressed context-specific youth challenges (Whitley, Wright, \& Gould, 2016). The emergence of context-specific life skills points to the value in including local perspectives on youth needs and experiences when designing life skills programming in order to acknowledge the social context and background of these youth. The authors also reflected on the fact that the explicit life skills development strategies reported by the coaches were similar to those used by expert coaches in Western settings despite the lack of formal coaching training in the coach participants. Based on this finding, the authors suggested that a lack of coaching effectiveness training does not mean that life skills cannot be effectively taught. Rather, when coaches know the lived experiences and social context of their players and are also highly invested in making sport participation a life skills learning opportunity, positive developmental outcomes are likely to occur. However, coaches invested in positive youth development would still benefit from additional training to develop intentional coaching strategies and activities to promote life skills learning (Whitley, Wright, \& Gould, 2016). In an area of the world where research is still limited, this study contributed to the literature that provides evidence for intentional strategies employed by coaches to foster positive developmental outcomes for youth in South Africa. Future research can improve on this study by also exploring the extent to which coaches intentionally help athletes transfer the life skills they learn in the sport context to life at school, at home, and in their communities. 
Moreover, although sport participation and coaching strategies are valuable avenues through which youth can develop life skills, coaches often face barriers that diminish the potential positive impact of youth sport. In South Africa, barriers to higher sport participation include lack of sport resources (funding, facilities, equipment, transportation etc.), responsibilities at home, lack of competent and highly trained coaches, and low parental support (Whitley et al., 2013). Some of these barriers are consistent with those identified in Western contexts (Bean \& Forneris, 2017; Santos et al., 2017). That is, research indicates that even when coaches have been fortunate enough to participate in coaching education curriculum, there is limited focus in these courses on how to facilitate life skills development (Santos et al., 2017). Whitley, Gould, Wright, and Hayden (2017) outlined several additional barriers to emphasizing life skills development in underserved communities in South Africa. First, the competitive nature of sport creates pressure to teach tactical and technical sport skills over life skills. This goes hand in hand with limited time to spend emphasizing life skills development and transfer outside the sport setting. Second, life skills development is often absent from coaching philosophies to begin with. Last, coaches frequently stated that athletes may not buy-in to the life lessons they are trying to teach and it is also difficult to measure whether the skills they are teaching are in fact being developed. Identifying barriers to life skills development is a fundamental precursor to integrating life skills development into coaching practices and developing more effective youth sport programming (Whitley et al., 2017).

In summary, although no research currently exists that explores the role of coaches in youth life skills development in eSwatini, several strong studies (Meir, 2017; Whitley, Hayden, Gould, 2013; Whitley, Wright, \& Gould, 2016) exist that examine this topic in South Africa. The findings from two of those studies indicate that even with little training, youth coaches in South 
Africa are implementing intentional strategies to help young people develop life skills to overcome the most salient community challenges (i.e. health-related challenges, substance abuse, poverty, and crime). These strategies include role modeling appropriate behaviors, providing a safe sport context with empathetic coach-athlete relationships, providing opportunities for selfreflection and practicing of life skills, and promoting discussion. The findings from South Africa can be used to inform youth sport programming in eSwatini, where there is some overlap in the developmental challenges of youth. These include poor living conditions, unemployment, inadequate educational systems, risk for major health issues such as HIV/AIDS, lack of adult mentors, and exposure to crime and risky behaviors. Specifically, the studies in South Africa suggest that sport-based life skills programming in eSwatini that involves youth coaches should consider including formal life skills education for coaches to maximize their effectiveness. In the absence of any formal coaching frameworks in eSwatini, providing coaches with educational opportunities to increase their competency is justified. In addition, involving the community in a collaborative manner in curriculum design and program implementation will likely result in stronger youth development outcomes. Last, given the limited research on coaching life skills in non-Western contexts and in Southern Africa, findings from studies in North America and Europe may also provide useful best-practice guidelines alongside input from local voices in eSwatini who can speak to strengths and resources already present in the local context.

\section{Role of coaches in positive youth development and sport for development}

The role of coaches in fostering life skills learning during youth sport participation has been widely explored in North American and Western contexts (Camiré, Forneris, Trudel, \& Bernard, 2011; Gould \& Carson, 2008; Gould et al., 2007; Holt et al., 2017). Gould, Collins, Lauer and Chung (2007) examined the coaching strategies employed by outstanding high school 
football coaches $(N=10)$ who were finalists for the NFL 'Coach of the Year' award. Coaches (9 Caucasian, 1 Asian American) had an average of 30.8 years coaching experience and 9 of 10 of the coaches had formal coaching training. Alongside their winning record, these coaches were also identified nationally as coaches who meaningfully impacted the holistic development of their athletes. Coaches completed a 15-minute Coaches Survey that assessed coaching beliefs and also participated in a 60 to 120 -minute phone interview. Interviews were analyzed using hierarchical content analysis to identify major themes across the interviews (Gould et al., 2007).

Analyses revealed two main dimensions: effective coaching strategies and player development strategies (Gould et al., 2007). Under effective coaching strategies, two higher order themes (working with players and dealing with others) focused on specific strategies such as building caring relationships with players, setting clear expectations, and providing individualized feedback. Other strategies included making practices fun, serving as a role, and communicating effectively with parents, officials, and other coaches. Under player development strategies, two higher order themes (performance enhancement strategies and teaching life skills) described the use of team building, goal-setting, and motivational strategies. Strategies such as reinforcing academic performance, teaching positive values and skills, and focusing on transfer of life skills were also included. The authors discussed the importance of building the coachathlete relationship and using it as the foundation for more well-thought out and intentional strategies to develop life skills. Emphasis was also placed on tailoring feedback and coaching to the individual needs of each athlete and being consistent with life skills and personal development foci (Gould et al., 2007).

The authors also published a second manuscript crafted from data gathered from the same sample of high school football coaches (Collins, Gould, Lauer, \& Chung, 2009). The focus of 
this study was to identify the philosophical beliefs of outstanding youth coaches. Content analysis revealed the following guiding philosophical beliefs as higher order themes: 1) sport participation results helps develop young people; 2) the coach plays an important role in facilitating player development; 3) player development is impacted by multiple coaching factors and external environmental factors; and 4) developmental objectives for players include things like life skills development, academic, and sportsmanship behaviors. Findings from this study indicated that all the coaches had coaching philosophies grounded in beliefs that the psychological, social, physical, and academic development of their athletes was the primary coaching objective. Notably, coaches reported that the development of these social and emotional life skills actually contributed to the team's performance success as well. This is a noteworthy finding because it supports to idea that when player personal development is prioritized, athletic performance is not sacrificed; it is enhanced. There is therefore a pivotal link between a coaching philosophy that emphasizes positive development outcomes and actual onthe-field practices. Coaches often feel competing pressures to focus on winning over personal development so educating coaches that personal development and performance can successfully be integrated is an important future direction (Collins et al., 2009).

In addition, coaches reported that the refinement and strengthening of their coaching philosophy was a process that occurred continuously over time (Collins et al., 2009). This supports the value in encouraging coaches to engage in reflective practice and periodically revisit their coaching philosophy and strategies. These two studies provided evidence for the specific coaching philosophies and strategies that coaches can use to foster positive developmental outcomes in youth athletes. The selection of award winning coaches allowed for coaching strategies to be identified in youth coaches who have largely had a lot of performance and 
positive youth development success. This can be used to inform effective coach life skills training. However, there may well be youth coaches who are highly effective at facilitating life skills development who are not "the winningest coaches" so restricting the current sample to only award-winning coaches may limit generalizability of the findings. Furthermore, the selected coaches only coached male sports so these coaching strategies may not be effective with female athletes (Collins et al., 2009).

A more recent study examined the role of coaches as facilitators of life skills outcomes and positive youth development in Portuguese hockey players (Santos, Camiré, \& Campos, 2016). Santos and colleagues (2016) conducted interviews ( $M=19 \mathrm{~min})$ with 11 (9 males, 2 females) purposively sampled youth club hockey coaches in Portugal. Coaches had between 4 and 24 years of coaching experience and all coaches had a bachelor's degree and a coaching certificate. Athletes in these youth clubs were between the ages of 6 and 18 years old and trained at least 2 times per week for 50 minutes. Thematic analysis was used to analyze the interview responses (Santos et al., 2016).

Overall, coaches reported that the field hockey environment as well as other sporting codes are contexts where youth can develop positive developmental outcomes and learn life skills such as respect, hard work, commitment, and team work (Santos et al., 2016). However, despite a belief in the role of sport and intentional coaching strategies in personal development, few coaches were able to articulate deliberate strategies that they used and instead relied on more implicit approaches such as creating a fun sport environment to facilitate athlete personal development. In addition, concerns were voiced over the pressure to deliver performance outcomes in competitive hockey clubs (Santos et al., 2016). 
The findings from this study are consistent with other studies (Camiré et al., 2011;

Camiré et al., 2013) that have found that coaches struggle to articulate their strategies and also that coaches view performance and life skills foci as incompatible (Gould et al., 2007). It also points to the continued exploration that is necessary to examine the merits of implicit versus explicit life skills development coaching approaches, which will be explored momentarily (Bean $\&$ Forneris, 2016). Furthermore, several of the coaches stated that coaching education curricula are lacking in positive youth development emphases and do not teach coaches how to facilitate personal development outcomes (Santos et al., 2016). This study therefore provided several key insights for positive youth development and life skills learning through youth sport. These include the need for further coach education on the successful integration of life skills objectives and performance foci, strategies to facilitate life skills development, and opportunities to practice those strategies. Despite these valuable findings, consideration should be made that the coaching sample included few female coaches and also focused on coaches in an elite setting where performance mandates are much more stringent than in community sport settings.

Findings from two review studies outline several key coaching processes that best facilitate the emergence of positive development and life skills outcomes from sport participation. Holt and colleagues (2017) propose that PYD and life skills learning through sport can occur through implicit and explicit pathways. Implicit learning refers to the development of life skills without intentional coaching efforts to discuss life skills learning while explicit learning outlines the role of strategic, intentional, and deliberate efforts to promote positive developmental outcomes (Bean \& Forneris, 2016). Holt's (2017) model of positive youth development suggests that implicit learning can occur through sport participation when a positive youth development climate has been established. That is, when there is an empathetic and caring 
relationship between the coach and the athlete as well as supportive peer relationships, youth are more likely to have a positive sport experience that enables life skills learning. The explicit learning pathway occurs when, in the presence of a PYD climate, intentional life skills building activities and transfer activities are included during sporting activities. The role of the coach in youth sport programming with an objective of life skills learning is two-fold: 1) the coach must ensure a PYD climate through creating a strong coach-athlete relationship and a supportive peer environment; 2) the coach must use deliberate life skills building strategies. Findings from Gould and colleagues (2007) study of successful youth coaches, which was described previously, support these results.

Sackett and Gano-Overway (2017) present a range of best-practice coaching strategies for life skills development. According to the authors, effectively coaching life skills begins with planning for life skills development. That is, even before beginning to coach, it is valuable to be intentional in developing a coaching philosophy and identifying the core life skills that will be developed. The development of coaching philosophy that includes PYD principles and clear personal development objectives is a foundational step for youth coaches. The coaching philosophy serves as the blueprint for everything that follows. The next important step is to create a positive youth development climate. A PYD climate is one where athletes feel emotionally and psychologically safe as well as competent and autonomous. This PYD climate can be attained by ensuring that the needs of athletes are acknowledged, providing choice and feedback, and facilitating problem-solving. Alongside the supportive climate, the coach can facilitate life skills learning through the building of caring and empathetic relationships with their athletes. Strategies that have been found to be effective in building strong coach-athlete relationships include openly sharing feelings, getting to know the athlete on a personal level, 
using encouragement and advice-giving, managing conflict and challenges in a gentle and fair manner, and helping the athlete achieve their goals (Sackett \& Gano-Overway, 2017).

Finally, the coach can use explicit instructional strategies to promote life skills learning (Sackett \& Gano-Overway, 2017). One of the most effective strategies is providing athletes with opportunities to practice the life skills by integrating life skills learning in the sport activity. The use of teachable moments to provide unplanned opportunities for life skills practice is also recommended. A complementary teaching strategy is to engage athletes in discussion to reflect on the value of developing specific life skills as well as explore their application to other life domains. The authors also outline the necessity for coaches to set clear expectations for their athletes and hold them accountable to rules and appropriate behavior. An additional effective strategy is modeling appropriate behavior as well as reinforcing life skills use during sport participation by encouraging life skills use when it is observed (Sackett \& Gano-Overway, 2017).

Although this list of best-practices for coaching life skills provides a solid starting point for youth coaches aiming to promote life skills learning for their athletes, coaches often do not know how to implement these strategies and lack confidence in doing so. Therefore, using more structured models that incorporate these strategies for implementing life skills as well as developing coaching programming that trains coaches how to implement life skills learning is necessary. Some of the more well-known instructional models for life skills education through sport include Danish' (2004) Sports United to Promote Education and Recreation (SUPER; Danish, 2004) and Hellison's (2011) Teaching Personal and Social Responsibility through sport (TPSR; Hellison, 2011). Both models are well-established frameworks that use explicit activities to promote life skills development through youth sport participation (Holt, 2008). 
The SUPER model is an 18-module framework that aims to help youth understand that the mental skills developed during sport participation can contribute to both performance excellence as well as personal excellence in creating a meaningful life (Danish, 2004). A significant focus is placed on learning how to set goals and overcoming obstacles to goal attainment. Each session is peer-led and is composed of three activities: sport-specific skill learning, life skills learning, and playing the sport. Each of the 18 modules include specific activities that are designed to help achieve the objectives of the day and are as follows: 1) developing a team; 2) dare to dream; 3) setting goals (part 1); 4) setting goals (part 2); 5) setting goals (part 3); 6) making your goal reachable; 7) making a goal ladder; 8) identifying and overcoming obstacles to reaching goals; 9) seeking help from others; 10) using positive self-talk; 11) learning to relax; 12) managing emotions; 13) developing a healthy lifestyle; 14) appreciating differences; 15) having confidence and courage; 16) learning to focus on your personal performance; 17) identifying and building on your strengths; and 18) goal setting for life. Examples of youth life skills programs based on the SUPER model include First Tee Golf, the Rugby Advantage Program, and the Hokowhitu Program in New Zealand (Danish, 2004).

Training coaches in how to implement a more structured model such as the SUPER model in their coaching may be a useful way to provide coaches with the skills to effectively facilitate youth life skills development. The inclusion of very specific and structured life-skills building activities may be helpful in taking a more intentional approach to sport-based life skills development (Danish, 2004). An alternative life skills education model that could be used to teach youth coaches how to integrate life skills into their coaching is Hellison's (2011) TPSR model. One of the strengths of this model is the option to tailor the life skills focus to values and skills that are appropriate to the cultural and youth context that the program operates in 
(Martinek \& Hellison, 2011). In addition, the model emphasizes teaching coaches how to use intentional strategies to facilitate the learning of life skills and also the transfer of those skills to domains outside of sport. The model's emphasis on transfer is a unique component of the framework. This model will be elaborated upon in the ensuing section of the literature review.

In summary, the role of coaches in youth life skills development through sport has been broadly explored in North American and Western context. Consequently, a strong body of literature exists that outlines the coaching strategies and philosophical beliefs that can maximize coach effectiveness in athlete positive developmental outcomes. These include strategies such as creating a caring environment, investing in an empathetic coach-athlete relationship, role modeling appropriate behaviors, providing deliberate opportunities to practice life skills, and intentionally discussing the transfer of life skills to domains outside of sport. However, despite the progress that has been made in identifying these useful coaching strategies, coaches report that they still struggle to implement these strategies (Santos et al., 2016). This stems both from low coach knowledge of how to effectively coach life skills as well as a lack of coach education curricula that teach coaches how to integrate life skills learning with sport-specific skills development. Future studies may consider employing more formal models to teach coaches how to deliver life-skills focused sport programming. This might be a useful approach to take in eSwatini where limited coaching education frameworks exist to teach coaches how to facilitate positive youth development.

\section{Teaching personal and social responsibility through sport}

Hellison’s (2011) ‘teaching personal and social responsibility’ (TPSR) model is a wellestablished framework for sport-based youth development and life skills learning (Jacobs et al., 2017). The TPSR model is designed to help youth develop the necessary skills to take more 
responsibility for their well-being and for the welfare of others (Hellison, 2011; Martinek \& Hellison, 2016). It is grounded in the belief that youth participation in physical activity and sport should focus on building character and better kids, not solely physical skill development (Hellison, 2011). The model's foundational values are based in principles of holistic positive development, youth centered approaches, and fostering human decency (Martinek \& Hellison, 2016). Teaching personal and social responsibility programs are committed to values-based learning where youth can learn about themselves and the world, achieve small successes that build self-efficacy, become better problem-solvers, and develop their social support skills. This will ultimately have a long-term impact on their lives. This approach to youth physical activity and sport education operates on the premise that although physical activity and sport are unique opportunities for social and emotional development, growth does not happen automatically and needs solid strategies, goals, and teaching to promote youth development (Hellison, 2011). This is consistent with research emphasizing that positive developmental outcomes associated with sport are contingent upon a wide range of factors including the explicit pedagogical strategies employed by the coach or adult facilitator (Coakley, 2011; Holt et al., 2017).

Under the overall umbrella goal of teaching kids to be personally and socially responsible, the TPSR framework includes five responsibility levels or goals that the students need to take ownership of along their developmental journey (Hellison, 2011; Martinek \& Helison, 2016). The levels represent a progression of values that become more complex as the student develops. Youth do not necessarily progress in a linear fashion along the levels so movement along the levels should be individualized based on situations and dispositions of students. The five responsibility levels are (Hellison, 2011; Martinek \& Hellison, 2016): 
I. Respecting the rights and feelings of others - self-control, right to peaceful conflict resolution, right to be included regardless of skill level, gender etc., and the right to have cooperative peers. The overall aim of this level is to create a safe learning environment where the rights of others are respected. This is accomplished through intentionally practicing working together, developing self-control, and managing emotions, attitudes, and behaviors.

II. Effort and cooperation - self-motivation, exploration of effort and new tasks, and getting along with others. This level focuses on the role of effort in helping students improve themselves and their life situations as well as the role that students have in choosing to put forth effort (i.e. self-motivation) and take responsibility for their growth. It also teaches students the importance of cooperation in creating a positive learning environment where participation, mastery, and improvement is emphasized over comparison to others.

III. Self-direction - on-task independence, goal-setting progression, and courage to become self-aware and resist peer pressure. This level increases the emphasis on helping youth take responsibility for their own well-being (less teacher-directed) and the amount of effort they place on different tasks. It helps build their capacity to look within themselves and acknowledge areas of improvement in order to subsequently work towards unique personal goals.

IV. Helping others and leadership - caring and compassion, sensitivity and responsiveness, and inner strength. Throughout this level the emphasis is on helping students develop interpersonal skills of sensitivity and compassion such as listening without judgement, and helping without being arrogant. Students at this level understand that others may 
have different viewpoints, needs, and feeling from their own. More complex helping behaviors may involve leadership and contributing to the well-being of others.

V. Transfer outside the gym - trying these ideas in other areas of life, and being a positive role model for others, especially younger kids. This final level of the model is the most important in facilitating the holistic development of youth.

In implementing a TPSR approach to any physical activity program, program leaders are expected to use daily themes or strategies that become a consistent part of the youth experience (Hellison, 2011). These themes are: 1) gradual empowerment; 2) self-reflection; 3) integrating TPSR into physical activities; 4) transfer to real-life situations; and 5) being relational with youth.

- Gradual empowerment: becoming empowered to make positive choices for ourselves is a pre-requisite to being able to build a productive life. The TPSR model does acknowledge the social and peer influences that influence one's ability to make good choices but believes that developing individual empowerment can help overcome some of these restraints. Strategies for empowerment may include student's sharing thoughts in a group setting, making decisions within the physical activity lesson, engaging in peer coaching, and taking on leadership roles.

- Self-reflection: engaging in self-reflection activities such as thoughtfulness and knowing the self is necessary for empowerment and identifying areas of growth.

- Embedding TPSR into physical activities: truly integrating the lesson with the physical activity and not simply adding-it-on at the end or at the beginning of the game. 
- Transfer of TPSR ideas into real-life situations: purposeful exploration during lesson time where students explore the possibilities of making these choices in real life. This is the ultimate goal of TPSR programs.

- Being relational with kids: the program leader is able to recognize that each child is different and they will each have their own strengths, individuality, voice, and decisionmaking abilities.

The five themes should be addressed within the daily structure of the TPSR program. The programmatic structure or daily curriculum structure of any TPSR program is as follows (Hellison, 2011; Martinek \& Hellison, 2016):

1. Relational time: an opportunity for the leader to interact one-on-one with the students before the daily program begins to cultivate the leader-youth (coach-athlete) relationship and create a caring sport climate.

2. Awareness talk: a brief discussion in which the leader outlines the responsibility levels that the group should be focusing on that day. The key components of the awareness talk are brevity and allowing the youth to contribute. Strategies may include posting the levels on the wall, relating the responsibilities to current program experiences, and developing one liners that are catchy and will stick with the youth.

3. Physical activity: this is the bulk of the lesson and is where the TPSR values and responsibilities are integrated with physical activity. In the earlier stages the leader can do more instructing while the students are still learning the lower level responsibilities but students should gradually be empowered.

4. Group meeting: discussion post-physical activity about positive contributions made by students, what worked and didn't work about the day in general, and how things can be 
improved. The purpose of this meeting is to allow the students to develop their group processes and decision-making skills. Group meetings also requires competence in level I skills such as respect and also helps develop level IV skills such as compassion and listening to others.

5. Self-reflection time: this last reflection time shifts the focus to the self and self-evaluation or reflection as guided by the responsibility levels. Students are given the opportunity to ask themselves how well they respected the feelings of others, how much effort they put into the activities etc. Notably, within one lesson a student may display behavior that shifts between different levels of development. Leaders may therefore vary in how they choose to ask students to evaluate themselves every lesson.

All TPSR programs utilize the same daily structure, core themes, and responsibility levels. They also all share a similar mission of facilitating social and emotional life skills development in young people but they may vary somewhat in how they implement their programming.

\section{Application of the TPSR model}

The TPSR model has been used as the guiding framework in a multitude of youth development programs and amongst professionals who believe in youth-centered pedagogies (Gordon \& Doyle, 2015; Hellison, 2011; Martinek \& Hellison, 2016). Youth programs grounded in the TPSR framework have been implemented in a range of settings including after school programs (the vast majority), physical education programs, mentoring initiatives that train adolescents how to teach TPSR to younger kids, outdoor activities programs, and community settings (limited) (Caballero-Blanco, Delgado-Noguera, \& Escartí Carbonell, 2013; Gordon \& Doyle, 2015; Martinek \& Hellison, 2016). The majority of TPSR programs have been 
implemented in the United States and have primarily targeted at-risk and under-privileged youth although programming has also been developed for special populations such as refugees (Caballero-Blanco et al., 2013; Whitley, Coble, \& Jewell, 2016). Recently, an increased international focus has emerged with programs operating in Canada, Spain, New Zealand, and Ireland (Gordon \& Doyle, 2015).

The framework has shown success in elementary-aged kids, youth aged 12-18, and also youth aged 16-21 years old (Caballero-Blanco et al., 2013). Program length has ranged from as high as 9-months to cover a full academic year, to programs that are only several weeks in length, with most programs meetings once or twice per week for hourly sessions. A wide range of different sports have been co-opted into the physical activity portion of the program ranging from more traditional sports such as basketball, soccer, and volleyball, that the majority of programs have utilized, to fencing, martial arts, or simple cooperation activities (CaballeroBlanco et al., 2013).

The TPSR framework is considered to be an adaptable model that provides opportunities for programs to creatively vary in their theoretical and pedagogical approach to promoting responsible behavior. That is, as long as the core values, responsibility levels, and program leader themes of the TPSR model are used as the foundation of the program, creative differences in pedagogies are encouraged (Gordon, 2009; Martinek \& Hellison, 2016). Wright and Burton (2008) examined the implementation and short-term outcomes of a TPSR-based physical education curriculum that was established at a high school in a Southern state in the USA. The Tai Chi Tiger program consisted of 50-minute lessons that were run twice per week for 10 weeks during the Fall semester. The primary program instructor was the lead author of the study who had 10 years of experience designing and implementing TPSR programs and was also a certified 
tai chi instructor. No explicit training to implement the program was therefore included. Youth participants were 23 African American boys $(n=9)$ and girls $(n=14)$ in the same physical education class at the school. The program sessions followed the daily structure of the TPSR model. Emphasis was placed during the first couple of sessions on developing self-control and participation using a more teacher-centered approach. As the sessions progressed, students were given more opportunities to make group decisions and eventually led several of the physical activity and tai chi exercises. Half way through the program the instructor began to include more opportunities for group discussion about life skills, stress reduction, and goal setting (Wright \& Burton, 2008).

Several different data collection methods were used to evaluate the program (Wright \& Burton, 2008). Six youth participated in 30-minute interviews that asked questions about what they liked, disliked, and would want to have changed about the program. A research assistant who was a nonparticipant also observed each session and took notes. Each participant was asked to complete a 13-item responsibility log at the end of each session. The responsibility log included 5 items about TPSR delivery e.g. "The instructor encouraged everyone to participate and try hard today", 4 items about the group's overall responsibility e.g. "Overall, everyone in class showed respect and good self-control today", and 4 items about individual responsibility e.g. "I was able to lead/demonstrate in today's lesson." Each item was assessed using a 5-point Likert scale from 1 (strongly disagree) to 5 (strongly agree). In addition, on several occasions, youth participants were asked to write reflections on the life skills topics that had been discussed that day. Learner assessments were also included that used true/false, multiple choice, and openended questions to assess learning of TPSR life skills. A combination of inductive and deductive content analysis was used to analyze the program evaluation data (Wright \& Burton, 2008). 
Data from the youth interviews and responsibility logs indicated that overall youth had positive experiences in the program and learned to take on new responsibilities in leading group exercises and student stations (Wright \& Burton, 2008). Youth got better at these skills over time as they learned to show others respect and control their own behavior. Youth indicated that being given opportunities to lead and practice skills was a well-liked component of the program.

Findings also supported youth perceptions that they could potentially transfer some of these life skills and use them to interact with others, manage stress outside of the physical education class, and be more successful in school.

However, the program implementers did encounter significant barriers in keeping the students engaged and motivated (Wright \& Burton, 2008). Tai chi is a sport that includes many slow and repetitive movements that frequently caused kids to lose focus. Many students also reported finding the discussion (lecture-style) and self-reflection sessions boring (Wright \& Burton, 2008). Future programs should therefore carefully consider the choice of physical activity or sport in the program. Tai chi was a useful sport to teach skills related to stress management and conflict resolution that are highly applicable to life because it focuses on breath and slow movements. However, it was difficult to keep the attention of the youth because it was so slow-paced. Being creative in how the group discussion and reflection sessions are implemented should be carefully considered in order to actively engage the youth participants. Furthermore, although the integration of the TPSR program into the physical education curriculum allowed for the easy implementation of the program, the large number of children made it difficult to manage the group size and keep all students engaged. As a result, group size decisions should be carefully made in future programming. Last, it is necessary to include more rigorous evaluation methods to assess the positive developmental outcomes of TPSR-based 
programs and to assess transfer to domains outside of the sport context, given that this is an explicit component of the framework. The Youth Experiences Survey 2.0 (YES 2.0; Hansen \& Larson, 2005) and the Life Skills Transfer Survey (LSTS; Weiss, Bolter, \& Kipp, 2014) may be appropriate assessment tools to measure general life skills learning and transferability of skills respectively. Both measures will be briefly described.

The YES 2.0 is a self-report measure that assesses positive and negative youth experiences and general life skills learning from organized youth activities (Hansen \& Larson, 2005). The YES 2.0 assesses personal and interpersonal domains of development and is composed of 6 scales of positive experiences and five scales of negative experiences. The positive developmental scales are identity, initiative, basic skills, team work and social skills, positive relationships, and social capital and adult networks. The negative developmental scales are stress, inappropriate adult behavior, negative influence, social exclusion, and negative group dynamics. It is a 70-item measure that rates responses on each item from ' $1=$ yes definitely' to '4= not at all' (Hansen \& Larson, 2005). Adequate internal reliability and validity has been found in studies using adolescent populations (Hansen, Larson, \& Dworkin, 2003; Larson, Hansen, \& Moneta, 2006). Although the YES 2.0 is strongly grounded in positive developmental principles, the use of the YES 2.0 in youth programming should be carefully considered amongst other evaluation tools given its 70-item length.

The Life Skills Transfer Survey (LSTS; Weiss et al., 2014) is a 50-item self-report assessment of transfer of life skills to domains outside of sport. The LSTS assesses 8 life skills that include: managing emotions, helping others, getting help from others, meeting and greeting, making healthy choices, goal setting, resolving conflict, and appreciating diversity. Each item assesses behaviors exemplifying each life skill and is preceded by a stem that states, "Because of 
participating in X organized activity...”. Items are rated on a 5-point scale of ' $1=$ really not true for me' to '5- really true for me'. There is strong psychometric support for the use of the LSTS in youth populations (Weiss et al., 2014). In addition, the LSTS was originally validated using a TPSR-based youth program (Weiss et al., 2014), which provides support for its use in future TPSR programming. However, further validation of the scale amongst youth in different cultural contexts is necessary.

A more recent TPSR-based program that has had significant success is the 'Girls Just Wanna Have Fun' (GJWHF) sport-based youth development program in Ontario, Canada (Bean, Forneris, \& Halsall, 2014; Bean, Kendellen, \& Forneris, 2016). The aim of the program was to increase female sport participation and provide opportunities for life skills development. Youth participants were 10 girls aged 11-14 years old from low income families who were part of the local boys and girls club (BGC). Program design merged the TPSR framework with Danish and colleagues (2004) Sports United to Promote Education and Recreation (SUPER) program model that was described previously. The authors chose to combine the two models because they liked the explicit life skills learning strategies that are included in the SUPER model. Bean and colleagues (2014) used an extended version of the awareness talk (i.e. 25 minutes) portion of the TPSR model to infuse activities from the SUPER model. Examples of those activities included a deep breathing activity where youth learned diaphragmatic breathing for emotion regulation, the 'Dare to dream' activity where youth explored their dreams for the future and discussed them with their peers, and structured leadership opportunities where participants led the physical activity component of the session. A more structured activity, called the "Rose and Thorn" activity was also used during relational time where participants shared a highlight and challenge 
from the previous week that helped build the relationship between coach and youth (Bean et al., 2016).

Program structure involved one 75-minute session once per week for nine months (Bean et al., 2014). The original TPSR daily structure was retained although no individual reflection time was included: relational time (10 minutes)- awareness talk (25 min)- PA (25 min)- group debrief (10 min). A different sport was played every session and included yoga, cooperative games, lacrosse, volleyball and basketball. The GJWHF program was run by five female staff ( 2 BGC staff and 3 university students). All leaders participated in a 1-day training facilitated by a professor at the local university who had expertise in youth development and program implementation. Program leaders received training in youth development principles and strategies, program implementation as well as TPSR specifics. Each leader received a manual that had been created for the program. Programs leaders also met before and after each program session (Bean et al., 2014).

Process evaluation goals focused on the fidelity of program implementation, successes and challenges of implementing the GJWHF program, and youth experiences during the program. (Bean et al., 2014). A leader logbook was used that asked program leaders the same questions after every session: date, number of participants, educational goal or life skill focus, successful implementation of life skill- why or why not, how did the session go? (what went well and what didn't go well i.e. challenges) - and group rating on TPSR components (self-control, effort, self-coaching, leadership) on a rating scale of 1 (needs work) to 4 (great). The leader logbook was the primary assessment of fidelity to the TPSR model (Bean et al., 2014).

Semi-structured interviews were also conducted with the youth participants and program leaders after the program concluded (Bean et al., 2014). Youth interviews focused on personal 
development due to program, and experiences in the program. Sample questions included: "What did you learn in the program?" "What did you like and dislike about the program?" "What did the leaders teach you?" "What was it like working with the leaders?" "What do you believe had impacted you the most during this program?" "Is there anything you hoped would have happened in or after the program that did not happen?" Program leaders' interviews focused on their experiences implementing the program, and the impact of the program on their students. Questions included: "How was the program perceived by the youth?" "What challenges or success did you experience related to implementing the program?" "What strategies did you use to keep the youth engaged?" "Which ones were most effective?" "What suggestions do you have for improving the program?” (Bean et al., 2014).

Inductive thematic analysis was used to analyze the interview transcripts (Bean et al., 2014). Findings indicated that 23 of the 30 sessions were implemented with strict adherence to the TPSR structure and using the TPSR strategies e.g. gradual empowerment. The 8 sessions that did not adhere to the TPSR format only made slight changes to daily formatting. Strong fidelity to the TPSR model therefore helps explain the four strong themes of success that were as follows: 1) Using structured activities such as the 'Rose and Thorn' activity can be helpful during relational time; 2) Intentional leadership development opportunities need to be included; 3 ) Providing opportunities to participate in many different forms of physical activity is effective; and 4) Open communication between leaders and high communication about concerns, observations, changes is valuable. Challenges identified in the program were unreliable transportation, the size of the facility, which was too small for the group, ensuring that activities are not too similar to school work, and monitoring for social cliques (Bean et al., 2014). 
The GJWHF program had several key strengths (Bean et al., 2014). First, the inclusion of activities such as the 'Rose and Thorn' were well-received by the participants and helped create a positive group climate and build trust between the girls and the leaders. Participants also really enjoyed the leadership opportunities that they were given. These activities are good examples of more structured activities that can be used in the TPSR model in comparison to the somewhat vague suggestions in previous research (Bean et al., 2014). Moreover, the combined inclusion of both the relationship-building activity and the leadership opportunity may have helped the girls feel comfortable enough with their peers to then engage in leadership roles. In addition, including multiple sports was found to increase youth enjoyment in the program, so future initiatives may consider including multiple sport opportunities. This is consistent with TPSR research stating that providing youth with opportunities to learn new sports not only keeps them engaged in the program but it also helps them develop a sense of competency and pride (Whitley, Coble, Jewell, 2016). However, other studies do support the value of grounding TPSRbased programming in only a single sport that is loved by the local community (Cryan \& Martinek, 2017; Wright, Dyson, \& Moten, 2012). An area of improvement for the study was the length of facilitator training. Previous TPSR research indicates that adequate leader training is often difficult to achieve but it is worth investing more time into comprehensive training (Whitley, 2012; Wright, Whitley, \& Sabolboro, 2012). In addition, transfer of life skills was not measured at all, which is a critical component of the model to assess.

The adaptability of the TPSR model is also evident from its applicability across different cultural contexts. Hellison (2011) recognizes that the goals of the program and the responsibility levels are social constructions that can be modified to better fit different contexts as long as the core TPSR spirit is retained (Gordon, 2009; Martinek \& Hellison, 2016). A good example of a 
culturally adapted TPSR-based program is the Refugee Sport Club (RSC) in Lansing, Michigan (Whitley \& Gould, 2010; Whitley, Coble, Jewell, 2016). Two semester-long programs were offered once per week for an hour for youth refugees aged 8-12 and 13-18 years. The RSC is an example of a TPSR program that effectively adapted the program to the cultural context of the participants and also used creative pedagogical techniques. Specifically, the authors acknowledged early on in the program development phase that youth refugees will have different developmental and community needs than other youth. Therefore, an initial assessment with youth was conducted where having fun, learning different sports, being valued as a team member, and building strong relationships with adults were identified as the greatest needs of the population. These goals were then combined with the TPSR responsibility levels to guide the developmental objectives of the program. Within program implementation, the RSC used several innovative pedagogical strategies. For example, due to language differences between the youth and the facilitators and across the youth group, facilitators in the Refugee Sport Club used large flash-cards with drawings depicting the responsibility levels to promote understanding of the responsibility levels. They also created a special 'Reflection Corner' where sign-posts of the responsibility levels were set up as well as different visual evaluation tools (e.g. thumbs up or down) (Whitley \& Gould, 2010; Whitley, Coble, Jewell, 2016).

There were several noteworthy strengths of the RSC program. First, the RSC's employment of a needs assessment to attune the program to the local youth experience was ultimately a major strength of the program. This approach is consistent with Hellison's (2011) emphasis on individualizing TPSR approaches to meet the needs of the participants. Future programming should consider using this participatory-action approach to youth programming whereby the youth voice is included in program design very early on in the research process. In 
addition, the pedagogical strategies employed by the RSC could be considered for future programs working with language barriers and with younger developmental groups where visual aids might be useful. Last, it is noteworthy that the RSC program was grounded in a clear theory i.e. Ha and Lyras (2013) conceptual framework for acculturation. It was the inclusion of this theory that led the authors to explore the specific needs of the refugee youth, which was a decision that ultimately strengthened the program. The inclusion of a theoretical framework of youth development or behavior change in future programming should therefore strongly be considered.

An additional example of tailoring the program goals and emphases to fit the local needs is reflected in Whitley's (2012) work in the Kayamandi Township in South Africa. In this brief, 1-week long TPSR-based program (Ikhaya sports program), youth ( $n=70)$ aged 6-10 and 11-14 participated in five 60-minute sessions that were divided by age group. Facilitator training occurred on a daily basis for one hour before the session. Each training included instruction about TPSR principles, exploration of positive youth development approaches, implementation of the TPSR model, and personal reflection on motivations for coaching. During program implementation, the first two TPSR sessions were conducted by the first author and the coaches simply observed then as they grew more comfortable they began taking over instruction. Approximately 25-30 children attended each session. Program goals were established collaboratively with a non-governmental organization (NGO) already working in the area. The three main goals were identified as youth safety, enjoyment and fun, and some learning of personal and social responsibility. In addition, emphasis during sessions was placed on learning respect, teamwork, and transfer of skills instead of all 5 responsibility levels. No formal assessments were used to measure the learning outcomes or participation experience of the youth 
participants. However, the author did provide observations indicating student learning and enjoyment. Specifically, personal and social responsibility outcomes were observed through youth participants' application and understanding of respect and teamwork concepts during sessions. Participants also reported that they enjoyed learning about these concepts. Preliminary indicators of transfer of life skills to domains outside of sport was also noted from participant insession statements about how concepts could be applied to home and school life (Whitley, 2012) A strength of Whitley's (2012) brief program in the Kayamandi township was the collaborative approach that the author took to make decisions about program emphasis and implementation. A weak point of this study was the very brief training session that facilitators completed. This was partially a product of the amount of time given to the author by the NGO to conduct the training as well as the program goal to introduce TPSR to the coaches and not make them experts. However, it might help explain why coaches were low in energy and engagement levels and were also reluctant to give honest and critical feedback as they may have not felt confident in their ability to implement the program. In addition, evaluation of program effectiveness was based on observation alone, which would be stronger when used in combination with other qualitative and quantitative evaluation tools. Future programming should consider conducting a thorough needs assessment in the community they wish to operate in to gain a holistic understanding of the youth context, challenges, and needs. This information can then be used to design TPSR programming that meets the developmental needs of local youth. In addition, employing multiple assessments methods that can be used to triangulate data related to program effectiveness should be considered.

Regardless of the approach of the program, the setting in which it is implemented, or the population it is serving, all TPSR programs have a commitment to transforming communities 
and the lives of youth (Martinek \& Hellison, 2016). Specifically, TPSR programs are dedicated to promoting pro-social values and developmental outcomes such as compassion and relational learning in youth participants (Martinek \& Hellison, 2016). Two reviews of TPSR programming indicate similar positive developmental outcomes for youth as a result of their participation (Caballero-Blanco et al. 2013; Hellison \& Walsh, 2002). Hellison and Walsh (2002) reviewed 26 studies conducted between 1970 and 2001 that used the personal and social responsibility model (RM) (as it was known then) to teach life skills to at-risk youth in the US. Caballero-Blanco and colleagues (2013) review was an expansion upon Hellison and Walsh's (2002) work. Multiple studies have demonstrated improvements in self-control, effort, and helping or cooperative behaviors (Bean et al., 2016; Cryan \& Martinek, 2017; Escarti, Gutiérrez, Pascual, \& Marín, 2010). On-task independence has increased, and youth have had success reaching goals, directing their own learning, and developing strong interpersonal relationships (Caballero-Blanco et al. 2013; Hellison \& Walsh, 2002). A range of studies also support the transfer of skills such as self-control, effort, and maturity to the classroom where participants have shown stronger academic performances, higher attendance, and lower levels of violence (Caballero-Blanco et al. 2013; Hellison \& Walsh, 2002; Hemphill \& Richards, 2016).

Other positive behavioral changes include more constructive interactions with others, helping and leadership behaviors, positive relationships, and an increased sense of belonging (Cryan \& Martinek, 2017). Qualitative accounts of participant experiences during TPSR programs indicate high levels of enjoyment, experiencing caring adult relationships, developing a sense of belonging, and feeling safe (Caballero-Blanco et al. 2013; Escarti et al., 2010; Hellison \& Walsh, 2002; Whitley, Coble \& Jewell, 2016). Overall, findings indicate that youth are experiencing positive developmental outcomes as a result of their participation in TPSR- 
based programs. However, these findings are primarily from programs operating in Western contexts where youth may be facing different individual and social challenges than youth in Southern Africa and eSwatini. Therefore, despite some evidence for cross-cultural applicability, TPSR needs to be explored in different cultural contexts (Wright, Jacobs, Ressler, \& Jung, 2016).

Although the TPSR model is popular and has been applied in a range of different youth contexts, criticism has been directed at the limited empirical evidence for the model (i.e. identifying the mechanisms of positive effect) and specifically the lack of evidence for transfer of learning (TOL). Hellison and Walsh's (2002) review of the TPSR literature indicated that the majority of research designs were case studies and only 6 of the studies were published in research-based journals. In addition, a significant proportion of the evaluations were qualitative with little attention to methodological rigor. Therefore, although these programs were doing good work, increased efforts needed to be directed toward the use of validated quantitative assessments, stronger qualitative approaches, and quasi-experimental designs where possible (Hellison \& Walsh, 2002).

Caballero-Blanco and colleagues (2013) review demonstrated that over a decade later qualitative methods continued to be the primary evaluation tool for TPSR programs. For example, Wright and colleagues (2012) explored the participant experiences and program effectiveness of a TPSR-based program in Memphis, Tennessee. The YMCA Community Action Program (Y-CAP) Kung Fu Club was a long-term TPSR program for 10-13-year-old African American males at risk of dropping out of school. A case study design was used to explore participant experiences $(n=4)$ using two 15-20-minute interviews: one initial interview and a follow-up interview. Additional qualitative assessment methods included direct observation of 
program implementation and instructor self-reflection. Both of these qualitative methods used the Tool for Assessing Responsibility-Based Education (TARE) to identify the teaching strategies and leader themes employed by the instructor (Wright et al., 2012). The TARE was developed to observationally assess the extent to which teaching practices aligned with the core principles and objectives of the TPSR model (Escarti, Wright, Pascual, \& Gutierrez, 2015). Two versions of the TARE have been developed: one observational tool and one post-teaching reflection tool that can be completed by the instructor or coach (Escarti et al., 2015).

The TARE is divided into three sections: 1) observable teaching strategies; 2) personalsocial responsibility themes; and 3) student responsibility (Escarti et al., 2015). The observable teaching strategies section identifies nine core teaching strategies that instructors should be employing during TPSR programming to foster responsibility outcomes in youth participants. These strategies are: modeling respect, setting expectations, providing opportunities for success, fostering social interaction, assigning manageable tasks, providing leadership opportunities, giving choices and voices, role in assessment, and encouraging transfer. The personal-social responsibility themes section includes the leader themes identified as central to the TPSR model: 1) integration; 2) transfer; 3) empowerment; and 4) teacher-student relationship. The student responsibility behaviors correspond with the responsibility levels of the TPSR model i.e. selfcontrol, participation, effort, self-direction, and caring. To assess the degree to which the nine teaching strategies are employed, an interval system is employed whereby the observer indicates every 5-minutes whether or not any of the nine strategies have been employed during that interval. The other two sections holistically assess at the end of the observation period the extent to which personal-social responsibility themes were employed and student behaviors were present using a 0 to 4 Likert scale (Escarti et al., 2015). 
The TARE observational tool and the TARE post-teaching reflection have both been employed in multiple studies as useful measures of program evaluation, assessment of fidelity, and evaluation of the link between teaching strategies and student outcomes (Escarti et al., 2015; Hellison, 2011; Hemphill, Templin, \& Wright, 2015). The teaching strategies identified in the TARE can also be used in the coach/instructor training period of TPSR programs to provide coaches with pedagogical strategies that will lead to responsibility outcomes. That is, during training, coaches can discuss the differences between the strategies and also practice and role play the use of those strategies. Future studies wishing to evaluate outcomes of TPSR programming and examine program fidelity to TPSR principles might choose to use the TARE in conjunction with other quantitative measures of student learning. The TARE has also since been revised to create the TARE 2.0 (Escarti et al., 2015), which made minor adjustments to the teaching strategies section, shifting from a binary system (present vs. not present) of assessment to a Likert scaling system $(0=$ absent to $4=$ very strong $)$. The sample interval was also shortened from 5-minutes to 3-minutes. In addition, the student behaviors were expanded to include nine personal-social responsibility behaviors instead of five and are assessed using the same interval sampling methodology as the observed teaching behaviors. The nine student behaviors are: participation, engagement, showing respect, cooperating with peers, encouraging others, helping others, leading, expressing voice, and asking for help (Escarti et al., 2015).

Although the use of assessment tools such as the TARE represented advancements in reliability and validity of qualitative methods employed by TPSR programs, the heavy emphasis on qualitative methods as primary evaluation strategies continued to limit the rigor and generalizability of findings from those programs. However, Caballero-Blanco and colleagues (2013) review did indicate that programs with stronger methodological rigor had been 
increasing. For example, the previously described Tai Chi Tiger TPSR-based program for African American boys and girls evaluated data from several different sources to strengthen methodological rigor (Wright \& Burton, 2008). That is, data was triangulated from interviews with youth participants, observations from the research assistant, responsibility logs completed by youth participants, and brief learner assessments of TPSR skills (Wright \& Burton, 2008). Although these evaluation strategies were stronger than previous studies, data was still primarily qualitative.

An example of a TPSR-based program that used a more rigorous mixed-methods approach was Escarti and colleagues (2010) study in Spain. Participants were youth aged 13 and 14 years old in two physical education classes at two high schools in Valencia, Spain. Students from one school ( $N=15,12$ boys and 3 girls) were randomly assigned as the intervention group while students from the second school $(N=15,11$ boys and 4 girls $)$ were the comparison group. In the intervention group, the TPSR program occurred during physical education classes twice per week for 1.5 hours from November to May, which added up to approximately 30 sessions. The daily structure of each session was consistent with the TPSR framework and the responsibilities of the instructor were also aligned with TPSR themes (i.e. empowerment, integration of PA with responsibility levels, transfer, and being relational with the students). The physical education teacher was the main instructor and received a 30-hour training with 3 modules focusing on the theoretical basis of the TPSR model, previous application of the TPSR model, and strategies for implementing TPSR. The instructor also received readings and a manual (Escarti et al., 2010).

Youth learning outcomes were assessed using a validated quantitative measure (i.e. the Multidimensional Scales of Perceived Self-Efficacy) as well as interviews with youth and classroom teachers (Escarti et al., 2010). The Multidimensional Scales of Perceived Self- 
Efficacy (MSPSE; Bandura, 1990) was used to measure personal and social self-efficacy of youth participants at 3-time points (baseline, post-intervention, and 6-month follow-up). The MSPSE is a self-report measure of self-efficacy and is composed of 57 items and nine subscales representing Bandura's nine proposed domains of self-efficacy: enlisting social resources (4 items), academic achievement (9 items), self-regulated learning (11 items), leisure-time skill and extracurricular activities ( 8 items), self-regulatory efficacy to resist peer-pressure ( 9 items), meet others expectations (4 items), social self-efficacy (4 items), self-assertive efficacy (4 items), and enlisting parental and community support (4 items). A 7-point Likert scale is used to rate responses to each item from 1 (not well at all) to 7 (very well). The authors chose to only use the four subscales most relevant to their research i.e. enlisting social resources, self-regulated learning, self-regulatory efficacy to resist peer pressure, and social self-efficacy. Youth were also interviewed and asked questions concerning their level of participation in the program, any changes in behavior, achievement of TPSR aims, what they learned, whether anything was transferred to outside of school, and whether parents or teachers have noticed changes. In addition, classroom teachers were interviewed and asked what changes in learning, behavior, and attitude they had noticed in their students. The quasi-experimental research design and the mixed-methods evaluation strategies of this study were therefore more rigorous than in the past.

Critiques of TPSR-based research have also indicated that although TPSR programming continues to expand, there is limited research on whether the TPSR framework is successful in transferring learning to other domains of life (Gordon \& Doyle, 2015), and if so, what specific strategies or model components lead to those transferred outcomes (i.e. mechanisms of success). Walsh, Ozaeta, and Wright (2010) examined the transference of life skills learned in a TPSR program, Coaching Club, to other domains of life. Youth participants were K-5 students $(N=13$, 
11 boys and 2 girls) aged 9-11 years old. Coaching Club met once per week for two years. Effectiveness of transfer was assessed using 30-minute interviews with youth participants and 30-60 minute interviews with adults who could attest to transfer of learning to the school setting. Field notes were also maintained by the instructors of the program. Results indicated that transference of skills such as respecting the rights and feelings of others was experienced by all participants. The majority of youth (10 of 13) indicated that they transferred effort, working hard, and working as a team to the school setting. A similar proportion of students indicated that they transferred self-direction, goal setting, and working autonomously to school. Helping and leadership behaviors were also transferred for the majority of students (11 of 13). These findings were supported by the adults (i.e. classroom teachers at school) (Walsh et al., 2010). Although there was some evidence for the transfer of learning, there is a need to assess transfer in different ways including more individualized quantitative assessments as well as through evaluations of more concrete school behaviors e.g. attendance, helping behaviors, and positive communication with the teacher. In addition, it is necessary to identify the program structures or implementation strategies that directly lead to positive outcomes and transferred life skills.

In recent years, attempts have been made to address this gap in empirical evidence through fidelity studies that help elucidate whether fidelity to TPSR model components is the mechanism that leads to positive youth outcomes and transfer to other life domains. That is, these studies assess the extent to which programs are implementing TPSR principles as well as the relationship between high fidelity to TPSR models and strong developmental outcomes in youth participants i.e. cause-effect implications. Cryan and Martinek (2017) explored the fidelity of a TPSR-based Soccer Coaching Club for at-risk sixth grade boys $(N=14)$ of Latino ethnicity. The Soccer Coaching Club was a six-week after-school program that met twice per week for 2 
hours. The program directed had participated in extensive coursework in TPSR programming while the six students who served as program staff received 2 classroom training sessions to learn TPSR principles and strategies. Trainees were assessed at the end of the training to evaluate their learning (Cryan \& Martinek, 2017).

A mixed-method evaluation approach was used to assess program fidelity and participant learning outcomes. This included field notes from each session, focus groups with teachers, and a validated quantitative measure, the Personal and Social Responsibility Questionnaire (PSRQ; Li, Wright, Rukavina, \& Pickerings, 2008). The field notes incorporated observations about the use of empowerment, integration, transfer, and relationship-building strategies in each session, which are considered to be the core indicators of TPSR fidelity. The focus groups with classroom teachers examined transfer of student learning outcomes to the classroom while the PSRQ assessed student learning outcomes but was also used as a component of fidelity. The PSRQ is a 14-item self-report measure composed of 2 scales with 7 items each: personal responsibility and social responsibility. Social responsibility aligns with the two TPSR levels of respect and caring for others while the personal responsibility scale aligns with the two TPSR levels of effort and self-direction. Notably, the scale does not measure the fifth responsibility level of transfer. A 6point Likert scale ranging from 1 (strongly disagree) to 6 (strongly agree). It is a psychometrically valid instrument with adequate internal consistency (0.79-0.81) (Cryan \& Martinek, 2017).

Findings indicated that fidelity was high, as indicated by the consistent use of TPSR strategies during sessions (Cryan \& Martinek, 2017). In addition, there was a significant increase in social responsibility (respecting rights and feelings of others, and helping behaviors), $t(13)=$ 2.33, $p<0.05$, but there was no significant change in personal responsibility (effort and 
participation, and self-direction), $t(13)=0.05, p<0.05$. Teacher interviews reported positive behavioral changes in youth including contributing in class, positively interacting with others, helping and leadership behaviors, positive relationships and increased confidence, and an increased sense of belonging (Cryan \& Martinek, 2017). Overall, the program was successful in attaining high fidelity to the model and subsequently also promoting positive student outcomes and transfer of learning. This suggests that the TPSR model itself may be a mechanism through which positive developmental outcomes and transfer of learning can be achieved. Further, the inclusion of a validated measure was a strength of the program as few studies incorporate validated quantitative forms of assessment. However, there was no explicit mention of a theory that was driving the design and implementation of the program, which may promote stronger life skills outcomes in future initiatives.

One study that was grounded in a strong theoretical framework was Gordon, Jacobs and Wright's (2016) examination of the fidelity of a TPSR-based leadership program for at-risk middle school boys. The program itself was a long term, 2-year program that met twice per week for 75 minutes. Between 6 and 14 boys attended each session. University coaches implemented the TPSR programming and were trained by the research team's director. Coach training focused on positive youth development principles and the TPSR model. No further details were given. Gordon and colleagues (2016) study was grounded in the social and emotional learning (SEL) framework and primarily aimed to examine whether higher fidelity to the TPSR model could lead to SEL outcomes. The SEL theory emphasizes youth development of five core competencies (self-awareness, self-management, social awareness, relationship skills, and decision-making) in order to promote skill development in emotion regulation, building strong social connections, making healthy choices, and working towards goals. These skills are pivotal 
for the youth success in all domains of their lives and is considered to be a core educational outcome in many countries around the world. The authors used semi-structured interviews with participants, coaches, and staff at the school, field notes, and a TPSR check-list to explore fidelity and youth outcomes. The TPSR checklist was completed at the end of every session. This checklist includes discussion of implementation of the TPSR daily structure, responsibility levels, and key strategies. It also includes a section that lists teaching strategies that are conducive to promoting responsibility outcomes as well as student behaviors that are consistent with responsibility acts (Gordon et al., 2016).

Results indicated that fidelity to the TPSR model was high and the TPSR approach was found to be highly aligned with the SEL framework (Gordon et al., 2016). Specifically, the TPSR responsibility levels aligned strongly with the SEL outcomes e.g. respect aligned with self/social awareness and leadership aligned with relationship skills. In addition, the active learning strategies employed in the TPSR model aligned with the emphasis on active learning in SEL theory. Further, the group discussion and reflection time in the TPSR daily structure aligned with the SEL core competency of developing self and social awareness. Last, all five SEL competencies were indicated as outcomes in the student interviews: self-awareness, social awareness, self-management, relationship, and positive decision-making. This study therefore provided strong support that, when implemented with high fidelity, the TPSR can promote the development (i.e. mechanism of impact) of social and emotional learning outcomes. However, there was no focus in the current study on transfer of learning to other domains of the lives of youth participants.

Several studies have also attempted to identify the factors (i.e. implementation strategies and program structure) contributing to higher transfer of learning. Bean, Kendellen, and Forneris 
(2016) examined the pedagogical strategies that most strongly contributed to transfer of learning in the aforementioned GJWHF program for young girls in Ontario, Canada. At the time of the study the program had been running for 2 years. Data was collected using semi-structured interviews $(M=31.33 \mathrm{~min})$ with eight youth participants. Interview questions explored youth perceptions of how the GJWHF program helped them develop life skills and transfer them to domains outside of sport. Questions included: "What skills have you learned in the program?" "Do you plan to use the skills you've learned in the program in your life?" "What within GJWHF helped you to apply the skill to youth life?" Inductive thematic analysis was used to analyze the interview transcriptions (Bean et al., 2016).

Youth participants identified a range of intrapersonal (emotion regulation, focus, goal setting) and interpersonal skills (respect, responsibility, social skills) that they developed during the GJWHF program that they transferred to other domains of their lives (Bean et al., 2016). These domains included school, home, peer groups, and physical activity sessions during GJWHF. The specific strategies that youth identified as most helpful in developing and transferring these life skills were: 1) the rose and thorn activity (respect)- share one positive and one challenging experience from past week; 2) deep breathing (emotion regulation)- taking deep breaths when overwhelmed; 3) spaghetti exercise (emotion regulation): imagine feeling like spaghetti to relax; 4) power bracelets (emotion regulation, positive self-talk): make bracelets with word on it that is helpful in tough situations; 5) focus grid (focus)- focus on grid and find certain amount of numbers in set time; 6) dare to dream (goal setting, positive future orientation)- write down dream and discuss with others; 7) knights, horses, cavaliers activity (social skills, team work, inclusion)- cooperative game that requires team work, communication, and social support. 8) Photographs (respect, appreciating differences, confidence)-portfolio 
pictures taken; and 9) integrating PA into each session (PA competence, perseverance, emotion regulation)-integrating PA and providing choice for PA (Bean et al., 2016).

Overall, Bean and colleagues (2016) study contributed to a greater understanding of how community programming can contribute to positive developmental outcomes (that also transfer). Specifically, the key to this success was the use of intentional strategies to develop life skills and promote transfer. In addition, the female only-environment with youth proved to be a helpful environment in which girls could gain confidence in their PA skills and learn life skills, and also helped them continue to increase their engagement in sport and PA. The long-term nature of the program may also have been a strong contributing factor for transference of skills. Future programming can strengthen the work started by Bean and colleagues by including multiple forms of assessment that triangulate observational data using both quantitative and qualitative methods.

Overall the aforementioned studies reported high fidelity to TPSR principles and strategies and also presented evidence that high fidelity leads to positive developmental outcomes in participants and also transfer of learning. More importantly, through their exploration of fidelity to TPSR principles and transfer of learning, these studies presented strong evidence for specific practical strategies that would be more likely to promote positive youth development in TPSR programming:

- Using structured activities such as those used in the SUPER model is helpful during relational time and the awareness talk. Well thought-out structured activities provide opportunities to practice skills and also create a positive group climate (Bean et al., 2014).

- The explicit teaching strategies included on the TARE (Tool for Assessing Responsibilitybased Education) are foundational strategies for every facilitator to develop in order to help 
participants create a meaningful sport experience (Wright et al., 2012). The nine teaching strategies on the original TARE and now the revised TARE 2.0 are: modeling respect, setting expectations, providing opportunities for success, fostering social interaction, assigning manageable tasks, providing leadership opportunities, giving choices and voices, role in assessment, and encouraging transfer (TARE 2.0; Escarti et al., 2015). These teaching strategies can be used in the coach training period to provide coaches with pedagogical strategies that will lead to responsibility outcomes. The TARE 2.0 can also be used as an observational tool to assess fidelity of TPSR program implementation to TPSR themes and learning strategies (Escarti et al., 2015).

- Adopting a youth-centered approach of empowering kids and giving them a chance to lead and participate in discussion is a necessary inclusion as it is the strongest contributor to creating a sense of personal responsibility (Whitley \& Gould, 2010).

- Creating a caring environment is the foundation of positive developmental outcomes in youth programming. Respect and unconditional positive regard from the facilitator to the participant is pivotal. In addition, the facilitator must bring high energy and should individualize their approach to each participant (Buckle \& Walsh, 2013; Whitley, 2012; Whitley \& Gould, 2010; Wright et al., 2012)

- There is great value in assessing local needs and challenges of youth to inform program design (Whitley, Coble, Jewell, 2016).

- Programming should provide intentional leadership opportunities such as teaching physical activity to younger kids or allowing kids who excel in certain sports to take on leadership positions for sessions utilizing those sports (Bean et al., 2014; Whitley, Coble, Jewell, 2016). 
- The ratio of facilitators to participants shouldn't exceed 1:5 and groups should include 15 participants at a maximum. This size is good for group activities, provides the opportunity for quality one-on-one interactions, and allows for a caring climate to be achieved (Cryan \& Martinek; Whitley \& Gould, 2010). Breaking the large group into smaller groups of five or six with two facilitators per group can also help build social connection and peer relationships and increases behavioral management (Bean et al., 2014).

- Programs should strongly consider grounding their TPSR program in a theory of behavior change, development, or learning. A handful of TPSR programs (Escarti et al., 2010; Gordon et al., 2016; Walsh et al., 2010; Whitley, Coble, \& Jewell, 2016) have successfully done so using theories such as social learning theory, social and emotional learning theory, framework for acculturation, and possible selves theory. However, the majority of programs do not include a theory as a foundation for their work.

- It can be challenging to implement a youth program that includes discussion components in a developmentally appropriate way as this varies according to cultural context and age of the participants. Careful assessment and consideration of the developmental capabilities of the potential participants is therefore necessary (Whitley \& Gould, 2010).

- It is worth considering dividing groups according to gender. A female only-environment with youth has been shown to be a helpful environment in which girls can gain confidence in their physical activity skills, learn life skills, and develop a commitment to continue their engagement in sport and physical activity (Bean et al., 2016).

Specific to transfer of learning, several important considerations should be made:

- TPSR programs need to be aware of the larger social and community-level environment that youth are surrounded by. Transfer of skills is exponentially more difficult when the youth 
are surrounded by social contexts that don't support the same values as the program. Youth will subsequently receive contradictory messages from the program compared to their social context, which can lower the likelihood of transfer. Extending TPSR programming to include partnerships with organizations that engage parents in collectively working towards changing school and community contexts (Collective Parental Engagement) may be one useful approach (Jacobs et al., 2017).

- In situations where it is difficult to forge larger partnerships, explicit strategies can be used to promote transfer. "Hugging" refers to discussion-based activities where similarities are discussed between sport learning and school or home application i.e. hugging. "Bridging" refers to teaching youth how to overcome challenges in the TPSR context that can then be used in overcoming problems in an entirely new situation. Moreover, greater emphasis may need to be placed on how young people can transfer skills to the larger environment when the reality is that they may receive resistance to that transfer (Jacobs et al., 2017).

- Use explicit strategies and provide opportunities for practice (Jacobs et al., 2017). Providing youth with opportunities to make choices helps facilitate learning. Transfer of learning is then facilitated through "reflection-on-action", which allows youth to work through their own cognitive process and figure out how that may work next time, in a different context (Gordon \& Doyle, 2015; Jacobs et al., 2017). Good examples of useful structured activities can be found in Bean and colleagues (2016) study.

- Transfer should be included in discussion from the very beginning of the program. It should be infused in as many sections of the TPSR daily structure as possible but should especially be emphasized in the group discussions (Bean et al., 2016; Whitley, Coble, Jewell, 2016; Walsh et al., 2010). 
- Long-term programming of approximately 9 months with at least 10 sessions is optimal for transference to occur (Catalano, Berglund, Ryan, Lonczak, \& Hawkins, 2004).

Evidence from the TPSR-based youth programming presented in this section indicate that the TPSR model may be a useful guiding framework to help coaches deliver life skills-focused sport coaching. In eSwatini, where research is limited on the role of coaches in youth life skills development, the TPSR model and the best coaching practices outlined in the previous section could provide the foundation for sport-based youth development initiatives that use coaches to deliver the programming. However, it is necessary to remember that each of the identified TPSR programs were designed and implemented within specific populations that each have their own youth challenges and needs. Future explorations of TPSR programming with different youth populations and cultural contexts therefore need to sufficiently explore how the model might operate differently in those social environments as well as the strategies most effective in promoting life skills outcomes. These future research endeavors might begin by identifying the needs and lived experiences of youth in that context and then further examine the specific coaching/facilitator strategies that lead to life skills outcomes and positive sport participation experiences.

\section{Theoretical framework}

When designing youth health promotion and behavior change programming, understanding and using theory is pivotal in developing a program that integrates the factors that most strongly influence behavior and most effectively create change (Eldredge et al., 2016). However, in the youth development literature in general (Roth \& Brooks-Gunn, 2016) and specifically in PYD through sport (Holt et al., 2017), there is still significant growth that needs to occur in understanding the processes, critical program components, and theoretical 
underpinnings of successful youth development programming (Coalter, 2015; Holt et al., 2017;

Roth \& Brooks-Gunn, 2016). Future youth programs should therefore take careful consideration

to systematically approach program development and ground program design in clear theories of youth development and learning. The current dissertation will use Green and Kreuter's (1991)

Precede-Proceed model to guide the development of the youth sport-based development program proposed in this dissertation (Porter, 2015). In addition, two theories of learning and youth development will be used as the theoretical underpinnings of the program.

\section{Precede-Proceed model}

The Precede-Proceed model is a systematic planning approach for health promotion programming from the field of public health that emphasizes the use of the following five main approaches: 1) social ecological perspectives (multi-level health determinants); 2) community participation in planning and design; 3) population-level lens; 4) integration of theory and evidence from real-world application; and 5) quality of life emphasis instead of simply health or behavior change. The model is divided into 8 phases: 4 phases that describe the steps involved in understanding the health needs of a community and then effectively planning programming (Precede); and 4 phases that outline implementation and evaluation of programming (Proceed) (Porter, 2015)

The four phases of the Precede section of the model aid in creating a logic model (i.e. theory of the problem) that identifies the health issue and its impacts on quality of life, as well as the relations between health determinants/causes and the development and maintenance of the health issue (Porter, 2015; Eldredge et al., 2016). Phase 1 is the social needs assessment phase where the community is co-opted to identify the priority areas for quality of life improvement. Community priorities are integral to identify when aiming to design programming that is well- 
received and impactful. Phase 2 is an epidemiological assessment of the primary health issues, the environment, and the health behaviors contributing to those health issues. Phase 3 expands upon the physical, social and economic determinants of health from phase 2 by examining the wider educational and ecological factors contributing to the health issue. Specifically, the individual reinforcing factors such as knowledge and skills are identified, the enabling resources and skills that facilitate change are explored, and the reinforcing factors for successful behavior change are identified i.e. PRE factors. Once these determinants have been identified, change objectives for the program can then be outlined (Porter, 2015).

Phase 4 identifies the policy, regulatory, and organizational factors (PRO) that may help or hinder intervention implementation, and then identifies the steps and intervention approach that will address the phase 3 factors (Porter, 2015). That is, a logic model of the problem is created and the needs assessment findings are used to match evidence-based and theoretically driven interventions to the desired outcomes (goals and objectives). This step is where decisions are made about 'how' the health change or quality of life outcome will be achieved. Program design components can then be identified and integrated into a theoretical framework that outlines the factors that most strongly influence behavior (cause-effect) and therefore the factors that would be most effective in creating change (Porter, 2015).

The Proceed section of the model then emphasizes the steps that need to follow planning and design of health programming i.e. implementation (phase 5), fidelity and process evaluation (phase 6), impact evaluation of intervention on phase 3 (PRE) factors (phase 7), and outcome evaluation of environmental factors and behavioral outcomes (phase 8) (Porter, 2015). The program implementation phase (phase 5) is the stage in which the program is delivered to participants. The process evaluation phase (phase 6) focuses on 'how' the program was 
implemented in terms of quality and quantity of the intervention (Porter, 2015; Eldredge et al., 2016). This phase is valuable in identifying how program elements lead to program outcomes. This can include explorations of who received the program versus who the program was intended for. It can also refer to the dose of program delivery (how much of the intended program modules were implemented) or fidelity of program delivery i.e. was the program delivered in the manner with which it was intended to be delivered. Impact and outcome evaluation refers to the efficacy or effectiveness of the program i.e. an assessment of whether the presence of the program had an impact on the change objectives or quality of life of the program recipients (Porter, 2015; Eldredge et al., 2016).

\section{Needs assessment/pilot phase (PRECEDE) to inform dissertation feasibility study}

Based on the guidelines of the Precede-Proceed model, a needs assessment/pilot study was conducted in eSwatini in the Summer of 2017 as the starting point for the dissertation feasibility study. Data was collected using focus groups with emaSwati youth $(N=112$, male $=50$, female $=62)$ and interviews with youth coaches $(N=9,2$ females and 7 males $)$, community members ( $N=6,4$ females and 2 males), and key informants ( $N=6,3$ females and 3 males) who were experts in the HIV/AIDS prevention field in eSwatini. The objectives of the needs assessment were to examine the perceptions of emaSwati youth and adults in the following areas: 1) the biggest developmental challenges facing youth in eSwatini, with a specific emphasis on HIV/AIDS; 2) the factors contributing to youth susceptibility to HIV/AIDS in eSwatini; 3) the life skills or competencies that may reduce risk for youth HIV/AIDS infection; 4) the perceived needs and capacity of the community in responding to youth HIV/AIDS; and 5) the youth sport experience in eSwatini, which included perceptions of sport as a platform to develop life skills or competencies that could help youth overcome developmental challenges and reduce risk for 
youth HIV/AIDS infection. The purpose of collecting this data from the needs assessment/pilot phase was to inform the design and implementation of a brief sport-based HIV/AIDS prevention (SBHP) intervention that would use sport as a platform to teach the life skills or competencies needed to protect young emaSwati from HIV/AIDS infection.

Preliminary findings from the needs assessment have been integrated into the PRECEDE phases as follows:

\section{Phase 1: Priority areas for quality of life issues}

Findings from the needs assessment indicated that community members, HIV experts, and coaches were most concerned about the developmental trajectory of emaSwati youth in the current generation. Specifically, they described concerns related to youth growing up and living a life of poverty with little personal meaning, limited contribution to society, and high likelihood of experiencing significant stigma, health-related issues and reduced quality of life due to contracting HIV/AIDS.

\section{Phase 2: Health behavior issues, environment, and health outcomes}

Community members, HIV experts, and coaches reported that the most significant health outcomes for emaSwati youth are high risk for contracting HIV/AIDS especially in the 15-24 years old age-group, and poor overall development (cognitive, emotional, and social development). HIV/AIDS has been a health epidemic in eSwatini for several decades and continues to disproportionally affect emaSwati youth, and especially young girls. Participants stated that the risky health behaviors contributing to risk for HIV/AIDS are early sexual debut, transactional sex, intergenerational sex, and unprotected sex. It was also further reported that these risky health behaviors are occurring within an environment of parental neglect, negative peer cultures, lack of role models, limited access to quality education, poverty, and crime. 
Phase 3: (PRE) Predisposing, reinforcing, and enabling factors contributing to health behavior

$\underline{\text { issues }}$

Overall, key informants (i.e. HIV/AIDS experts) expressed that HIV/AIDS is an immensely complex issue in eSwatini with a range of macro-level and environmental contributing factors as well as interpersonal and individual-level challenges. Effectively addressing HIV/AIDS prevention in emaSwati youth is therefore an endeavor that takes time, considerable investment, and multi-disciplinary expertise.

Specific to predisposing individual factors for risk behaviors related to HIV/AIDS, HIV experts stated that youth susceptibility to HIV/AIDS in eSwatini is not so much influenced by knowledge of HIV transmission and prevention strategies. Rather, HIV/AIDS has been a major epidemic in eSwatini for several decades now and countless prevention efforts have been launched and directed at youth since then. Consequently, emaSwati youth are saturated with HIV/AIDS transmission and prevention information. Knowledge is therefore not a major prevention issue. Rather, it is the knowledge-to-skills translation that is problematic whereby emaSwati youth are lacking the life skills necessary to navigate sexual decision-making, relationships, and gender dynamics. Further, participants identified firmly entrenched beliefs related to power dynamics in relationships, consent, and gender roles that are significant individual predisposing factors.

Related to health behaviors contributing to overall healthy development, the needs assessment also revealed individual factors (knowledge and psychosocial factors) specific to perceptions about sport participation. First, sport is loved by youth in eSwatini and is perceived as an opportunity to get away from the daily challenges youth face. Youth recognize the potential role of sport in health and wellness as well as for learning life skills such as discipline, managing 
emotions, respect for different people, focus, responsibility, commitment, cooperation, hard work, self-confidence, perseverance, team work, and fair play. EmaSwati youth also reported that the life skills they learn in sport can transfer to other domains of their lives: 1) using focus and commitment in school; 2) persevering in all areas of life when you face challenges; 3 ) respect for teachers, friends, and family members; 4) discipline and responsibility at home and in school; 5) working hard in school; and 6) working as a team at schooling for group projects. Overall, youth have positive perceptions of sport within the context of healthy development and believe that sport can help them overcome the major community challenges the face in the following ways: 1) Sport can be a positive distraction from the major developmental challenges youth face; 2) Sport can teach youth life skills that helps them overcome challenges; 3) Sport is a place where youth can find people who share similar struggles i.e. sense of belonging; 4) Sport can be a constructive activity to engage in instead of risky behaviors; and 5) Sport can help youth build self-esteem and confidence to better face life's challenges. Overall, youth expressed positive attitudes and cognitions related to participating in sport, learning new sports, and learning life skills through sport participation.

In terms of the reinforcers of risky health behaviors, participants i.e. community members, HIV experts, and coaches, also expressed that poor youth decisions related to engaging in risky health behaviors are reinforced by peer environments that perpetuate unhealthy discourse related to unprotected sex and male dominance in sexual decision-making. Further, youth often don't receive any comprehensive sex education opportunities in school in order to help them make healthier decisions. This was reported to stem from parental resistance to sex education in schools due to beliefs that talking about sex will increase sexual activity. EmaSwati youth are also lacking the adult mentorship needed to guide their healthy development and reinforce 
healthier life decisions. Within this context of limited positive role models, coaches expressed that there is great potential for coaches to play a positive reinforcement role in the development of emaSwati youth as coaches are aware of the community challenges that youth are facing and are also highly bought-in to the educator and mentorship role that they could play in the lives of youth athletes. Further, despite lack of training, coaches are in their own way reinforcing positive youth decision-making by attempting to teach skills during sport participation that transcend the sport setting and transfer to career and life domains. Some of the strategies coaches identified were role modeling, engaging youth in discussion, and investing in the coach-athlete relationship. Coaches also reported that they are open and willing to engage in coach education and training to develop positive youth development coaching strategies to better reinforce and support healthy youth development.

Finally, findings from the needs assessment also identified enabling skills and environmental factors that could support successful youth development and lowering of HIV/AIDS risk. Specifically, HIV/AIDS experts and community members identified life skills such as self-belief, social \& personal responsibility, goal-setting, decision-making, self-efficacy, and emotional expression as key skills to develop to support positive youth development and lower risk for HIV contraction. Community members also stated that many emaSwati youth are growing up without father figures and adult mentors to guide their development so providing those positive role models who are supportive and caring will enable their healthy development. In addition, they expressed the need for more initiatives and programming to positively engage youth in their own development. These could include sport-based programming that the community members thought would be very well received. 
Phase 4: (PRO) Policy, regulatory, and organizational factors contributing to health behavior issues and steps to inform intervention design

At the organizational, regulatory, and policy level, the needs assessment results also elucidated several factors that might hinder the implementation of sport-based youth development programming. First, HIV/AIDS experts stated that the youth environment is so saturated with HIV/AIDS prevention programming that youth are "immune" to potential programming impacts. It was therefore suggested that more creative initiatives need to be developed to engage emaSwati youth in prevention efforts. It was agreed that sport could be a viable option for a creative and engaging context through which to educate youth and teach them life skills. At the organizational and resource level, community members, coaches, and HIV/AIDS experts also identified challenges such as limited resources for youth programming, lack of sporting infrastructure, lack of resources to train coaches to facilitate holistic sport programming, and few qualified professionals in sport-for-development.

Based on the preliminary results from the needs assessment/pilot phase, several decisions were made to guide the development of the dissertation feasibility study. First, sport is a beloved and creative context through which to engage emaSwati youth in positive development. Using sport as the platform for youth programming in my dissertation programming was therefore an appropriate path forward. Second, HIV/AIDS prevention is an immensely complex issue that requires long-term investment, strong community connections, and a multidisciplinary approach. The dissertation feasibility study therefore took out the HIV/AIDS component and instead focused on developing the life skills that HIV/AIDS experts identified as most valuable for HIV/AIDS prevention and for overall health youth development i.e. PRE factors identified in phase 3. These included: self-belief, social \& personal responsibility, goal-setting, decision- 
making, self-efficacy, and emotional expression. Third, youth within the 15-24 years old demographic have already developed a strong set of beliefs related to relationships, gender roles, sexual intimacy etc. It would therefore be more effective to engage younger age demographics in youth development programming. Fourth, emaSwati youth are lacking caring and empathetic adult mentors. Given that coaches believed in their role as mentors and educators for youth athletes, they were an appropriate population to engage with to implement sport-based positive youth development dissertation programming. Fifth, coaches were keen to learn strategies and approaches to strengthen their ability to facilitate life skills learning for their athletes. Using the Teaching Personal and Social Responsibility (TPSR) model to guide coach education for the dissertation study was therefore a viable option. Last, emaSwati youth were interested in engaging in mixed-gender sport-based programming where they learn multiple sports. The dissertation program was therefore designed to include these elements.

The figure below provides a simple logic model for the current dissertation feasibility study i.e. health issue (youth development and HIV/AIDS infection), quality of life (future of poverty, stigma and reduced quality of life due to HIV/AIDS, low contribution to society), determinants of youth development (lack of life skills, lack of role models, poor education, risky health behaviors), and the health program (sport-based life skills development). 
Figure 1.

Logic Model (Precede) of factors contributing to positive development of Swazi youth

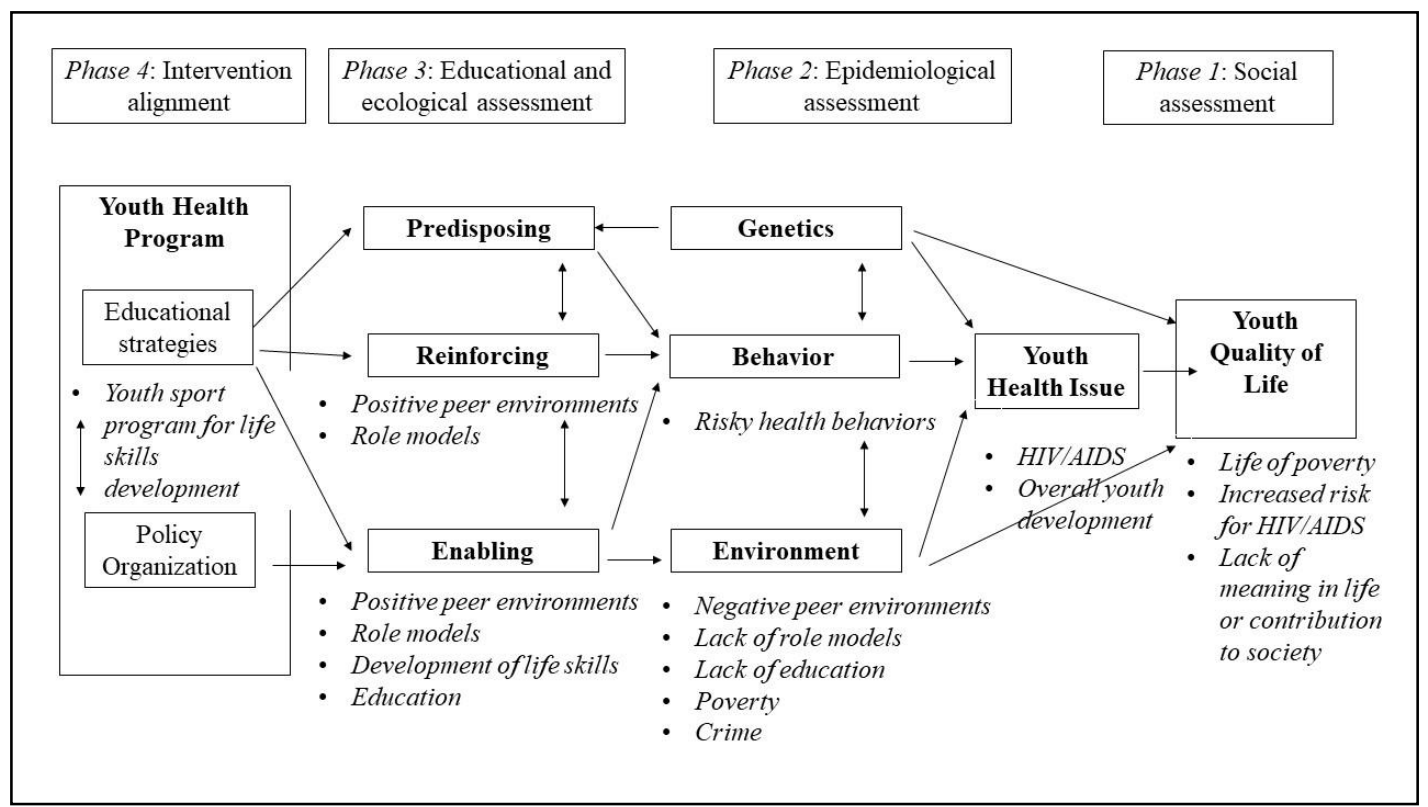

Youth sport program: Theoretical framework

Consistent with the Precede-Proceed model, after conducting the needs assessment, the sport-based youth life skills development program was designed and developed using findings from the needs assessment, evidence from the literature (i.e. TPSR programming research), and was clearly grounded in theory. The next section focuses on the theories that grounded program development. This dissertation integrated major tenets from two different theories: social cognitive theory was embedded within the framework of positive youth development that outlines the value of a supportive sport environment and a caring, empathetic role model (i.e. coach) in facilitating life skills development.

Schulenkorf and colleagues (2016) review of 437 peer-reviewed articles of sport programming with developmental outcomes (2000-2013) indicates that positive youth 
development (PYD) has been the most cited theoretical framework for applied SFD programs. Positive youth development makes sense as a theoretical framework for youth development because it is grounded in the belief that all youth are intrinsically capable of developing the resources and skills necessary to live healthy and fulfilling lives (Holt et al., 2017). Youth simply need some guidance in how to nurture those skills (Holt et al., 2017). Moreover, SFD programs in general have been strongly criticized for the "deficit approach" that is often adopted by these programs where youth in underprivileged communities are viewed as deficient and in need of saving from top-down organizations (Coakley, 2011). A PYD framework takes the opposite approach and acknowledges the inherent capacity of all youth to create meaningful futures for themselves with a little bit of help. Positive youth development is a strengths-based approach that emphasizes the interplay between the individual and their social environment to promote the development of positive life skills outcomes (Holt et al., 2017).

Although PYD has been a popular framework for SFD programs, it was only more recently that an evidence-based PYD model for life skills development through sport was crafted, which has both "explanatory power [as well as] practical utility" as any theory should (Holt et al., 2017, p. 37). That is, it helps to: 1) explain the processes and critical components of youth programs that lead to developmental outcomes; and 2) provide practical recommendations for practitioners and implementers of these programs. As previously outlined in the literature review, this model of PYD through sport proposes that youth development through sport participation can occur through implicit and explicit pathways (Holt et al., 2017). The implicit pathways are facilitated through the creation of PYD climates where there is an empathetic and caring coach-athlete relationship and supportive peer interactions. The explicit pathways occur through life skills building activities where the coach intentionally provides opportunities for 
youth to develop those resources and strengths that every child is capable of developing. The TPSR model that will be used in this dissertation is grounded in PYD principles of youthcentered approaches where positive and enabling sport environments are created and explicit activities are employed that build youth assets (i.e. life skills) and agency (i.e. perceived ability to employ those assets to create change) (Hinson et al., 2016; Martinek \& Hellison, 2016).

The second theory that will ground this dissertation is Bandura's Social Cognitive Theory (Bandura, 2001). Social cognitive theory views adolescent development through the lens of personal agency and the fundamental right of all humans to be able to exercise control over the quality of their own life and their personal development. Personal agency is understood through four core features: intentionality; forethought; self-reactiveness; and self-reflectiveness. Intentionality refers to a future action that the individual commits to executing, therefore underscoring the capacity of every individual to be able to choose and regulate their own behavior. Forethought adds another layer to personal agency by outlining the role of planning, goal-setting, and prioritization in helping individuals be motivated to make positive decisions for themselves that will lead to constructive outcomes. This is valuable in the face of competing social influences where young people need to use self-direction to make decisions and behave in ways that contribute to creating a meaningful life for themselves (Bandura, 2001).

After creating an intention and then planning for how that intention can be met, selfreactiveness is the next step in regulating and motivating behavior in order to meet those goals and plans i.e. moving from thought to action (Bandura, 2001). This involves self-monitoring, subscribing to a set of values or personal standards, and engaging in self-corrections or selfregulatory processes in response to meeting or failing to meet personal standards. The last layer of personal agency is self-reflectiveness. Self-reflectiveness allows the individual to meta- 
cognitively reflect on the meaning of their own lives and the thoughts, actions, values, and motivation that lead to certain outcomes. This process of self-reflection on thoughts and actions is what reveals the individual's sense of self-efficacy i.e. the individual's "belief in their capability to exercise some measure of control over their own functioning and over environmental events" (Bandura, 2001, p.10). Within personal agency, self-efficacy lies at the very core because self-regulatory behaviors will be strongly influenced by the extent to which an individual believes that their behaviors can in fact produce those positive outcomes for themselves (Bandura, 2001).

Within this concept of personal agency and control over quality of life, social cognitive theory also outlines the 3 modes through which human agency is controlled: personal, proxy, and collective (Bandura, 2001). Personal agency involves the intentionality, forethought, selfreactiveness, and self-reflectiveness core features that are all within the control of the individual. However, there are many social contexts where young people do not possess the necessary skills or cannot have direct control over the outcomes they desire so they need to enlist the support of someone else who can act on their behalf. Parent or adult mentors are often the people that serve as agency proxies for young people. Notably, enlisting the help of others requires some sense of personal self-efficacy to even be able to ask for help. The last form of agency, collective agency, refers to shared group beliefs of self-efficacy and the power of coordinated efforts within a social system to achieve positive outcomes. For example, collective agency for young people as a group might refer to their shared beliefs, self-efficacy, knowledge and skills to change the quality of life of young people within their communities. These three modes of human agency will overlap and interact to influence personal development (Bandura, 2001). 
Several sport-based youth development programs have made use of social cognitive theory and its central concept of perceived self-efficacy and human agency. As previously described, the Buffalo City Soccer School (BCSS) in the Eastern Cape Province of South Africa was grounded in social cognitive theory (Draper \& Coalter, 2016). To briefly review, youth male participants were part of a soccer league that involved 3 weekly soccer training sessions and also 2 interactive weekly group life skills sessions. The interactive sessions focused on life skills such as problem solving, leadership, teamwork, self-awareness, decision-making, and self-confidence. As a result of the program, youth participants reported improvements in life skills related to selfefficacy (i.e. confidence, self-belief, self-discipline, communication etc.). In addition, participants reported learning outcomes related to future-thinking, prioritizing, and making positive decisions for their future, which aligns with the 'intentionality' component of Bandura's (2001) conceptualization of self-efficacy. The findings from the program supported the relevance of grounding the program in Bandura's (2001) concepts of perceived self-efficacy and agency.

An additional sport-based youth development study that effectively integrated selfefficacy and social cognitive theory was Escarti and colleagues (2010) TPSR-based youth sport program in Spain. The details of the 9-month program were described in an earlier session. Briefly, the study aimed to examine changes in self-efficacy of at-risk 13 and 14-year-old youth in two physical education classes at two high schools in Valencia, Spain. One class was assigned as the control group while the other was the intervention group. The authors grounded their study in social cognitive theory because of the wealth of research that suggests that adolescents high in perceived self-efficacy for coping with stressors and meeting social demands are less likely to experience serious stress and more likely to persevere (Bandura, 1997; Escarti et al., 2010). The TPSR model was hypothesized to be an effective framework to build self-efficacy due to its 
focus on building life skills such as personal and social responsibility (i.e. by providing opportunities to intentionally practice those skills) in young people and providing opportunities to achieve success in the TPSR activities. That is, as levels of personal and social responsibility increased, levels of perceived personal and social self-efficacy would also increase. Through the TPSR framework, the authors explored whether 4 different self-efficacy skills could be built: 1 ) enlisting social resources; 2) self-regulated learning; 3) self-regulatory efficacy; and 4) social self-efficacy. As described previously in more detail, youth outcomes were assessed using the MSPSE (Bandura, 1990) as well as interviews with youth and classroom teachers (Escarti et al., 2010).

Findings from the student interview indicated that overall students had positive experiences due to the caring relationship with the instructor and also due to the positive changes they observed in their own behavior and the behavior of their peers (Escarti et al., 2010). Students also reported improvements in self-control and respect for others (less insulting, more conversation, admitting mistakes), communication and cooperation skills, teamwork, willingness to discuss problems and speaking up when something could be better. Students also stated that life skills transferred to other areas of school and to the home environment. Results from the teacher interviews indicated a strong belief in the effectiveness of the TPSR model as students showed changes in conflict resolution, respect and responsibility, and listening skills. Findings from the MSPSE indicated an increase in self-efficacy for enlisting social resources in the intervention group $(F(2,56)=4.260, p=.019)$ as well as an increase in self-efficacy for selfregulated learning i.e. perception of ability for self-control and managing peer dynamics ( $F(2$, 56) $\left.=3.759, p=.029, \eta^{2}=.118\right)($ Escarti et al., 2010). 
The other two subscales (social self-efficacy and self-regulatory efficacy) had no significant effects (Escarti et al., 2010). The authors concluded that through increases in personal and social responsibility, youth participants were also able to show changes in perceived selfefficacy to manage social resources, which is a marker of high self-control and ability to resist peer pressure. The authors suggested that it was the teaching methods (i.e. providing youth with opportunities to self-regulate behaviour and set attainable goals) and use of self-reflection practices that led to these increases in self-efficacy. Future studies might strengthen the findings from this study by supplementing the MSPSE with a quantitative assessment of personal and social responsibility.

The aforementioned studies provide support for the use of both positive youth development and social cognitive theory as useful theories to ground youth sport programming and specifically TPSR programming. The emphasis of PYD on creating positive sporting environments and treating youth as inherently capable of becoming successful complements the emphasis of social cognitive theory on human agency and the active role that youth may play in their development. The use of both implicit and implicit PYD learning pathways may also provide the right social environment for self-efficacy beliefs to emerge in youth sport participants.

\section{Summary of Literature Review}

Youth in eSwatini are facing significant health-related, economic, social, and resource challenges that are impeding their ability to create meaningful futures for themselves. In addition, due to the HIV/AIDS epidemic in eSwatini, a considerable proportion of youth are single or double orphans without adult role models to guide their development. Although there are government-led initiatives that operate at the community, and national, level to support youth 
development, adoption of these services is limited. There is therefore a need to find more creative and engaging youth initiatives that provide supportive and caring environments for the healthy development young Swazis.

Sport may be one potential avenue to explore for youth development programming in eSwatini. Sport has been found to be an appropriate context for youth to cultivate socially desirable skills and be exposed to positive role models such as coaches. Several studies in eSwatini indicate that youth are keen to participate in sport. However, there are major resource barriers for youth participation in sport and formal sport-based youth development programs are scarce. In South Africa, where there is some overlap in the developmental challenges that youth face, there is evidence for the success of sport-based youth programming. Specifically, sport has been found to help South African youth develop the cognitive, emotional, and social life skills necessary to help them address the demands of everyday life. In addition, evidence from South Africa indicates that coaches can play valuable roles in facilitating these outcomes through creating empathetic coach-athlete relationships, using intentional coaching strategies, and providing youth with opportunities to practice life skills.

However, consistent with literature in North America, coaches often do not have the education or training to adequately foster life skills outcomes in youth sport participants. Therefore, because sport participation does not automatically lead to positive developmental outcomes, adequate formal and informal education of youth coaches is necessary. Several models have been proposed as effective frameworks to guide coaches in facilitating youth life skills outcomes. One such model is the teaching personal and social responsibility (TPSR) model. The TPSR model aims to teach youth how to be responsible for their own well-being and the welfare of others. This model has had significant success in promoting a range of life skills 
outcomes in underprivileged and at-risk youth across North America, Spain, New Zealand, and Canada. It is also conceptualized as a model that provides the option to tailor the life skills focus to values and skills that are appropriate to the cultural and youth context that the program operates in. The TPSR model may therefore be an appropriate model to guide the development of a coach-led sport-based life skills program for youth in eSwatini. Training local coaches how to implement a TPSR-based youth program in eSwatini will also provide an opportunity to evaluate how the model might operate differently in a cultural context where youth face unique developmental challenges. 


\section{Appendix A: Sport Program Outline Program Goals}

1) To be physically active

2) To learn new sports and games

3) To have fun

4) To learn life skills and responsibilities

5) To teach coaches new coaching strategies

\section{General Program Structure}

Each day of the program will follow the same TPSR daily structure: 1) relational time (10 min); 2) awareness talk (20 min); 3) physical activity (30 $\mathrm{min})$; 4) group reflection (10 $\mathrm{min})$; and 5) individual reflection $(5 \mathrm{~min})$. The details of each of those components are as follows:

\section{$\underline{\text { Relational Time }(10 \mathrm{~min})}$}

\section{Goal:}

Take attendance

Provide youth with a chance to briefly relax and reset after their day at school

Provide coaches with a chance to interact with youth and get to know them. The focus should be on building a caring and meaningful relationship with as many youth as possible

Provide coaches with an opportunity to individually check-in on how youth have implemented the life skills into their life outside of the sport setting

Coach strategies:

$\checkmark \quad$ Set up some sport equipment so youth can play around and relax

$\checkmark \quad$ Walk around and check-in with as many youth as possible

$\circ$ Make sure to call each youth by their name

- Ask them about their day

○ Comment on behaviors that reflect responsibility levels or life skills e.g. respect

- Smile and engage with the youth enthusiastically

$\checkmark$ Take attendance

- This can be a task that is assigned to a different youth each day as an opportunity to take responsibility for a task. Explain how youth can conduct this task respectfully.

$\checkmark$ Use TARE 2.0 teaching strategies where applicable

$\checkmark$ Use responsibility themes

$\circ$ Empower youth

- Emphasize transfer of skills

○ Put kids first (youth-centered) 


\section{Awareness Talk (20 min)}

Goal:

Teach youth a life skill or responsibility level

Use structure activity to learn life skill

Actively engage youth in learning about a new life skill

- Empower them to take responsibility

Coach strategies:

$\checkmark$ Split the large group into smaller groups, each led by 1-2 coaches. Sit in a circle with the youth.

$\checkmark$ Take a couple of moments to settle the groups: shake out legs and arms, roll shoulders and neck, deep breaths

$\checkmark$ Introduce the life skill concept. Introduce activity that teaches life skill concept

$\checkmark$ ACTIVITY

$\checkmark$ Engage the youth in discussion: don't lecture

$\checkmark$ Use TARE 2.0 teaching strategies where applicable

$\checkmark$ Use responsibility themes

○ Empower youth

- Emphasize transfer of skills

○ Put kids first (youth-centered)

$\checkmark$ Encourage all youth to participate

○ Direct questions at specific youth and then refer back to the group after each response

$\checkmark$ Use scenarios to illustrate the life skill or responsibility level

○ For example: "When you accidentally trip someone while you're playing soccer, what do you do?"

$\checkmark$ Use probes and follow up questions (e.g. tell me more, or why) after youth comments

○ "What does respect mean to you?"

○ "How can you be a good teammate?"

○ "If I were watching you, how would I know that you were being respectful?"

$\checkmark$ Team cheer at end of awareness talk to transition to physical activity

\section{Physical Activity (30 min)}

Goal:

Have fun

Participate in physical activity

Learn a new sport

Integrate physical activity with life skills

Empower youth to practice life skills and take responsibility for their behavior

Coach strategies: 
$\checkmark$ Use at least one timeout to check-in with youth on their use of the life skill/responsibility focus of the day

○ "How are we doing with being respectful so far?"

$\checkmark$ Use intentional teaching strategies

○ Nine TARE 2.0 teaching strategies

O Use high-fives

$\circ$ Use encouragement

- Address disruptive behavior by using time-outs or pulling those youth to the side

$\circ$ Use teachable moments i.e. when something happens during the activity that is applicable to the life skill lesson, point it out and briefly discuss it

$\checkmark$ Provide youth with opportunities to lead as often as possible

$\checkmark$ Use responsibility themes

- Empower youth

- Emphasize transfer of skills

○ Put kids first (youth-centered)

\section{Group Reflection (10 min)}

Goals:

Provide youth with an opportunity to express how they felt about the day

* Empower youth to feel confident to speak up and also to be respectful of one another's opinions

Think about how the lesson of the day can be applied to other domains of life

Coach strategies:

Sit in circle in two groups

Use 1-2 minutes to help the group reset and calm down

- Deep breaths

- Light stretch

Encourage youth to reflect on their experiences of the day

○ "What were the positives and negatives of the day?"

- "How did the group perform in practicing the life skill and learning a new sport?

○ "How might the life skills of the day apply to life at home and at school?"

○ "What could be better for tomorrow?"

Use the creative drawings and signs of the responsibility levels to help youth refer to the life skills and responsibility levels

Encourage youth to be respectful of one another during this sharing phase

- Speak one at a time; don't interrupt

$\circ$ Be honest. Every opinion is encouraged 


\section{$\underline{\text { Individual Reflection (5 } \mathrm{min})}$}

Goals:

Reflect on own attitudes and behaviors of the day

\# Reflect on how to apply the life skills and responsibility lessons of the day to own life

Coach strategies:

Youth sit quietly to reflect in the reflection corner

Encourage youth to reflect on the following:

○ "How do you think you did today with the sport session and practicing the life skill/responsibility?" [Use thumbs up, thumbs down, thumbs to the side to assess]

○ "How will you use what you learned today at home tonight and at school tomorrow?"

$\checkmark$ Allow youth to share answers to those questions after a couple of moments of reflection 
Table 1: Outline of the responsibility level and life skills focus for each session as well as the awareness talk activity and physical activity of the day

\begin{tabular}{|c|c|c|c|c|}
\hline $\begin{array}{c}\text { Session } \\
\#\end{array}$ & $\begin{array}{c}\text { Responsibility } \\
\text { level }\end{array}$ & Life skill Focus & Awareness Talk Activity & Sport/Physical Activity \\
\hline $\begin{array}{c}\text { Week } 1 \\
1\end{array}$ & $\begin{array}{l}\text { Introduction and } \\
\text { overview of } \\
\text { responsibility } \\
\text { levels. }\end{array}$ & $\begin{array}{l}\text { Getting to know one } \\
\text { another }\end{array}$ & N/A & Ice breakers, warm-up games \\
\hline 2 & $\begin{array}{l}\text { Respect \& self- } \\
\text { control (1) } \\
\text { Transfer (5) }\end{array}$ & $\begin{array}{l}\text { Respect } \\
\text { Emotion regulation }\end{array}$ & $\begin{array}{l}\text { Rose and thorn activity } \\
\text { (respect as people share) } \\
\text { Deep breathing }\end{array}$ & Volleyball \\
\hline 3 & $\begin{array}{l}\text { Respect \& self- } \\
\text { control (1) } \\
\text { Transfer }(5)\end{array}$ & $\begin{array}{l}\text { Respect } \\
\text { Emotion regulation }\end{array}$ & $\begin{array}{l}\text { Spaghetti exercise } \\
\text { Guided muscle relaxation }\end{array}$ & $\begin{array}{l}\text { Yoga and stretching: } 3 \text { parts } \\
\text { of yoga (movement, breath, } \\
\text { meditation) }\end{array}$ \\
\hline 4 & $\begin{array}{l}\text { Participation \& } \\
\text { effort (2) } \\
\text { Transfer (5) }\end{array}$ & $\begin{array}{l}\text { Teamwork } \\
\text { Communication }\end{array}$ & Telephone riddle & Soccer \\
\hline 5 & $\begin{array}{l}\text { Self-direction (3) } \\
\text { Transfer (5) }\end{array}$ & $\begin{array}{l}\text { Goal setting } \\
\text { Confidence }\end{array}$ & $\begin{array}{l}\text { Goal setting } \\
\text { Believe in yourself }\end{array}$ & Basketball \\
\hline $\begin{array}{c}\text { Week } 2 \\
6\end{array}$ & $\begin{array}{l}\text { Respect \& self- } \\
\text { control (1) } \\
\text { Transfer (5) }\end{array}$ & $\begin{array}{l}\text { Responsibility } \\
\text { Self-talk/thought control }\end{array}$ & $\begin{array}{l}\text { Power stones } \\
\text { Positive self-talk }\end{array}$ & Soccer \\
\hline 7 & $\begin{array}{l}\text { Participation \& } \\
\text { effort (2) } \\
\text { Transfer (5) }\end{array}$ & $\begin{array}{l}\text { Teamwork } \\
\text { Communication }\end{array}$ & Toxic Waste game & $\begin{array}{l}\text { Cooperative games/physical } \\
\text { fitness drills }\end{array}$ \\
\hline 8 & $\begin{array}{l}\text { Self-direction (3) } \\
\text { Transfer (5) }\end{array}$ & $\begin{array}{l}\text { Decision-making, } \\
\text { courage, and peer } \\
\text { pressure }\end{array}$ & $\begin{array}{l}\text { New planet - Decision-making } \\
\text { activity }\end{array}$ & Basketball \\
\hline 9 & $\begin{array}{l}\text { Self-direction (3) } \\
\text { Transfer (5) }\end{array}$ & $\begin{array}{l}\text { Future-orientation } \\
\text { Hard work }\end{array}$ & Dare to dream & Volleyball \\
\hline
\end{tabular}




\begin{tabular}{|c|c|c|c|c|}
\hline & & Confidence & & \\
\hline 10 & $\begin{array}{l}\text { Caring \& leadership } \\
(4) \\
\text { Transfer (5) }\end{array}$ & $\begin{array}{l}\text { Social skills: compassion, } \\
\text { caring, responding to } \\
\text { other. Giving help to } \\
\text { others. }\end{array}$ & $\begin{array}{l}\text { Compliments activity. STAR } \\
\text { technique. }\end{array}$ & Ultimate frisbee \\
\hline $\begin{array}{c}\text { Week } 3 \\
11\end{array}$ & $\begin{array}{l}\text { Respect \& self- } \\
\text { control (1) } \\
\text { Participation \& } \\
\text { effort (2) } \\
\text { Transfer (5) }\end{array}$ & $\begin{array}{l}\text { Respect; appreciating } \\
\text { difference } \\
\text { Relaxation }\end{array}$ & Individual differences activity & Athletics \\
\hline 12 & $\begin{array}{l}\text { Self-direction (3) } \\
\text { Transfer (5) }\end{array}$ & $\begin{array}{l}\text { Goal-setting } \\
\text { Perseverance }\end{array}$ & $\begin{array}{l}\text { Movement game with barriers } \\
\text { to goals }\end{array}$ & Volleyball \\
\hline 13 & $\begin{array}{l}\text { Caring \& leadership } \\
(4) \\
\text { Transfer (5) }\end{array}$ & $\begin{array}{l}\text { Social skills: compassion } \\
\text { and caring } \\
\text { Conflict resolution }\end{array}$ & $\begin{array}{l}\text { Teddy bear, turtle, owl, and } \\
\text { shark conflict style }\end{array}$ & Netball \\
\hline 14 & $\begin{array}{l}\text { Caring \& leadership } \\
\text { (4) } \\
\text { Transfer (5) } \\
(1),(2),(3)\end{array}$ & Leadership & $\begin{array}{l}\text { Leadership activity: who is a } \\
\text { leader you respect? What } \\
\text { makes them a good leader? } \\
\text { How can you be a leader? } \\
\text { Obstacle course activity }\end{array}$ & Soccer \\
\hline 15 & $\begin{array}{l}\text { Debrief } \\
(1),(2),(3),(4),(5)\end{array}$ & N/A & $\begin{array}{l}\text { Rose and thorn activity } \\
\text { Summary of all life skills } \\
\text { lessons }\end{array}$ & Mini-competitions \\
\hline
\end{tabular}




\section{Daily Session Outline}

$* * * * * *$ Week $1 * * * * *$

\section{Session 1}

Responsibility level: Introduction and outline of responsibility levels

Life skill: Getting to know one another

Awareness talk activity: N/A

Sport/Physical activity: Ice-breakers and warm-up games

\section{Relational time (10 $\mathrm{min})$}

Props/equipment needed: bean bags and buckets

Let youth run around and try to throw bean bags into the buckets

Coach walks around chatting with youth

Awareness talk (extended to $30 \mathrm{~min}$ for day 1)

1. Brief outline of responsibility levels for program

* Ask youth what they think each level means - behaviors that reflect each level of responsibility

* Use creative signs to present the responsibility levels in drawings and in SiSwati words

Respect: respect the feelings of your peers and try to understand their perspective.

Participation and effort: participate with energy and enthusiasm in all activities even if they are challenging or difficult.

Self-direction: accept responsibility for your own actions, set goals, and be strong in resisting peer pressure.

Caring and leadership: show your peers kindness and support and be willing to step up and lead.

Transfer: learning to apply the skills you learn in the sport program to your life in school and at home.

2. Create group agreements

Aim: to create a safe and engaging environment for all youth

* Generate a list of group agreements that are important to the youth participating. For example: avoid negative language and use positive and empowering language. Create a list of these group agreements using "I" statements i.e. "I promise to respect others and listen while they talk." 
* Debrief: why do we need group agreements? How will we make sure we stick to these group agreements?

3. Create team cheer

* As a group ask the youth to come up with a team cheer

Physical activity (30 min)

Ice-breaker games

1. Group Juggling

a. Form a circle with everyone standing up facing the inside of the circle. The leader of the group will begin with one object in hand (i.e. a small ball). The leader will ask one group member to repeat their name, and then the leader will gently toss the object to that group member. The group member will reply "Thank you, (the leader's name)!" The leader will reply by saying, "Your welcome, (the individual's name)!? The object will continue around the circle in the same manner, making sure everyone has received the object, until the object ends up in the hands of the original leader.

b. NOTE: During the first round, once a group member has tossed the object, have them cross their arms to prevent repetition. The same pattern will start again with the leader adding more objects. Once an object has been dropped, the pattern starts all over with the first object. The leader should mix up sizes and shapes of objects (i.e. a rubber chicken, toilet paper, etc.)

2. Samies game

a. Explain that this game is about forming and reforming groups as quickly as possible. Don't worry if you are not even into the first group by the time the next group is called, just head to the next group. The idea is to meet many different groups of people as fast as possible.

b. Suggestions:

Get into a group of three...

Get into a group of $5 \ldots$

Find a partner who is the same height as you

Find everyone else born in the same month as you

Get into a group of 3 and make the letter " $\mathrm{H}$ " with your bodies on the floor/grass

3. String Balloons

a. Materials: String, balloons, and a whistle

b. Give participants a piece of 12" string and a balloon to blow up. After blowing up the balloon, the string should be tied to the balloon and the other end tied to the right or left ankle. After everyone has completed tying their balloons, instruct participants to stand in a circle with their hands behind their backs, standing on one foot. It can be either foot. When the whistle blows, the group moves and around each person, trying to pop someone else's balloon. Once a balloon is popped, that person sits down. The winner is the last person with the balloon still inflated and attached to the ankle.

\section{Group reflection (5 min)}

Gather in circle

Ask youth to share something they enjoyed during the session 
See you all tomorrow!

(No self-reflection time for first session)

\section{Session 2}

Responsibility level: Respect \& self-control (1) AND transfer (5)

Life skill: Respect and emotion regulation

Awareness talk activity: Rose and thorn activity (show respect as people share), deep breathing

Sport/Physical activity: Volleyball

\section{Relational time (10 $\mathrm{min})$}

Set up equipment for youth to play around with and reset from their day

Coaches spend time getting to know youth

Awareness talk (20 min)

1. Sit in groups in circle. Take a couple of breaths to reset.

2. Rose and thorn activity

a. Start with exploration of respect. Ask group: What does it mean to be respectful of others? Why is it important to be respectful of others?

b. Rose and thorn activity: think of one positive experience and one challenging or negative experience from the past week. Prompt youth to share with group. Use respectful behavior in listening to the experiences of others.

3. Deep breathing

a. Start with describing how we all sometimes experience very strong emotions like anger or sadness and we don't know how to deal with those emotions. Ask group: Raise your hand if you sometimes feel very strong emotions. What do you usually do when you feel such strong emotions?

b. Explanation: Belly breathing is a skill that can help you when you experience very strong emotions. It helps you let go of them and relax your body.

c. Instructions: While sitting or laying in a comfortable position place one hand on your belly and your other hand on your chest. Now breathe in slowly into your stomach; it should feel like a balloon is expanding in your belly...your hand on your stomach will rise as you breathe in while the hand on your chest stays still. Breathe in for 3 seconds, hold the breath for 2 seconds, and then exhale for 3 seconds focusing on relaxing your body. [Practice this for a couple of moments]

d. Ask group: What are two times at home or at school when you could use belly breathing? What are two times during sport when you could use belly breathing?

\section{Physical activity (30 min)}

Team cheer to open session 
Address group: all try our best to be respectful of one another while we play and to use deep breathing if we become frustrated or overwhelmed by emotions.

Volleyball drills

Integrate moments of respect and keeping emotions in check

Team cheer to close session

\section{Group reflection (10 $\mathrm{min})$}

Sitting in a circle, ask youth to reflect on their experiences of the day as a group:

○ "What were the positives and negatives of the day?"

○ "How did the group perform in practicing being respectful and keeping emotions in check?

o "How might respect and keeping emotions in check be used at home and at school?"

○ "What could be better for tomorrow?"

Use the creative drawings and signs of the responsibility levels to help youth refer to the life skills and responsibility levels

\section{Self-reflection ( $5 \mathrm{~min})$}

Sitting in a circle in the reflection corner, ask youth to reflect on the following:

○ "How do you think you did today with the sport session and practicing being respectful and keeping your emotions in check?" [Use thumbs up, thumbs down, thumbs to the side to assess]

o "How will you use what you learned today at home tonight and at school tomorrow?"

\section{Session 3}

Responsibility level: Respect \& self-control (1) AND transfer (5)

Life skill: Respect and emotion regulation

Awareness talk activity: Spaghetti exercise and guided muscle relaxation

Sport/Physical activity: Yoga and stretching: 3 parts of yoga (movement, breath, meditation)

Relational time (10 $\mathrm{min})$

Set up equipment for youth to play around with and reset from their day

Coaches spend time getting to know youth

Check in about lesson from previous day

Awareness talk (20 min)

1. Sit in groups in a circle. Take a couple of breaths to reset.

2. Reconnect to emotion regulation and belly breathing activity from the day before. Ask group: Who can tell me what we learned about yesterday in our group chat? Who can give an example of moments at home or at school when we can use belly breathing? 
3. Spaghetti exercise

a. Intro: today we are going to learn another skill to help us relax when we feel strong emotions or when we feel stressed from everything that is happening at home and at school.

b. Explanation: Present the concept of stress and relaxation by talking about uncooked and cooked spaghetti. When you feel stressed-out your muscles or body often get tense or hard, like stiff, uncooked spaghetti. When you feel relaxed your body feels more like warm, soft, cooked spaghetti. [Distribute pieces of cooked and uncooked spaghetti for the youth to explore]

c. Guide youth in tensing ( 3 seconds) and then relaxing different parts of their body: hands in ball, biceps, scrunch up face, tense quads. Ask youth: how does it feel different when you tense or relax different parts of your body? How did you feel before the activity and how do you feel now?

Physical activity (30 min)

$\checkmark$ Team cheer to open session

$\checkmark$ Yoga and stretching: 3 parts of yoga (movement, breath, meditation)

$\checkmark$ Practicing breathing

$\checkmark$ Team cheer to close session

Group reflection (10 $\mathrm{min})$

Sitting in a circle, ask youth to reflect on their experiences of the day as a group:

○ "What were the positives and negatives of the day?"

$\bigcirc$ "How did the group perform in practicing the spaghetti exercise and learning some yoga and stretching?

○ "How might you use the relaxation spaghetti exercise from today at home or at school?"

○ "What could be better for tomorrow?"

Use the creative drawings and signs of the responsibility levels to help youth refer to the life skills and responsibility levels

Self-reflection ( $5 \mathrm{~min})$

Sitting in a circle in the reflection corner, ask youth to reflect on the following:

○ "How do you think you did today with the yoga session and practicing the spaghetti exercise?" [Use thumbs up, thumbs down, thumbs to the side to assess]

o "How will you use what you learned today at home tonight and at school tomorrow?" 
Responsibility level: Participation \& effort (1) AND transfer (5)

Life skill: Teamwork and communication

Awareness talk activity: Telephone riddle

Sport/Physical activity: Soccer

\section{Relational time (10 $\mathrm{min})$}

Set up equipment for youth to play around with and reset from their day

Coaches spend time getting to know youth

Check in about lesson from previous day

Awareness talk (20 min)

1. Sit in groups in circle. Take a couple of breaths to reset.

2. Introduction: today we're going to learn a bit about teamwork and communication. Ask group: what does teamwork mean? What are the positive effects of teamwork? How does communication fit with teamwork?

3. Telephone riddle activity:

- Instructions: Set up in a line for standard telephone game.

- Telephone: the group sends a message from one to another by whispering. Only the next person should be able to hear the message.

- Separate the riddle or message in segments so that multiple members takes a turn being at the front of the line.

○ Members get one try to whisper the message to the person next to them in line.

- Have the last person write down the message on the board.

o No edits are allowed to be made to what is written on the board.

- Then tell the group the message is a riddle and they have 5 minutes to solve it. The group members are allowed to discuss what they remember from the different messages and work together to try and solve the riddle.

Options:

- Offer life-lines if the group is stuck and wants to clarify one of the messages (either give them the correct message or let them send it through the telephone line again).

- Tell the group at the beginning that the message will be a riddle.

Physical activity (30 min)

$\checkmark$ Team cheer to open session

$\checkmark$ Address group: all do our best to give $100 \%$ effort, to practice teamwork and communication throughout the soccer drills and to encourage one another to work as a team and communicate

$\checkmark$ Soccer drills

$\checkmark$ Team cheer to close session

Group reflection (10 $\mathrm{min})$ 
Sitting in a circle, ask youth to reflect on their experiences of the day as a group:

○ "What were the positives and negatives of the day?"

○ "How did the group perform in practicing communication and teamwork and learning some soccer drills?

- Group examples: if a teammate is struggling to understand one of the soccer drills, what can we do as helpful teammates? One of your teammates makes a beautiful pass, how do we respond?

○ "How might teamwork and communication be used at home and at school?"

"Use the creative drawings and signs of the responsibility levels to help youth refer to the life skills and responsibility levels

\section{Self-reflection (5 $\mathrm{min})$}

Sitting in a circle in the reflection corner, ask youth to reflect on the following:

○ "How do you think you did today with soccer today and practicing teamwork and communication?" [Use thumbs up, thumbs down, thumbs to the side to assess]

o "How will you use what you learned today at home tonight and at school tomorrow?"

\section{Session 5}

Responsibility level: Self-direction (1) AND transfer (5)

Life skill: Goal-setting and confidence

Awareness talk activity: Goal-setting, Believe in yourself

Sport/Physical activity: Basketball

\section{Relational time (10 min)}

Set up equipment for youth to play around with and reset from their day

Coaches spend time getting to know youth

Check in about lesson from previous day

Awareness talk (20 min)

1. Sit in groups in circle. Take a couple of breaths to reset.

2. Address team: Already at the end of week 1! Wow! Ask group: How are you all feeling in terms of energy? 1 finger if you feel very tired, 5 fingers if you feel comfortable and happy, and 10 fingers if you feel very excited.

3. Focus of day: thinking about goals. What is a goal (not a goal in soccer)? What are some examples of goals you have made for yourself in the past? When we make goals for ourselves, we always want to state them in a positive way and as something that we can DO....e.g. I will learn new sports!

a. What is one goal that you have for yourself during this sport program?

b. When we set goals, it is important to think about "how" we will achieve those goals because they do not magically happen. For example, if your goal is to learn 
a new sport, how can you achieve that? What must you do? "I will listen to the coaches and my peers and participate in the activities."

4. Short example activity: Lava Mountain \& Magic Shoes

a. Select one teammate to be the group's champion. The task of the champion is to get from point A (the start) to point B (the mountain), $10 \mathrm{~m}$ apart, to plant the team flag. Ask group: What is the goal of the champion?

b. Before we start, as a group let's list the reasons why we should be confident that we can reach the mountain. What are our strengths as a team? [Write on big sheet]

c. However, there is volcanic lava between the starting point and the top of the mountain, and the champion cannot walk on that lava. However, the rest of the team has magic lava shoes that allow them to walk on the lava. How will you get the champion to the top of the mountain? You may work as a team.

d. How do you all feel now that you figured out how to get the champion to the mountain? (feels really good!...important to believe in ourselves that we can accomplish goals!)

Physical activity (30 min)

- Team cheer to open session

○ Address group: Set a group goal for the basketball session. Ask each team member to set a goal for themselves

- Basketball drills

○ Team cheer to close session

Group reflection (10 $\mathrm{min})$

Sitting in a circle, ask youth to reflect on their experiences of the day as a group:

○ "What were the positives and negatives of the day?"

○ "How did the group perform in learning basketball and setting/achieving goals?

- Everyone did really well! Let us be confident in ourselves and others!

○ "How might you set goals at home and at school?"

○ "What could be better for next week?"

Use the creative drawings and signs of the responsibility levels to help youth refer to the life skills and responsibility levels

Self-reflection (5 min)

Sitting in a circle in the reflection corner, ask youth to complete the student learning quiz ○ Identify and give examples of 3 life skills you learned this week

$* * * * * *$ Week $2 * * * * *$

Session 6 
Responsibility level: Respect \& self-control (1) AND transfer (5)

Life skill: Responsibility and self-talk/thought control

Awareness talk activity: Power stones, Positive self-talk

Sport/Physical activity: Soccer

\section{Relational time (10 $\mathrm{min})$}

Set up equipment for youth to play around with and reset from their day

Coaches spend time getting to know youth

Check in about lesson from previous day

Awareness talk (20 min)

1. Sit in groups in circle. Take a couple of breaths to reset.

2. Address group: words can be very powerful! What we say to others can have strong effects on how that person feels. Think about these situations:

a. You work very hard to do a good job on a homework assignment and your teacher tells you that you are lazy and that the work is bad. How do you feel?

b. Someone in your class at school spends a lot of time doing their hair nicely and they really like their new hairstyle. A classmate at school says, "Eish, your hair looks bad." How does that person feel?

c. Can anyone think of an example of words being powerful in their own lives? Gather some examples from the group.

Words are powerful. We need to remember that what we say to other people can make them feel either good or bad. So how can we use our words to be good teammates today?

3. Power stones activity:

a. Intro: words can also be powerful in how we treat ourselves. When we go through difficult times, can we be a friend to ourselves by telling ourselves kind things?

b. Prepare a basket of pebbles or stones that have been painted in different colors. Each team member can pick a stone in a color that they like.

c. On a white board at the front, brain storm with the group a list of words that help youth feel strong when they are going through difficult times.

d. Each youth can pick one of the words or come up with their own words and write it on their stone with permanent marker. They can put the stone next to where they sleep at home as a reminder of a positive word when life is difficult

Physical activity (30 min)

$\checkmark$ Team cheer to open session

$\checkmark$ Address group: all try our best to be positive in how we talk to ourselves and also how we talk to others during these soccer drills.

$\checkmark$ Soccer drills

$\checkmark$ Team cheer to close session 


\section{Group reflection (10 $\mathrm{min})$}

Sitting in a circle, ask youth to reflect on their experiences of the day as a group:

○ "What were the positives and negatives of the day?"

○ "How did the group perform in practicing being encouraging and positive to others and ourselves and learning some new soccer drills?

○ "How might you use positive words at home and at school?"

○ "What could be better for tomorrow?"

Use the creative drawings and signs of the responsibility levels to help youth refer to the life skills and responsibility levels

\section{Self-reflection (5 min)}

Sitting in a circle in the reflection corner, ask youth to reflect on the following:

o "How do you think you did today with the soccer and with practicing being positive with others and yourself? [Use thumbs up, thumbs down, thumbs to the side to assess]

○ "How will you use what you learned today at home tonight and at school tomorrow?"

\section{Session 7}

Responsibility level: Participation \& effort (1) AND transfer (5)

Life skill: Teamwork and communication Awareness talk activity: Toxic Waste game

Sport/Physical activity: Cooperative games/physical fitness drills

\section{Relational time (10 $\mathrm{min})$}

Set up equipment for youth to play around with and reset from their day

Coaches spend time getting to know youth

Check in about lesson from previous day

Awareness talk (20 min)

1. Sit in groups in circle. Take a couple of breaths to reset.

2. Address group: last week we talk a bit about teamwork and communication. What do you all remember about those topics?

a. Since last week, how have you used teamwork and communication at home or at school?

3. Toxic waste activity:

a. Set up \& equipment:

- Open space preferable with one or two obstacles

- At least 10 pieces of rope tied to a ring that will hold a tennis ball.

- Each piece of rope should have a knot no more than 1 inches from the end not attached to the ring. 
- Two stakes are placed a distance apart (at least 10-15 yards, the farther apart the harder the task) the stakes need to hold the tennis ball (2 pieces of pipe can work as stakes).

b. Play \& Rules:

- The tennis ball is extremely dangerous nuclear waste that needs to be transported to a safe zone. The only way to safely transport is with a special device (the ring with the rope connected to it) that will keep the radiation contained. If the ball touches the ground everyone becomes contaminated and the team must restart.

- Each member must hold at least one piece of rope.

- Each piece of rope must be held behind the knot. If any team member comes in contact with the rope in from of the knot that become mildly contaminated which causes them to lose their eyesight.

- The team must work together to lift the tennis ball off stake 1 and move it to stake two while following all the rules just listed. If they quickly finish you can have them try it without talking, one person talks, half the group blindfolded, etc. basically make it harder.

c. Debrief:

- What made the activity hard? How did you meet this challenge?

- What made you successful?

- How did you organize to get the toxic waste across?

- Did someone lead? How did this happen? What was it like to lead? How would it be different if someone else had lead?

Physical activity (30 min)

$\checkmark$ Team cheer to open session

$\checkmark$ Address group: all try our best to participate and give $100 \%$ effort, to communicate with our teammates and work together during the drills and games.

$\checkmark$ Cooperative games/physical fitness drills

$\checkmark$ Team cheer to close session

Group reflection (10 $\mathrm{min})$

Sitting in a circle, ask youth to reflect on their experiences of the day as a group:

○ "What were the positives and negatives of the day?"

○ "How did the group perform in using teamwork and communication during the cooperative games?

- "How might we use communication and teamwork at home and at school?"

○ "What could be better for tomorrow?"

Use the creative drawings and signs of the responsibility levels to help youth refer to the life skills and responsibility levels

Self-reflection (5 min)

Sitting in a circle in the reflection corner, ask youth to reflect on the following:

o "How do you think you did today with the games and practicing teamwork and communication??" [Use thumbs up, thumbs down, thumbs to the side to assess] 
o "How will you use what you learned today at home tonight and at school tomorrow?"

\section{Session 8}

Responsibility level: Self-direction (1) AND transfer (5)

Life skill: Decision-making, courage, and peer pressure

Awareness talk activity: New Planet - Decision-making activity

Sport/Physical activity: Basketball

\section{Relational time (10 $\mathrm{min})$}

Set up equipment for youth to play around with and reset from their day

Coaches spend time getting to know youth

Check in about lesson from previous day

Awareness talk (20 min)

- Sit in groups in circle. Take a couple of breaths to reset.

1. Address group: every day we have to make choices and decisions. We have to decide how hard we will study for a test at school... we have to decide how to respond to a difficult question in class...we have to choose between socializing with friends or going to practice your soccer skills and fitness. In life, some choices are better than others and will lead to better results for us if we make a good choice for ourselves. But sometimes making a decision can be hard because we want to make choices that are the same as our peers. But sometimes we know that the choices or behaviors of our peers are maybe not the best ones.

- What are some examples of difficult choices you all face with your peers?

2. New Planet Activity: Today we will do an activity to practice decision-making.

- Materials: copies of worksheet (1 per group on white paper).

- Directions: divide group into groups of 3-4. Explain that each group will receive a list of 20 people. However, due to air pollution, the earth's ozone is too thin. In a few days, the earth will be too hot for people to survive. NASA is going to send rocket to new planet so humans will not become extinct. However, only 10 of the 20 people can go to the new planet. Each group has 8 minutes to decide who will go. Ask each group to pick a recorder and a reporter.

Group process questions:

a. How did your group make its decisions?

b. What influenced your decisions?

c. What were some challenges? How did you handle conflict? Did you have to compromise?

Did a leader emerge? How did she/he lead?

\section{Physical activity (30 min)}

Team cheer to open session 
$\checkmark$ Address group: all try our best to think about the decisions we make both individually and as a group

$\checkmark$ Basketball drills

$\checkmark$ Team cheer to close session

Group reflection (10 $\mathrm{min})$

Sitting in a circle, ask youth to reflect on their experiences of the day as a group:

○ "What were the positives and negatives of the day?"

○ "How did the group perform in practicing decision-making and learning more basketball skills?

○ "How might we use decision making at home and at school with our friends?"

○ "What could be better for tomorrow?"

Use the creative drawings and signs of the responsibility levels to help youth refer to the life skills and responsibility levels

\section{Self-reflection ( $5 \mathrm{~min})$}

Sitting in a circle in the reflection corner, ask youth to reflect on the following:

○ "How do you think you did today with practicing decision-making and learning more about basketball?" [Use thumbs up, thumbs down, thumbs to the side to assess]

○ "How will you use what you learned today at home tonight and at school tomorrow?"

\section{Session 9}

Responsibility level: Self-direction (1) AND transfer (5)

Life skill: Future orientation, hard work, and confidence

Awareness talk activity: Dare to dream

Sport/Physical activity: Volleyball

\section{Relational time (10 $\mathrm{min})$}

Set up equipment for youth to play around with and reset from their day

Coaches spend time getting to know youth

Check in about lesson from previous day

Awareness talk (20 min)

1. Sit in groups in circle. Take a couple of breaths to reset.

2. Address group: Today we are going to dream together! We are going to think about what each and every one of us dreams of doing with their lives. To dream means that we believe in ourselves and our ability to do something good with our lives. How many of you have a dream job or a dream that you want to teach in your life?

3. Dare to dream activity 
a. Take a couple of moments to write down one or two dreams that you have for yourself. If you have a dream for your family, maybe write that down too.

b. As a group, we are now going to share our dreams with each other. After each person shares, I want us to practice being respectful. After each person shares we will do two claps for that person.

c. How can we help ourselves feel confident about reaching dreams?

Work hard!

Refer back to week on treating ourselves and others with positivity and the Power stones that we made. What can we tell ourselves to help us feel confident to reach our dreams?

We CAN do iiiiiiiitt!

Physical activity (30 $\mathrm{min})$

$\checkmark$ Team cheer to open session

$\checkmark$ Address group: all try our best to practice being confident and work hard toward getting better at volleyball. Before every drill, practice telling yourself, "I CAN do this. I can learn this new drill."

$\checkmark$ Volleyball drills

$\checkmark$ Team cheer to close session

Group reflection (10 $\mathrm{min})$

Sitting in a circle, ask youth to reflect on their experiences of the day as a group:

○ "What were the positives and negatives of the day?"

○ "How did the group perform in practicing being confident and working hard toward getting better at volleyball?

○ "How can we work hard toward our dreams and practice confidence at home and at school?"

○ "What could be better for tomorrow?"

Use the creative drawings and signs of the responsibility levels to help youth refer to the life skills and responsibility levels

\section{Self-reflection (5 min)}

Sitting in a circle in the reflection corner, ask youth to reflect on the following:

○ "How do you think you did today with working hard and practicing being confident?" [Use thumbs up, thumbs down, thumbs to the side to assess]

o "How will you use what you learned today at home tonight and at school tomorrow?" 
Responsibility level: Caring \& leadership (1) AND transfer (5)

Life skill: Social skills: compassion, caring, responding to others. Giving help to others.

Awareness talk activity: Compliments activity. STAR technique.

Sport/Physical activity: Ultimate frisbee

Relational time (10 $\mathrm{min})$

Set up equipment for youth to play around with and reset from their day

Coaches spend time getting to know youth

Check in about lesson from previous day

Awareness talk (20 min)

1. Sit in groups in circle. Take a couple of breaths to reset.

2. Compliments activity

a. Pair up each of the youth in the group. Ask students to have a positive conversation with their partner for a full one minute. During this time, they should compliment each other and make comments on positive things they noticed about their partner.

b. Debrief:

How did you feel about receiving a compliment?

How did you feel about giving a compliment?

Why is it important to embrace people's positive traits?

What happens when we only focus on negative traits?

3. Address group: learning to treat other people with kindness and caring not only involves giving compliments to others and saying nice things, it is also about our behavior, how we respond when we get angry, and what we do to help others.

Teach STAR problem-solving and interpersonal interactions technique.

- Simple strategy to use when we get angry or have conflict with someone else and we need to think about how we behave towards others.

- S: Stop and take a breath. T: Think of how we want to behave and alternative responses/behaviors. A: Anticipate consequences of each response. R: Respond with the best choice.

Discussion of examples of responding to feeling upset and also helping others:

a. When a team-mate trips us while playing soccer and we feel really angry, what do we do?

b. When we are playing volleyball and someone trips and hurts themselves, what do we do?

c. When we see that a teammate is having difficulty learning a new sport drill, what can we do?

Physical activity (30 min) 
$\checkmark$ Team cheer to open session

$\checkmark$ Address group: all try our best to show one another kindness and to help our teammates when they are struggling.

$\checkmark$ Ultimate frisbee drills

$\checkmark$ Team cheer to close session

\section{Group reflection (10 $\mathrm{min})$}

Sitting in a circle, ask youth to reflect on their experiences of the day as a group:

○ "What were the positives and negatives of the day?"

○ "How did the group perform in being kind to one another, helping one another and learning ultimate frisbee?

o "How can we be kind and helpful to others at home and at school?"

○ "What could be better for tomorrow?"

Use the creative drawings and signs of the responsibility levels to help youth refer to the life skills and responsibility levels

\section{Self-reflection (5 min)}

Sitting in a circle in the reflection corner, ask youth to complete the student learning quiz $\circ$ Identify and give an example of 3 life skills learned that week

$* * * * * *$ Week $3 * * * * *$

\section{Session 11}

Responsibility level: Respect \& self-control (1) AND participation \& effort (2)

AND transfer (5)

Life skill: Respect: appreciating difference, relaxation

Awareness talk activity: Individual differences activity

Sport/Physical activity: Athletics

\section{Relational time (10 min)}

Set up equipment for youth to play around with and reset from their day

Coaches spend time getting to know youth

Check in about lesson from previous day

Awareness talk (20 min)

1. Sit in groups in circle. Take a couple of breaths to reset.

2. Individual differences activity:

a. Split the group into two. Introduce idea that everyone is different and these differences are what make us unique. 
b. EXERCISE: For each round, ask students to form a line, without talking, according to:

Age

Height

Number of siblings

Birth month

c. DEBRIEF: What was challenging about this activity? What was easy? How did it feel not to be able to speak?

What kinds of differences did we see between people in this activity?

How else are people different in life?

What are the positive effects of people being different?

How do we make sure that people's differences are accepted?

Physical activity (30 min)

$\checkmark$ Team cheer to open session

$\checkmark$ Address group: all try our best to participate, give $100 \%$ effort, and to be respectful of the differences in our athletics ability.

$\checkmark$ Athletics

$\checkmark$ Team cheer to close session

\section{Group reflection (10 min)}

Sitting in a circle, ask youth to reflect on their experiences of the day as a group:

○ "What were the positives and negatives of the day?"

○ "How did the group perform in practicing being respectful, giving $100 \%$, and respecting differences in athletic ability?

○ "How can we be respectful of differences at home and at school?"

○ "What could be better for tomorrow?"

Use the creative drawings and signs of the responsibility levels to help youth refer to the life skills and responsibility levels

\section{Self-reflection (5 min)}

Sitting in a circle in the reflection corner, ask youth to reflect on the following:

○ "How do you think you did today with the athletics and practicing embracing/respecting differences?" [Use thumbs up, thumbs down, thumbs to the side to assess]

○ "How will you use what you learned today at home tonight and at school tomorrow?" 
Responsibility level: Self-direction (3) AND transfer (5)

Life skill: Goal-setting and perseverance

Awareness talk activity: Movement game with barriers to goals

Sport/Physical activity: Volleyball

\section{Relational time (10 $\mathrm{min})$}

Set up equipment for youth to play around with and reset from their day

Coaches spend time getting to know youth

Check in about lesson from previous day

Awareness talk (20 min)

1. Sit in groups in circle. Take a couple of breaths to reset.

2. Address group: last week we spoke about goals that we wanted to achieve and also dreams that we have for ourselves. However, it can sometimes be more difficult than we think to reach our goals and dreams. How many of you have experienced obstacles in trying to reach goals in the past?

3. Movement game:

a. The point of this exercise is to think about what holds us back from reaching our goals. Break up into two lines. Set up the lines parallel to each another so you are facing someone in the other line with $1 \mathrm{~m}$ between the lines. This should form a tunnel of sorts. One team member will stand at one end of the tunnel. Can I get a volunteer champion?

b. Imagine that this tunnel is the path that you need to take to reach your goals. I'd like you to look down the path/tunnel and envision your goals at the end of the tunnel. What does it look like to reach your goals? How important is it to you to reach those goals?

c. Okay, now walk forwards towards your goal. Wow, you met your goal pretty easily! What does that feel like?

d. Now try again. This time I'd like the rest of you to stick out a leg, an arm etc. to create obstacles for the Champion to move through the tunnel. Champion, try to move along the path to your goal. What did that feel like?

e. Champion, try one more time.

f. Who else wants to try? [repeat with 2 more people]

Debrief:

$\checkmark$ What kinds of obstacles get in the way of us reaching our goals and dreams?

$\checkmark$ How can we overcome those obstacles?

$\checkmark$ What lesson can we learn from this activity?

Physical activity (30 $\mathrm{min})$

Team cheer to open session 
$\checkmark$ Address group: all try our best to persevere and keeping pushing even if we encounter an obstacle or the drill is difficult.

$\checkmark$ Volleyball drills

$\checkmark$ Team cheer to close session

Group reflection (10 $\mathrm{min})$

Sitting in a circle, ask youth to reflect on their experiences of the day as a group:

○ "What were the positives and negatives of the day?"

○ "How did the group perform in overcoming obstacles, persevering, and learning more volleyball skills?

○ "How can we persevere and not give up at home and at school?"

○ "What could be better for tomorrow?"

Use the creative drawings and signs of the responsibility levels to help youth refer to the life skills and responsibility levels

\section{Self-reflection ( $5 \mathrm{~min})$}

Sitting in a circle in the reflection corner, ask youth to reflect on the following:

o "How do you think you personally did today with the volleyball and with practicing never giving up and working through obstacles?" [Use thumbs up, thumbs down, thumbs to the side to assess]

o "How will you use what you learned today at home tonight and at school tomorrow?"

\section{Session 13}

Responsibility level: Caring \& leadership (4) AND transfer (5)

Life skill: Social skills: compassion and caring. Conflict resolution

Awareness talk activity: Teddy bear, turtle, shark, and owl conflict style

Sport/Physical activity: Netball

\section{Relational time (10 $\mathrm{min})$}

Set up equipment for youth to play around with and reset from their day

Coaches spend time getting to know youth

Check in about lesson from previous day

Awareness talk (20 min)

1. Sit in groups in circle. Take a couple of breaths to reset.

2. Address group: In life we do not always get along with everyone. Sometimes our parents annoy us, sometimes our friends get on our nerves, sometimes we have disagreements with our teachers. Having disagreements is something that we will all experience once in a while. However, we all deal with conflict in different ways. Today we will learn about how we each might have a different style of dealing with conflict/disagreements.

3. Conflict styles activity 
a. Present the teddy bear, turtle, shark, and owl. Explain to group that each of these animals responds to conflict differently. Can you guess how each of them respond? What is the consequence/result of each of these conflict styles?

- Teddy Bear

○ Does not like conflict at all! When there is conflict, the teddy bear will always give in to the wishes of the other person

- Result: Can be seen as weak

- Turtle

- Avoiding conflict is easier than dealing with it. Runs away from situation that might cause conflict (hides in shell)

○ Result: May never get what they want because they hide

- Shark

○ Puts themselves before others at all costs. The shark is looking to win and attack in an argument

- Result: Can be seen as a bully

- Owl

- Views disagreements as a problem to be solved where everyone can be happy at the end of it. The owl will work hard to find the best solution for everyone

$\circ$ Result: Everyone is happy in the end...BUT, it does require a lot of time and energy

Debrief: How can we be more like the owl when we have disagreements with others?

$\checkmark$ Listen, be respectful

$\checkmark$ Even when we have conflict, we treat one another with kindness and we respect each other's' feelings

Physical activity (30 min)

$\checkmark$ Team cheer to open session

$\checkmark$ Address group: all try our best to resolve conflicts with kindness and respect

$\checkmark$ Netball drills

$\checkmark$ Team cheer to close session

Group reflection (10 min)

Sitting in a circle, ask youth to reflect on their experiences of the day as a group:

○ "What were the positives and negatives of the day?"

o "How did the group perform in practicing resolving conflict like an owl and learning more about netball?

○ "How can we apply the owl strategies to life at home and at school?"

○ "What could be better for tomorrow?"

Use the creative drawings and signs of the responsibility levels to help youth refer to the life skills and responsibility levels 


\section{Self-reflection (5 min)}

Sitting in a circle in the reflection corner, ask youth to reflect on the following:

- "How do you think you personally did today with the netball and with being like an owl when there were disagreements?" [Use thumbs up, thumbs down, thumbs to the side to assess]

- "How will you use what you learned today at home tonight and at school tomorrow?"

\section{Session 14}

Responsibility level: Caring \& leadership (4) AND transfer (5), (1), (2), (3)

Life skill: Leadership

Awareness talk activity: Leadership activity: who is a leader you respect? What

makes them a good leader? How can you be a leader? Obstacle course activity

Sport/Physical activity: Soccer

\section{Relational time (10 min)}

Set up equipment for youth to play around with and reset from their day

Coaches spend time getting to know youth

Check in about lesson from previous day

Awareness talk (20 min)

1. Sit in groups in circle. Take a couple of breaths to reset.

2. Address group: today we are going to talk a bit about leadership.

Who is a leader you respect?

What kind of things do good leaders do and say?

What makes someone a bad leader?

How can you be a leader during the sport session today?

3. Obstacle course activity:

a. All participants in the group will be blindfolded except for one, the leader. This leader will be giving instructions to the blindfolded participants. The blindfolded participants have to stand in a straight line, with their hands on the shoulders of the person in front of them. When the time starts, the leader has to guide these participants through an obstacle course in the shortest time possible. The leader has to shout instructions: "Turn left, Walk 2 steps forward..." and so on. The leader is not allowed to touch the team members but only allowed to give instructions. In the course of moving through the obstacles, they are not allowed to let go of their partner's hip. The round is complete when the last person has passed through the finish line.

b. Change the leader and repeat the exercise if there is enough time

Debrief: 
How did it feel to be blindfolded and not being able to see where you were headed?

Did it feel comforting that there was a voice that was guiding you through the obstacle? Did you trust your leader?

Did the leader give good/specific instructions to your team?

What was it like to be the leader giving instructions?

** The person giving the instruction can be like the leader in any situation in life. There will be many situations in life where there is a leader or boss that will guide you. You have to be able to rely on the leader to help you. And if you are the leader, you have to help your team trust you and believe in your ability to lead them. Remember though, you don't have to know everything to be a leader. All you have to be sometimes is one step ahead.

\section{Physical activity (30 min)}

$\checkmark$ Team cheer to open session

$\checkmark$ Address group: all try our best to take initiative, show others what helpful behavior looks like during the drills and games.

$\checkmark$ Soccer drills

$\checkmark$ Team cheer to close session

\section{Group reflection (10 min)}

Sitting in a circle, ask youth to reflect on their experiences of the day as a group:

○ "What were the positives and negatives of the day?"

○ "How did the group perform in practicing leadership and learning new soccer drills?

○ "How can we apply leadership and helpful others to life at home and at school?"

○ "What could be better for tomorrow?"

Use the creative drawings and signs of the responsibility levels to help youth refer to the life skills and responsibility levels

\section{Self-reflection (5 min)}

Sitting in a circle in the reflection corner, ask youth to reflect on the following:

○ "How do you think you did today with leadership and learning new soccer drills?

[Use thumbs up, thumbs down, thumbs to the side to assess]

o "How will you use what you learned today at home tonight and at school tomorrow?"

\section{Session 15}

Responsibility level: Debrief, (1), (2), (3), (4), (5)

Life skill: N/A

Awareness talk activity: Summary of all life skills lessons, Rose and thorn activity Sport/Physical activity: Mini competitions

\section{Relational time (10 min)}


Set up equipment for youth to play around with and reset from their day

Coaches spend time getting to know youth

Check in about lesson from previous day

Awareness talk (15 min)

1. Rose and thorn activity

a. During this sport program, what did you enjoy or find positive, and what did you find challenging?

2. Summary of life skills lessons

a. On the white board, let us make a list of all of the things we learned over the past 3 weeks.

Physical activity (35 $\mathrm{min})$

$\checkmark$ Team cheer to open session

$\checkmark$ Address group: This is our last session as a group. Let us all try our best to practice all the skills we have learned this week: be respectful, give $100 \%$ effort, work as a team, communicate, treat each other with kindness, and be a leader.

$\checkmark$ Mini-competitions in multiple sports

$\checkmark$ Team cheer to close session

Group reflection (10 $\mathrm{min})$

Sitting in a circle, ask youth to reflect on their experiences of the day as a group:

○ "How did we do as a group in practicing the life skills we learned over the past 3 weeks in the sport session today? [Thumbs up, down, or sideways]

o "How might we apply the life skills we learned over the past 3 weeks to life at home and at school?"

Use the creative drawings and signs of the responsibility levels to help youth refer to the life skills and responsibility levels

Self-reflection (5 min)

Sitting in a circle in the reflection corner, ask youth to complete the student learning quiz

○ Identify and give an example of 3 life skills learned that week 


\section{References}

Andersen, M.B. (2000). Doing sport psychology, Champaign, IL: Human Kinetics.

Basic Spaghetti Toes. (n.d.). Retrieved from http://rainbowreach.com/Spaghetti\%20Toes.pdf

Bean, C.N., Forneris, T., \& Halsall, T. (2014). Girls just wanna have fun: a process evaluation of a female youth-driven physical activity-based life skills program. SpringerPlus, 3, 401.

Bean, C.N., Kendellen, K., \& Forneris, T. (2016). Moving beyond the gym: Exploring life skill transfer within a female physical activity-based life skills program. Journal of Applied Sport Psychology, 28, 274-290.

Berger, B.G. (1994). Coping with stress: The effectiveness of exercise and other techniques. Quest, 46,100-119.

Danish, S., Forneris, T., Hodge, K., \& Heke, I. (2004). Enhancing youth development through sport. World Leisure Journal, 46(3), 38-49.

Escartí, A., Gutiérrez, M., Pascual, C., \& Marín, D. (2010). Application of Hellison's teaching personal and social responsibility model in physical education to improve self-efficacy for adolescents at risk of dropping-out of school. The Spanish Journal of Psychology, 13(2), 667-676.

Gordon, B., Jacobs, J.M., \& Wright, P.M. (2016). Social and emotional learning through a teaching personal and social responsibility based after-school program for disengaged middle-school boys. Journal of Teaching in Physical Education, 35, 358-369.

Heart-Mind-Online. (n.d.). Retrieved from https://heartmindonline.org/resources/7-heart-mindcentered-youth-leadership-activities

Janssen, J. (2000). Peak performance playbook. Cary, NC: Winning the Mental Game.

Janssen, J. (2007). The team captain's leadership manual: The complete guide to developing team leaders whom coaches respect and teammates trust. Cary, NC: Winning the Mental Game.

Papacharisis, V., Theofanidis, G., \& Danish, S. (2007). Education through the physical: The effectiveness of teaching life skills program in physical education. In L.A. Chiang (Ed.), Motivation of exercise and physical activity (pp. 67-77). Nova Science Publishers.

Shih, H., \& Susanto, E. (2010). Conflict management styles, emotional intelligence, and job performance in public organizations. International Journal of Conflict Management, 21 (2), 147-168.

Weinberg, R. S. (2002). Goal setting in sport and exercise: Research to practice. In J. L. Van Raalte \& B. W. Brewer (Eds.), Exploring sport and exercise psychology (pp. 25-48). Washington, DC, US: American Psychological Association.

Whitley, M. A. (2012). The Ikhaya sport programs in the Kayamandi Township. Agora para la Educación Física y el Deporte, 14(1), 115-136.

Whitley, M. A., Coble, C., \& Jewell, G.S. (2016) Evaluation of a sport-based youth development programme for refugees. Leisure/Loisir, 40(2), 175-199.

Whitley, M, \& Gould, D. (2010). Psychosocial development in refugee children and youth through the personal-social responsibility model. Journal of Sport Psychology in Action, $1(3), 118-138$.

Williams, J.M., \& Harris, D.V. (2001). Relaxation and energizing techniques for regulation of arousal. In J.M. Williams (Ed.) Applied sport psychology: Personal growth to peak performance (pp.229-246). Mountain View, CA: Mayfield. 
Coach training structure:

\section{Appendix B: Coach Training Manual}

$\checkmark$ Four sessions of 4-hours each. Combination of didactic (psychoeducation) presentations, discussion, self-reflection, and active learning activities.

Overall coach training learning outcomes:

To be able to define, describe, discuss, and apply values, principles, and skills related to positive youth development approaches to youth coaching

To express and examine personal experiences and motivations in sport and coaching

* To create a coaching philosophy that is grounded in positive youth development principles

To be able to define, describe, and discuss values and principles related to the teaching personal and social responsibility (TPSR) model of life skills education through sport

To identify and apply teaching strategies used in TPSR programs

To review and analyze current and previous TPSR programs

To collaboratively construct the youth sport program outline

To practice activities proposed in the sport program

\section{Introduction}

* Primary researcher introduction of area of study, doctoral project, and aims of the sport program. Thank coaches for being willing to participate.

* Each coach will introduce themselves to the group: name, where they are from, sports that they coach, how they got into coaching.

* Ice breakers:

- Talent show: everyone shares a unique or humorous talent that they have

- In common game: without speaking, identify 3 things they have in common

- Marooned game: if you were marooned on an island, what 5 things would you bring with you?

- Two truths and a lie

* Coaches share expectations for the coach training and also the sport program 


\section{Session 1: Positive Youth Development Approaches to Coaching}

Objectives:

- To be able to define, describe, and discuss the values, theory, and principles related to positive youth development approaches to youth coaching

- To identify, define, discuss, and apply teaching strategies to create caring and empathetic youth sport environments

$\circ$ To be able to define, describe, and discuss the values, theory, and principles related to communication, positive coaching, transformational leadership, and creating masteryoriented and autonomy-supportive environments

- To practice implementing PYD coaching skills through experiential and problem-based learning

1. Values and principles of positive youth development (PYD) through sport

○ Activity: On one side of the flash card, write down words that describe why you personally value sport. On the other side, write down words that describe what the purposes are of youth sport. Group discussion to share ideas. [Use big poster card to gather all ideas together]. Zoom in on idea that sport can be a context where young people develop into healthy adults.

$\circ$ Didactic presentation of principles and values underlying PYD

$\checkmark$ Strengths-based approach - all youth have potential for positive developmental change no young person is a problem to be solved; they are a resource to be developed. (Camiré, Forneris, Trudel, \& Bernard, 2011; Collins, Gould, Lauer, \& Chung, 2009; Holt \& Neely, 2011),

$\checkmark$ Organized activities "enable individuals to lead a healthy, satisfying, and productive life, as youth and later as adults, because they do gain the competence to earn a living, to engage in civic activities, to nurture others, and participate in social relations and cultural activities.

$\checkmark$ Youth develop as a result of their interactions with their environment - thus social environments, peers, and adult leaders shape youth development

$\checkmark$ Big question: how can we shape youth environments and programming to help youth develop?

- Group discussion: How do you think the development of young people is viewed and supported in Swaziland? What have you all seen as coaches and as people who have lived or grown up here?

$\circ \quad$ Didactic presentation of principles and values underlying PYD through sport

$\checkmark$ Youth sport is a "fertilizer" of development - social environment of sport, where young people interact with peers and with adult figures, can be a context for development - both positive and negative outcomes, because it depends on how the sport environment is intentionally structured (Coakley, 2011). 
$\checkmark$ Psychological skills that can be developed through sport: "personal skills or assets, including cognitive, social, emotional, and intellectual qualities necessary for youth to become successfully functioning members of society". "Life skills required to deal with the demands and challenges of everyday life."

$\checkmark$ Negative outcomes: misuse of alcohol, performance-enhancing drugs, unhealthy competition.

$\checkmark$ Positive outcomes: self-esteem, emotion-regulation, problem-solving, social skills.

$\circ$ Group discussion: from your own experiences as athletes and coaches, what kinds of negative and positive outcomes can be associated with youth sport? Why do you think sport can play this type of developmental role? [Use big poster to write down all the ideas] [Add outcomes that are supported by research to the list]

D Didactic presentation of research-related to PYD outcomes of youth sport

$\checkmark 5$ C's of PYD (Lerner et al., 2005): competence, confidence, character, caring/compassion, and connection. Plus $6^{\text {th }} \mathrm{C}$ of 'contribution' when all previous $5 \mathrm{C}$ 's are present.

$\checkmark \quad$ Role of sport in providing learning experiences (Dworkin, Larson, \& Hansen, 2003): "experiences that teach you something or expand you in some way, that give you new skills, new attitudes, or new ways on interacting with others". Six domains of learning experiences - (personal development) identity work, developing initiative, emotion regulation, (interpersonal development) teamwork and social skills, positive relationships including norms and diverse peer groups, and developing adult networks.

- Group discussion: which of these 6 C's do you as a coach feel like you already focus on? What does it look like in coaching to focus on each of these C's? (coaching behaviors that facilitate development of 6 C's)

$\circ$ Didactic presentation of conditions necessary for sport to be a context for PYD

$\checkmark$ "By itself, the act of sport participation among young people leads to no regularly identifiable development outcomes" (Coakley, 2011)

$\checkmark$ PYD outcomes influenced by: 1) the culture of the sport environment; 2) the social connections established during sport participation; 3) meaning and values associated with sport participation; 4) whether the youth athlete feels physically safe and valued; and 5) the role of the coach in the extent to which they explicitly teach their athletes to take responsibility for their own well-being and that of others.

$\checkmark$ Features of developmental contexts that lead to PYD outcomes: 1) safe environment and facilities; 2) consistent rules and expectations; 3) caring and supportive relationships; 4) opportunities for belonging; 5) positive group norms; 6) support for autonomy and selfefficacy; 7) opportunities for skill-building

- Group discussion: what does this all mean for youth coaches? If we look at the factors that influence whether or not youth develop PYD outcomes through sport, where does the role of the coach come in? How can the coach help produce these outcomes?

$\checkmark$ Planning PYD strategies into coaching practice and making athletes practice life skills

- Group discussion: Coaches thoughts on the following definition of coach effectiveness? Coaching effectiveness (Côté \& Gilbert, 2009): "the consistent application of integrated professional, interpersonal, and intrapersonal knowledge to improve athletes, 
competence, confidence, connection, and character" (p. 316).

What kinds of opportunities and barriers are there for you as coaches to embody this definition of coaching? How can we as coaches and community members help young people become invested collectively in making their communities better?

2. Teaching strategies to create safe and empathetic youth sport environments

- Group discussion: how do you develop meaningful relationships with your athletes?

$\checkmark$ Ideas: Get to know the personalities, physical abilities, and family background of your athletes - use of individual meetings (encourage honesty and feedback), personal disclosure (share personal coach experiences), team-building activities, weekly athletes journal (share everyday experiences in sport and life to share with coach).

$\circ$ Didactic presentation of relationship-building strategies

$\checkmark$ COMPASS model (Rhind \& Jowett, 2010): conflict management, openness, motivation, positivity, advice, support, and social networks.

Conflict management: expectations, consequences of unmet expectations, cooperation when discussing conflict situations.

Openness: non-sport communication (discussions about life outside of sport), talk about anything (coach is approachable for any issue), and other awareness (coach notices and attempts to understand how the athlete feels).

Motivation: reciprocal motivation from coach to athlete and athlete to coach. Four strategies: effort, motivate the other, fun (make interactions enjoyable), and demonstrating ability (coach shows that they have the competence to help athlete meet their goals while athletes show that they can meet coach expectations).

Positivity: 3 strategies: adaptability (taking an individualized approach to each athlete's needs), fairness, and external pressures (positively dealing with events outside of sport). Advice: Giving one's opinion on problems encountered in a positive and open way in 3 areas: sport communication, reward feedback, and constructive feedback.

Support: showing commitment to athlete for both personal and sport issues. 3 strategies: assurance (commitment to athlete), sport-specific support (positive response to sport performance e.g. after failure), and personal support.

Social networks: spending social time with athletes.

$\checkmark$ Carl Rogers conditions for building empathetic relationships (Rogers, 1962):

Empathy: taking time to understand the emotional experience of your athletes.

Congruence: being authentic, honest, and genuine with athletes -

Unconditional positive regard: create a sport environment where athletes feel they can share anything without fear of being criticized or punished.

- Self-reflection: using the COMPASS model, what kinds of strategies might you use as a coach within each of those areas? How do you extend the COMPASS model to also include creating a supportive peer/social environment amongst the athletes? How do these relationship-building strategies fit within how adults and young people are expected to interact in Swazi culture?

- Group discussion: [Share individual reflection ideas with group - make a collective list]. Compare to Gould et al (2007) strategies to lay foundation for life skills development. 
3. Teaching strategies related to communication and positive coaching, transformational leadership, and creating mastery-oriented and autonomy-supportive environments

○ Activity: communication using PITCH model

$\checkmark$ Components of effective communication using the PITCH model (Vealey 2005; Martens, 2012): productive, informational, time it, consistent, and honest.

$\checkmark$ Discussion and activity for each component of PITCH model.

$\circ$ Didactic presentation on transformational leadership

$\checkmark$ Definition (Vella, Oades, \& Crowe, 2013): a form of leadership "that occurs when leaders broaden and enlarge the interest of those whom they lead; act morally; motivate followers to go beyond individual self-interest for the good of the group and address and engage each individual follower in true commitment."

$\checkmark$ Idea that as a coach we can be a leader who truly inspires change in the athletes we coach i.e. we "transform them".

$\checkmark 5$ components of transformational leadership: appropriate role modeling, intellectual stimulation, individual consideration (includes fostering acceptance of group goals), inspirational motivation, and contingent reward.

- Group discussion: How do you think you already embody some of these transformational leadership practices? What do each of these components of transformational leadership look like in practice?

$\circ$ Didactic presentation of strategies to create a mastery-supportive and autonomy supportive sport environment

$\checkmark$ After creating a caring and supportive coach-athlete relationship, the coach is then in a unique position to help athletes become more autonomous and build their self-efficacy (confidence) to make positive behavioral choices (Conroy \& Coatsworth, 2007)

$\checkmark$ AGT concerned with competence. SDT concerned with competence, autonomy, and relatedness; all needed to increase athlete motivation. Achievement goal theory (AGT): performance/ego goals (normative evaluation and outperforming others) vs. mastery/task goals (effort, personal improvement, and mastery). Task goals associated with a healthier motivational climate.

$\checkmark$ Coach can create a sport environment that supports mastery, autonomy-support, relatedness, and effort.

$\checkmark$ (Conroy \& Coatsworth, 2007) 1) Soliciting athlete input: providing choices in practice, asking athletes for their opinions, listening to athlete opinions. 2) Praising autonomous behavior: praise for good choices, praise for attitude, praise for effort.

$\checkmark$ (Smith, Smoll, Cumming, 2007): 4 coaching behaviors - positive re-inforcement, mistake-contingent encouragement, corrective instruction given in a positive and encouraging fashion, and sound technical instruction. Re-defining success: being the best you can be, having fun, and giving maximum effort. Giving individualized attention to all athletes (individual goals).

$\checkmark$ (Keegan, Spray, Harwood, \& Lavallee, 2010): positive and constructive feedback (taking a growth mindset vs. a fixed mindset), autonomy support instead of controlling leadership style, positive emotional responses (don't use fear), equal treatment (feedback, attention, 
and playing time), coaching activities (use of fun, teaching when skills are low, using variety)

- Group discussion: how could we use these coaching behaviors during our coaching? What kinds of specific examples can you think of? How do you think youth in Swaziland might respond to these coaching strategies?

$\circ$ Experiential learning: Role play how you might respond to the following scenarios

* Your team just lost their third game in a row. The following practice it's obvious that morale is low, and players are disengaged from practice. What steps might you take with your players.

* One of your high performing players after a weekend at home has suddenly become moody. The player isn't performing at their usual level and doesn't seem to be focused on practice. How might you try to assist this player?

* You've been trying to teach a new technique to one of your players but they struggle to comprehend the movements needed. How might you help this player better understand what's needed?

* You've noticed that your players struggle when momentum goes against them in games and they also struggle with making decisions on their own during games. However you cannot be on the pitch to encourage them or hold their hand through every decision. How might you teach your players to work through issues on their own during games/matches and stay motivated?

* One of your players comes to you in tears, saying another player you consider a captain is bullying them. How would you handle this situation?

* You just started coaching a new team and it is clear that the players don't know, trust, or really get along with one another and they also seem hesitant to really follow your coaching instructions. How might you approach that situation?

* You have an athlete who has a tendency to lose her temper rather violently when things don't go her way, and especially when she loses. How might you help this athlete with emotion regulation and dealing with failure?

* An administrator at your school interrupts one of your practices one day. In front of all your athletes the administrator starts yelling at you and tries to draw you into a big confrontation. How do you respond?

\section{Session 2: Developing a PYD-Based Coach Identity and Coaching Philosophy} Objectives:

To reflect, explore, and discuss personal experiences in sport

To reflect, explore, and discuss coach motivations for being involved in sport in Swaziland 
To create a coaching philosophy grounded in PYD principles

1. Exploring personal coach experiences in sport

$\circ$ Experiential writing activity: create a brief narrative telling the story of your own sport experience getting to where you are now. What was the role of sport in your own life growing up? Were there any critical experiences that served as turning points or strongly shaped your direction? Were there any coaches that play significant roles (positive or negative) in shaping how you view sport or how you view coaching?

- Group story telling: each coach will share their story with the group. Group will discuss the similarities and differences in each coach's story.

2. Exploring youth context and youth sport experiences in Swaziland

$\circ$ Group brainstorm and discussion: create list of phrases and words describing youth developmental experience in Swaziland and challenges facing young people.

- Group discussion: What role can sport play in the development of young people? What does the youth sport environment look like in Swaziland? What are the barriers to youth sport participation in Swaziland? What are the barriers to using sport as a context for development? What kinds of physical resources, financial, and personnel resources do we need to invest in to make youth sport a context for holistic development?

3. Exploring coach motivations

○ Brief activity: Who am I as a coach? 10 words to describe who I am as a coach or what my role is as a coach. Share with group.

- Brief activity: Rank the following in terms of importance/prioritizing for you as a coach - winning, fun, physical development, psychological and social development. Discuss as a group. Question for group: Is it possible to value performance and life skills outcomes equally and give them the same emphasis in coaching? How so? What might the barriers be to doing this?

- Didactic presentation and group discussion: Pyramid of Teaching Success in Sport

○ (Gilbert et al., 2010) PofTSS - working through the different levels of teaching success as described by the PofTSS

- Didactic presentation and group discussion: Collins et al (2009) philosophical beliefs of outstanding high school coaches - linking philosophical beliefs to on-the-field practices.

$\checkmark$ Which beliefs resonate personally with the coaches? Before examining the strategies given by the authors, how might those philosophical beliefs be implemented? (i.e. what do they look like in practice?) 
4. Creating a coaching philosophy grounded in PYD principles

- Activity: On one side of flash card, write down words that describe what you think a coaching philosophy is. On the other side write down why you think those words are important. On a second flash card, describe one of your most memorable coaches, and take a guess at what you think their coaching philosophy was.

- Group sharing and discussion: what: beliefs/values, morals, goals, mindset, standards, guidelines, objectives, purposes, expectations....why: what the coach stands for, represents you as a person, shapes how you interact with athletes, necessity for all successful coaches. [Use big white board to compile all suggestions] [Every coach has a different philosophy...but every good coach has an athlete-centered philosophy]

$\checkmark$ Coaching philosophy definition: beliefs, values, and ethics that guide our coaching actions, and particularly how those coaching behaviors impact the development and lives of the athletes. A coaching philosophy considers coach objectives for athletes and coach style to influence behavior. (things you value, things you want to achieve, things you want athlete to develop, beliefs and principles about playing the game)

$\checkmark$ Why is it important?

- An indicator of key elements of coaching approach: What are the coach's beliefs about how athletes learn and grow? What are their values as a coach?

- Coaches' attitudes, beliefs, and values influence their athletes' values in sport.

- Although many coaches feel teaching life skills and values are important, many coaches struggle to articulate how they do so.

- Through reflective processes, coaches may determine how their personal values might be displayed in sport.

- By developing a coaching philosophy - coaches are able to articulate the cognitive process of linking their beliefs to action.

○ Like going on a trip if you knew where you wanted to go but didn't know how to get there.

$\checkmark$ "Success can come in many different ways. Success can be scoring a touchdown, making the football team, or having fun in an environment and being accepted in an elite group. Success can be being disciplined on the football field or walking away from a fight. Success can be grades in school and passing all their classes this year. Success can be measured in many different ways." (Collins et al., 2009)

$\checkmark$ "Success is peace of mind which is a direct result of self-satisfaction in knowing you made the effort to become the best of which you are capable." John Wooden

○ Workshop: Coaches work independently and also in consultation with one another to create a coaching philosophy. Coaches will have several research articles available to them to skim to help them think about philosophical beliefs of other coaches, key PYD concepts etc. (Vella, Oades, \& Crowe, 2011; Camiré, Forneris, Trudel, \& Bernard, 2011; Lumpkin \& Cuneen, 2001; Van Mullem \& Brummer, 2013; Gilbert et al., 2010; Watson et al., 2011) 
Some questions to consider before starting:

a. What is the mission of the school or the team that I coach?

b. What are the performance demands of the sport (hence, what type of commitment is needed from the athletes?)

c. What is the developmental level of the athletes?

As a coach right now:

1. Am I teaching what I want my athletes to learn through sport? (what are those things?)

2. Are my athletes having positive experiences in sport?

3. Am I appropriately balancing winning with athlete development?

Workshop: Steps to creating a coaching philosophy (Lumpkin \& Cuneen, 2001; Mullem \& Brummer, 2013)

1. Identify your values and why you value those things: How did I develop these values? Who were my mentors?

2. Establish a personal belief system: What do I value in sport? What is the purpose of sport? What do I want to achieve (goals)? What do I want my athletes to develop? How do I think athletes learn best?

3. Determine personal and athlete standards of performance: What behaviors do I expect from myself and my athletes? How do these behaviors align with what I want my athletes to learn/develop through sport participation?

4. Write your coaching philosophy i.e. things you value, things you want to achieve, things you want athlete to develop, beliefs and principles about playing the game. Be sure to describe how all of these things link together with one another!

\section{Session 3: Teaching Personal and Social Responsibility Model (TPSR)}

Objectives:

- To define, describe, and discuss the foundational values, structure, themes, and responsibility levels of the TPSR model

- To review and analyze how the TPSR model has been applied to other youth development contexts

- To identify, discuss, and apply teaching strategies (TARE) and leader themes that promote the development of the TPSR responsibility outcomes

- To practice the teaching strategies (TARE) through experiential learning

- To apply the leader themes and TARE teaching strategies to real-world youth sport scenarios 
1. Getting to know the TPSR model

- Didactic presentation of the values, responsibility levels, leader themes, and daily structure of the TPSR model

$\checkmark$ Work through TPSR handouts!

$\checkmark$ Teaching personal and social responsibility (TPSR) model (Hellison, 2011) - designed to help youth develop the necessary skills to take more responsibility for their well-being and for the welfare of others

$\checkmark$ Values: youth participation in physical activity should be about building character and better kids, holistic positive development, youth-centered, values-based learning where youth can learn about themselves and the world, achieve small successes that build selfefficacy, become better problem-solvers, and develop their social support skills.

$\checkmark$ Intentional approach to helping youth develop life skills: does not happen automatically!

$\checkmark \quad$ Five responsibility levels or goals for youth participants: respecting the rights and feelings of others (I), effort and cooperation (II), self-direction (III), helping others and leadership (IV), and transfer outside gym (V).

$\circ$ Group discussion: would you add to or change any of these responsibility level goals based on the life skills that you think young Swazi's need to develop?

$\checkmark \quad$ TPSR daily structure: relational time, awareness talk, physical activity, group meeting, and self-reflection.

$\checkmark$ TPSR leader themes: 1) gradual empowerment; 2) self-reflection; 3) integrating TPSR into physical activities; 4) transfer to real-life situations; and 5) being relational with youth.

- Activity: work through an example of what one TPSR session would look like that incorporated a focus on one responsibility level, used the daily structure, and integrated the leader themes.

$\circ$ Group discussion: Questions or concerns about the model. What kinds of things stand out to you? What challenges or opportunities might you see for yourself in trying to implement this model? What components of the model might need to be changed to work within the context of Swaziland?

2. Using the TARE 2.0 assessment tool to explore teaching strategies and student outcomes associated with the model

- Group discussion: Looking at the nine student behaviors on the TARE 2.0 (these behaviors align with the student responsibility levels), what do those student behaviors look like in practice? For example, how do you know if someone is engaged or showing respect? [Generate list of observable behaviors for each student behavior outcome] If we explore these student behaviors within the Swazi culture, how do these behaviors fit? Are any of them culturally inappropriate? What other behaviors should we add to the list that aren't included here but are important in Swazi culture?

O Group discussion: TARE 2.0 teaching strategies are - modeling respect, setting expectations, providing opportunities for success, fostering social interaction, assigning manageable tasks, providing leadership opportunities, giving choices and voices, role in 
assessment, and encouraging transfer. What are the concrete behaviors that demonstrate these teaching strategies?

- Application of teaching strategies activity: Looking at each of the nine TARE 2.0 teaching strategies, how might we use those teaching strategies in each of the daily structure sections of the TPSR program i.e. applying the teaching strategies to relational time, awareness talk, physical activity, group meeting, and reflection time.

- Real-life examples: Consider the following real-life examples and reflect on how you could use two of the coaching strategies.

* An athlete is struggling to learn one of the sport drills during the physical activity time and seems to be getting discouraged.

* Two athletes have a disagreement during practice.

* You have an athlete on your team who has a difficult home environment and struggles with very low confidence and self-esteem.

* During the physical activity portion of the session, an athlete accidentally trips another player. The athlete apologizes in a kind and sincere way to the other athlete.

3. Exploring current and previous TPSR programs

$\circ$ Group discussion: Explore and discuss the strengths and weaknesses, what you liked and what you didn't like, of three TPSR programs

$\checkmark$ Girls Just Wanna Have Fun (Bean et al., 2014; Bean et al., 2016)

$\checkmark$ Refugee Soccer Club (Whitley, Coble, \& Jewell, 2016; Whitley \& Gould, 2010)

$\checkmark$ Ikhaya Sport Program (Whitley, 2012)

\section{Session 4: Sport Program Design and Implementation}

Objectives:

To collaboratively design the content and implementation of the sport program

To practice implementing the different components of the program, especially the life skills activities and awareness talk components

To build confidence in coach ability to implement the sport program

To practice using the TARE post-teaching reflection

To reflect on and evaluate the coach training program

1. Design and/or review proposed sport program outline

o Suggestions for changes or additions

- Suggestions for adding any more creative elements - translations for signs in reflection corner etc.

- Concern about any aspect of the program design

○ Input on the name of the program - suggestion: 'Temidlalo Nemfundvo' 
2. Practice the awareness talk activities and facilitating the group reflection o Practice the structured activities that are integrated into the awareness talk.

3. Practice completing the modified TARE post-teaching reflection

4. Final thoughts, questions, comments, or concerns

5. Coach training feedback

\section{Group discussion:}

1. What do you think were the strengths of the coach training program?

2. What do you think were the weaknesses of the coach training program?

3. How do you think the coach training program could be improved?

Please respond to the following statements about the coach training program. Put a check in the box that most accurately represents how you feel about the statement:

Strongly Agree (SA), Agree (A), Neither agree nor disagree (N), Disagree (D), Strongly Disagree $(S D)$

\begin{tabular}{|l|l|l|l|l|l|}
\hline $\begin{array}{l}\text { The coach training program prepared me to create a caring } \\
\text { and supportive sport environment }\end{array}$ & & & & & \\
\hline $\begin{array}{l}\text { The coach training program helped me think about my } \\
\text { coaching motivations and identity }\end{array}$ & & & & & \\
\hline $\begin{array}{l}\text { The coach training program prepared me to incorporate life } \\
\text { skills development into my coaching }\end{array}$ & & & & & \\
\hline $\begin{array}{l}\text { The coach training program prepared me to incorporate the } \\
\text { TPSR model into my coaching }\end{array}$ & & & & & \\
\hline $\begin{array}{l}\text { Overall I found the coach training program engaging and } \\
\text { enjoyable }\end{array}$ & & & & & \\
\hline I feel prepared to implement the youth sport program & & & & & \\
\hline I feel confident to implement the youth sport program & & & & & \\
\hline
\end{tabular}




\section{Coach Handout - Daily Structure and Coach Strategies}

\section{$\underline{\text { Relational Time }(10 \mathrm{~min})}$}

\section{Goal:}

\section{Take attendance}

Give youth a chance to briefly relax and reset after their day at school Interact with youth and get to know them. The focus should be on building a caring and meaningful relationship with as many youth as possible

Check in individually with youth on how they have implemented the life skills into their life outside of the sport setting

Coach strategies:

$\checkmark$ Set up some sport equipment so youth can play around and relax

$\checkmark$ Walk around and check-in with as many youth as possible

- Make sure to call each youth by their name

- Ask them about their day

○ Comment on behaviors that reflect responsibility levels or life skills e.g. respect

$\circ$ Smile and engage with the youth enthusiastically

$\checkmark$ Take attendance

- This can be a task that is assigned to a different youth each day as an opportunity to take responsibility for a task. Explain how youth can conduct this task respectfully.

$\checkmark$ Use TARE 2.0 teaching strategies where applicable

$\checkmark$ Use responsibility themes

○ Empower youth

- Emphasize transfer of skills

○ Put kids first (youth-centered)

\section{$\underline{\text { Awareness Talk (20 min) }}$}

\section{Goal:}

Teach youth a life skill or responsibility level

Use structure activity to learn life skill

Actively engage youth in learning about a new life skill

○ Empower them to take responsibility

Coach strategies:

$\checkmark$ Split the large group into smaller groups, each led by 1-2 coaches. Sit in a circle with the youth. 
Take a couple of moments to settle the groups: shake out legs and arms, roll shoulders and neck, deep breaths

$\checkmark$ Introduce the life skill concept. Introduce activity that teaches life skill concept

$\checkmark$ ACTIVITY

$\checkmark$ Engage the youth in discussion: don't lecture

$\checkmark$ Use TARE 2.0 teaching strategies where applicable

$\checkmark$ Use responsibility themes

- Empower youth

- Emphasize transfer of skills

○ Put kids first (youth-centered)

$\checkmark$ Encourage all youth to participate

○ Direct questions at specific youth and then refer back to the group after each response

Use scenarios to illustrate the life skill or responsibility level

○ For example: "When you accidentally trip someone while you're playing soccer, what do you do?"

$\checkmark$ Use probes and follow up questions (e.g. tell me more, or why) after youth comments

○ "What does respect mean to you?"

○ "How can you be a good teammate?"

○ "If I were watching you, how would I know that you were being respectful?"

$\checkmark$ Team cheer at end of awareness talk to transition to physical activity

\section{Physical Activity (30 min)}

\section{Goal:}

Have fun

Participate in physical activity

Learn a new sport

Integrate physical activity with life skills

Empower youth to practice life skills and take responsibility for their behavior

Coach strategies:

$\checkmark$ Use at least one timeout to check-in with youth on their use of the life skill/responsibility focus of the day

○ "How are we doing with being respectful so far?"

$\checkmark$ Use intentional teaching strategies

- Nine TARE 2.0 teaching strategies

O Use high-fives

$\circ$ Use encouragement

- Address disruptive behavior by using time-outs or pulling those youth to the side

$\circ$ Use teachable moments i.e. when something happens during the activity that is applicable to the life skill lesson, point it out and briefly discuss it 
$\checkmark$ Provide youth with opportunities to lead as often as possible

$\checkmark$ Use responsibility themes

○ Empower youth

- Emphasize transfer of skills

○ Put kids first (youth-centered)

\section{Group Reflection (10 min)}

Goals:

Give youth an opportunity to express how they felt about the day

Empower youth to feel confident to speak up and also to be respectful of one another's opinions

Help youth think about how the lesson of the day can be applied to other domains of life

Coach strategies:

Sit in circle in two groups

Use 1-2 minutes to help the group reset and calm down

- Deep breaths

○ Light stretch

Encourage youth to reflect on their experiences of the day

○ "What were the positives and negatives of the day?"

○ "How did the group perform in practicing the life skill and learning a new sport?

○ "How might the life skills of the day apply to life at home and at school?"

○ "What could be better for tomorrow?"

Use the creative drawings and signs of the responsibility levels to help youth refer to the life skills and responsibility levels

Encourage youth to be respectful of one another during this sharing phase

- Speak one at a time; don't interrupt

$\circ$ Be honest. Every opinion is encouraged

\section{Individual Reflection (5 min)}

\section{Goals:}

Encourage youth to reflect on own attitudes and behaviors of the day

Encourage youth to reflect on how to apply the life skills and responsibility lessons of the day to own life

Coach strategies:

Youth sit quietly to reflect in the reflection corner 
Encourage youth to reflect on the following:

○ "How do you think you did today with the sport session and practicing the life skill/responsibility?" [Use thumbs up, thumbs down, thumbs to the side to assess]

- "How will you use what you learned today at home tonight and at school tomorrow?"

$\checkmark$ Allow youth to share answers to those questions after a couple of moments of reflection 


\section{Coach Handout - Responsibility Levels}

\section{Respecting the rights and feelings of others}

- Self-control, right to peaceful conflict resolution, right to be included regardless of skill level, gender etc., and the right to have cooperative peers.

- Overall aim of this level is to create a safe learning environment where the rights of others are respected. This is accomplished through intentionally practicing working together, developing self-control, and managing emotions, attitudes, and behaviors.

\section{Effort and cooperation}

- Self-motivation, exploration of effort and new tasks, and getting along with others.

- Emphasis on the role of effort in helping students improve themselves and their life situations as well as the role that students have in choosing to put forth effort (i.e. selfmotivation) and take responsibility for their growth.

- Teaches students the importance of cooperation in creating a positive learning environment where participation, mastery, and improvement is emphasized over comparison to others.

\section{Self-direction}

○ On-task independence, goal-setting progression, and courage to become self-aware and resist peer pressure.

- Emphasis on helping youth take responsibility for their own well-being (less teacherdirected) and the amount of effort they place on different tasks.

- Helps build youth capacity to look within themselves and acknowledge areas of improvement in order to subsequently work towards unique personal goals.

\section{Helping others and leadership}

○ Caring and compassion, sensitivity and responsiveness, and inner strength.

- Emphasis is on helping students develop interpersonal skills of sensitivity and compassion such as listening without judgement, and helping without being arrogant.

- Students at this level understand that others may have different viewpoints, needs, and feeling from their own. More complex helping behaviors may involve leadership and contributing to the well-being of others.

\section{Transfer outside the gym}

- Applying these ideas in other areas of life, and being a positive role model for others, especially younger kids.

- This final level of the model is the most important in facilitating the holistic development of youth. 


\section{Coach Handout - Coach Themes}

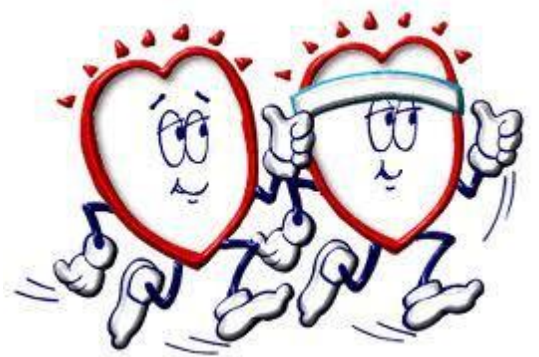

\section{Integration: extent to which} responsibility goals and life skills are integrated into the physical activity.
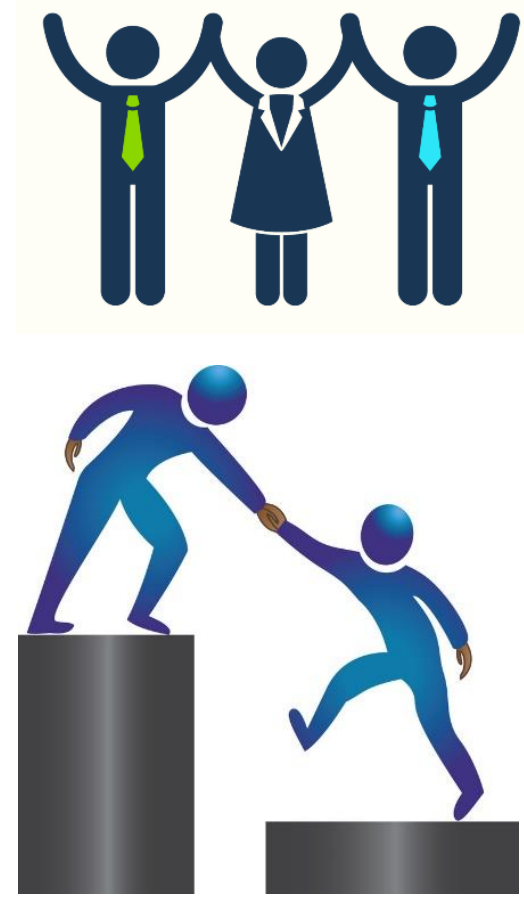

\section{Empowerment: extent to} which the coach shares responsibility with students e.g. opportunities for decision-making, leading etc.

\section{Coach-Athlete Relationship:} extent to which students are treated as individuals deserving respect, choice, and voice

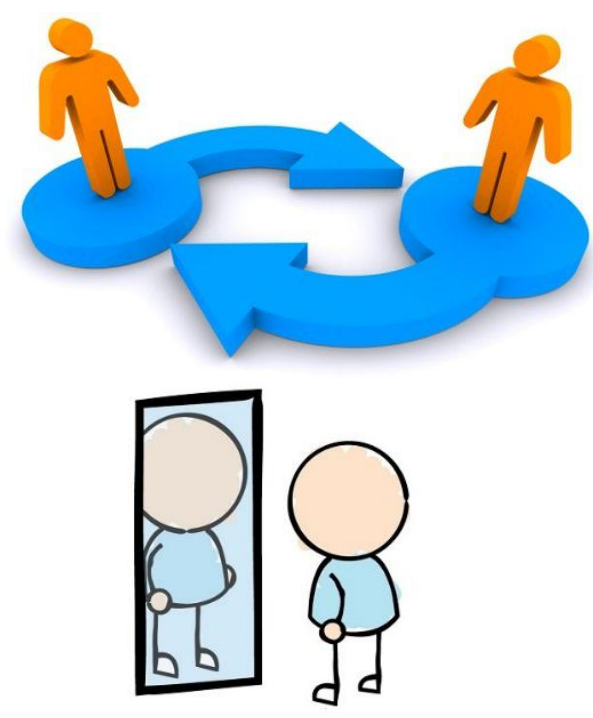

Transfer: extent to which connections being made to the application of life skills in other settings

Self-reflection: encouraging youth to engage in selfreflection activities such as thoughtfulness and knowing the self. 


\section{Coach Handout - Teaching Strategies}

\begin{tabular}{|c|c|}
\hline Modeling Respect & $\begin{array}{l}\text { Coach models respectful communication. This would involve } \\
\text { communication with the whole group or individual students. Looks like: } \\
\text { appropriate communication and instruction and unconditional positive } \\
\text { regard. Does not look like: rolling out the ball, losing temper, or } \\
\text { embarrassing students. }\end{array}$ \\
\hline $\begin{array}{c}\text { Setting } \\
\text { Expectations }\end{array}$ & $\begin{array}{l}\text { Coach explains or refers to explicit behavioral expectations. These } \\
\text { could relate to skill performance, safe practices, rules and procedures, or } \\
\text { etiquette. }\end{array}$ \\
\hline $\begin{array}{l}\text { Opportunities for } \\
\text { Success }\end{array}$ & $\begin{array}{l}\text { Coach structures lesson so that all students have the opportunity to } \\
\text { successfully participate and be included regardless of individual } \\
\text { differences. }\end{array}$ \\
\hline $\begin{array}{c}\text { Fostering Social } \\
\text { Interaction }\end{array}$ & $\begin{array}{l}\text { Coach structures activities that foster positive social interaction. This } \\
\text { could involve student-student interaction through cooperation, } \\
\text { teamwork, problem solving, conflict resolution or debriefing. }\end{array}$ \\
\hline Assigning Tasks & $\begin{array}{l}\text { Coach assigns specific responsibilities or tasks (other than leadership) } \\
\text { that facilitate the organization of the program or a specific activity. This } \\
\text { could look like taking attendance, setting up equipment, keeping } \\
\text { score/records, or officiating a game. }\end{array}$ \\
\hline Leadership & $\begin{array}{l}\text { Coach allows students to lead or be in charge of a group. This could } \\
\text { look like demonstrating for the class, leading a station, teaching/leading } \\
\text { exercises for the whole class, or coaching a team. }\end{array}$ \\
\hline $\begin{array}{c}\text { Giving Choices } \\
\text { and Voices }\end{array}$ & $\begin{array}{l}\text { Coach gives students a voice in the program. This could involve group } \\
\text { discussions, voting as a group; individual choices, students asking } \\
\text { questions, making suggestions, sharing opinions, evaluating the coach } \\
\text { or program. }\end{array}$ \\
\hline $\begin{array}{c}\text { Role in } \\
\text { Assessment }\end{array}$ & $\begin{array}{l}\text { Coach allows students to have a role in learner assessment. This could } \\
\text { take the form of self- or peer-assessment related to skill development, } \\
\text { behavior, attitude, etc.; it could also involve goal-setting or a negotiation } \\
\text { between teacher and student on their grade or progress in the class. }\end{array}$ \\
\hline Transfer & $\begin{array}{l}\text { Coach directly addresses the transfer of life skills or responsibilities } \\
\text { from the lesson beyond the program. This could include links such as: } \\
\text { the need to work hard and persevere in school; the importance of being } \\
\text { a leader in your community; keeping your self-control to avoid a fight } \\
\text { after school; setting goals to achieve what you want in sports; the need } \\
\text { to be a good team player when you grow up and get a job; or the value } \\
\text { of thinking for yourself to avoid peer-pressure. }\end{array}$ \\
\hline
\end{tabular}




\section{Coach Handout - Self-Reflection for Daily Debrief}

Questions to reflect on:

1.What did I like about facilitating today's session?

2.What did I not like about facilitating today's session?

3.What went well for me in facilitating today's session?

4.What was the most difficult for me in facilitating today's session?

5.How could we improve the session for tomorrow? 


\section{References}

Bean, C.N., Forneris, T., \& Halsall, T. (2014). Girls just wanna have fun: a process evaluation of a female youth-driven physical activity-based life skills program. SpringerPlus, 3, 401.

Bean, C.N., Kendellen, K., \& Forneris, T. (2016). Moving beyond the gym: Exploring life skill transfer within a female physical activity-based life skills program. Journal of Applied Sport Psychology, 28, 274-290.

Camiré, M., Forneris, T., Trudel, P., \& Bernard, D. (2011). Strategies for helping coaches facilitate positive youth development through sport. Journal of Sport Psychology in Action, 2, 92-99.

Cassidy, T., Potrac, P., \& McKenzie, A. (2006). Evaluating and reflecting upon a coach education initiative: The CoDe of Rugby. The Sport Psychologist, 20, 145-161.

Coakley, J. (2011). Youth sports: What counts as “positive development?" Journal of Sport and Social Issues, 35(3), 306-324.

Collins, K., Gould, D., Lauer, L., \& Chung, Y. (2009). Coaching Life Skills through Football: Philosophical Beliefs of Outstanding High School Football Coaches. International Journal of Coaching Science, 3(1), 29-54.

Conroy, D.E., \& Coatsworth, J.D. (2007). Assessing autonomy-supportive coaching strategies in youth sport. Psychology of Sport and exercise, 8, 671-684.

Côté, J., \& Gilbert, W. (2009). An integrative definition of coaching effectiveness and expertise. International Journal of Sports Science \& Coaching, 4(3), 307-323.

Dworkin, J.B., Larson, R. \& Hansen, D. (2003). Adolescents' accounts of growth experiences in youth activities. Journal of Youth and Adolescence, 32(1), 17-26.

Gilbert, W., Nater, S., Siwik, M., \& Gallimore, R. (2010). The pyramid of teaching success in sport: Lessons from applied science and effective coaches. Journal of Sport Psychology in Action, 1, 86-94.

Hellison, D. R. (2011). Teaching personal and social responsibility through physical activity. Champaign, IL: Human Kinetics.

Holt, N.L., \& Neely, K.C. (2011). Positive youth development through sport: A review. Revista Iberoamericana de Psicología del Ejercicio y el Deporte, 6(2), 229-316.

Keegan, R., Spray, C., Harwood, C., \& Lavallee, D. (2010). The motivational atmosphere in youth sport: coach, parent, and peer influences on motivation in specializing sport participants. Journal of Applied Sport Psychology, 22, 87-105.

Krathwohl, D.R. (2002). A revision of Bloom's taxonomy: An overview. Theory into Practice, 41(4), 212-218.

Lerner, R.M., Almerigi, J.B., Theokas, \& Lerner, J.N. (2005). Positive youth development: A view of issues. Journal of early Adolescence, 25(1), 10-16. doi: $10.1177 / 0272431604273211$

Lumpkin, A., \& Cuneen, J. (2001). Developing a personal philosophy of sport. Journal of Physical Education, Recreation \& Dance, 72(8), 40-43.

Martens, R. (2012). Successful Coaching (4th ed.). Champaign: Human Kinetics.

Martinek, T., \& Hellison, D. (2016). Teaching personal and social responsibility: Past, present and future. Journal of Physical Education, Recreation \& Dance, 87(5), 9-13.

McCullick, B.A., Belcher, D., \& Schempp, P.G. (2005). What works in coaching and sport instructor certification programs? The participants' view. Physical education and Sport Pedagogy, 10(2), 121-137. 
Mesquita, I., Ribeiro, J., Santos, S., \& Morgan, K. (2014). Coach learning and coach education: Portuguese expert coaches' perspective. The Sport Psychologist, 28, 124-136.

Nelson, L., Cushion, C., \& Potrac, P. (2013). Enhancing the provision of coach education: The recommendations of UK coaching practitioners. Physical Education and Sport Pedagogy, 18(2), 2014-218.

Rhind, D.J., \& Jowett, S. (2010) Relationship maintenance strategies in the coach-athlete relationship: The development of the COMPASS model, Journal of Applied Sport Psychology, 22(1), 106-121. doi: 10.1080/10413200903474472

Rogers, C.R. (1962). The interpersonal relationship: the core of guidance. Harvard Educational Review, 32, 416-529

Smith, R.E., Smoll, F.L., \& Cumming, S.P. (2007). Effects of motivational climate intervention for coaches on young athletes' sport performance anxiety. Journal of Sport \& Exercise Psychology, 29, 39-59.

Van Mullem, \& Brunner, D. Developing a successful coaching philosophy: A step-by-step approach. Strategies, 26(3), 29-34. doi: 10.1080/08924562.2013.779873

Vealey, R. (2005). Coaching for the inner edge. Fitness Info Technology, Morgantown, WV

Vella, S., Oades, L., \& Crowe, T. (2011). The role of the coach in facilitating positive youth development: Moving from theory to practice. Journal of Applied Sport Psychology, 23, 33-48.

Vella, S. A., Oades, L. G. \& Crowe, T. P. (2013). A pilot test of transformational leadership training for sports coaches: Impact on the developmental experiences of adolescent athletes. International Journal of Sports Science and Coaching, 8 (3), 513-530.

Watson, J.C., Connole, I., \& Kadushin, P. (2011). Developing young athletes; A sport psychology based approach to coaching youth sports. Journal of Sport Psychology in Action, 2, 113-122.

Whitley, M. A. (2012). The Ikhaya sport programs in the Kayamandi Township. Agora para la Educación Física y el Deporte, 14(1), 115-136.

Whitley, M. A., Coble, C., \& Jewell, G.S. (2016) Evaluation of a sport-based youth development programme for refugees. Leisure/Loisir, 40(2), 175-199.

Whitley, M, \& Gould, D. (2010). Psychosocial development in refugee children and youth through the personal-social responsibility model. Journal of Sport Psychology in Action, 1(3), 118-138

Wright, P. M., \& Craig, M. W. (2011). Tool for assessing responsibility-based education (TARE): Instrument development and reliability testing. Measurement in Physical Education and Exercise Science, 15, 1-16. 


\section{Appendix C: Demographics Survey \\ Youth}

Name:

Age:

Gender: __ Male __ Female __ Other

Ethnicity:

Year in school:

\section{Coaches}

Demographics

Name:

Age:

Gender: __ Male __ Female __ Other

Ethnicity:

Previous coaching experience

Type of sport:

Competitive level:

Age group:

Context:__ School _ Community _ Club

Previous coach education/training/certificate (please describe any if applicable): 


\section{Appendix D: Demographics and Personal and Social Responsibility Questionnaire (PSRQ)}

Name:

It is natural to behave both well and poorly. We are interested in how you normally behave at school and at home. Please answer the following statements honestly by checking the box that best represents your behavior.

\begin{tabular}{|l|l|l|l|l|l|l|}
\hline & $\begin{array}{c}\text { Strongly } \\
\text { disagree (1) }\end{array}$ & $\begin{array}{c}\text { Disagree } \\
\text { (2) }\end{array}$ & $\begin{array}{c}\text { Somewhat } \\
\text { disagree (3) }\end{array}$ & $\begin{array}{c}\text { Somewhat } \\
\text { agree (4) }\end{array}$ & $\begin{array}{c}\text { Agree } \\
\text { (5) }\end{array}$ & $\begin{array}{c}\text { Strongly } \\
\text { agree (6) }\end{array}$ \\
\hline 1. I respect others. & & & & & & \\
\hline 2. I respect my teachers. & & & & & & \\
\hline 3. I help others. & & & & & & \\
\hline 4. I encourage others. & & & & & & \\
\hline 5. I am kind to others. & & & & & & \\
\hline 6. I control my temper. & & & & & & \\
\hline 7. I am helpful to others. & & & & & & \\
\hline 8. I participate in all of the activities. & & & & & & \\
\hline 9. I try hard. & & & & & & \\
\hline 10. I set goals for myself. & & & & & & \\
\hline 11. I try hard even if I do not like the activity. & & & & & \\
\hline 12. I want to improve. & & & & & \\
\hline 13. I give a good effort. & & & & & \\
\hline 14. I do not make any goals. & & & & & \\
\hline
\end{tabular}




\section{Appendix E: Multidimensional Scales of Perceived Self-Efficacy (MSPSE)}

Name:

Instructions: We are interested in how well you feel you do the following things. Read each statement carefully. Indicate how you feel about each statement.
Check the " 1 " box
if you Very Strongly Disagree
Check the " 2 " box
if you Strongly Disagree
Check the " 3 " box
if you Mildly Disagree
Check the "4" box
if you are Neutral
Check the " 5 " box
if you Mildly Agree
Check the "6" box
if you Strongly Agree
Check the "7" box
if you Very Strongly Agree

\begin{tabular}{|c|c|c|c|c|c|c|c|}
\hline Enlisting social resources (ESR) & $\begin{array}{c}\text { Very } \\
\text { strongly } \\
\text { disagree } \\
(1)\end{array}$ & $\begin{array}{c}\text { Strongly } \\
\text { disagree } \\
(2)\end{array}$ & $\begin{array}{c}\text { Mildly } \\
\text { disagree } \\
(3)\end{array}$ & $\begin{array}{c}\text { Neutral } \\
\text { (4) }\end{array}$ & $\begin{array}{c}\text { Mildly } \\
\text { agree } \\
(5) \\
\end{array}$ & $\begin{array}{c}\begin{array}{c}\text { Strongly } \\
\text { agree }\end{array} \\
(6)\end{array}$ & $\begin{array}{c}\text { Very } \\
\text { strongly } \\
\text { agree } \\
(7)\end{array}$ \\
\hline $\begin{array}{l}\text { 1.How well can you get teachers to help you when } \\
\text { you get stuck on schoolwork? }\end{array}$ & & & & & & & \\
\hline $\begin{array}{l}\text { 2.How well can you get another student to help you } \\
\text { when you get stuck on schoolwork? }\end{array}$ & & & & & & & \\
\hline $\begin{array}{l}\text { 3.How well can you get adults to help you when yo } \\
\text { have social problems? }\end{array}$ & & & & & & & \\
\hline $\begin{array}{l}\text { 4.How well can you get a friend to help you when } \\
\text { you have social problems? }\end{array}$ & & & & & & & \\
\hline
\end{tabular}




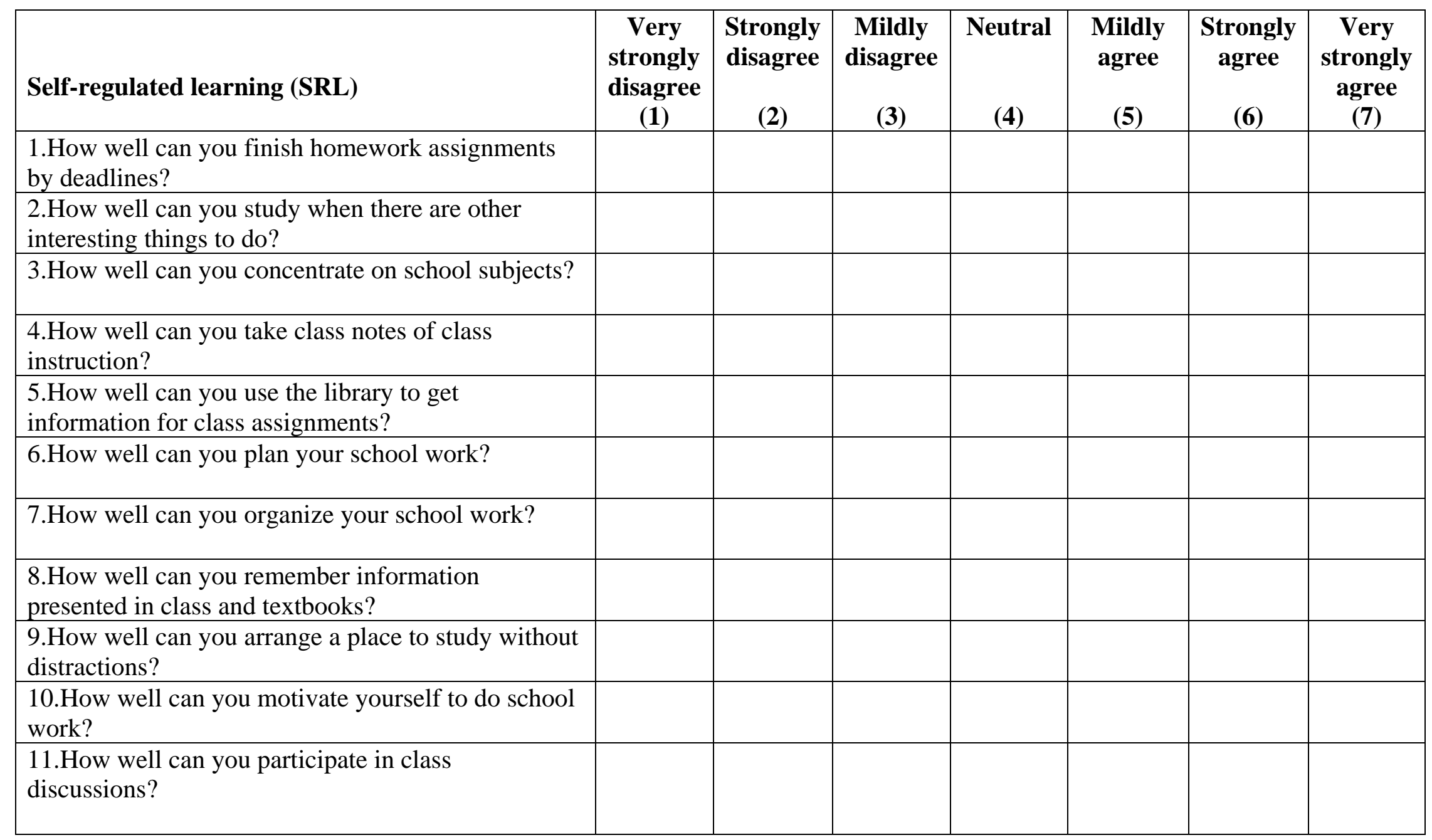




\begin{tabular}{|c|c|c|c|c|c|c|c|}
\hline $\begin{array}{l}\text { Self-regulatory efficacy to resist peer pressure } \\
\text { (SRE-pp) }\end{array}$ & $\begin{array}{c}\text { Very } \\
\text { strongly } \\
\text { disagree } \\
(1) \\
\end{array}$ & $\begin{array}{c}\text { Strongly } \\
\text { disagree } \\
(2) \\
\end{array}$ & $\begin{array}{c}\text { Mildly } \\
\text { disagree } \\
(3) \\
\end{array}$ & $\begin{array}{c}\text { Neutral } \\
\text { (4) }\end{array}$ & $\begin{array}{c}\text { Mildly } \\
\text { agree } \\
(5) \\
\end{array}$ & $\begin{array}{c}\text { Strongly } \\
\text { agree } \\
(6) \\
\end{array}$ & $\begin{array}{c}\text { Very } \\
\text { strongly } \\
\text { agree } \\
(7) \\
\end{array}$ \\
\hline \multicolumn{8}{|l|}{$\begin{array}{l}\text { 1.How well can you resist peer pressure to do things } \\
\text { in school that can get you into trouble? }\end{array}$} \\
\hline \multicolumn{8}{|l|}{$\begin{array}{l}\text { 2.How well can you stop yourself from skipping } \\
\text { school when you feel bored or upset? }\end{array}$} \\
\hline \multicolumn{8}{|l|}{$\begin{array}{l}\text { 3.How well can you resist peer pressure to smoke } \\
\text { cigarettes? }\end{array}$} \\
\hline \multicolumn{8}{|l|}{$\begin{array}{l}\text { 4.How well can you resist peer pressure to drink } \\
\text { beer, wine, or liquor? }\end{array}$} \\
\hline \multicolumn{8}{|l|}{$\begin{array}{l}\text { 5.How well can you resist peer pressure to smoke } \\
\text { marijuana? }\end{array}$} \\
\hline \multicolumn{8}{|l|}{ 6.How well can you resist peer pressure to use pills? } \\
\hline \multicolumn{8}{|l|}{$\begin{array}{l}\text { 7.How well can you resist peer pressure to use } \\
\text { crack? }\end{array}$} \\
\hline \multicolumn{8}{|l|}{$\begin{array}{l}\text { 8.How well can you resist pressure to have sexual } \\
\text { intercourse? }\end{array}$} \\
\hline 9.How well can you control your temper? & & & & & & & \\
\hline
\end{tabular}




\begin{tabular}{|l|c|c|c|c|c|c|}
\hline Social self-efficacy (SRE) & $\begin{array}{c}\text { Very } \\
\text { strongly } \\
\text { disagree } \\
(\mathbf{1})\end{array}$ & $\begin{array}{c}\text { Strongly } \\
\text { disagree }\end{array}$ & $\begin{array}{c}\text { Mildly } \\
\text { disagree }\end{array}$ & $\begin{array}{c}\text { Neutral } \\
\text { (2) }\end{array}$ & $\begin{array}{c}\text { Mildly } \\
\text { agree }\end{array}$ & $\begin{array}{c}\text { Strongly } \\
\text { agree } \\
\text { strongly } \\
\text { agree } \\
\text { (7) }\end{array}$ \\
\hline $\begin{array}{l}\text { 1.How well can you make and keep friends of the } \\
\text { opposite sex? }\end{array}$ & & & & & & \\
\hline $\begin{array}{l}\text { 2.How well can you make and keep friends of the } \\
\text { same sex? }\end{array}$ & & & & & & \\
\hline $\begin{array}{l}\text { 3.How well can you carry on conversations with } \\
\text { others? }\end{array}$ & & & & & \\
\hline $\begin{array}{l}\text { 4.How well can you work in a group? } \\
\text { (5) }\end{array}$ & & & & & & \\
\hline
\end{tabular}

\begin{tabular}{|c|c|c|c|c|c|c|c|}
\hline Self-assertive self-efficacy (SASE) & $\begin{array}{l}\text { Very } \\
\text { strongly } \\
\text { disagree } \\
\quad(1)\end{array}$ & $\begin{array}{c}\text { Strongly } \\
\text { disagree } \\
(2)\end{array}$ & $\begin{array}{c}\text { Mildly } \\
\text { disagree } \\
\text { (3) }\end{array}$ & $\begin{array}{l}\text { Neutral } \\
\text { (4) }\end{array}$ & $\begin{array}{c}\text { Mildly } \\
\text { agree } \\
(5)\end{array}$ & $\begin{array}{c}\text { Strongly } \\
\text { agree } \\
(6)\end{array}$ & $\begin{array}{l}\text { Very } \\
\text { strongly } \\
\text { agree } \\
(7)\end{array}$ \\
\hline \multicolumn{8}{|l|}{$\begin{array}{l}\text { 1.How well can you express your opinions when } \\
\text { other classmates disagree with you? }\end{array}$} \\
\hline \multicolumn{8}{|l|}{$\begin{array}{l}\text { 2.How well can you stand up for yourself when you } \\
\text { feel you are being treated unfairly? }\end{array}$} \\
\hline \multicolumn{8}{|l|}{$\begin{array}{l}\text { 3.How well can you deal with situations where } \\
\text { others are annoying you or hurting your feelings? }\end{array}$} \\
\hline $\begin{array}{l}\text { 4.How well can you stand firm to someone who is } \\
\text { asking you to do something unreasonable or } \\
\text { inconvenient? }\end{array}$ & & & & & & & \\
\hline
\end{tabular}




\section{Appendix F: Student Learning Quiz \\ Life Skills}

Name:

Date:

In this program we have discussed a number of life skills and responsibilities you can develop here and apply in places such as home and the classroom. In the space below, write down three life skills or responsibilities we have discussed, and give an example (using complete sentences) of how you could use each skill in another setting - that is, outside the sport program.

Skill 1:

Example:

Skill 2:

Example:

Skill 3:

Example: 


\section{Appendix G: Coach Focus Group Guide}

1. How was the sport program received by the youth?

a. Follow-up: Positively? Negatively? Gender differences in response? Enjoyment?

2. What challenges did you experience related to implementing the sport program?

3. What successes did you experience related to implementing the program?

4. What strategies did you use to keep the youth engaged and learning?

5. Which ones were most effective? Why?

6. Which ones were least effective? Why?

7. What suggestions do you have for improving the sport program?

8. Any additional comments? 


\section{Appendix H: Youth Focus Group Guide}

1. Did you learn anything in the sport program?

2. What did you like about the sport program? Why?

3. What did you dislike about the sport program? Why?

4. What did the coaches teach you? What was it like working with the coaches?

5. What do you believe had impacted you the most during this sport program?

6. Did you learn any life skills during the sport program?

a. Follow-up: If so, which life skills stand out to you?

7. Do you think you can use any of these life skills in your life at home, at school, or with your friends?

a. Follow-up: If so, how can you use the skills you've learned in the sport program in your life?

b. Follow-up: What within the sport program helped you to apply the skills to your own life?

8. Is there anything you hoped would have happened in or after the sport program that did not happen? 


\section{Appendix I: Teacher Interview Guide}

1. Have you observed any learning or changes (e.g. behaviors) among the students since they participated in the sport program?

a. If so, can you describe these changes or give examples?

2. What do you think caused these changes in behavior?

3. Have you heard of any comments that the students have made about the sport program?

a. If so, what are some examples of those comments?

4. As someone who observed the whole sport program, how do you think the students responded to the program?

5. What life skills do you think are important for the student to learn to be successful in life that should be included in the sport program?

6. Do you have any thoughts on the strengths of the sport program?

7. Do you have any thoughts on the weaknesses or areas of improvement of the sport program?

8. Do you have any additional comments? 
Appendix J: Tool for Assessing Responsibility-Based Education (TARE) - Post-Teaching

\section{TARE Observation Record}

\section{Reflection}

Observer Name:

Date: Day of Week: M T W Th F

Start Time:

End Time:

\section{School Information}

School Name: School District:

Locale: Urban Suburban Rural Private School Level: Elementary Middle High K-12

Other

\section{Coach Information}

Teacher Name: Teacher Gender:

Teacher Race/Ethnicity: Is teacher certified/licensed in PE?:

Observation \#: of for this teacher

\section{Student Information:}

Approximate Number in Class: Gender: All male All female Coeducational Race/Ethnicity: all white all minority mixture of white and minority Special Education Included: Yes No Not sure

\section{Part I: Brief overview of lesson(s)}

Provide some information on the context, content, and goals of the lesson(s) being reported. Include any overall comments or reflections about the session. 


\section{Part II: Responsibility-Based Teaching Strategies}

For the time period being reported, use the scale provided to rate your use of each of the nine responsibility-based teaching strategies below. More explicit definitions for these strategies can be found at the end of this form. After selecting your rating, provide some comments to justify that rating, i.e. give concrete examples of things you did and said that would serve as evidence. In cases where you realize you did not make full use of the strategy, you may want to identify ways that you could have or that you might in future lessons.

\begin{tabular}{|l|l|l|l|l|l|l|}
\hline Teaching Strategy & 4 & 3 & 2 & 1 & 0 & \\
\hline Modeling Respect & & & & & & \\
\hline Setting Expectations & 4 & 3 & 2 & 1 & 0 & \\
\hline $\begin{array}{l}\text { Opportunities } \\
\text { For Success }\end{array}$ & 4 & 3 & 2 & 1 & 0 & \\
\hline $\begin{array}{l}\text { Fostering Social } \\
\text { Interaction }\end{array}$ & 4 & 3 & 2 & 1 & 0 & \\
\hline Assigning Tasks & 4 & 3 & 2 & 1 & 0 & \\
\hline Leadership & 4 & 3 & 2 & 1 & 0 & \\
\hline $\begin{array}{l}\text { Giving Choices } \\
\text { and Voices }\end{array}$ & 4 & 3 & 2 & 1 & 0 & \\
\hline Role in Assessment & 4 & 3 & 2 & 1 & 0 & \\
\hline Transfer & 4 & 2 & 1 & 0 & \\
\hline
\end{tabular}

(0) Absent: None of the coach's words or actions convey or align with this strategy.

(1) Weak: Not generally implemented but may be reflected in some isolated words or actions on the coach's part.

(2) Moderate: Some of the coach's words and actions connect to this strategy during the lesson.

(3) Strong: Implemented well and evidenced at several points in the lesson through the words and actions of the coach.

(4) Very Strong: Seamlessly implemented in multiple ways throughout the lesson through the words and actions of the coach. 


\section{Part III: Student Responsibility}

After reflecting on your own teaching strategies, provide a holistic rating for these general areas of student responsibility. More explicit definitions for these student responsibility behaviors can be found at the end of this form. Consider observed student behavior and interaction throughout the lesson. Keep in mind that current application of this rubric assesses the group overall and not individual students.

\begin{tabular}{|l|l|l|l|l|l|l|}
\hline Student behavior & & & & & & Comments to Justify Rating \\
\hline Participation & 4 & 3 & 2 & 1 & 0 & \\
\hline Engagement & 4 & 3 & 2 & 1 & 0 & \\
\hline Showing respect & 4 & 3 & 2 & 1 & 0 & \\
\hline Cooperation with peers & 4 & 3 & 2 & 1 & 0 & \\
\hline Encouraging others & 4 & 3 & 2 & 1 & 0 & \\
\hline Helping others & 4 & 3 & 2 & 1 & 0 & \\
\hline Leading & 4 & 3 & 2 & 1 & 0 & \\
\hline Expressing voice & 4 & 3 & 2 & 1 & 0 & \\
\hline Asking for help & 4 & 3 & 2 & 1 & 0 & \\
\hline
\end{tabular}

(4) Very Strong - All students displayed this responsibility throughout the lesson with no observed exceptions.

(3) Strong - Most students displayed this responsibility throughout the lesson with only minor and/or isolated exceptions.

(2) Moderate - Many students displayed this responsibility but many did not; several exceptions were observed.

(1) Weak - Some students displayed this responsibility, but many did not; exceptions were frequent and/or serious enough to impede learning.

(O) Very Weak - Few, if any, students displayed this responsibility while the majority struggled to do so; exceptions were frequent and/or serious enough that at least some portions of the lesson were rendered ineffective. 


\section{Extended Description of Responsibility-Based Teaching Strategies:}

- Modeling Respect (M): Teacher models respectful communication. This would involve communication with the whole group or individual students. Looks like: appropriate communication and instruction and unconditional positive regard. Does not look like: rolling out the ball, losing temper, or embarrassing students.

- Setting Expectations (E): Teacher explains or refers to explicit behavioral expectations. These could relate to skill performance, safe practices, rules and procedures, or etiquette.

- Opportunities for Success (S): Teacher structures lesson so that all students have the opportunity to successfully participate and be included regardless of individual differences.

- Fostering Social Interaction (SI): Teacher structures activities that foster positive social interaction. This could involve student-student interaction through cooperation, teamwork, problem solving, conflict resolution or debriefing. [This only counts if it is structured by the teacher; rolling out the ball does not count.]

- Assigning Tasks (T): Teacher assigns specific responsibilities or tasks (other than leadership) that facilitate the organization of the program or a specific activity. This could look like taking attendance, setting up equipment, keeping score/records, or officiating a game.

- Leadership (L): Teacher allows students to lead or be in charge of a group. This could look like demonstrating for the class, leading a station, teaching/leading exercises for the whole class, or coaching a team.

- Giving Choices and Voices (V): Teacher gives students a voice in the program. This could involve group discussions, voting as a group; individual choices, students asking questions, making suggestions, sharing opinions, evaluating the teacher or program.

- Role in Assessment (A): Teacher allows students to have a role in learner assessment. This could take the form of self- or peer-assessment related to skill development, behavior, attitude, etc.; it could also involve goal-setting or a negotiation between teacher and student on their grade or progress in the class.

- Transfer (Tr): Teacher directly addresses the transfer of life skills or responsibilities from the lesson beyond the program. This could include links such as: the need to work hard and persevere in school; the importance of being a leader in your community; keeping your self-control to avoid a fight after school; setting goals to achieve what you want in sports; the need to be a good team player when you grow up and get a job; or the value of thinking for yourself to avoid peer-pressure.

\section{Extended Description of Responsibility-Based Student Behaviors}

- Participation: Student is 'on task', i.e. following directions and participating in activities or tasks organized by the teacher.

- Engagement: Student seems to have a high level of interest and motivation for the task or educational activity which could be evidenced in their level of active contribution.

- Showing Respect: Student is actively showing respect to others, i.e. making eye contact, paying attention to others, or active listening.

- Cooperation: Student demonstrates the social skills needed to work effectively with others in accomplishing a common task.

- Encouraging Others: Student offers social support to others in proactive ways.

- Helping Others: Student takes on helping roles.

- Leading: Student takes on a leadership role with regard to an educational task.

- Expressing Voice: Student makes suggestions, shares opinions, and/or reflects in ways that express their personality and individuality.

- Asking for Help: Student seeks out assistance and asks for help from teacher or peers. 


\section{Appendix K: TPSR Implementation Checklist}

Date:

Session number:

What went well in the session?
Coach name:

Sport/physical activity:

What were the challenges in the session?

Which of the Levels (goals) was directly addressed in this lesson? (mark all that apply)

Level One (respect)

Level Two (self-motivation)

Level Three (self-direction)

Level Four (caring)

Level Five (transfer)

Which of these Teaching Strategies was used in this lesson? (mark all that apply)

Modeling respect

Setting expectations

Providing opportunities for success

Fostering social interaction

Assigning management tasks

Promoting leadership

Giving choices and voices Involving students in assessment Addressing transfer of life skills
Which components of the Lesson Format were used in this lesson? (mark all that apply)

Relational time Awareness talk Physical activity with responsibility Group meeting Reflection time

Which of these Student Behaviors could be seen in this lesson? (mark all that apply)

Participating

Engaging

Showing Respect

Cooperating

Encouraging others

Helping others

Leading

Expressing voice

Asking for help

Additional comments: 


\section{Appendix L: Coach Consent Form Only Minimal Risk Consent Information Form (without HIPAA)}

Principal Investigator

Department

Protocol Number

Study Title

Swaziland

Co-Investigator(s)

\author{
Dr. Damien Clement \\ Sport and Exercise Psychology
}

1803056780

Coaching Life Skills through Sport: An Application of the TPSR Model to Youth Sport in

\section{Contact Persons}

In the event you experience any side effects or injury related to this research, you should contact Dr. Damien Clement at $(+1)$ 304293-0863 or Zenzi Huysmans at (+268) 76057944. After hours contact: Dr. Damien Clement at (+1) 304-293-0863. If you have any questions, concerns, or complaints about this research, you can contact Damien Clement at (+1) 304-293-0863 or Zenzi Huysmans at (+268) 76057944 (email: zehuysmans@mix.wvu.edu).

For information regarding your rights as a research subject, to discuss problems, concerns, or suggestions related to the research, to obtain information or offer input about the research, contact the Office of Research Integrity and Compliance at (+1) 304-293-7073. In addition if you would like to discuss problems, concerns, have suggestions related to research, or would like to offer input about the research, contact the Office of Research Integrity and Compliance at (+1) 304-293-7073.

\section{Introduction}

You, have been asked to participate in this research study, which has been explained to you by Zenzi Huysmans, M.S. Sport and Exercise Psychology. This study is being conducted by Zenzi Huysmans, M.S. Sport and Exercise Psychology, and Dr. Damien Clement, Ph.D. Sport and Exercise Psychology in the Department of Sport and Exercise Psychology at West Virginia University.

This research is being conducted to fulfill the requirements for a doctoral project in Sport and Exercise Psychology in the Department of Sport and Exercise Psychology at West Virginia University, under the supervision of Dr. Damien Clement, Ph.D. Sport and Exercise Psychology.

\section{Purpose(s) of the Study}

The purpose of this study is to explore the challenges and successes of implementing a brief youth sport program that provides young people with opportunities to participate in sport and learn life skills. WVU expects to enroll approximately 40 subjects in this study.

\section{Description of Procedures}

This study involves participating in a 2-day youth sport for development training and then implementing a sport program for youth in the Mahlanya community for 75 minutes every weekday for 3 weeks. All sport session outlines will be provided to you, so you are not responsible for creating them. This study also involves the completion of daily reflections on the sport sessions you implement as well as a brief (20-minutes) audio-recorded interview at the end of the sport program. Video recordings of the sport sessions may take place to observe how the sessions are implemented. During the interview at the end of the program, you do not have to answer all of the questions.

\section{Discomforts}

There are no known or expected risks from participating in this study.

\section{Alternatives}

You do not have to participate in this study.

\section{Benefits}

You will gain new skills and knowledge on how to integrate sport coaching with life skills development for youth. The knowledge gained from this study may also eventually benefit others. 


\section{Financial Considerations}

You will receive $\$ 50$ for participating in this study.

\section{Confidentiality}

Any information about you that is obtained as a result of your participation in this research will be kept as confidential as legally possible. Your research records and test results, just like hospital records, may be subpoenaed by court order or may be inspected by the study sponsor or federal regulatory authorities (including the FDA if applicable) without your additional consent. In addition, there are certain instances where the researcher is legally required to give information to the appropriate authorities. These would include mandatory reporting of infectious diseases, mandatory reporting of information about behavior that is imminently dangerous to your child or to others, such as suicide, child abuse, etc.

Audio-recordings and videotapes will be kept locked up and will be destroyed as soon as possible after the research is finished. In any publications that result from this research, neither your name nor any information from which you might be identified will be published without your consent.

\section{Voluntary Participation}

Participation in this study is voluntary. You are free to withdraw your consent to participate in this study at any time. Refusal to participate or withdrawal will not affect your status in the community and will involve no penalty to you. In the event new information becomes available that may affect your willingness to participate in this study, this information will be given to you so that you can make an informed decision about whether or not to continue your participation.

You have been given the opportunity to ask questions about the research, and you have received answers concerning areas you did not understand. Upon signing this form, you will receive a copy.

I willingly consent to participate in this research.

Signatures

Signature of Subject

\begin{tabular}{lll}
\hline Printed Name & Date & Time \\
\hline
\end{tabular}

The participant has had the opportunity to have questions addressed. The participant willingly agrees to be in the study.

Signature of Investigator or Co-Investigator

\begin{tabular}{lll}
\hline Printed Name & Date & Time \\
\hline
\end{tabular}




\section{Appendix M: Youth Assent Form Youth Assent Form}

\section{Principal Investigator}

Department

Protocol Number

Study Title

Swaziland

Co-Investigator(s)
Dr. Damien Clement

Sport and Exercise Psychology

1803056780

Coaching Life Skills through Sport: An Application of the TPSR Model to Youth Sport in

\section{Contact Persons}

If you are hurt from being in this research, you should contact Dr. Damien Clement at (304) 293-0863. (After hours contact: Dr. Damien Clement at (+1) 304-293-0863 or Zenzi Huysmans at +268 76057944). If you have any questions, concerns, or complaints about this research, you can contact Dr. Damien Clement at $(+1)$ 304-293-0863 or Zenzi Huysmans at $(+268)$ 76057944 (email: zehuysmans@ @mix.wvu.edu). For information regarding your rights as a person in research or to talk about the research, call the Office of Research Integrity \& Compliance at (+1) 304-293-7073.

\section{Introduction}

You, , have been asked to participate in this research study, which has been explained to you by Zenzi Huysmans, M.S. Sport and Exercise Psychology.

\section{Purpose(s) of the Study}

The purpose of this study is to explore the challenges and successes of implementing a brief youth sport program that provides young people with opportunities to participate in sport and learn life skills. WVU expects to enroll approximately 40 subjects in this study.

\section{Description of Procedures}

This study will be done during afternoon club at the Moya Center in the Mahlanya community. You will be asked to complete two short surveys (one at the beginning and one at the end of the sport program) and participate in a sport program that will take place for 75 minutes every weekday for 3 weeks. You may also be asked to participate in a brief audio-recorded interview (15 minutes) at the end of the sport program. The surveys will each take 20 minutes to complete. You do not have to answer all of the questions. Daily sport sessions may be video-recorded to ensure that the sport lesson is being taught correctly.

\section{Discomforts}

Some of the questions may be difficult and you may not enjoy trying to answer them. The sport program will require that you are participate in physical activity, which may be physically tiring.

\section{Benefits}

You may enjoy participating in the sport program with your peers and making friends. The results from this study may help other people.

\section{Confidentiality}

We promise that anything we learn about you in this study will be kept as secret as possible.

\section{Voluntary Participation}

You do not have to do this. No one will be mad at you if you refuse to do this or if you decide to quit. You have been allowed to ask questions about the research, and all of your questions were answered. 
I willingly agree to be in this research.

\section{Signatures}

Signature of Subject

\begin{tabular}{llc}
\hline Printed Name & Date & Time \\
\hline
\end{tabular}

The minor has had the opportunity to have questions addressed. The minor willingly agrees to be in the study.

Signature of Investigator or Co-Investigator

\begin{tabular}{lcc}
\hline Printed Name & Date & Time \\
\hline
\end{tabular}




\title{
Appendix N: Parental Consent Form Only Minimal Risk Parental or Guardian Consent (Without HIPAA)
}

\author{
Principal Investigator \\ Department \\ Protocol Number \\ Study Title \\ Swaziland

\section{Co-Investigator(s)} \\ Dr. Damien Clement \\ Sport and Exercise Psychology \\ 1803056780 \\ Coaching Life Skills through Sport: An Application of the TPSR Model to Youth Sport in
}

\section{Contact Persons}

In the event your child experiences any side effects or injury related to this research, you should contact Dr. Damien Clement at $(+1)$ 304-293-0863 or Zenzi Huysmans at (+268) 76057944. After hours contact: Dr. Damien Clement at (+1) 304-293-0863. If you have any questions, concerns, or complaints about this research, you can contact Damien Clement at (+1) 304-293-0863 or Zenzi

Huysmans at (+268) 76057944 (email: zehuysmans@ @ix.wvu.edu).

For information regarding your child's rights as a research subject, to discuss problems, concerns, or suggestions related to the research, to obtain information or offer input about the research, contact the Office of Research Integrity and Compliance (+1) 304293-7073.

In addition if you would like to discuss problems, concerns, have suggestions related to research, or would like to offer input about the research, contact the Office of Research Integrity and Compliance at (+1) 304-293-7073.

\section{Introduction}

Your child, , has been asked to participate in this research study, which has been explained to you and your child by Zenzi Huysmans, M.S. Sport and Exercise Psychology. This study is being conducted by Zenzi Huysmans, M.S. Sport and Exercise Psychology, and Dr. Damien Clement, Ph.D. Sport and Exercise Psychology in the Department of Sport and Exercise Psychology at West Virginia University.

This research is being conducted to fulfill the requirements for a doctoral project in Sport and Exercise Psychology in the Department of Sport and Exercise Psychology at West Virginia University, under the supervision of Dr. Damien Clement, Ph.D. Sport and Exercise Psychology.

\section{Purpose(s) of the Study}

The purpose of this study is to explore the challenges and successes of implementing a brief youth sport program that provides young people with opportunities to participate in sport and learn life skills. WVU expects to enroll approximately 40 subjects in this study.

\section{Description of Procedures}

This study involves the completion of two short surveys (one at the beginning and one at the end of the sport program) and participation in a sport program that will take place for 75 minutes every weekday for 3 weeks. Your child may also be asked to participate in a brief audio-recorded interview ( 15 minutes) at the end of the sport program. The surveys will each take 20 minutes for your child to complete. Your child does not have to answer all of the questions. You will have the opportunity to see the session outlines for the sport program as well as the surveys before signing this consent form. The sport program will take place during the afternoon club at the Moya Center in the Mahlanya community. Approximately 40 subjects are expected to participate in this study. Daily sport sessions may be video-recorded to ensure that the sport lesson is being taught correctly.

\section{Risks and Discomforts}

There are no known or expected risks to your child from participating in this study, except for the mild frustration associated with answering the questions and also the physical exertion of playing sport.

\section{Alternatives}

Your child does not have to participate in this study. 


\section{Benefits}

Your child may enjoy participating in the sport program with their peers and making friends. The results from this study may help other people.

\section{Financial Considerations}

No payments will be made for participating in the study.

\section{Confidentiality}

Any information about your child that is obtained as a result of their participation in this research will be kept as confidential as legally possible.

Your child's research records and test results, just like hospital records, may be subpoenaed by court order or may be inspected by the study sponsor or federal regulatory authorities without your additional consent.

Audio-recordings and videotapes will be kept locked up and will be destroyed as soon as possible after the research is finished. In any publications that result from this research, neither your child's name nor any information from which your child might be identified will be published without your consent.

\section{Voluntary Participation}

Refusal to participate or withdrawal will not affect your child's future care or status in school and will involve no penalty to you.

\section{Signatures}

Upon signing this consent, you will receive a copy.

I willing consent to allow my child to participate in this research.

Signature of Parent or Guardian

Printed Name Date Time

Signature of Investigator or Co-Investigator

Printed Name

Date

Time 


\section{Appendix O: Teacher Consent Form Only Minimal Risk Consent Information Form (without HIPAA)}

Principal Investigator

Department

Protocol Number

Study Title

Co-Investigator(s)

\author{
Dr. Damien Clement \\ Sport and Exercise Psychology
}

1803056780

Coaching life skills through sport: An application of the TPSR model to youth sport in Swaziland

Zenzi Huysmans

\section{Contact Persons}

In the event you experience any side effects or injury related to this research, you should contact Dr. Damien Clement at $(+1) 304-$ 293-0863 or Zenzi Huysmans at (+268) 76057944. After hours contact: Dr. Damien Clement at (+1) 304-293-0863. If you have any questions, concerns, or complaints about this research, you can contact Damien Clement at (+1) 304-293-0863 or Zenzi Huysmans at (+268) 76057944 (email: zehuysmans@mix.wvu.edu).

For information regarding your rights as a research subject, to discuss problems, concerns, or suggestions related to the research, to obtain information or offer input about the research, contact the Office of Research Integrity and Compliance at (+1) 304-293-7073. In addition if you would like to discuss problems, concerns, have suggestions related to research, or would like to offer input about the research, contact the Office of Research Integrity and Compliance at (+1) 304-293-7073.

\section{Introduction}

You, have been asked to participate in this research study, which has been explained to you by Zenzi Huysmans, M.S. Sport and Exercise Psychology. This study is being conducted by Zenzi Huysmans, M.S. Sport and Exercise Psychology, and Dr. Damien Clement, Ph.D. Sport and Exercise Psychology in the Department of Sport and Exercise Psychology at West Virginia University.

This research is being conducted to fulfill the requirements for a doctoral project in Sport and Exercise Psychology in the Department of Sport and Exercise Psychology at West Virginia University, under the supervision of Dr. Damien Clement, Ph.D. Sport and Exercise Psychology.

\section{Purpose(s) of the Study}

The purpose of this study is to explore the challenges and successes of implementing a brief youth sport program that provides young people with opportunities to participate in sport and learn life skills. WVU expects to enroll approximately 40 participants.

\section{Description of Procedures}

This study involves participating in a brief (20 minute) audio-recorded interview. You do not have to answer all of the questions.

\section{Discomforts}

There are no known or expected risks from participating in this study, except for the mild frustration associated with answering the questions.

\section{Alternatives}

You do not have to participate in this study.

\section{Benefits}

You may not receive any direct benefit from this study. The knowledge gained from this study may eventually benefit others.

\section{Financial Considerations}

There are no special fees for participating in this study.

\section{Confidentiality}

Any information about you that is obtained as a result of your participation in this research will be kept as confidential as legally possible. Your research records and test results, just like hospital records, may be subpoenaed by court order or may be inspected by 
the study sponsor or federal regulatory authorities (including the FDA if applicable) without your additional consent. In addition, there are certain instances where the researcher is legally required to give information to the appropriate authorities. These would include mandatory reporting of infectious diseases, mandatory reporting of information about behavior that is imminently dangerous to your child or to others, such as suicide, child abuse, etc.

Audiotapes or videotapes will be kept locked up and will be destroyed as soon as possible after the research is finished. In any publications that result from this research, neither your name nor any information from which you might be identified will be published without your consent.

\section{Voluntary Participation}

Participation in this study is voluntary. You are free to withdraw your consent to participate in this study at any time. Refusal to participate or withdrawal will not affect your status in the community and will involve no penalty to you. In the event new information becomes available that may affect your willingness to participate in this study, this information will be given to you so that you can make an informed decision about whether or not to continue your participation.

You have been given the opportunity to ask questions about the research, and you have received answers concerning areas you did not understand. Upon signing this form, you will receive a copy.

I willingly consent to participate in this research.

Signatures

Signature of Subject

\begin{tabular}{lll}
\hline Printed Name & Date & Time
\end{tabular}

The participant has had the opportunity to have questions addressed. The participant willingly agrees to be in the study.

Signature of Investigator or Co-Investigator

\begin{tabular}{lll}
\hline Printed Name & Date
\end{tabular}

